Graduiertenkolleg 1024 Interdisziplinäre Umweltgeschichte Naturale Umwelt und gesellschaftliches Handeln in Mitteleuropa

\author{
Manfred Jakubowski-Tiessen \\ Patrick Masius \\ Jana Sprenger (Hg.)
}

\title{
Schauplätze der Umweltgeschichte in Niedersachsen
}

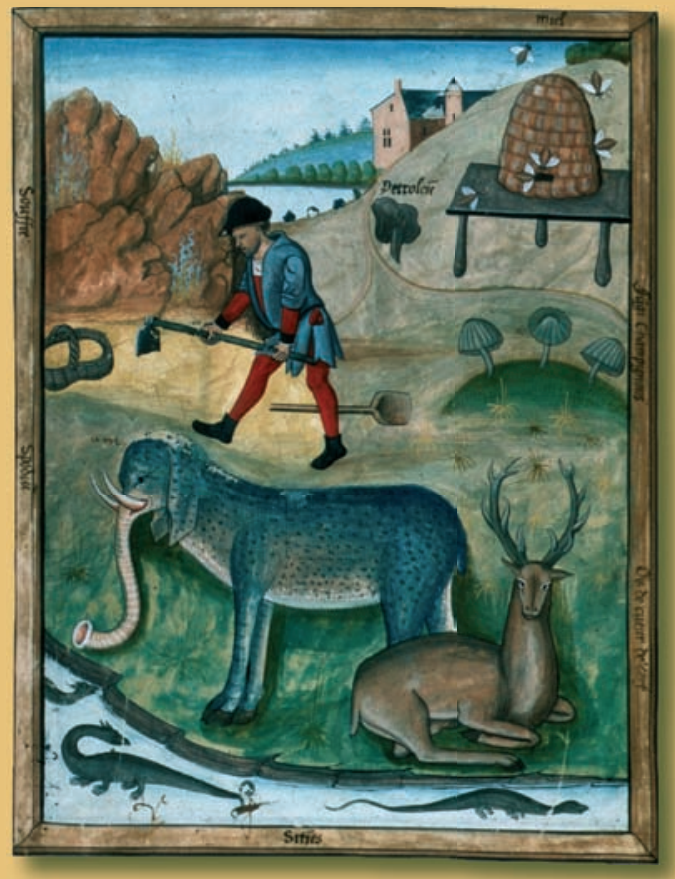



Manfred Jakubowski-Tiessen, Patrick Masius, Jana Sprenger (Hg.) Schauplätze der Umweltgeschichte in Niedersachsen

Dieses Werk ist lizenziert unter einer Creative Commons Namensnennung Weitergabe unter gleichen Bedingungen 4.0 International Lizenz.

(9) (1) () 
erschienen in der Reihe der Universitätsdrucke im Universitätsverlag Göttingen 2014 
Manfred Jakubowski-Tiessen, Patrick Masius und Jana Sprenger (Hg.)

Schauplätze der Umweltgeschichte in Niedersachsen

\section{Werkstattbericht}

Graduiertenkolleg 1024

Interdisziplinäre Umweltgeschichte

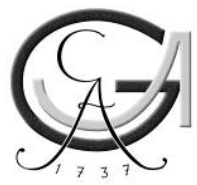

Universitätsverlag Göttingen 2014 


\title{
Bibliographische Information der Deutschen Nationalbibliothek
}

Die Deutsche Nationalbibliothek verzeichnet diese Publikation in der Deutschen Nationalbibliographie; detaillierte bibliographische Daten sind im Internet über $<$ http://dnb.ddb.de $>$ abrufbar.

\author{
Anschrift des Graduiertenkollegs \\ Graduiertenkolleg 1024 \\ Interdisziplinäre Umweltgeschichte \\ Naturale Umwelt und gesellschaftliches Handeln in Mitteleuropa \\ Georg August Universität Göttingen \\ Bürgerstr. 50 \\ 37073 Göttingen \\ URL http://www.anthro.uni-goettingen.de/gk/
}

Dieses Buch ist auch als freie Onlineversion über die Homepage des Verlags sowie über den OPAC der Niedersächsischen Staats- und Universitätsbibliothek (http://www.sub.uni-goettingen.de) erreichbar. Es gelten die Lizenzbestimmungen der Onlineversion.

Redaktion, Satz, Layout: Patrick Masius, Jana Sprenger Umschlaggestaltung: Jutta Pabst

Titelabbildung: Titelbild unter freundlich genehmigter Verwendung einer Abbildung aus MS 12322 Bibliothèque Nationale Paris, Section des Manuscriptes Occidentaux.

Verlag und Herausgeber weisen darauf hin, dass die Verantwortung für die Nutzung von Bildmaterial bei den Beitragsautoren liegt. Wo nicht ohnehin das Recht am Bildzitat in Anspruch genommen werden kann, sind etwaige Schutzverletzungen unbeabsichtigt oder irrtümlich.

(C) 2014 Universitätsverlag Göttingen

http:/ / univerlag.uni-goettingen.de

ISBN: 978-3-86395-153-5 


\section{Vorwort}

\section{Manfred Jakuboreski-Tiessen, Patrick Masius E Jana Sprenger}

Der sechste Band der Reihe „Schauplätze der Umweltgeschichte“ konzentriert sich auf Niedersachsen und ist maßgeblich das Produkt zweier Projektseminare im Sommersemester 2012 und im Wintersemester 2012/13. Zum ersten Mal stammt der Großteil der Beiträge nicht von Mitgliedern des Graduiertenkollegs „Interdisziplinäre Umweltgeschichte“, sondern von Studierenden der Geschichtswissenschaft und der Biologie. ${ }^{1}$ Damit vereinigt der Band, der bisherigen interdisziplinären Tradition der Göttinger Umweltgeschichte folgend, Beiträge junger Geistes- und Naturwissenschaftler. Diese Kombination hat nach unserer Einschätzung eher zu einer Bereicherung jedes einzelnen Beitrages geführt als zu den gewohnten Prinzipiendiskussionen. Insbesondere im Seminarbetrieb gestaltete sich die fächerübergreifende Zusammenarbeit außerordentlich fruchtbar.

Niedersachsen zeichnet sich durch eine hohe Vielfalt von Naturräumen aus. Die verschiedenen Landschaftsstrukturen erstrecken sich überwiegend von West nach Ost und verfügen über ein sehr unterschiedliches Nutzungspotential: Die Küstenregion im Norden, die Geest mit ihren zahlreichen Hoch- und Niedermooren, die Lössbörden im Bergvorland, das sich daran anschließende Berg- und Hügelland sowie im Südosten der Harz als Mittelgebirge. ${ }^{2}$ In Abhängigkeit von der jeweiligen Region entwickelten sich im Laufe der Geschichte unterschiedliche Mensch-

\footnotetext{
1 Die Auswahl von Texten der Studierenden wird ergänzt durch Beiträge von Manuela Armenat, Detlef \& Tina Creydt sowie der Herausgeber, Patrick Masius und Jana Sprenger.

2 Vgl. Thiem W (1993) Naturräumliche Grundlagen. In: H.-U. Jung, L. Schätzl (Hg.) Atlas zur Wirtschaftsgeographie von Niedersachsen. S. 13.
} 
Umwelt-Interaktionen. Zu den wichtigsten umweltgeschichtlichen Themen in Niedersachsen gehören 1) Forstwirtschaft und Jagd einschließlich landwirtschaftlicher Nutzung des Waldes, Binnenfischerei und Moorwirtschaft, 2) Landwirtschaft: Feld-, Obst- und Gartenbau sowie Heidewirtschaft, 3) Landeskulturmaßnahmen wie beispielsweise Gemeinheitsteilungen, Meliorationen, Gewässerregulierungen und Küstenschutz, 4) Bergbau und Energiegewinnung sowie 5) Naturschutz und Denkmäler. ${ }^{3}$ Der vorliegende Band stellt exemplarisch umweltgeschichtliche „Schauplätze“ zu verschiedenen Themenschwerpunkten vor, ohne dabei eine Vollständigkeit anzustreben. Drei Autorinnen widmen sich verschiedenen Aspekten der Küstennutzung und des Naturschutzes an der Nordsee. Zwei Beiträge stellen den Wandel der Kulturlandschaft in den Mittelpunkt. Drei Texte beschäftigen sich mit Bergbau bzw. der Gewinnung von Mineralien und drei weitere konzentrieren sich auf bestimmte Denkmäler, die ganz spezielle Formen von Natur-Kultur-Interaktionen exemplarisch in Erinnerung rufen. Die Beiträge wurden für den Band von Nord nach Süd sortiert und zur besseren Orientierung auf einer Übersichtskarte zusammengestellt (Abb. 1).

Wie aus der Karte ersichtlich ist, haben wir uns nicht streng an die politischen Grenzen Niedersachsens gehalten: Ein Beitrag aus Hessen und ein Artikel aus Thüringen komplettieren den Band. Die ausgewählten Themen liefern einen umweltgeschichtlichen Querschnitt mit überraschenden Details und inspirierenden Perspektiven. ${ }^{4}$ Wir danken allen Teilnehmerinnen und Teilnehmern für ihre Beiträge und ihr Engagement während der Projektlaufzeit.

\footnotetext{
${ }^{3}$ Vgl. Steinsiek P-M u. Laufer J (2012) Quellen zur Umweltgeschichte in Niedersachsen vom 18. bis zum 20. Jahrhundert. Ein thematischer Wegweiser durch die Bestände des Niedersächsischen Landesarchivs. Vandenhoeck \& Ruprecht, Göttingen.

${ }_{4}^{4}$ Wir hoffen, dass noch fehlende Themen (wie z. B. Moore) in einem Nachfolgeband behandelt werden.
} 


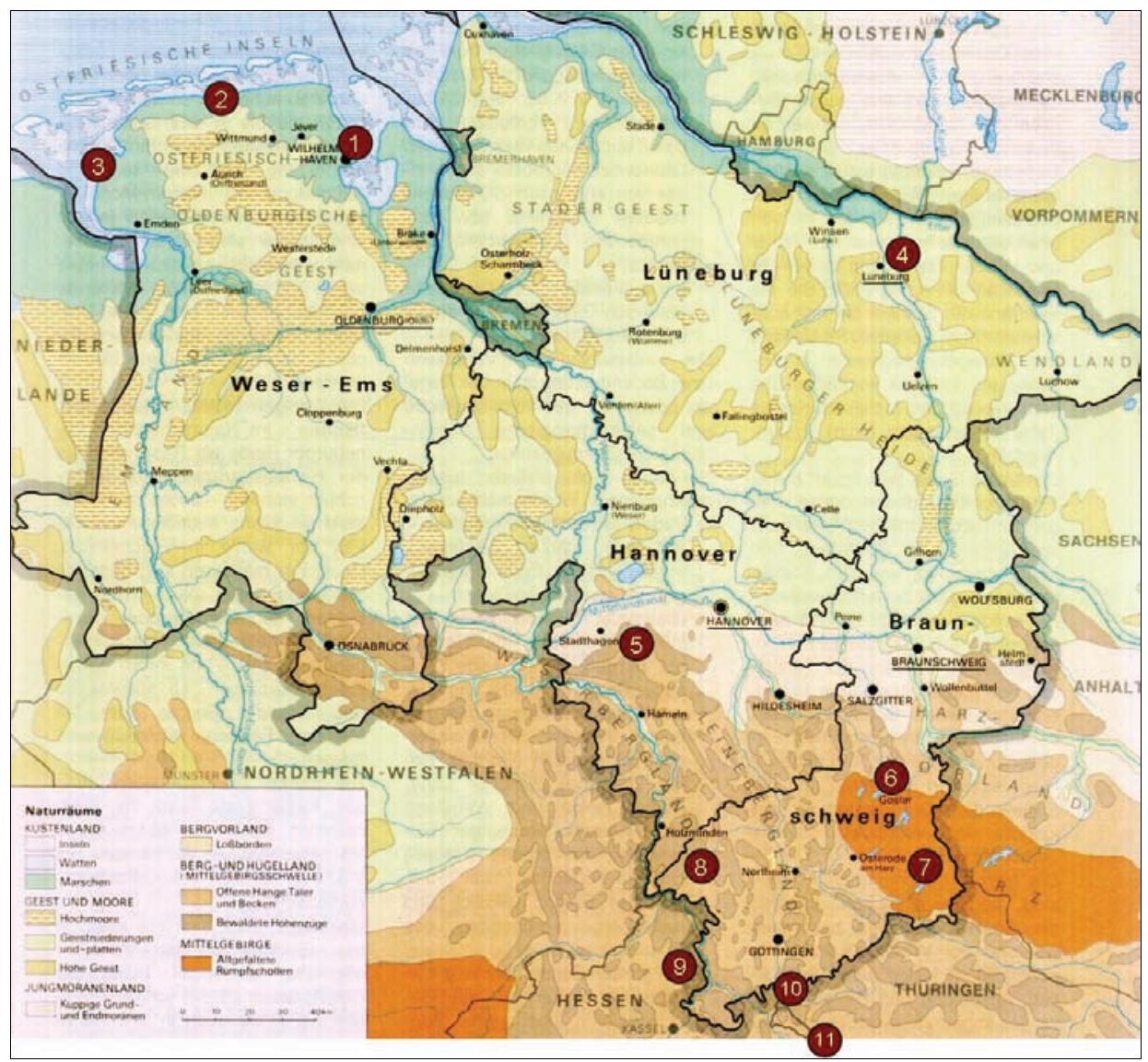

Abb. 1: Schauplätze der Umweltgeschichte in Niedersachsen: 1) Flussseeschwalben in Wilhelmshaven, 2) Nationalpark Wattenmeer, 3) Störtebekerdeich, 4) Salziges Lüneburg, 5) Erntedankfeste am Bückeberg, 6) Weltkulturerbe Goslar und Rammelsberg, 7) Silberbergbau in St. Andreasberg, 8) Pferdezucht im Solling, 9) Nutzungsgeschichte des Reinhardswaldes, 10) Das Grüne Band, 11) Otterstein in Kaltennordheim (Kartengrundlage „Naturräume in Niedersachsen“ aus Seedorf u. Meyer (1992) Landeskunde Niedersachsen. Neumünster). 



\section{Inhaltsverzeichnis}

Vom Bootsanleger zum Bruthabitat

Die Flussseeschwalbenkolonie im Banter See in Wilhelmshaven

(Jana Sprenger) ....................................................................................................

Das Wattenmeer als Nationalpark

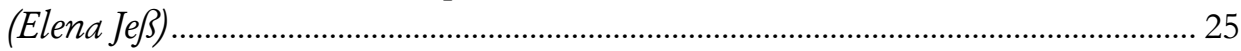

Der Störtebekerdeich

Wechselwirkungen zwischen Mensch und Meer an der Nordseeküste

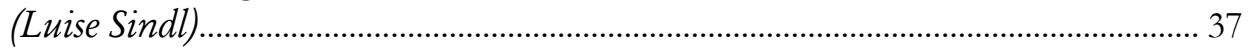

Salziges Lüneburg

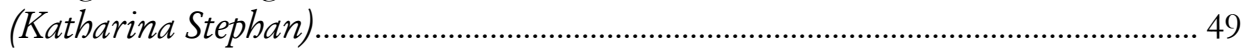

Die Reichserntedankfeste am Bückeberg

Volksgemeinschaft an der Weser

(Ann-Kathrin Mogge).

Bergwerk Rammelsberg, Altstadt von Goslar und Oberharzer Wasserwirtschaft Weltkulturerbe und Kulturlandschaft

(Manuela Armenat)...

„Aes rarum“

Zur Bedeutung des Silberbergbaus in der Oberharzer Stadt Sankt Andreasberg (Franziska Völkel). 
Die Pferdezucht im Solling und ihre Auswirkung auf die Kulturlandschaft und Siedlungsstruktur des Ortes Neuhaus

(Detlef Creydt E Tina Creydt)....

Nutzungsgeschichte des Reinhardswaldes

(Irina Kollo)

Das Grüne Band Deutschland

(Michael Unger).

Der Otterstein in Kaltennordheim

Eine Geschichte der Kreuzotter

(Patrick Masius). 


\section{Vom Bootsanleger zum Bruthabitat: Die Flussseeschwalbenkolonie im Banter See in Wilhelmshaven}

Jana Sprenger

\section{Die Banter-See-Kolonie ${ }^{1}$}

Der Banter See in Wilhelmshaven, ursprünglich Teil der ausgedehnten Hafenanlagen der Nordseestadt, wird alljährlich zur Bühne eines Naturschauspiels. Auf einer alten Kaianlage am Nordufer des Sees, welche im Zweiten Weltkrieg noch als Liegeplatz für Unterseeboote diente, brüten Flussseeschwalben (Sterna hirundo). Jedes Frühjahr finden sich hier viele hundert dieser schlanken Seevögel zur Brut und Jungenaufzucht ein. Aufgrund der Bedeutung für die bedrohte Seeschwalbenart erhielt das Brutgebiet bereits 1969 den Schutzstatus eines Naturdenkmals. Die Geschichte der Kolonie am Banter See ist eng verwoben mit dem Schicksal weiterer Nistplätze innerhalb der städtischen Hafenanlagen; sie ist geprägt von zahlreichen Populationsschwankungen, die sich aus Umwelteinflüssen, aber insbesondere auch aus verschiedenen Wechselwirkungen mit dem Menschen ergaben. Manche Brutareale wurden zerstört, andere neu gestaltet, die Vögel wurden mehrfach vertrieben und später aktiv wiederangesiedelt. Während die zunehmende Urbanisierung und die damit verbundenen Habitatzerstörungen zu den Ursachen eines weltweiten Verlusts von Artenvielfalt gezählt werden, gelten Städte andererseits

\footnotetext{
1 Ich bedanke mich bei Herrn Prof. Dr. Peter H. Becker (Institut für Vogelforschung) für Fotos, Literatur und wertvolle Hinweise.
} 
Jana Sprenger

gleichzeitig oft als Zentren der Biodiversität. ${ }^{2}$ Zahlreiche Tierarten konnten die Lebensräume, die der Mensch für sich selbst errichtete, zu ihrem Vorteil nutzen und sich den neuen Gegebenheiten anpassen. ${ }^{3}$ Im Gegensatz zu den ausgeräumten und überdüngten Flächen der modernen Landwirtschaft bieten städtische Bereiche mit ihren Grünanlagen, Gärten, Waldarealen und Stadtbrachen strukturreiche Lebensräume, in denen viele Organismen zudem vor anthropogener Verfolgung durch Jagd oder landwirtschaftliche Schädlingsbekämpfung geschützt sind. ${ }^{4}$ Dies zeigt auch, dass das Überleben vieler Arten nicht unbedingt von unberührten $\mathrm{Na}$ turlandschaften abhängig ist, sondern vielmehr von der Akzeptanz ihrer menschlichen Nachbarn. ${ }^{5}$ Zahlreiche Studien beschäftigen sich besonders mit der urbanen Vogelwelt. So wurden in Berlin mehr Brutvogelarten als in den meisten deutschen Naturschutzgebieten nachgewiesen und die Artenzahlen in Hamburg übertreffen die der Bundeshauptstadt durch die zusätzliche Präsenz von Küstenvögeln. ${ }^{6}$

Der Beitrag beleuchtet die Geschichte der Wilhelmshavener Seeschwalben, deren Koloniestandorte von Beginn an in hohem Maße durch anthropogene Aktivitäten beeinflusst wurden. Der Bootsanleger am Banter See ist ein anschauliches Beispiel für die Nutzung städtischer Habitate durch Küstenvögel und für die Bedeutung, die sowohl alte Baustrukturen als auch künstlich gestaltete Nistplätze als Brutstandorte für See- und Wasservögel entwickeln können.

\section{Von Menschen und Seeschwalben in Wilhelmshaven}

\subsection{Die Stadt und der Banter See}

Die Stadt Wilhelmshaven liegt am nordwestlichen Ufer des Jadebusens, einer durch mittelalterliche Sturmfluten entstandenen Meeresbucht westlich der Wesermündung. Ihre Entstehungsgeschichte begann 1852 mit Verhandlungen zwischen dem Königreich Preußen und dem Großherzogtum Oldenburg zum Bau eines preußischen Stützpunktes zur Verteidigung der Küstenlinie. Mit der Unterzeichnung des Vertrags im Juli 1853 erhielt Preußen ein Areal zum Bau der Anlagen und verpflichtete sich, die oldenburgische Küste gegen Angriffe zu schützen. Der Stützpunkt wurde im Juni 1869 eingeweiht und erhielt im August 1873 Stadtrechte. ${ }^{7}$ Von Beginn an wurde seine Entwicklung, dem Gründungszweck entsprechend, wesentlich durch die Ansprüche der Marine geprägt. So war auch der Banter See bis zur Mitte des 20. Jahrhunderts als Zwischen- und Westhafen Teil der weitläufi-

\footnotetext{
2 Siehe z. B. Review in Werner u. Zahner (2009), S. 8.

3 O'Connor (2013), S. 1.

${ }^{4}$ Siehe z. B. Reichholf (2010), S. 24 f.

${ }^{5}$ Reichholf (2007), S. 309.

${ }^{6}$ Reichholf (2010), S. 19.

7 Vgl. Koop u. Mulitze (1999), S. 7 ff.
} 
gen Hafenanlagen. Erst 1949 bauten die Alliierten zwischen dem heutigen See und dem angrenzenden Großen Hafen den Grodendamm, um die westlichen Hafenbecken vom Meer zu trennen. ${ }^{8}$ In Folge der Abtrennung und des jahrzehntelangen Regeneintrages entwickelte sich aus den ehemaligen Hafenbereichen ein Süßwassersee, der als Naherholungsgebiet zunehmend Bedeutung gewann. ${ }^{9}$ Auch heute sind an den Ufern des Gewässers neben Kleingartensiedlungen auch Wassersportvereine sowie die mit einem Sandstrand ausgestattete Badebucht „Klein Wangerooge“ zu finden. ${ }^{10}$ Der bei Tauchern beliebte Banter See besitzt eine Ausdehnung von 2,62 x 0,58 km und weist eine durchschnittliche Wassertiefe von 10-13 m auf. ${ }^{11}$ Die Schrebergärten am nördlichen Ufer grenzen mit nur wenigen Metern Abstand direkt an die Westseite der Flussseeschwalbenkolonie.

\subsection{Besiedlung, Vertreibung, Rückkehr - Die wechselvolle Geschichte der Seeschwalbenkolonie im Banter See}

In den Hafenanlagen von Wilhelmshaven befinden sich sowohl zwei historische als auch zwei aktuelle Koloniestandorte der Flussseeschwalbe (Abb. 1). Von 1948 bis 1959 brüteten die Tiere mit durchschnittlich etwa 30 Paaren im ehemaligen Landschaftsschutzgebiet Vogelwarteninsel (1953-1957) im Südosten der Stadt. Der Höchststand wurde dort 1953 mit 70 Paaren erreicht. Durch den Wiederaufbau des Hafens gingen die Brutplätze der Vogelwarteninsel verloren. ${ }^{12}$ Mindestens seit den 1960er Jahren nutzten Flussseeschwalben außerdem einen Brutplatz im heutigen Nordhafen, der jedoch in den 80er Jahren - ebenfalls durch Bauarbeiten zerstört wurde (s. u.). Gegenwärtig siedeln die Vögel in einer großen Kolonie auf der alten Kaianlage im Banter See sowie in zwei kleineren Gruppen auf Betontrümmern und einem Brutfloß im Marinearsenal. ${ }^{13}$ Der Standort im Banter See besteht aus sechs voneinander getrennten Betoninseln (A-F), die, in einer Reihe angeordnet, in ca. $15 \mathrm{~m}$ Entfernung vom Nordufer in den See ragen (Abb. 2). ${ }^{14}$ Die einzelnen Inseln haben jeweils eine Ausdehnung von etwa 5 x $11 \mathrm{~m}$ und eine Gesamtfläche von $360 \mathrm{~m}^{2}$. Eine siebte Plattform, die teilweise von Wasser überspült wird, ordnet sich quer zu den übrigen an und kann von den Tieren nur als Sitzgelegenheit genutzt werden. Die sechs Hauptinseln werden jeweils durch eine

\footnotetext{
8 Koop u. Mulitze (1999), S. 47.

${ }_{9}$ Brune (1986), S. 76.

${ }_{10}$ Die Kleingärten am nördlichen und süd-östlichen Ufer wurden nach dem Zweiten Weltkrieg angelegt. Der Badestrand am südlichen Ufer wurde bereits in den 1920er Jahren ausgebaut (ebd.).

11 Unterwasserclub Manta Wilhelmshaven e.V. (www.uwc-manta.de/node/14, Abruf: 11.02.2014).

12 Vgl. Bub et al. (1962), S. 21 ff. bzw. 49.

13 Das heutige Marinearsenal wurde am Standort der ehemaligen Kriegsmarinewerft ab 1957 neu errichtet und dient unter anderem der Reparatur und Instandhaltung der technischen Ausrüstung der Marine (Stadt Wilhelmshaven, www.wilhelmshaven.de/hafen_marine/marinearsenal.htm, Abruf: 11.02.2014). Die Brutplätze der Seeschwalben befinden sich im von der Marine vergleichsweise wenig genutzten nord-östlichen Bereich des Hafenbeckens.

14 Vgl. zum Aufbau und Biotopmanagement des Koloniestandortes: Becker (1996), S. 266 ff.
} 
$60 \mathrm{~cm}$ hohe Betonmauer vor Überflutung geschützt. Der Boden ist mit hellem, grobkörnigem Kies gefüllt und wird jedes Jahr mit fortschreitender Saison zunehmend von Vegetation bedeckt, die von den Küken als Versteckmöglichkeit genutzt werden kann. Gegen Ende der Brutsaison werden rund um die Kaianlage Flösse installiert, um erschöpften Jungvögeln Ruheplätze für ihre ersten Flugversuche anzubieten, da sie aufgrund der hohen Betonmauern nicht schwimmend zurück auf die Brutinseln gelangen können. Eine Bojenkette verhindert während des gesamten Sommers eine Annäherung von Wassersportlern.

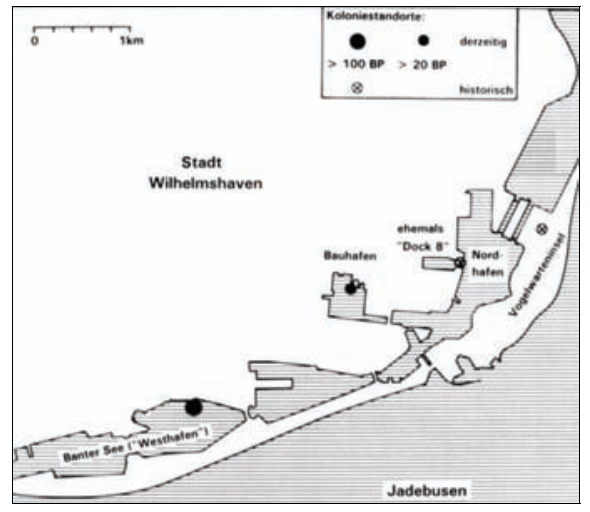

Abb. 1: Aktuelle und historische Brutkolonien in den Hafenanlagen von Wilhelmshaven (Becker 1996, S. 266).

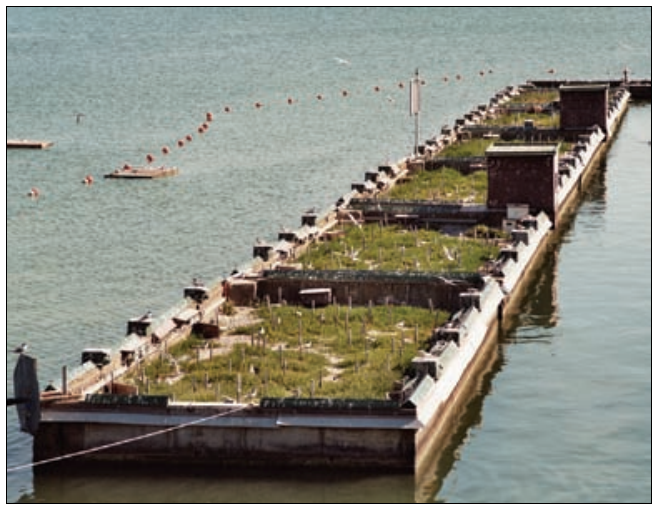

Abb. 2: Der Koloniestandort Banter See mit den sechs Betoninseln der ehemaligen Kaianlage (eigenes Foto).

Schon in den 1950er und 60er Jahren siedelten nachweislich Flussseeschwalben auf dem ehemaligen Bootsanleger im neu geschaffenen Banter See. Die Kolonie wurde zu dieser Zeit auch bereits durch das Institut für Vogelforschung wissenschaftlich betreut, indem regelmäßig Küken beringt wurden. ${ }^{15}$ Fehlende Schutzbestimmungen führten jedoch mitunter sowohl zur unabsichtlichen als auch zur mutwilligen Zerstörung von Gelegen und zum Tod von Jungvögeln. Im Juli 1962 berichtete die Wilhelmshavener Zeitung unter der Überschrift „Seeschwalbengelege rücksichtslos zerstört" von den chaotischen Zuständen in der Brutkolonie:

„Der Besuch der kleinen Kolonie, die erfreulicherweise im Stadtgebiet entstand, ließ nicht nur Gedankenlosigkeit, sondern auch Rücksichtslosigkeit gegenüber den Tieren erkennen. Dutzende von Eiern wurden aus den Gelegen genommen und an einer Stelle zusammengetragen. [...] Zertretene Eier lassen aber auch erkennen, dass unabsichtlich manches Gelege vernichtet wurde. Solche Zerstörungen lassen sich natürlich nicht vermeiden, wenn unerfahrene Besucher die kleine Seeschwalbenkolonie besuchen. Es gehört nämlich ein geschultes Auge dazu, wenn man ohne Flurschaden durch die Kolonie gelangen will. Ebenso werden und wurden junge

15 Vgl. Becker (1996), S. 267. 
Seeschwalben zertreten. Denn oft verstecken sich die kleinen Vögelchen im Bewuchs, wenn der Mensch in ihre Nähe kommt.“16

Weiterhin wurde der Angelsport für die Verluste von Eiern und Jungvögeln verantwortlich gemacht. Die stundenlange Anwesenheit der Angler auf den Inseln halte die Altvögel von ihren Nestern fern und führe somit zur Auskühlung von Gelegen und Küken. Der Artikel sprach sich für ein allgemeines Betretungsverbot der Kolonie während der Brutzeit aus. Einige Jahre später, im Mai 1969, wurde schließlich durch die Untere Naturschutzbehörde der Stadt Wilhelmshaven

„eine Fläche von rd. 360 qm im Bereich der Betonmauer-Reste der ehemaligen Kaizunge im Zwischenhafen, [...], südwestlich der Prince-Rupert-School und rd. $600 \mathrm{~m}$ westlich der Banter Ruine, als Brutstätte der Flußseeschwalbe (sterna hirundo) zum Naturdenkmal erklärt."17

Durch die Ausweisung wurde ,jegliche Störung wie Betreten, Heranschwimmen, Anlanden mit Booten sowie Annäherung mit Wasserski auf eine Entfernung von unter $50 \mathrm{~m}^{\text {" } 18}$ verboten. Trotz dieser Schutzbemühungen ging die Zahl der brütenden Flussseeschwalben im Laufe der 70er Jahre zurück, bis sie schließlich ganz ausblieben. Für das Verschwinden der Vögel werden anthropogene Einflüsse verantwortlich gemacht. Offenbar gelang es trotz des gesetzlichen Schutzes nicht, Freizeitgäste von den Inseln fernzuhalten. ${ }^{19}$

Die Tiere siedelten sich daraufhin auf Betontrümmern in dem ehemaligen $\mathrm{Ha}$ fenbecken „Dock 8“ an (Abb. 3). Dort hatte es bereits mindestens seit den 1960er Jahren Brutaktivitäten gegeben, die nach der Aufgabe des Standortes am Banter See merklich anstiegen. Obwohl das Dock 8 ebenfalls von Kleingärten umgeben war, ließen die Vögel sich durch die Anlieger nicht beeinträchtigen. In diesem Fall konnten die Ufergrundstücke und die damit verbundene Abschirmung offenbar sogar Störungen der Kolonie verhindern. ${ }^{20}$ Anfang der 1980er Jahre brüteten 60 bis 90 Seeschwalbenpaare auf den Inseln. ${ }^{21}$ Doch trotz der guten Voraussetzungen und eines außergewöhnlich hohen Bruterfolgs blieben die Tiere auch an diesem Nistplatz nur wenige Jahre ungestört. Pläne zum Neubau des Nordhafens gefährdeten 1983 die Existenz der Trümmerinseln: Für die in Niedersachsen bestandsbedrohten Vögel musste ein alternativer Brutstandort gefunden werden. ${ }^{22}$ Das Institut für Vogelforschung bereitete daraufhin in Zusammenarbeit mit den Behörden die alte Kaianlage im Banter See für eine erneute Besiedlung vor. Mit den Jahren

\footnotetext{
${ }^{16}$ Seeschwalbengelege rücksichtslos zerstört. In: Wilhelmshavener Zeitung, 7. Juli 1962.

${ }^{17}$ Amtliche Bekanntmachung. In: Wilhelmshavener Zeitung, 28. Mai 1969.

18 Ebd.

${ }^{19} \mathrm{Vgl}$. Becker (1996), S. 267.

20 Vgl. Becker (1984), S. 111 f.

${ }^{21}$ Becker (1996), S. 267.

22 Hier und im Folgenden: Becker (1984), S. 111 ff.
} 
hatte der Bewuchs stark zugenommen und sogar Büsche mussten entfernt werden. Die einzelnen Inseln wurden mit Schotter, Kies und Sand aufgefüllt und die Querseiten, welche zu diesem Zeitpunkt noch nicht durch eine Betonmauer geschützt waren, wurden mit Holzbohlen gegen Wassereinbrüche abgedichtet (Abb. 4). Zudem sollten Hinweisschilder und eine Bojenkette Annäherungen von Nachbarn und Wassersportlern verhindern. Obwohl im Frühjahr 1983 immer wieder Seeschwalben am Banter See gesehen wurden, kam es dort nicht zum Nestbau; noch hatten die Tiere offenbar keinen Grund, ihren etablierten Standort zu verlassen. Außerdem hatten auf der alten Kaianlage starke Regenfälle ein Durchsickern von Wasser durch die neu gebauten Bohlenwände verursacht. Im folgenden Jahr jedoch hatten die Bauarbeiten im Dock 8 bei der Ankunft der Vögel bereits begonnen; die Seeschwalben hatten ihren bewährten Nistplatz verloren. Dementsprechend wurden die Maßnahmen zur Umsiedlung intensiviert. Um weitere Wassereinbrüche zu verhindern, wurde die Sand- und Kiesauffüllung der Inseln erhöht. Zusätzlich sollten nun Tonbandaufnahmen von Koloniegeräuschen ebenso wie Seeschwalbenattrappen aus Kunststoff Aktivität am Brutstandort vortäuschen. Obwohl einige Vögel weiterhin erfolglos versuchten, auf den nun mit Schuttbergen bedeckten Betontrümmern im Dock 8 zu brüten, konnten die Umsiedlungsbemühungen in diesem Jahr wesentliche Erfolge erzielen. Rund die Hälfte der Tiere brütete 1984 am Banter See. Schon ein Jahr später stieg diese Zahl noch einmal erheblich an. Durch den ehemaligen Brutstandort im Dock 8 verläuft heute der Lüneburgkai am Rande des Nordhafens. ${ }^{23}$

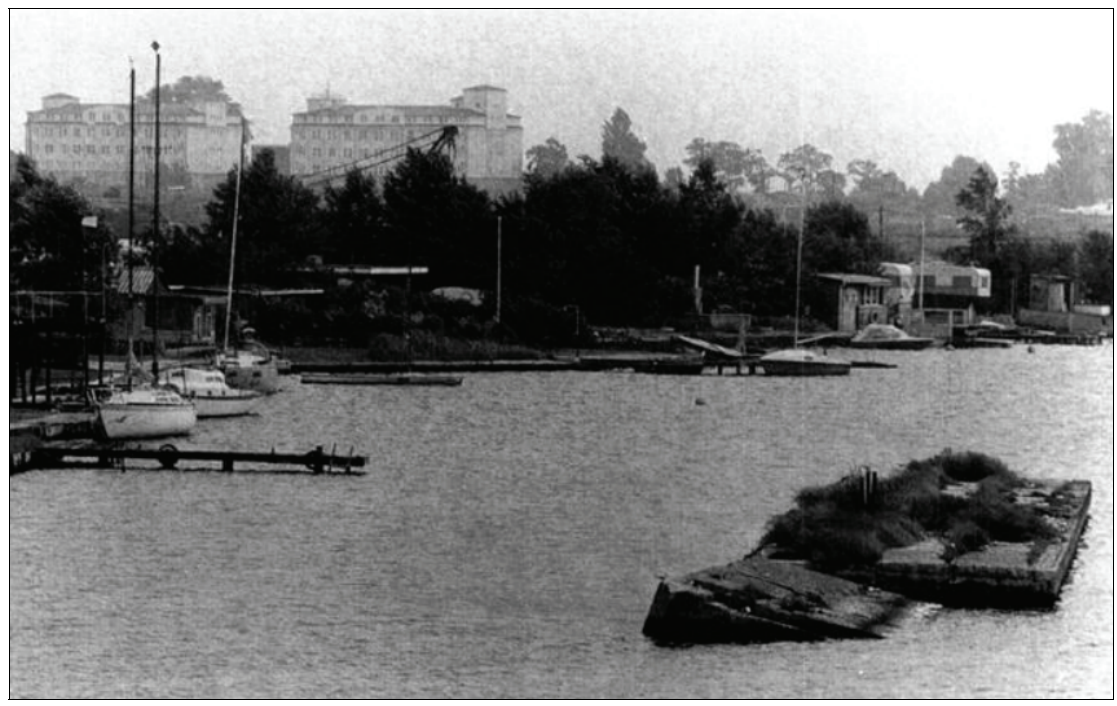

Abb. 3: Der ehemalige Koloniestandort im Dock 8, am Rande des heutigen Nordhafens. Die Betontrümmer wurden durch den Hafenneubau zerstört (Becker (1996), S. 270).

${ }^{23}$ Becker (1996), S. 267. 


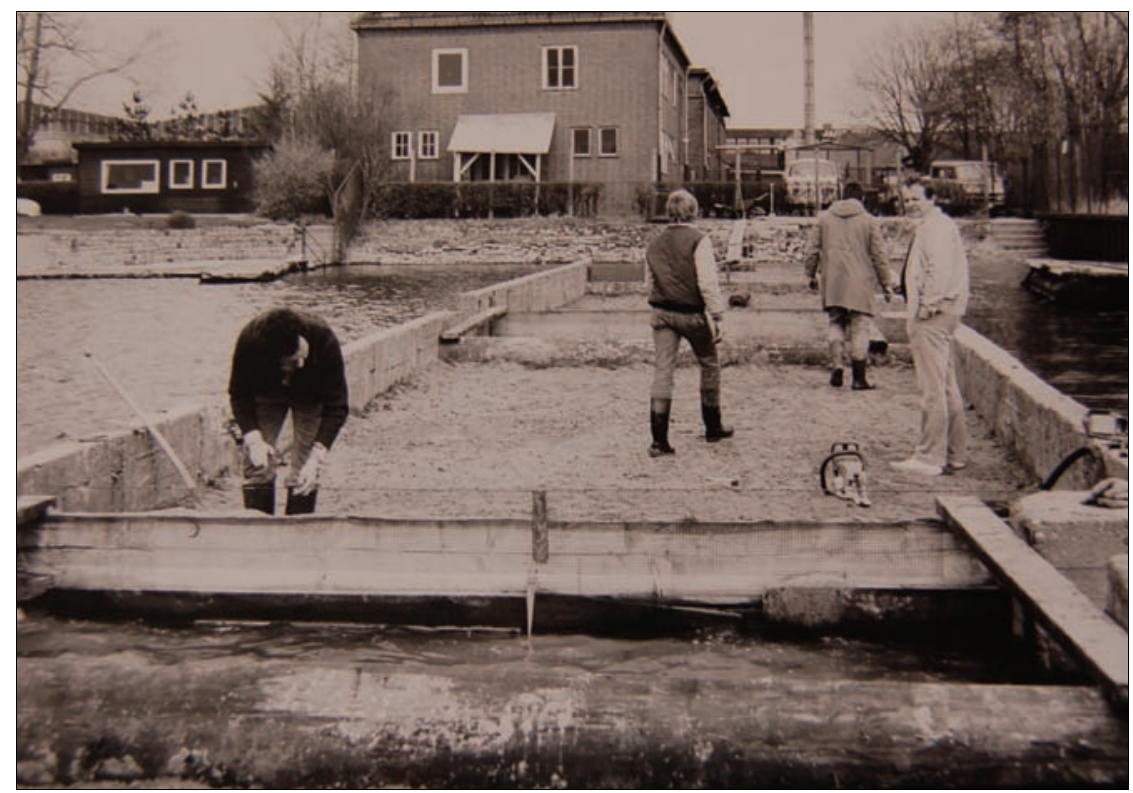

Abb. 4: April 1983: Vorbereitung des Koloniestandortes im Banter See für die Umsiedlung der Seeschwalben, ausgelöst durch den drohenden Verlust des Brutplatzes im Dock 8 (Foto: Institut für Vogelforschung). ${ }^{24}$

Im Laufe der Zeit wurden die Brutbedingungen am Banter See weiter optimiert. So konnten beispielsweise 1991 die Bohlenwände an den Längsseiten der Inseln durch Betonmauern ersetzt werden. Drei Jahre später, 1994, finanzierte der Naturschutzbund Deutschland (NABU) zur Abwehr von Wanderratten einen $30 \mathrm{~cm}$ breiten Plastikstreifen, der in einem $45^{\circ}$ Winkel an den Außenseiten der Mauern angebracht wurde (siehe Abb. 2). ${ }^{25}$ Weiterhin wird zur Erhaltung des offenen Nistareals nach jeder Brutsaison die Vegetation auf den Inseln entfernt. ${ }^{26}$

Der Koloniestandort am Banter See verfügt im Vergleich zu Brutgebieten auf den Wattenmeerinseln über zahlreiche Vorteile für die Flussseeschwalben. Neben dem durch das Biotopmanagement erzielten Schutz vor Hochwasser und terrestrischen Beutegreifern besteht eine geringere Exposition gegenüber Witterungseinflüssen sowie ein Zugang zu ergänzenden Nahrungsressourcen in den Binnenge-

\footnotetext{
${ }^{24}$ Das im Hintergrund erkennbare vordere Gebäude dient noch heute als Forschungsstation und beherbergt Materialien, mobile Laborgeräte und Unterkünfte. Es ist Teil einer 1935 erbauten Kasernenanlage für den U-Bootstützpunkt im Zwischenhafen (Koop u. Mulitze (1999), S. 13). Der Großteil der umgebenden Anlage wurde inzwischen abgerissen.

${ }^{25}$ Die als Rattenschutz verwendeten Dachstreifen müssen bis heute regelmäßig ersetzt werden. Nach der Anfangsfinanzierung durch den NABU wurde dies durch die Herstellerfirma (Protektorwerk INEFA, Gaggenau) übernommen.

${ }^{26} \mathrm{Zu}$ den Ausbauarbeiten in den 90er Jahren vgl. Becker (1996), S. 268 ff.
} 
wässern rund um Wilhelmshaven. Limnische Fischbestände können für die Ernährung der Seeschwalben eine große Rolle spielen. ${ }^{27}$

Die durchschnittliche Besiedlung des Koloniestandortes lag in den Jahren 1984 bis 1996 bei etwa 90 Brutpaaren und zeigte einen stetigen Bestandszuwachs. ${ }^{28}$ Ende der 1990er Jahre brüteten bereits über 200 Paare in der Kolonie; der bisherige Höchststand wurde 2004 mit über 500 Paaren erreicht; seit 2005 ist dagegen ein Rückgang der Anzahl brütender Seeschwalbenpaare nachweisbar. ${ }^{29}$ Gerade in der Anfangszeit wurde das stetige Wachstum der Kolonie durch sehr hohe jährliche Bruterfolge begünstigt. ${ }^{30}$ Seit Beginn des 21. Jahrhunderts erfolgte jedoch ein deutlicher Einbruch. Zwischen 1992 und 2001 zogen die Vögel durchschnittlich 1,37 Küken pro Paar auf, während von 2002 bis 2009 nur noch 0,46 Jungvögel pro Paar flügge wurden. ${ }^{31}$ Eine mögliche Ursache für diese Entwicklungen ist Nahrungsknappheit während der Jungenaufzucht durch einen Rückgang der Heringsbestände in der Nordsee, welcher nicht nur die Banter-See-Kolonie beeinflusst, sondern die gesamte Küstenpopulation. ${ }^{32}$

\subsection{Die Flussseeschwalben in Wissenschaft und Öffentlichkeit}

Die außergewöhnliche Infrastruktur der Banter-See-Kolonie ermöglichte von Anfang an eine wissenschaftliche Begleitung der Populationsentwicklung. Die Lebensgeschichten einzelner Individuen dieser langlebigen ${ }^{33}$ Seevogelart konnten über mehr als zwei Jahrzehnte dokumentiert werden.

Flussseeschwalben sind vergleichsweise kleine, schlanke Seevögel mit einer Körpermasse von 107-158 g und einer Flügellänge von 26-29 cm. ${ }^{34}$ Die weißgrauen Vögel bekommen zur Brutzeit eine schwarze Kopfkappe und leuchtendrote Beine (Abb. 5). Von der ähnlichen Küstenseeschwalbe (Sterna paradisaea) sind sie unter anderem durch einen geringfügigen Größenunterschied, längere Beine und meist eine schwarze Spitze am Schnabel zu unterscheiden, die allerdings unterschiedlich stark ausgeprägt sein oder sogar fehlen kann. ${ }^{35}$ Flussseeschwalben verbringen als Langstreckenzieher nur den Sommer auf der Nordhalbkugel. Sie

\footnotetext{
27 Siehe z. B. Becker et al. (1987); Frank (1992).

${ }_{28}$ Becker (1998), S. 225; nach einer wahrscheinlich durch Immigration zu erklärenden außergewöhnlich hohen Besiedung 1990 nahm der Bestand vorübergehend allerdings wieder leicht ab (Becker (1996), S. 270).

${ }^{29}$ Szostek u. Becker (2012), S. 318.

30 Vgl. Becker (1996), S. 279.

${ }^{31}$ Szostek u. Becker (2012), S. 318.

32 Ebd., S. 323; siehe auch Dänhardt u. Becker (2011).

${ }^{3}$ Das Durchschnittsalter bekannter Brutvögel betrug in verschiedenen Untersuchungen 9-10 Jahre; es werden jedoch auch Brutvögel registriert, die älter als 20 Jahre sind (vgl. Review in Becker u. Ludwigs (2004), S. 118).

34 Vgl. ebd., S. 121. Die genannten Werte sind Ergebnisse einer ausgewählten Studie in Deutschland. Andere Untersuchungen können geringfügig abweichen.

${ }^{35}$ Svensson et al. (1999), S. 186.
} 
nisten in Kolonien oder auch einzeln sowohl in Küstenbereichen als auch an Gewässern des Binnenlandes. Die Vögel ernähren sich hauptsächlich von Fischen und Krustentieren, indem sie im Sturzflug ins Wasser eintauchen und einzelne Beutetiere fangen. Ihre wichtigsten Nahrungsfische an der Nordsee sind Heringsartige (Clupeiformes), Stinte (Osmerus eperlanus), Plattfische (Pleuronectiformes) und Seenadeln (Syngnathidae); aber auch Crustaceen wie Garnelen (Crangon crangon) und Schwimmkrabben (Portunidae) sind für ihre Ernährung von Bedeutung. ${ }^{36}$ Die Seeschwalben der Banter-See-Kolonie haben auch Zugriff auf limnische Gewässer und erbeuten zusätzlich beispielsweise Flussbarsche (Perca fluviatilis), Rotfedern (Scarclinius erythrophthalmus) und Dreistachelige Stichlinge (Gasterosteus aculeatus).

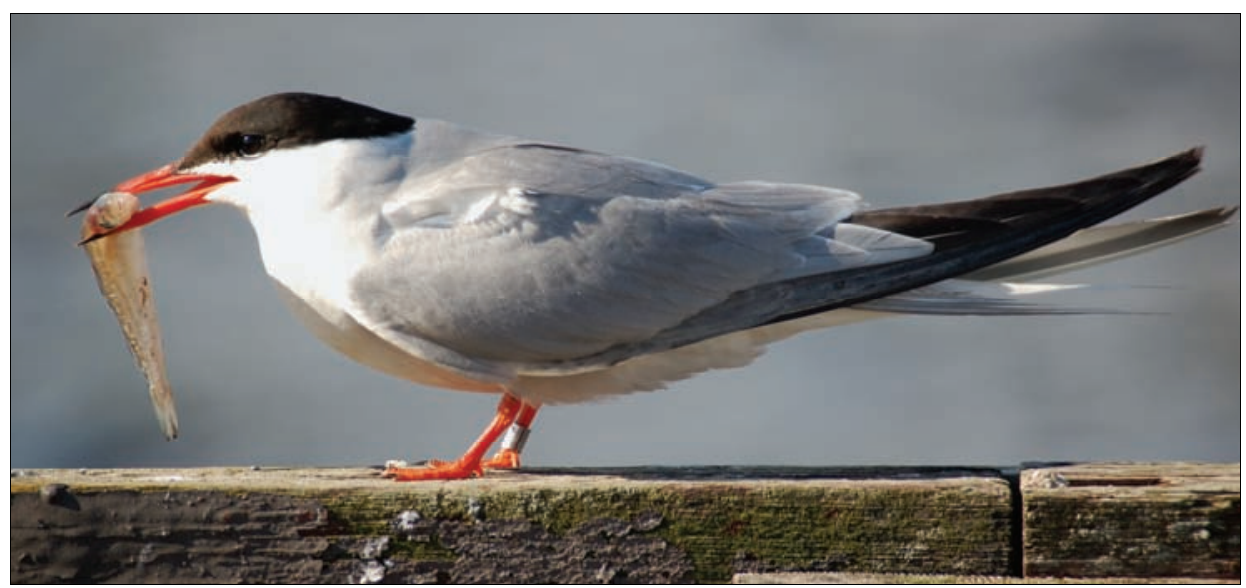

Abb. 5: Flussseeschwalbe im Brutkleid (eigenes Foto).

Ein Kernstück der Forschung am Banter See ist seit 1992 ein aufwändiges elektronisches System, mit dessen Hilfe Langzeitdaten über die Lebensgeschichten vieler einzelner Vögel gesammelt werden, die in Kombination Aussagen über Populationsentwicklungen geben können. ${ }^{37}$ Kurz vor dem Ausfliegen wird allen Küken ein kleiner passiver Sender mit einem individuellen alphanumerischen Identifikationscode subkutan injiziert. ${ }^{38}$ Über die Kolonie verteilt befinden sich Sitzkisten mit Antennen (Abb. 6), welche die Sender aktivieren und ablesen können und die Informationen an ein zentrales Speichersystem weitergeben. Einige Sitzkisten enthalten zusätzlich elektronische Waagen, sodass auch das jeweilige Gewicht eines dort Platz nehmenden Vogels bestimmt wird. Durch mobile Antennen, die zeitweise um die einzelnen Nester gelegt werden, werden zudem die jeweiligen Brutpaare identifiziert (Abb. 7). Die elektronischen Daten können ein Betreten der

\footnotetext{
36 Becker et al. (1987).

37 Vgl. Becker (1996), S. 289 ff.; Becker (2010).

38 Siehe Becker u. Wendeln (1996).
} 
Kolonie jedoch nicht vollständig ersetzen. Unter anderem zum Auslegen der Nestantennen, zum Vermessen von Eiern und zum Beringen und Wiegen von Küken finden regelmäßige Kontrollgänge auf den Inseln statt. Für Verhaltensstudien stehen zwei Beobachtungshütten zwischen den Inseln B und C sowie D und E zur Verfügung.

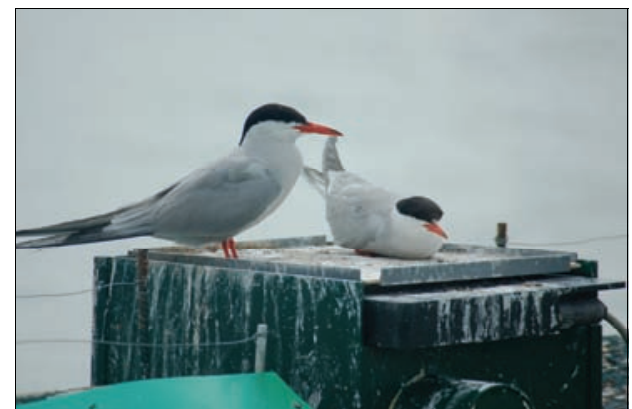

Abb. 6: Flussseeschwalben auf einer Sitzkiste mit Antenne und elektronischer Waage (eigenes Foto).

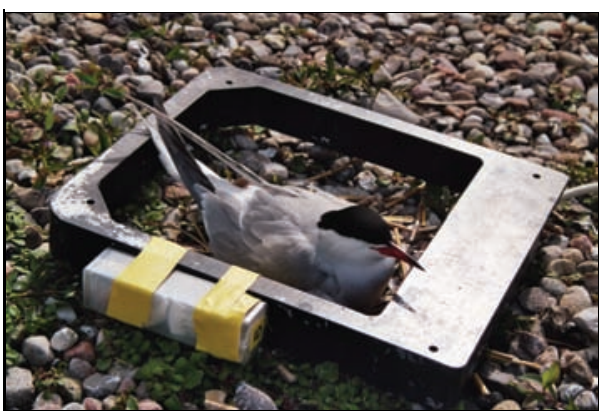

Abb. 7: Brütende Flussseeschwalbe mit Nestantenne (eigenes Foto).

Die Seeschwalben am Banter See geraten regelmäßig in die Aufmerksamkeit der Öffentlichkeit. So berichtet die Wilhelmshavener Zeitung, die bereits in den 1960er Jahren über den Standort geschrieben hatte, jedes Jahr über die aktuellen Entwicklungen und Forschungsarbeiten. Seit 2008 ist die Flussseeschwalbe zudem Symboltierart der Stadt. ${ }^{39}$ Das Institut für Vogelforschung bietet regelmäßig Führungen durch die Station an, die es ermöglichen, die Tiere zu beobachten und einen Einblick in die Datenerfassung zu erhalten. Von besonderem Interesse sind dabei meist die einzigartigen Möglichkeiten der individuellen Identifizierung einzelner Seeschwalben und der Verlauf ihrer Lebensgeschichten. Die Brutpaare Lotti und Otto sowie Imke und Karl wurden 2005 in einer treffend „Big Brother am Banter See“ genannten NDR-Produktion sogar zu Filmstars. Wenn das Schicksal einzelner Seeschwalben über eine ganze Saison begleitet wird oder sogar über Jahre und Jahrzehnte bekannt ist, können sich zu den Tieren individuelle Empathien entwickeln. In der Pressemitteilung zu seinem Dokumentarfilm schrieb Ralph Schieke:

„Wenn ein Vogel vor uns saß, dessen Namen und gesamte Geschichte wir kannten und den wir seit Wochen beobachtet hatten und der gerade alle seine drei Jungen verloren hat und nach diesen Jungen ruft - da kann man nur Mitleid empfinden.“40

Die besonders auf Kinder und Jugendliche ausgerichtete Website „Mit Flussseeschwalben auf Du und Du - Vogelforschern über die Schulter geguckt" (lotti-

\footnotetext{
${ }^{39}$ Halama u. Brenner (2008).

40 Schieke (2005).
} 
web.de) bietet seit Mai 2013 ein Informationsportal zur Biologie der Flussseeschwalben sowie der Bedeutung der Banter-See-Kolonie für Naturschutz und Wissenschaft. Auf der durch den Europäischen Fonds für regionale Entwicklung, die Niedersächsische Wattenmeerstiftung sowie die Niedersächsische Bingo-Umweltstiftung geförderten Internetseite verdeutlichen zahlreiche Videos typische Verhaltensweisen der Tiere und während der Brutsaison ermöglicht eine Livecam direkte Einblicke in die Kolonie. Die Wilhelmshavener Zeitung berichtete schon im Oktober 2013 von über 30.000 Besuchern auf der Seite. ${ }^{41}$

Seit den folgenschweren Störungen durch Freizeitgäste in den 1960er und 70er Jahren fanden am Banter See viele Veränderungen statt. Zwar waren die Seeschwalben schon damals gern gesehene Nachbarn; dies konnte jedoch das Betreten und Annähern durch einzelne Personen und in der Folge zerstörte Nester oder unterkühlte Küken nicht verhindern. Da die seit drei Jahrzehnten in der Kolonie stattfindenden wissenschaftlichen Arbeiten im Gegensatz dazu den Bruterfolg nicht herabsetzen, haben die Seeschwalben ihnen gegenüber eine hohe Toleranz entwickelt und lassen sich von den menschlichen Eindringlingen nicht im Brutgeschäft stören. Die intensive Öffentlichkeitsarbeit des Instituts für Vogelforschung und das Interesse der Medien leisten einen wichtigen Beitrag für eine konfliktfreie Nachbarschaft von Seeschwalben mit Anliegern und Freizeitgästen am Banter See.

\section{Zum Schutz der Flussseeschwalbe in Kulturlandschaften}

Neben natürlichen Regulatoren wie Lebensraumdynamiken, Witterungsverhältnissen, Nahrungsverfügbarkeit, Prädation und Konkurrenz wirken zahlreiche anthropogene Faktoren auf die Entwicklung von Flussseeschwalbenpopulationen ein. Zu den größten Gefährdungen gehören Habitatverluste; daneben spielen beispielsweise Störungen am Brutplatz, die Akkumulation von Umweltchemikalien in den Tieren ${ }^{42}$ oder Jagd in den Überwinterungsgebieten - die europäischen Populationen überwintern in Westafrika - eine Rolle. ${ }^{43}$

Flussseeschwalben besiedeln, wie ihr Name bereits andeutet, auch Gewässer im Binnenland. Der Verlust unverbauter Flussläufe und der sich dynamisch wandelnden offenen Sand- und Kiesbänke entlang ihres Verlaufs bedeuteten für die Seeschwalben, die unbewachsene oder nur mit geringer Vegetation bedeckte Pionierstandorte favorisieren, einen erheblichen Rückgang geeigneter Brutstandorte. Die vollständigen Auswirkungen dieser Entwicklungen, die zu einem großen Teil bereits im 19. Jahrhundert stattfanden, lassen sich aufgrund fehlender Populationsdaten nicht bestimmen. Der Lech in Bayern ist jedoch ein eindrucksvolles Beispiel des 20. Jahrhunderts für die Folgen dieser Biotopverluste. Durch Fluss-

\footnotetext{
41 Röbbelen (2013).

42 Vgl. u. a. Dittmann et al. (2012). Beispielsweise kann die Ablagerung toxischer Umweltchemikalien in Eiern den Bruterfolg herabsetzen (z. B. Muñoz Cifuentes u. Becker (1998), S. 19 f.).

43 Hier und im Folgenden: Becker u. Sudmann (1998), S. 293 ff.
} 
baumaßnahmen und zusätzliches Eiersammeln verschwand hier zwischen 1905 und 1934 ein Bestand von 300 Brutpaaren. ${ }^{44}$ Nachdem die Binnenlandpopulationen in den 1980er Jahren in vielen Regionen Deutschlands ein kritisches Minimum erreichten, wurden zahlreiche künstliche Nistplätze als Ersatz für die verlorenen naturnahen Flussbetten angelegt. Besonders durch die Ausbringung von BrutflöBen konnte der Abwärtstrend der Bestände in vielen Bundesländern gestoppt werden. Eine erfolgreiche Besiedlung von Brutflößen ließ sich in den 90er Jahren beispielsweise im Naturschutzgebiet Breesener See in Mecklenburg-Vorpommern, 45 und in verschiedenen Seen und Tongruben am Oberrhein ${ }^{46}$ sowie am Niederrhein ${ }^{47}$ beobachten. Ein Drittel der Flussseeschwalben im deutschen Binnenland, etwa 500 Paare, brütete 1996 auf Flößen und künstlichen Inseln, darunter die Gesamtpopulation von Bayern, Baden-Württemberg, Rheinland-Pfalz und Nordrhein-Westfalen. Lediglich im Osten und Nordosten von Deutschland fanden sich Binnenlandkolonien auf natürlichen Standorten. ${ }^{48}$ Durch ihre Flexibilität in der Brutplatzwahl, die beispielsweise im Fall von Bremen sogar Flachdächer einschlieBen kann, und besonders durch ihre Akzeptanz künstlicher Inseln kam die Flussseeschwalbe während eines Symposiums in Wilhelmshaven im Oktober $1997 \mathrm{zu}$ dem Spitznamen „Floßseeschwalbe“.49 In Folge der Populationsschwankungen in den letzten Jahrzehnten wurde der nationale Gefährdungsstatus der Art in Deutschland mehrfach geändert. Nachdem sie in den 1990er Jahren aufgrund positiver Bestandsentwicklungen von der Roten Liste gestrichen worden war, wurde sie 2007 angesichts der Bestandseinbrüche an der Küste wieder aufgenommen. ${ }^{50}$

Künstlichen Inseln kommt, besonders im Binnenland, eine hohe Bedeutung für den Schutz der Flussseeschwalbe zu. Die Besiedlung solcher Standorte bringt allerdings auch neue Probleme für die Vögel mit sich. Ungewöhnlich hohe Nestdichten können zu verringertem Bruterfolg durch erhöhte intraspezifische Aggression sowie folgenschwere Prädatorenübergriffe führen. ${ }^{51}$ Zwar können sich große Seeschwalbenkolonien effektiv gegen Angriffe von Möwen und Rabenvögeln verteidigen, jedoch sind sie weiterhin anfällig gegen nächtliche Beutegreifer, die besonders in dicht besiedelten Brutgebieten erheblichen Schaden anrichten können. So wurde der Bruterfolg am Banter See in einigen Jahren durch Wanderratten (Rattus norvegicus) und Waldohreulen (Asio otus) deutlich reduziert. ${ }^{52}$

\footnotetext{
${ }_{44}$ Zum Habitatverlust an mehreren bayerischen Flüssen siehe auch Raab (1998).

${ }^{45}$ Loose (1998).

46 Rupp (1998); Dienemann (1998).

${ }^{47}$ Sudmann (1998).

48 Vgl. Becker u. Sudmann (1998), S. 294 f.

49 Ebd., S. 300. Weitere Literaturverweise zur Besiedlung von Flachdächern in Becker u. Ludwigs (2004), S. 92.

50 Vgl. Becker (1996), S. 298 f.; Szostek u. Becker (2012), S. 313.

51 Sudmann (1998).

52 Vgl. Becker (1996), S. 279 ff.
} 
Zur Überprüfung des Bruterfolgs unterliegen sowohl natürliche als auch künstliche Brutstandorte häufig einem unterschiedlich intensiven Monitoring. Die Reaktionen von Flussseeschwalben auf Störungen durch den Menschen ähneln ihrem Verhalten gegenüber terrestrischen Prädatoren. Eine Studie aus dem Jahr 1997 untersuchte das Abwehrverhalten verschiedener Flussseeschwalbenkolonien auf der Nordseeinsel Minsener Oog, welche für die Vögel über lange Jahre eines der wichtigsten Brutgebiete im Wattenmeer darstellte. ${ }^{53}$ Das Unterschreiten einer spezifischen Fluchtdistanz erwidern die Vögel mit Alarm- und Angriffsflügen. Sie kreisen über dem Eindringling und stoßen mitunter in Sturzflügen auf ihn hinab, wobei sie ihn sowohl mit Schnabel, Flügeln und Füßen als auch mit Kotspritzen attackieren. Dabei sind Fluchtabstand und Angriffsbereitschaft wesentlich von den jeweiligen Voraussetzungen des Brutstandortes, darunter der Topographie, aber auch der Gewöhnung der Tiere an das folgenlose Eindringen von Menschen (Habituation), abhängig. Eine der auf Minsener Oog betrachteten Kolonien befand sich in unmittelbarer Nähe einer Station des Wasser- und Schifffahrtsamtes Wilhelmshaven im Nordosten der sonst unbewohnten Insel. Die hier Beschäftigten mussten die Kolonie an Arbeitstagen mehrmals täglich durchqueren. Die Seeschwalben dieses Nistgebietes, die seit den 1940er Jahren in unmittelbarer Nähe der Station brüteten, zeigten deutlich verringerte Fluchtdistanzen (ca. $55 \mathrm{~m}$ ), kreisten in geringerem Abstand über den Eindringlingen und besaßen, im Vergleich zu anderen Inselkolonien, eine um das zwanzigfache erhöhte Angriffsbereitschaft. ${ }^{54}$

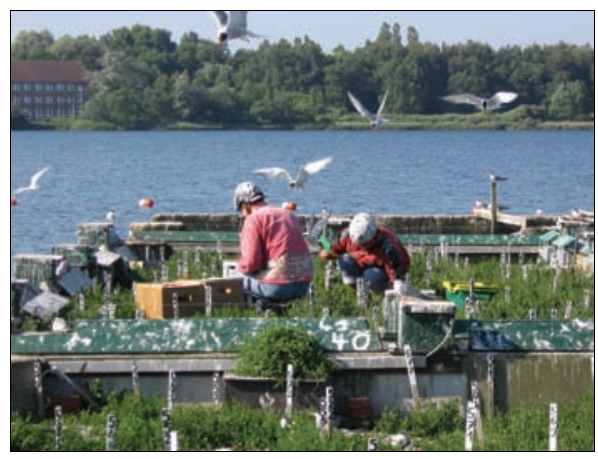

Abb. 8: Monitoring in der Banter-SeeKolonie (Foto: Institut für Vogelforschung).

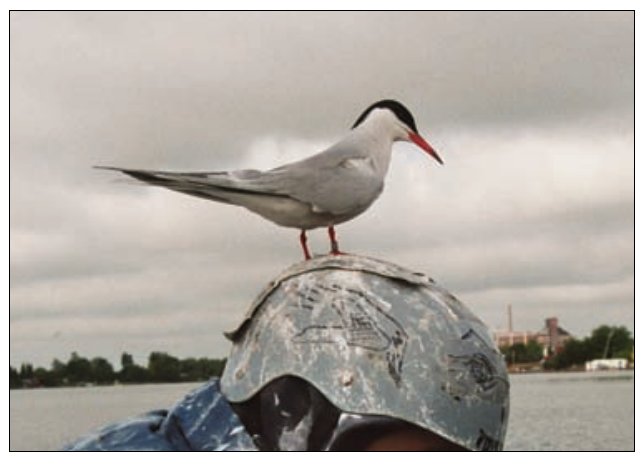

Abb. 9: Flussseeschwalbe während des Monitorings (eigenes Foto).

In der Kolonie im Banter See lassen sich noch erheblich geringere Fluchtdistanzen beobachten (Abb. 8). Während der späten Brut- und frühen Kükenphase, wenn die Alttiere ihre stärkste Nestbindung zeigen, fliegen häufig nur die Vögel in unmittel-

\footnotetext{
53 Vgl. im Folgenden: Siebolts (1998).

${ }^{54}$ Die erhöhte Angriffsbereitschaft in der Kolonie wird durch Konditionierung erklärt; so bringen die Tiere offenbar die regelmäßige „Flucht“ der menschlichen Eindringlinge mit ihrem eigenen aggressiven Abwehrverhalten in Verbindung (ebd., S. 275; Becker (1996), S. 281).
} 
barer Umgebung der Wissenschaftler auf. Vereinzelt müssen die Tiere sogar von ihren Nestern fortgeschoben werden, um diese kontrollieren zu können; oder sie lassen sich rufend auf den erforderlichen Schutzhelmen nieder (Abb. 9). Die am Banter See etablierten Vögel sind seit Jahrzehnten nicht nur an das passive Eindringen von Menschen in ihr Brutareal, sondern auch an das intensive Monitoring gewöhnt und viele der Tiere kamen bereits als Küken in regelmäßigen Kontakt mit den Wissenschaftlern. Die hervorragenden Brutbedingungen und der über lange Jahre außergewöhnliche Bruterfolg überwiegen die zum Teil täglichen Störungen. Es fällt jedoch auf, dass neue menschliche Verhaltensweisen zu erhöhtem Fluchtverhalten führen. Die ungewohnte Annäherung mit Booten an die Längsseiten der Brutinseln wird von den Vögeln in der Regel weniger toleriert als das Betreten der Kolonie durch die Wissenschaftler.

\section{Fazit: Menschen und Seeschwalben als Nachbarn?}

Die Flussseeschwalbenkolonien im Stadtgebiet von Wilhelmshaven können als Beispiele für die Bedeutung dienen, die künstlichen Niststandorten für den Schutz der Seeschwalben und anderer Kiesbrüter zukommen kann - sogar innerhalb städtischer Räume. Spätestens seit den 1960er Jahren zeigte sich in Wilhelmshaven ein öffentliches Interesse an den tierlichen Nachbarn, das in den letzten Jahrzehnten erheblich anstieg. Der Standort Banter See entwickelte sich von einem wenig beachteten brachliegenden Seeabschnitt zu einem attraktiven Ausflugsziel und einem Zentrum ökologischer Seevogelforschung. Die Stadt blickt dabei bereits auf eine langjährige, von Erfolgen und Fehlschlägen gekennzeichnete Nachbarschaft mit den Tieren zurück. Anthropogen verursachte Störungen und Arealverluste führten mehrmals zur Auflösung einzelner Kolonien und Neugründung an anderer Stelle. Die Seeschwalben wählten ihre Brutplätze in den städtischen Hafenanlagen ursprünglich selbst, erst später wurden die Standorte für die Besiedlung ausgebaut und optimiert. Die Wilhelmshavener Flussseeschwalben zeigen, ebenso wie die Tiere auf Minsener Oog oder auch die Brutpaare auf Flachdächern, dass eine Nachbarschaft mit dem Menschen bei günstigen Standortbedingungen und ausreichend Nahrungsangebot kein Hindernis für die Etablierung einer Kolonie darstellt. Der über lange Jahre außergewöhnlich hohe Bruterfolg am Banter See verdeutlicht die Vorteile des Standortes für die Seeschwalben. Durch die jüngsten, wahrscheinlich durch Nahrungsmangel bedingten Rückgänge im Bruterfolg wird jedoch deutlich, dass auch die hier siedelnden Flussseeschwalben von großräumigen Entwicklungen nicht unabhängig sind. Maßnahmen zum Schutz der Seevögel - sowohl an der Küste als auch im Binnenland - können nicht auf die jeweiligen Einzelstandorte beschränkt bleiben. Die Vögel in Wilhelmshaven sind nur temporäre Nachbarn, die zwar vorübergehend im Stadtgebiet siedeln, aber ihren Nahrungsbedarf oft nur unter Mitnutzung außerstädtischer Areale decken können. 


\section{Literatur}

Amtliche Bekanntmachung. In: Wilhelmshavener Zeitung, 28. Mai 1969.

Becker PH (1984) Umsiedlung einer Flußseeschwalben-Kolonie in Wilhelmshaven. Ber. Dtsch. Sekt. Int. Rat. Vogelschutz 24: 111-119.

Becker PH (1996) Flussseeschwalben (Sterna hirundo) in Wilhelmshaven. Oldenburger Jahrbuch 96 (Sonderdruck): 263-296.

Becker PH (1998) Langzeittrends des Bruterfolgs der Flußseeschwalbe Sterna birundo und seiner Einflußgrößen im Wattenmeer. Vogelwelt 119: 223-234.

Becker PH (2010) Populationsökologie der Flussseeschwalbe: Das Individuum im Blickpunkt. In: F. Bairlein, P. H. Becker (Hg.) 100 Jahre Institut für Vogelforschung „Vogelwarte Helgoland“ Aula-Verlag, Wiebelsheim, S. 137-155.

Becker PH, Frank D, Walter U (1987) Geographische und jährliche Variation der Ernährung der Flussseeschwalbe (Sterna hirundo) an der Nordseeküste. Journal of Ornithology 128 (4): 457-475.

Becker PH, Ludwigs JD (2004) Sterna birundo Common Tern. BWP Update Vol. 6 Nos 1 and 2: 91-137.

Becker PH, Sudmann SR (1998) Quo vadis Sterna hirundo? Schlußfolgerungen für den Schutz der Flußseeschwalbe in Deutschland. Vogelwelt 119: 293-304.

Becker PH, Wendeln H (1996) A new application for transponders in population ecology of the common tern. The Condor 99: 534-538.

Brune W (Hg.) (1986) Wilhelmshavener Heimatlexikon. Brune Druck- und Verlagsgesellschaft mbH, Wilhelmshaven.

Bub H, Goethe F, Hillen A (1962) Das Landschaftsschutzgebiet „Vogelwarteninsel“ in Wilhelmshaven. Oldenburger Jahrbuch 61: 21-80.

Dänhardt A, Becker PH (2011) Herring and Sprat Abundance Indices Predict Chick Growth and Reproductive Performance of Common Terns Breeding in the Wadden Sea. Ecosystems 14: 791-803.

Dienemann P (1998) Schwimmkampen als Brutflöße für Flußseeschwalben Sterna birundo. Vogelwelt 119: 251-252.

Dittmann T, Becker PH, Bakker J, Bignert A, Nyberg E, Pereira MG, Pijanowska U, Shore RF, Stienen E, Toft GO, Marencic H (2012) Large-scale spatial pollution patterns around the North Sea indicated by coastal bird eggs within an EcoQO programme. Environ Sci Pollut Res 19: 4060-4072. 
Frank D (1992) The Influence of Feeding Conditions on Food Provisioning of Chicks in Common Terns Sterna hirundo Nesting in the German Wadden Sea. Ardea 80: 45-55.

Koop G, Mulitze E (1997) Die Marine in Wilhelmshaven - Eine Bildchronik zur deutschen Marinegeschichte von 1853 bis heute. Bernhard \& Graefe Verlag, Bonn.

Loose J (1998) Ansiedlung von Flußseeschwalben Sterna birundo auf Kunstinseln. Ergebnisbericht aus dem Binnenland von Mecklenburg-Vorpommern. Vogelwelt 119: 253-258.

Muñoz Cifuentes J, Becker PH (1998) Eier der Flußseeschwalbe (Sterna hirundo) als Indikator für die aktuelle Belastung von Rhein, Weser und Elbe mit Umweltchemikalien. Z. Umweltchem. Ökotox. 10 (1): 15-21.

O’Connor T (2013) Animals as Neighbors: The Past and Present of Commensal Species. Michigan State University Press, East Lansing.

Raab S (1998) Verlust der Brutgebiete der Flußseeschwalbe Sterna birundo an den Flüssen des Bayerischen Voralpenlandes und Möglichkeiten der Wiederansiedlung. Vogelwelt 119: 265-270.

Reichholf JH (2007) Eine kurze Naturgeschichte des letzten Jahrtausends. S. Fischer, Frankfurt a. M.

Reichholf JH (2010) Vorwort: Städte - Inseln der Lebensvielfalt. In: Möllers F: Wilde Tiere in der Stadt. Knesebeck, München.

Rupp J (1998) Bestandsentwicklung der Flußseeschwalbe (Sterna birundo) auf künstlichen Nistflößen im Naturschutzgebiet Taubergießen. Naturschutz südl. Oberrhein 2: 217-220.

Schieke R (2005) Pressetext zur Ausstrahlung von „Big Brother am Banter See Ein Sommer mit Familie Seeschwalbe“ am 18. Dezember 2005, NDR.

Seeschwalbengelege rücksichtslos zerstört. In: Wilhelmshavener Zeitung, 7. Juli 1962.

Siebolts U (1998) Reaktionen der Flußseeschwalbe Sterna hirundo gegenüber Menschen in verschiedenen Brutkolonien. Vogelwelt 119: 271-277.

Sudmann SR (1998) Wie dicht können Flußseeschwalben Sterna hirundo brüten? Extremsituationen auf Brutflößen. Vogelwelt 119: 181-192.

Svensson L, Grant PJ, Mullarney K, Zetterström D (1999) Der neue Kosmos Vogelführer - Alle Arten Europas, Nordafrikas und Vorderasiens. Kosmos, Stuttgart. 
Szostek KL, Becker PH (2012) Terns in trouble: demographic consequences of low breeding success and recruitment on a common tern population in the German Wadden Sea. Journal of Ornithology 153: 313-326.

Werner P, Zahner R (2009) Biologische Vielfalt und Städte - Eine Übersicht und Bibliographie. Bundesamt für Naturschutz Skripten 245.

\section{Internetquellen}

Halama M, Brenner J (2008): Fische rauben und Partner ausspannen.

Flussseeschwalbe ist jetzt Symboltierart Wilhelmshavens - Bruterfolg in diesem Jahr. In: Nordwest-Zeitung Online, 19. Juli 2008, www.nwzonline.de/wilhelmshaven/fische-rauben-und-partnerausspannen_a_3,0,3931885205.html (Abruf: 11.02.2014).

Institut für Vogelforschung „Vogelwarte Helgoland“, www.lotti-web.de (Mit Flussseeschwalben auf Du und Du - Vogelforschern über die Schulter geguckt) (Abruf: 11.02.2014).

Röbbelen M (2013): Mit Flussseeschwalben auf Du und Du. In: WZ-online, 4. Oktober 2013, www.wzonline.de/nachrichten/lokal/artikel/mitflussseeschwalben-auf-du-und-du.html (Abruf: 11.02.2014).

Stadt Wilhelmshaven, www.wilhelmshaven.de/hafen_marine/marinearsenal.htm (Abruf: 11.02.2014).

Unterwasserclub Manta Wilhelmshaven e.V., www.uwc-manta.de/node/14 (Abruf: 11.02.2014). 



\title{
Das Wattenmeer als Nationalpark
}

\author{
Elena Jeß
}

\section{Einleitung}

Ein Wattenmeer ist ein Küstengebiet, das unter starker Beeinflussung der Gezeiten steht. Es liegt bei Ebbe trocken und wird bei Flut überschwemmt. Darüber hinaus verändern Wind, Wellen und Strömung ständig seine Gestalt. Eine weitere typische Eigenschaft ist die endlose Weite ohne merklichen Höhenunterschied. Das größte zusammenhängende Wattenmeer liegt an der norddeutschen Küste. ${ }^{1}$ Das Wattenmeer hat die Existenz der Menschen an der Nordseeküste über Jahrhunderte geprägt. Seine Fischgründe stellten eine der wichtigsten Nahrungs- und Ökonomiegrundlagen dar. Sturmfluten dagegen bedrohten die wirtschaftliche Existenz ebenso wie das menschliche Leben selbst.

Wattenmeere weisen durch ihre verschiedenen Landschaftselemente eine hohe Komplexität auf. Sie sind neben den Alpen eine der wenigen vom Menschen vergleichsweise geringfügig beeinflussten Landschaften Deutschlands. ${ }^{2}$ Diese Charakteristika schaffen die Grundlage für eine enorme Artenvielfalt. Zum Ökosystem Wattenmeer gehören neben dem Watt die Salzwiesen und Inseln. Es zählt zu den produktivsten Ökosystemen der Welt und bietet der Tierwelt einen wichtigen Lebensraum. ${ }^{3}$ Der Nationalpark Wattenmeer ist einer der größten Nationalparke Deutschlands. Seine Ausweisung zeugt von der hohen ökologischen, aber auch ästhetischen Bedeutung, die der Mensch dem Wattenmeer zuschreibt.

\footnotetext{
1 Niedrighaus et al. (2008).

2 Bunje (2003).

${ }^{3}$ Stock (1996).
} 
Elena Jeß

\section{Die Nordsee als Bedrohung}

Die Wahrnehmung des Wattenmeers hat sich im Laufe der Zeit verändert. ${ }^{4}$ Bereits in der Antike wurde die Küste besiedelt. Der Meeresspiegel veränderte sich in den kommenden Jahrhunderten kontinuierlich und die Küstenbewohner mussten sich immer wieder neuen Gegebenheiten anpassen. Sie bauten ihre Höfe auf natürlichen Erhebungen oder künstlich erschaffenen Hügeln, den sogenannten Warften. Stabile Deiche, die das ganze Jahr vor Überflutungen schützten, wurden erst seit dem 12. Jahrhundert angelegt. ${ }^{5}$ Dies erlaubte eine Ausdehnung des Siedlungsgebietes sowie der Landwirtschaft in die Marschen ${ }^{6}$. Die Notwendigkeit des Deichbaus führte zu politischen Zusammenschlüssen und prägte dadurch die gesellschaftliche Organisation nachhaltig. ${ }^{7}$ Trotz der verbesserten Deichbautechnik war die Angst vor Sturmfluten stets präsent. Dies spiegelt sich auch in der Literatur, beispielsweise in der Novelle „Der Schimmelreiter“ von Theodor Storm, wider:

„...Zur Linken hatte ich jetzt schon seit über einer Stunde die öde, bereits von allem Vieh geleerte Marsch, zur Rechten, und zwar in unbehaglichster Nähe, das Wattenmeer der Nordsee; zwar sollte man vom Deiche aus auf Halligen und Inseln sehen können; aber ich sah nichts als die gelbgrauen Wellen, die unaufhörlich wie mit Wutgebrüll an den Deich hinaufschlugen und mitunter mich und das Pferd mit schmutzigem Schaum bespritzten; dahinter wüste Dämmerung, die Himmel und Erde nicht unterscheiden ließ.“

Der Verlust von Bauernhöfen und ganzen Ländereien war nicht ungewöhnlich. Viele verloren durch Überschwemmungen ihre Existenz. Delumeau umschreibt das Meer ,als prominenten Ort in der mittelalterlichen und frühneuzeitlichen Lebenswelt, vor dem sich die Zeitgenossen fürchteten. " 8 Zusammenfassend lässt sich sagen, dass das Meer von den Menschen bis weit in das 18. Jahrhundert vornehmlich als gefährlich und zerstörerisch wahrgenommen wurde. Zwar hieß es, das Meer zu beherrschen verleihe Macht und Reichtum, doch wurde die Landschaft nicht als ästhetisch wahrgenommen. ${ }^{9}$

${ }^{4}$ CWSS (2006).

5 Allemeyer (2006).

${ }^{6}$ Die Marschbereiche liegen hinter den Deichen und können 5-20 km in das Binnenland ragen. Die Marsch wird heute hauptsächlich, abhängig vom Bodentyp, zur Viehhaltung oder zum Ackerbau genutzt.

7 Allemeyer (2006).

${ }^{8}$ Delumeau (1988).

${ }^{9}$ CWSS (2006). 


\section{Nationalpark Niedersächsisches Wattenmeer}

\subsection{Der Nationalpark}

Die Nationalpark-Idee stammt ursprünglich aus den USA und wurde erstmals 1872 mit dem Yellowstone-Nationalpark verwirklicht. Rund 100 Jahre später, 1970, wurde in Deutschland der Bayerische Wald als erster Nationalpark ausgewiesen. Der Grundgedanke eines Nationalparks ist, ursprüngliche Natur vor den Eingriffen des Menschen zu schützen. ${ }^{10}$ In Deutschland liegt die Ausweisung in der Verantwortung der Bundesländer. Im Bundesnaturschutzgesetz heißt es:

Nationalparke sind „einheitlich zu schützende Gebiete, die

- großräumig, weitgehend unzerschnitten und von besonderer Eigenart sind,

- $\quad$ in einem überwiegenden Teil ihres Gebiets die Voraussetzungen eines Naturschutzgebiets erfüllen und

- sich in einem überwiegenden Teil ihres Gebiets in einem vom Menschen nicht oder wenig beeinflussten Zustand befinden oder geeignet sind, sich in einen Zustand zu entwickeln oder in einen Zustand entwickelt zu werden, der einen möglichst ungestörten Ablauf der Naturvorgänge in ihrer natürlichen Dynamik gewährleistet.“

(Auszug aus dem Bundesnaturschutzgesetz $\int 24$ Abs. 1, Quelle: Bundesministerium für Justiz, Ausfertigungsdatum: 29.07.2009)

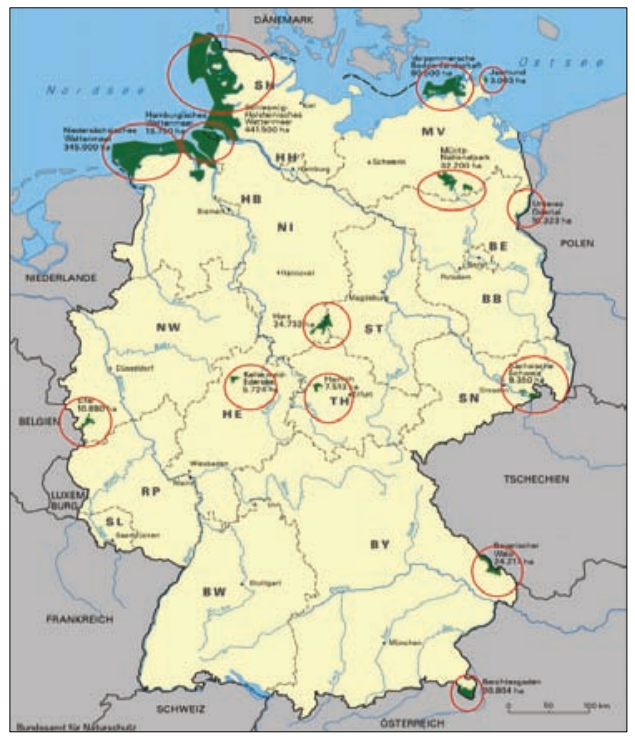

Abb. 1: Nationalparke in Deutschland (verändert nach BfN 2011).
Zurzeit gibt es in Deutschland insgesamt 14 Nationalparke mit einer Gesamtfläche von $10.294,96 \mathrm{~km}^{2}$, unter Berücksichtigung der Wasserflächen der Nord- und Ostsee. ${ }^{11}$ Ein Nationalpark ist in drei Schutzzonen unterteilt: Ruhezone, Zwischenzone und Erholungszone. Bei der Ruhezone handelt es sich um die Kernzone des Naturschutzes, die die höchste Schutzpriorität genießt. Gemäß dem zugrundeliegenden Prozessschutzkonzept soll verhindert werden, dass hier in natürliche Abläufe eingegriffen wird. Die beiden anderen Zonen sind für den Tourismus zugänglich und werden gepflegt. 
Mit $3.450 \mathrm{~km}^{2}$ ist das Niedersächsische Wattenmeer der zweitgrößte Nationalpark Deutschlands, geringfügig kleiner als das Schleswig-Holsteinische Wattenmeer. Es erstreckt sich von der Emsmündung im Westen bis nach Cuxhaven im Osten (Abb. 2). Zusammen mit dem Hamburgischen und Schleswig-Holsteinischen Wattenmeer ist das Niedersächsische Wattenmeer das größte zusammenhängende Wattgebiet der Welt. ${ }^{12}$

Die Anfänge des Naturschutzes in dem Gebiet des Niedersächsischen Wattenmeeres reichen bis in das Jahr 1907 zurück als hier ein Vogelschutzgebiet ausgewiesen wurde. Später wurden weitere kleinflächige Naturschutzgebiete geschaffen, wobei sich der Schutz lediglich auf die Inseln und die Küste beschränkte. ${ }^{13}$ In den frühen 1980er Jahren wurde das großflächige Landschaftsschutzgebiet „Ostfriesisches Wattenmeer" eingerichtet. Dieses umfasste bereits die Salzwiesen und das Emdener Watt, ließ aber die Inseln unberücksichtigt. 1983/84 begannen Verhandlungen über einen Nationalpark, der das gesamte Niedersächsische Wattenmeer und die Inseln unter Schutz stellen sollte. Im Dezember 1985 erließ das Ministerium für Landwirtschaft, Ernährung und Forsten die „Verordnung über den Nationalpark Niedersächsisches Wattenmeer“, die am 1. Januar 1986 in Kraft trat. Das Gebiet umfasste die Salzwiesen, das Watt und die Inseln. Zusammen betrug die Fläche $2.440 \mathrm{~km}^{2} .{ }^{14}$

Die Ausweisung als Nationalpark steht in Zusammenhang mit einem neuen Umweltbewusstsein nach der Ökologischen Revolution. Zunächst bezog sich die Schutzidee auf statische Landschaftselemente, wie Naturdenkmäler oder Biotope. Später wurde sie durch das auf einem dynamischen Naturverständnis basierende Naturschutzkonzept des Prozessschutzes ergänzt. Das neue Motto war „Natur Natur sein lassen“. 15 Dabei sieht der Schutz das Nicht-Eingreifen in das Ökosystem vor. Auf diese Weise sollen die natürlichen Prozesse in einem Ökosystem geschützt werden, ohne bestimmte Zielvorstellungen verwirklichen zu wollen. ${ }^{16}$

Im Juli 1999 löste das „Niedersächsische Nationalparke Gesetz Wattenmeer und Harz" die Verordnung ab. Zwei Jahre später kam es zu einer Neufassung des Gesetzes und in diesem Zuge zu einer Erweiterung des Gebietes auf $2.880 \mathrm{~km}^{2}$. Im Jahr 2010 wurde das Schutzgebiet seewärts erneut erweitert, sodass es bis heute eine Gesamtfläche von $3.450 \mathrm{~km}^{2}$ umfasst. ${ }^{17}$ Es besteht zu $40 \%$ aus Watt, zu $54,5 \%$ aus Wasser und zu 5,5\% aus Festland und Inseln. Im Niedersächsischen Wattenmeer entfallen 60,8 \% des gesamten Gebiets auf die Ruhezone. Die Zwischenzone hat einen Anteil von 38,6 \%. Die Erholungszone macht mit 0,6 \% einen relativ geringen Teil der Gesamtfläche aus (Abb. 2). ${ }^{18}$

\footnotetext{
12 CWSS (2006).

${ }^{13}$ Nitzschke (1971).

${ }^{14}$ Nationalpark Wattenmeer (2011).

${ }^{15}$ Bibelriether (1992).

16 Piechocki (2010).

${ }^{17}$ www.nationalpark-wattenmeer.de/nds/nationalpark/steckbrief.

$18 \mathrm{BfN}$ (2012).
} 


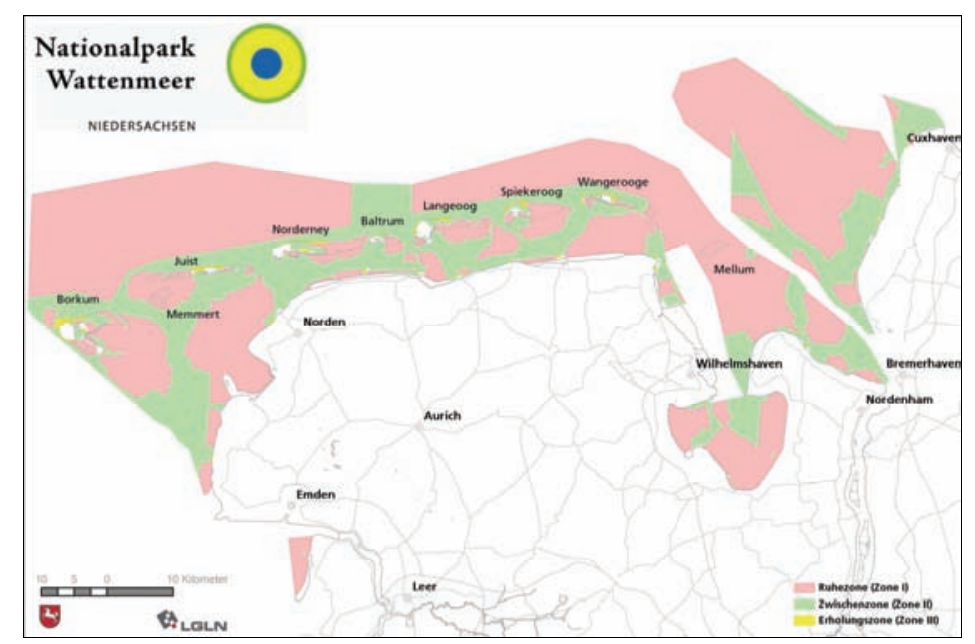

Abb. 2: Zoneneinteilung des Nationalparks. ${ }^{19}$

Das Niedersächsische Wattenmeer wurde bis heute zweimal von der UNESCO ausgezeichnet. 1993 wurde es als Biosphärenreservat ${ }^{20}$ ausgewiesen. Das Biosphärenreservat „Niedersächsisches Wattenmeer" hat die Ausdehnung des ursprünglichen Nationalparks von 1986. Im Jahr 2009 wurden das Niedersächsische und Schleswig-Holsteinische Wattenmeer mit einer Fläche von $10.000 \mathrm{~km}^{2}$ von der UNESCO zum Weltnaturerbe ernannt. ${ }^{21}$ Zwei Jahre darauf wurde das Gebiet um das Hamburgische Wattenmeer erweitert.

\subsection{Lebensraum Wattenmeer}

Die Formierung des Wattenmeers ist von Faktoren wie Tidenhub, Strömungen, Klima und Wettergeschehen, insbesondere Sturmfluten, abhängig. So ist das Ökosystem seit seinem Entstehen vor 6.000 Jahren weiterhin dynamisch und hat sich immer wieder neu geformt. Die heutige Gestalt des Wattenmeers ist außerdem Ergebnis zahlreicher Eingriffe des Menschen. Einflüsse wie Fischerei, Landwirtschaft oder der Bau der Deiche prägten die Landschaft. ${ }^{22}$

\footnotetext{
${ }^{19}$ www.nationalpark-wattenmeer.de/nds/karte-nationalpark-niedersaechsisches-wattenmeer-469 (Abruf: 10.03.2014).

${ }^{20}$ Ein Biosphärenreservat stellt eine Modellregion dar, in der der Mensch seinen Lebensraum nachhaltig nutzt. Daher handelt es sich in der Regel nicht um Natur-, sondern vielmehr um Kulturlandschaften. Die Idee ist, einen Ausgleich zwischen den Interessen der Natur und des Menschen zu finden. Die Landschaft muss charakteristisch sein und ein Bindeglied zwischen Naturschutz, Wirtschaft und nachhaltiger Nutzung darstellen (UNESCO-Kommission). Zurzeit existieren 14 Biosphärenreservate in Deutschland.

${ }^{21}$ Um die Voraussetzungen der UNESCO zu erfüllen, muss ein Standort sich durch Einzigartigkeit und strenge Schutzmaßnahmen auszeichnen (UNESCO-Kommission).

22 Gätje u. Reise (1998).
} 
Das Watt ist der Bereich, der zweimal am Tag trocken fällt und überflutet wird. Dabei entstehen verschiedene Wattarten, ${ }^{23}$ die sich bezüglich des Sauerstoffgehaltes im Boden sowie der Wassersättigung und -bewegung unterscheiden. Hierdurch werden unterschiedliche Bedingungen für Lebewesen geschaffen. Das Wattenmeer weist einen hohen Nährstoffgehalt auf und bildet die Grundlage für die Entwicklung einer hohen Vielfalt von Krebsen, Wattwürmern und Muscheln. Durch die starke Sonneneinstrahlung bei Ebbe können Seegras und Algen gut wachsen. ${ }^{24}$

Die Salzwiesen liegen zwischen Watt und Festland und sind eine charakteristische Komponente des Ökosystems. Sie werden nur bei extremem Hochwasser überspült. Der Salzgehalt im Boden ist zunächst noch sehr hoch. Im Laufe der Zeit führt die unregelmäßige Überflutung zu Sedimentanlagerung und schließlich zu Landgewinn. Irgendwann können sich Pionierpflanzen ansiedeln, die mit ihrem Wurzelwerk zu einer Befestigung des Bodens beitragen und auf diese Weise das Wachstum anderer Pflanzen fördern. Aus Abbildung 3 wird deutlich, welche schwierigen Lebensbedingungen für Pflanzen und Tiere in den Salzwiesen herrschen.

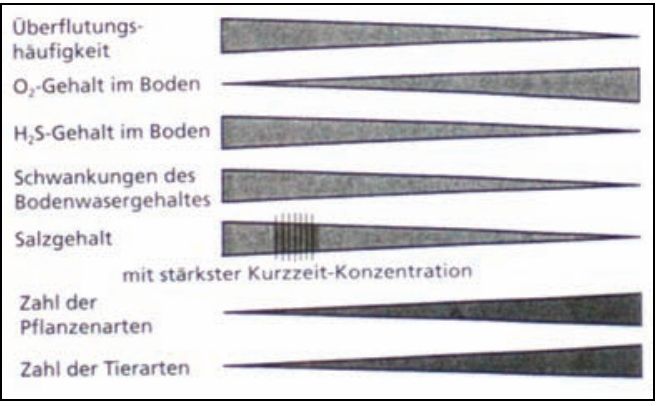

Abb. 3: Ökologische Faktoren der Salzwiesen (Smith u. Smith 2009).

Bei dem geringen Sauerstoff- und hohen Salzgehalt schaffen es nur wenige spezialisierte Arten, sich dauerhaft anzusiedeln. ${ }^{25}$ Die Salzwiesen sind Heimat zahlreicher Vögel, die sie als Brut-, Rast- und Nahrungsplatz nutzen. Außerdem wurden sie schon um die Jahrtausendwende zur Beweidung genutzt. ${ }^{26}$ Sie dienen auch heute noch der Rinderbeweidung und helfen bei der Deichsicherung. Da die Wiesen den Deichen vorgelagert sind, kann der Bereich als Puffer angesehen werden, der die Dünen, die oft die Obergrenze der Salzwiesen bilden, oder die Deiche vor dem Aufprall der Wellen schützt. ${ }^{27}$

Die Dünen sind das Ergebnis aus dem Zusammenwirken von Wind, feinem Sand, Hindernissen und Vegetation. Der Wind bläst den Sand über den Strand; er

\footnotetext{
23 Armenda (2004).

${ }^{24}$ CWSS (2006).

25 Smith u. Smith (2009).

${ }^{26}$ Ständige Arbeitsgruppe der Biosphärenreservate in Deutschland (1995).

27 Stock u. Wilhelmsen (2009).
} 
sammelt sich an kleinen Hindernissen und wird durch die Wurzeln von Pionierpflanzen festgehalten. Wird dieser Prozess nicht vom Meer unterbrochen, indem die Struktur weggespült wird, siedeln sich weitere Pflanzen an, woraufhin sich die Aggregation verfestigt. ${ }^{28}$ Niederschlag wäscht das Salz aus und schafft so bessere Ansiedlungsbedingungen für weitere Pflanzen und Tiere. Die Dünen bilden darüber hinaus einen natürlichen Küstenschutz und werden mancherorts von Menschen gefördert und stabilisiert. ${ }^{29}$

Aus Sicht des Naturschutzes ist das Gebiet aufgrund verschiedener Besonderheiten schützenswert. Es zeichnet sich durch seine hohe Biodiversität aus. Auf nur $0,03 \%$ der Bundesgebietfläche leben etwa $30 \%$ der in Deutschland bekannten Flechten, Moose und Blütenpflanzen. Jede fünfte Tierart im Nationalpark ist auf der Roten Liste zu finden. Außerdem sind hier mindestens 8.000 Tier- und 1.500 Pflanzenarten beheimatet; allein 200 Arten sind endemisch. ${ }^{30}$ Die Stellung der Inseln innerhalb des Ökosystems Wattenmeer wird oft als „Hot Spot“ der Diversität bezeichnet. Vom Nationalpark machen sie nur etwa $6 \%$ der Fläche aus, bilden jedoch bezogen auf die Artenvielfalt den bedeutendsten Teil. Von den über 8.000 Tierarten gelten etwa 7.000 als indigen. Das Wattenmeer ist zudem Heimat der Kegelrobben. Nachdem sie für Jahrhunderte aus diesem Bereich der Nordsee verschwunden waren, siedeln sich die Tiere seit einigen Jahrzehnten wieder vermehrt an. ${ }^{31}$

Mit seiner Rolle als „Kinderstube“ für Nordseefische, aber vor allem als Drehscheibe des ostatlantischen Vogelflugs ist das Ökosystem von internationaler Bedeutung. ${ }^{32}$ Jedes Jahr nutzen 10 bis 12 Millionen Zugvögel die Region als Zwischenstation. ${ }^{33}$ Aber auch viele in Deutschland beheimatete Arten brüten hier. Das Wattenmeer bietet ihnen ein reichhaltiges Nahrungsangebot. Die Energiereserven können gut für den Langstreckenflug oder für die Aufzucht der Jungvögel genutzt werden. Aufgrund dieser herausragenden Relevanz für die Vogelwelt wurde das Gebiet als EU-Vogelschutzgebiet ausgewiesen.

Die Salzwiesen zeichnen sich durch eine sehr hohe Artenzahl von Insekten und hochspezialisierten Wirbellosen aus. Allerdings werden die natürlichen Lebensgemeinschaften durch die Nutzung des Menschen, beispielsweise durch Beweidung, verändert. ${ }^{34}$ Aufgrund der extremen abiotischen Voraussetzungen der Salzwiesen zeigt sich hier eine deutliche Einnischung von Pflanzen und Tieren, die nur hier gedeihen und wachsen können. Darüber hinaus werden die Wiesen auch als Hochwasserrastgebiet von Vögeln genutzt.

\footnotetext{
28 Stock (1995).

29 Stock u. Wilhelmsen (2009).

${ }^{30}$ Niedringhaus et al. (2008).

31 Nationalpark Wattenmeer (2011).

32 Niedringhaus et al. (2008).

33 Stock u. Wilhelmsen (2009).

34 Stock (1996).
} 


\section{Tourismus und Akzeptanz}

\subsection{Tourismus im Nationalpark}

Seit Anfang des 19. Jahrhunderts gilt die deutsche Nordseeküste mit ihren Seeheilbädern als Erholungsort. ${ }^{35}$ Nach dem Ersten Weltkrieg entwickelte sich die Region zu einem der beliebtesten Reiseziele Deutschlands. Mitte der 1990er Jahre zählte man jährlich über 800.000 Touristen. Seit der Einrichtung des Nationalparks hat die Besucherzahl stetig zugenommen. Im Jahr 2006 verzeichnete die Region um das Wattenmeer 30 Millionen Übernachtungen und 16 Millionen Tagesgäste. ${ }^{36}$

Grundsätzlich können zwei Typen von Touristen mit ihren jeweiligen Erwartungen und Motiven unterschieden werden. ${ }^{37}$ Übernachtungsgäste wünschen sich von ihrem Urlaubsziel eine intakte Natur zum Radfahren, Wandern und Entspannen. Bei den Tagesausflüglern hingegen steht nicht das Natur-Erleben oder Entspannung im Fokus, sondern der Ausflug an sich, wie beispielsweise eine Bootstour oder eine Wattführung. Daraus ergibt sich zwischen den beiden Gästegruppen ein Interessenkonflikt. Während die einen nach Erholung suchen, steht bei den anderen das Erleben im Mittelpunkt. Etwa die Hälfte der Übernachtungsgäste stören sich an den Tagesausflüglern, denn diese beeinträchtigen Ruhe und Erholung. ${ }^{38}$ Als Gegenpol zum hektischen Leben in der urbanen Welt wünschen sich viele Menschen einen ungestörten Rückzugsort, wie ihn die Nordseeküste durch ihr Klima und ihre Naturbelassenheit bietet. ${ }^{39}$

Der Tourismus stellt gerade auf den Ostfriesischen Inseln oft den alleinigen Wirtschaftszweig dar. Das Gebiet kann in Bezug auf die Attraktivität für Touristen und den wirtschaftlichen Wert in drei Teilgebiete untergliedert werden. Den größten Erfolg erzielen die, inmitten des Nationalparks gelegenen, Ostfriesischen Inseln; dem schließt sich die Festlandküste an. An dritter Stelle steht das küstennahe Binnenland. ${ }^{40}$

\subsection{Akzeptanz der einheimischen Bevölkerung}

Die Ostfriesen blicken auf eine lange Geschichte mit dem Meer zurück. Sturmfluten und andere Gefahren mussten sie selbst bewältigen. Diese Selbstständigkeit wird durch den Nationalpark eingeschränkt. ${ }^{41}$ Traditionell wurde Fischfang und Viehhaltung betrieben; heute aber leben die Insulaner vom Tourismus. Über 80 \%

\footnotetext{
35 Niedringhaus et al. (2008).

36 Siecke (2006).

37 Hahne (1990).

38 Ebd.

$39 \mathrm{Vgl}$. Ellenberger et al. (1997).

40 Beckmann (2003).

${ }^{41}$ Ebd.; vgl. Jakubowski-Tiessen (2007).
} 
der Arbeitsplätze sind mit dem Fremdenverkehr verbunden. ${ }^{42}$ Die Inseln liegen innerhalb des Nationalparks und stehen somit unter strengem Schutz. Dies bedeutet für die Bewohner stark eingeschränkte Nutzungsmöglichkeiten. ${ }^{43}$ Aufgrund des beginnenden Massentourismus in den 1980er Jahren kam die Frage nach der touristischen Kapazität der Inseln auf. Schon damals wurde für eine Eindämmung des Tourismus appelliert und auf den wachsenden Konflikt zwischen wirtschaftlichem Wachstum und Umweltschutz hingewiesen. ${ }^{44}$ Die Folgen des Massentourismus sind unter anderem zusätzliche Schifffahrten, ein Ausbau der Infrastruktur und ein höherer Wasserbedarf. Dies wirkt sich negativ auf das Ökosystem aus. ${ }^{45}$

Vor diesem Hintergrund ergeben sich Konflikte zwischen Naturschützern und den Gemeinden der Ostfriesischen Inseln. Bei allen Akteuren besteht kein Zweifel daran, dass die Natur schützenswert ist und darüber hinaus als Einnahmequelle fungiert. Die Auseinandersetzung wird vielmehr über den Grad der Umsetzung des Umweltschutzes geführt. Ein sanfter Tourismus erscheint als goldener Mittelweg. ${ }^{46}$ Der Grundgedanke dabei ist, dem Massentourismus mit Umweltverträglichkeit und optimaler Wertschöpfung entgegen zu wirken. Die Insulaner fürchten eine Abnahme der Besucherzahlen durch die starken Einschränkungen. Die Restriktionen sollten ihrer Meinung nach nicht innerhalb des Nationalparks wirken, sondern gegen die Einflüsse von außen wie zum Beispiel die Rohölförderung. ${ }^{47}$

Rentsch untersuchte die Akzeptanz der Einheimischen in Bezug auf den Nationalpark Bayerischer Wald. ${ }^{48}$ Dabei wurde deutlich, je weiter die Ortsansässigen von dem Nationalpark entfernt lebten, desto größer war die Akzeptanz. Von diesem sogenannten „Akzeptanzkrater" kann laut des Sozio-ökonomischen Monitorings (SÖM) der Wattenmeer-Region keine Rede sein. Die Umfragen beziehen sich auf das Schleswig-Holsteinische Wattenmeer; es kann jedoch davon ausgegangen werden, dass sich die Stimmung der Einheimischen bezüglich des Nationalparks auch auf das Niedersächsische Wattenmeer übertragen lässt. Demnach wird der Nationalpark von den Einheimischen akzeptiert. $90 \%$ der Befragten assoziieren ihn mit etwas Positivem. Bei lediglich 0-2\% stößt er auf Ablehnung. Hier spielen vor allem wirtschaftliche Gründe eine Rolle (SÖM 2012).

\footnotetext{
42 Walter (2001).

${ }^{43}$ Davon ausgenommen ist die Erholungszone, die lediglich 0,6 \% ausmacht.

${ }^{44}$ Beckmann (2003).

45 Sieke (2006).

46 Stock et al. (1995).

47 Beckmann (2003).

${ }^{48}$ Rentsch (1988).
} 


\section{$5 \quad$ Fazit}

Das Wattenmeer ist geprägt von Wechselwirkungen zwischen Mensch und Natur. Sturmfluten bedrohten das Leben und forderten Innovationen zum Schutz von Siedlungen und Existenzen. Seit dem 12. Jahrhundert wurden erste Deichbautechniken entwickelt. Mit der stetigen Verbesserung des Deichbaus wurden die Auswirkungen des Meeres beherrschbarer. Nicht nur das Wattenmeer bestimmte das menschliche Dasein, sondern auch der Mensch nahm in bisher unbekanntem Ausmaß Einfluss auf das Ökosystem. Mit der sinkenden Gefahr verheerender Sturmfluten konnte sich die Sicht auf das Watt wandeln. Ästhetische Aspekte und ein neues Naturverständnis gewannen an Bedeutung. Obwohl der Küstenschutz auch aktuell noch eine große Herausforderung darstellt, hat sich das Wattenmeer in der Betrachtung zu einem attraktiven, schützenswerten Ort entwickelt. Die Region zählt zu einem der beliebtesten deutschen Reiseziele und ist gleichzeitig Nationalpark. Die Akzeptanz der einheimischen Bevölkerung bezüglich des Nationalparks scheint hoch. Die Menschen sind daran interessiert, das Ökosystem zu bewahren, womit sich ein markanter Wahrnehmungswandel - von bedrohlich zu schützenswert - zeigt.

\section{Literatur}

Allemeyer M (2006) Kein Land ohne Deich! Lebenswelten einer Küstengesellschaft in der Frühen Neuzeit. Vandenhoeck \& Ruprecht, Göttingen.

Amenda C (2004) Zukunftsperspektiven des Wattenmeers - Möglichkeiten zur Sicherung eines Ökosystems. Diplomarbeit, Hochschule Bremen.

Beckmann O (2003) Die Akzeptanz des Nationalpark Niedersächsisches Wattenmeer bei der einheimischen Bevölkerung. Lang, Frankfurt am Main.

Bibelriether H (1992) Natur Natur sein lassen. In: P. Prokosch (Hg.) Ungestörte Natur - Was haben wir davon? Tagungsbericht 6, Umweltstiftung WWFDeutschland, Husum.

Bunje J (2003) Lebensräume im Wandel. Flächenbilanz von Salzwiesen und Dünen im nds. Wattenmeer zwischen den Jahren 1966 und 1997 - eine Luftbildauswertung. Nationalparkverwaltung Niedersächsisches Wattenmeer, Wilhelmshaven.

Delumeau J (1988) Angst im Abendland. Die Geschichte kollektiver Ängste im Europa des 14. bis 18. Jahrhunderts. Rowohlt, Hamburg.

Ellenberg L, Scholz M, Beier B (1997) Ökotourismus. Reisen zwischen Ökonomie und Ökologie. Spektrum Akademischer Verlag, Heidelberg, Berlin, Oxford. 
Fehmel A (2004) Konfliktfeld Naturschutz am Beispiel der WattenmeerNationalparks. Studienarbeit, Freie Universität Berlin.

Gätje C, Reise K (1998) Ökosystem Wattenmeer: Austausch-, Transport- und Stoffumwandlungsprozesse. Springer-Verlag, Berlin, Heidelberg, New York.

CWSS - Gemeinsames Wattenmeer Sekretariat (2006) Das Wattenmeer: Kulturlandschaft vor und hinter den Deichen. Wissenschaftliche Buchgesellschaft, Darmstadt.

Hahne U (1990) Natur im Watt erleben: Bildungs- und Öffentlichkeitsarbeit im Nationalpark Schleswig - Holsteinisches Wattenmeer. Forschungsstelle für regionale Landeskunde, Flensburg.

Jakubowski-Tiessen M (2007) „Ökodiktatur? Nein danke!“ Der Streit um den „Nationalpark Schleswig-Holsteinisches Wattenmeer“. In: M.L. Allemeyer, M. Jakubowski-Tiessen, S.R. Rufino (Hg.) Von der Gottesgabe zur Ressource. Konflikte um Wald, Wasser und Land in Spanien und Deutschland seit der Frühen Neuzeit. Klartext, Essen, S. 85-95.

Niedringhaus R, Haeseler V, Janisch P (2008) Die Flora und Fauna der Ostfriesischen Inseln - Artenverzeichnisse und Auswertungen zur Biodiversität. Schriftenreihe Nationalparkverwaltung Niedersächsisches Wattenmeer 11.

Nitzschke H (1971) Leege - Bibliographie. In: Arb. Natur- und Landeskunde Ostfriesland 1, S. 129-212.

Piechoki R (2010) Schutz der Natur - Aber welcher und warum? Beck, München.

Rentsch G (1988) Die Akzeptanz eines Schutzgebietes - untersucht am Beispiel der Einstellung der lokalen Bevölkerung zum Nationalpark Bayerischer Wald. Münchener Geographische Hefte 57, Regensburg.

Siecke M (2006) WWF Deutschland. Bilanz über 20 Jahre Nationalpark Niedersächsisches Wattenmeer. abcdruck GmbH, Frankfurt am Main.

Smith T, Smith R (2009) Ökologie. 6. Aufl., Pearson Studium, München.

Ständige Arbeitsgruppe der Biosphärenreservate in Deutschland (Hg.) (1995) Biosphärenreservate in Deutschland: Leitlinien für Schutz, Pflege und Entwicklung. Springer, Berlin.

Stock M (1995) Watt - Lebensraum zwischen Land und Meer. Verlag Boyens \& Co, Heide.

Stock M (1996) Ökosystemforschung Wattenmeer. Synthesebericht Grundlagen für einen Nationalparkplan. Verlag Boyens \& Co, Heide.

Stock M, Wilhelmsen U (2009) Weltnaturerbe Wattenmeer. Wachholtz Verlag, Neumünster. 
Walter J (2001) Die Ostfriesischen Inseln. Studienarbeit, Universität Stuttgart.

\section{Internetquellen}

Bundesamt für Naturschutz (BfN): www.bfn.de/fileadmin/MDB/documents/themen/gebietsschutz/ntp2011.pdf.

Deutsche UNESCO-Kommission e.V.: www.unesco.de/biosphaerenreservate_uebersicht.html.

Nationalpark Wattenmeer Niedersachen: www.nationalparkwattenmeer.de/nds/nationalpark, Steckbrief; Artikel vom 24.01.2011: Geschichte des Nationalparks; Karte des Nationalparks Niedersächsisches Wattenmeer.

NI-VORIS (Niedersächsisches Vorschrifteninformationssystem): www.ndsvoris.de $/$ iportal $/$ ?quelle $=$ purl\&query $=$ WattenmeerNatPG + ND\&psml=bsvorisprod.psml\&doktyp $=$ Gesetze\&max $=$ true.

SÖM-Bericht 2012: Sozio-ökonomisches Monitoring in der Nationalpark-Region, Nationalpark Wattenmeer Schleswig-Holstein: www.nationalparkwattenmeer.de/sites/default/files/media/pdf/soem-bericht-2012.pdf. 


\section{Der Störtebekerdeich - Wechselwirkungen zwischen Mensch und Meer an der Nordseeküste}

Luise Sindl

\section{Einleitung}

Das Meer nahm seit jeher eine wichtige Rolle im Leben der Küstenbewohner ein. Sei es als Nahrungsgrundlage oder als Motiv für die Sehnsucht nach fernen Zielen. Umgekehrt beeinflusste der Mensch im Zuge seiner Besiedlung die Küste. Als Beispiel dient hier der Störtebekerdeich in der Nähe der Stadt Norden im Nordwesten Niedersachsens, der die letzte offene Meeresbucht der ostfriesischen Nordseeküste - die durch Meereseinbrüche und Sturmfluten entstandene Leybucht vom Deichhinterland trennt. Mit der Errichtung des Deiches wurde dem Meer ein Stück Land abgewonnen, auf dem nach der Deichschließung 1950 die neue Gemeinde Leybuchtpolder entstand. Damit waren die Baumaßnahmen an der Leybucht jedoch nicht beendet. Eine umfassende Küstenschutzmaßnahme im letzten Viertel des vergangenen Jahrhunderts veränderte erneut die Gestalt der Bucht und umfasste unter anderem die Erneuerung der Deichlinie.

Dieser kurze Abriss der Geschichte der Leybucht macht deutlich, dass sie sowohl dem Einfluss der Natur als auch - vor allem in jüngerer Zeit - größeren Eingriffen durch den Menschen unterlag. Gleichzeitig fand ein Wandel in der Wahrnehmung der Küste statt, der Auswirkungen auf die Handlungspraktiken der Küstenbewohner hatte. Auch das kann am Störtebekerdeich veranschaulicht werden. 


\section{Sturmfluten und ihre Ursachen}

Die ersten urkundlichen Erwähnungen von Sturmfluten an der Nordseeküste finden sich für das 9. Jahrhundert. Jedoch ist davon auszugehen, dass es sie auch schon vor diesen Aufzeichnungen gab ${ }^{1}$ und sie deshalb bei Analysen der Besiedlungsgeschichte des Küstenraumes einbezogen werden müssen. Aber auch „einfache" Meeresspiegelbewegungen prägten und prägen die Küstengestalt.

Sturmfluten führten in der Vergangenheit zur Entstehung großer Meeresbuchten wie der Leybucht, dem Dollart oder dem Jadebusen. ${ }^{2}$ Eine Sturmflut, die einen kleinen Einbruch der Küstenlinie verursachte, schuf im Frühen Mittelalter die Leybucht. Sie wurde im Laufe der Jahrhunderte durch weitere Sturmfluten vergröBert ${ }^{3}$ und erreichte im Oktober 1374 durch die Dionysusflut mit ca. 13.000 ha ihre größte Ausdehnung. ${ }^{4}$ Die Leybucht erstreckte sich von Norden, das durch die Flut seinen Zugang zum Meer erhielt, ${ }^{5}$ bis auf Sichtweite der Stadt Emden und im Osten bis nach Marienhafe (s. Abb. 1). ${ }^{6}$

Heutige Wasserbauexperten bezeichnen Sturmfluten als ,außergewöhnliche Wasserstandserhöhungen des Meeres, die einerseits durch die Gezeiten (Ebbe und Flut) und andererseits durch einen hohen Windstau verursacht werden. Fallen hohe astronomische Tiden (Springtiden) zeitlich mit sehr hohem Windstau zusammen, so kommt es zu besonders hoch auflaufenden Fluten".7 Die Ursachen sind dementsprechend sowohl in der Meteorologie (Windstärke und Windrichtung) als auch in der Hydrologie (Wasserstandsentwicklung vor der Sturmflut) zu suchen. Zusätzlich spielt die Morphologie eine Rolle, d. h. der Küstenverlauf und die Küstengestalt. Wird zum Beispiel Wasser durch die Sturmfluten in Flussmündungen gedrückt, kommt es dort zu besonders hohen Wasserständen. ${ }^{8}$ Sturmfluten treten an der Nordseeküste relativ häufig auf, ${ }^{9}$ besonders im Spätherbst und Frühling. ${ }^{10}$ Bei einer Fluthöhe von 2,80-3,80 m über NN spricht man von leichten, bei einer Fluthöhe über 3,80 m über NN von schweren Sturmfluten. ${ }^{11}$ Bei Meeresspiegelschwankungen wird zwischen eustatischen und isostatischen Effekten unterschieden. Mit eustatisch werden diejenigen Effekte bezeichnet, die durch das Festlegen von Wasser in Eis bzw. durch das Schmelzen des Eises hervorgerufen werden, während die isostatischen durch Ausgleichsbewegungen der Erdkruste (Ab-

\footnotetext{
1 Vgl. Egidius (2003), S. 27.

2 Vgl. Rapsch et al. (2006), S. 4.

${ }^{3}$ Vgl. Kramer u. Rohde (1992), S. 217.

4 Vgl. NLWKN: www.nlwkn.niedersachsen.de/portal/live.php?navigation_id=8442\&article _id=43552\&_psmand=26 (Abruf: März 2013).

${ }^{5}$ Vgl. Kramer u. Rohde (1992), S. 217.

${ }^{6}$ Vgl. Rapsch et al. (2006), S. 41.

${ }^{7}$ Egidius (2003), S. 27.

8 Vgl. Jakubowski-Tiessen (1992), S. 3.

${ }^{9}$ Vgl. ebd.

${ }^{10}$ Vgl. Egidius (2003), S. 27.

11 Vgl. ebd.
} 
senken oder Anheben) entstehen. Die Ausgleichsbewegungen sind abhängig von der Gewichtslast des Eises; schmilzt das Eis, verliert es an Gewichtskraft und die Erdkruste hebt sich nach oben. ${ }^{12}$ Verschiebt sich die Küstenlinie landeinwärts, spricht man von Transgression, bei einer Verschiebung seewärts von Regression. ${ }^{13}$

\section{Küstenkultur}

Die Veränderungen an der Nordseeküste waren durch eine fortschreitende Transgression gekennzeichnet, die aber immer wieder von Ruhephasen in der Meeresspiegelbewegung und teilweise sogar von Regressionen unterbrochen wurde. Da sich die Menschen den Meeresspiegelschwankungen anpassen mussten, war auch die Ausdehnung des Besiedlungsraumes einem ständigen Wandel unterworfen. ${ }^{14}$ Während längerer Regressionsphasen entstand neues Marschland. An Flüssen und Prielen war die Sedimentierung durch die geringe Gezeitenströmung besonders stark. An diesen Stellen entstanden höhere Uferwälle, die aufgrund ihrer Schutzfunktion bei hohen Wasserständen eine wichtige Rolle bei der Besiedlung der Küste spielten. Die erste in Deutschland nachgewiesene Siedlung entstand zwischen 1000 und 700 v. Chr. an der Hahnenkooper Mühle bei Rodenkirchen, auf dem Uferrücken eines Wasserlaufs. ${ }^{15}$

Hinter den Uferwällen wurden kaum Schwebstoffe abgelagert, sodass die Marschen auf der Seeseite höher wurden und sich eine Barrierewirkung einstellte. Daraufhin entwässerten die im Hinterland gelegenen Bereiche immer schlechter, was zur Entstehung von Mooren, Seen und Schilfsümpfen führte. Diese siedlungsfeindlichen Areale konnten erst durch die mit der Bedeichung einhergehende Entwässerung für den Menschen nutzbar gemacht werden. ${ }^{16}$

In Folge eines erneuten Meeresspiegelanstiegs und eines Absenkens der Küsten waren die Küstenbewohner aber letztendlich gezwungen, Schutzmaßnahmen zu ergreifen, um ihre Siedlungen zu erhalten.

\subsection{Schutzmaßnahmen}

Historisch können zwei unterschiedliche Phasen von Schutzmaßnahmen vor Sturmfluten unterschieden werden: die Wurten- und die Deichbauphase.

Der Wurtenbau begann ca. um 100 n. Chr. Bei Wurten handelt es sich um künstlich errichtete Erdhügel bestehend aus Mist und Marschboden (Klei), auf denen Siedlungen erbaut werden konnten. ${ }^{17}$ Meistens entstanden sie auf Uferwäl-

\footnotetext{
12 Vgl. Behre (1987), S. 9.

13 Vgl. ebd.

${ }^{14}$ Vgl. ebd., S. 11-15; Allemeyer (2006).

15 Vgl. Behre (1987), S. 19.

${ }^{16}$ Vgl. Meier (2005), S. 48 f.

17 Vgl Behre (1987), S. 25 f.
} 
len an Flussunterläufen oder an höheren Stellen im Küstengebiet. ${ }^{18}$ Entsprechend ihrer Größe kann zwischen Dorfwurten, die Platz für ganze Dörfer boten, Wohnwurten und Hauswurten, auf denen nur eine einzige Familie mit ihrem Hof Platz fand, unterschieden werden. Dorfwurten konnten eine Höhe von $10 \mathrm{~m}$ und eine Fläche bis zu 15 ha erreichen. ${ }^{19}$ In Abhängigkeit vom Anstieg des Sturmflut- und des Meeresspiegels wurden die Wurten immer weiter erhöht, ${ }^{20}$ bis sie nicht mehr ausreichend Schutz boten und der Deichbau den Wurtenbau ablöste.

Der Deichbau begann ungefähr 1000 n. Chr. ${ }^{21}$ Anfangs wurden noch kleinere Wurten im Schutz der Deiche errichtet, ${ }^{22}$ was sich aber mit der sukzessiven Verbesserung der Deiche änderte. Die Küstenbewohner bauten einzelne Ringdeiche um ihre Siedlungen und Äcker, die bis zum 13. Jahrhundert zu dem sogenannten „Goldenen Ring“, einer zusammenhängenden, parallel zur Küste verlaufenden Deichkette, verbunden wurden. ${ }^{23} \mathrm{Ab}$ dem 16. Jahrhundert führte die verbesserte Deichbautechnik dazu, dass die Landgewinne die durch Sturmfluten hervorgerufenen Landverluste überwogen. ${ }^{24}$ Ebenso wie die Wurten- wurde die Deichhöhe kontinuierlich dem steigenden Wasserstand angepasst. ${ }^{25}$

In Folge des Deichbaus und immer höher auflaufender Sturmfluten war die Küstenlinie von ständigen Veränderungen gekennzeichnet. Besonders anschaulich ist dies an der Leybucht und dem Störtebekerdeich festzumachen. Durch zahlreiche Einpolderungen (Abb. 1) ist von der ursprünglichen Größe der Bucht nur noch ein Bruchteil vorhanden. Dadurch verlor unter anderem die Stadt Norden ihren Zugang zum Meer und somit ihre Bedeutung als Hafenstadt.

1498 wurde mit der Rückgewinnung des durch die Angriffe des Meeres verlorengegangenen Landes begonnen, indem der erste Polder eingedeicht wurde. ${ }^{26}$ Bis zum Ende des 16. Jahrhunderts folgten weitere Eindeichungen. Aufgrund der technischen Möglichkeiten beschränkte man sich damals auf die Rückgewinnung flacher Randgebiete der Bucht, da diese schnell verlandeten und deren Einpolderungen somit einfacher waren. Ein zweiter Landgewinnungszeitraum erstreckte sich vom Beginn des 17. bis zum Ende des 19. Jahrhunderts. Das Anwachsen des Deichvorlandes wurde ohne größere menschliche Eingriffe abgewartet und erst, nachdem das Vorland eine ausreichende Größe erlangt hatte, wurde die Deichlinie vorverlegt. In diesem Zeitraum entstanden 13 neue Polder.

\footnotetext{
18 Vgl. Behre (1987), S. 29.

19 Vgl. Egidius (2003), S. 14, 17.

${ }^{20}$ Vgl. Behre (1987), S. 27, 31-34.

21 In unterschiedliche Quellen lassen sich zu dem Anfang des Deichbaus unterschiedliche Angaben (vom 9. bis zum 11. Jahrhundert n. Chr.) finden. Daher habe ich mich für den Mittelwert (1000 n. Chr.) entschieden.

22 Vgl. Egidius (2003), S. 17.

23 Vgl. Rapsch et al. (2006), S. 8.

24 Vgl. ebd., S. 34.

$25 \mathrm{Vgl}$. Meier (2005), S. 69.

26 In Bezug auf die Jahreszahlen der Einpolderungen gibt es auch hier Abweichungen in unterschiedlichen Quellen. Im Folgenden wird Bezug auf Kramer u. Rohde (1992) genommen.
} 
Von 1918 bis 1950 folgte die Errichtung mehrerer größerer Polder, von denen zuletzt der Leybuchtpolder durch den Bau des Störtebekerdeichs von 1947 bis 1950 fertiggestellt wurde. Durch diese zahlreichen Baumaßnahmen an der Küste der Leybucht, die nicht nur von Erfolg, sondern auch von vielen Rückschlägen durch Sturmfluten und Deichbrüche begleitet wurden, wurden insgesamt ca. 10.000 ha Land zurückgewonnen. Damit waren die Landgewinnungs- und Schutzmaßnahmen an der Leybucht vorläufig beendet. ${ }^{27}$

Die Besiedlung des Leybuchtpolders begann 1952 und führte schließlich zur Gründung der gleichnamigen Gemeinde am 1. Juli 1954. ${ }^{28}$ Damit wurde die Veränderung der Küstenlandschaft in der Leybucht erst einmal abgeschlossen.

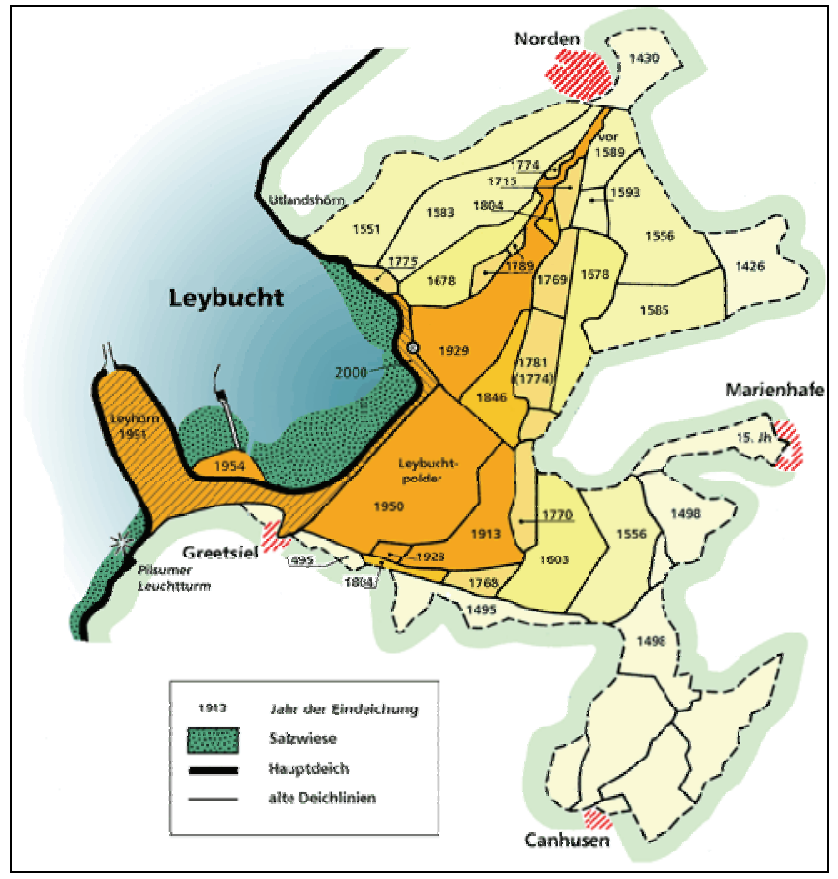

Abb. 1: Einpolderungen der Leybucht mit aktueller und alter Deichlinie. ${ }^{29}$

Neben dem traditionellen Deichbau umfassen heutige Schutzmaßnahmen auch Methoden wie Sandvorspülungen, um die Sandverluste durch Erosion auszugleichen, ${ }^{30}$ oder das Anlegen von Muschelbänken und Seegraswiesen, um Sedimentab-

27 Vgl. Kramer u. Rohde (1992), S. 217 ff.

28 Vgl. Homepage der Stadt Norden:

www.norden.de/index.phtml?object $=\mathrm{tx} \% 7 \mathrm{C} 1.806 .1 \% 7 \mathrm{C} \& \operatorname{ModID}=7 \& \mathrm{FID}=1652.527 .1$ (Abruf: März 2013).

${ }^{29}$ NLWKN: www.nlwkn.niedersachsen.de/portal/live.php?navigation_id=8442\&article_id= 43552\&_psmand=26 (Abruf: März 2013).

$30 \mathrm{Vgl}$. CPSL (2005), S. $20 \mathrm{ff}$. 
lagerungen zu fördern und zu stabilisieren. ${ }^{31}$ Außerdem versucht die Raumplanung eine nachhaltige Nutzung und Entwicklung der Küstenregion durch die Berücksichtigung sozialer, wirtschaftlicher und ökologischer Anforderungen zu verwirklichen. ${ }^{32}$ Solche Tätigkeiten sind neben dem ,herkömmlichen“ Schutz vor Sturmfluten und Erosion angesichts des mit dem Klimawandel einhergehenden Meeresspiegelanstiegs von großer Wichtigkeit.

Bei aktuellen Küstenschutzprojekten in der Leybucht zeigt sich, wie ökologische, wirtschaftliche und technische Aspekte miteinander in Einklang gebracht werden müssen. Obwohl nach Abschluss der Eindeichung 1950 vorgesehen war, keine weiteren Landgewinnungsmaßnahmen durchzuführen und stattdessen große Naturschutzgebiete entstehen zu lassen, die die Leybucht als offene Bucht erhalten sollten, ${ }^{33}$ wich man auf Grund weiterer Sturmfluten in den Jahren 1962 und 1976 von diesen Plänen ab. 1985 wurde mit dem Bau eines neuen Deiches begonnen, der als Teil einer umfassenden Entwässerungs- und Küstenschutzmaßnahme die alte Deichlinie des Störtebekerdeichs weiter in die Bucht hinein verschob (Abb. 2). So sollten Überschwemmungen im Küstengebiet vermieden werden. Die ursprüngliche Idee, die Bucht vollständig einzudeichen, wurde insbesondere aus Naturschutzgründen verworfen. Auch Beschwerden seitens des Fischerdorfes Greetsiel, das seinen Anschluss zum Meer und somit an touristischer Attraktivität verloren hätte, führten zu der Offenhaltung der Bucht. Im Oktober 2000 wurde der neue Störtebekerdeich geschlossen. Weitere Baumaßnahmen umfassten die Errichtung eines neuen Siels und Sperrwerks im westlichen Bereich des Deiches zur Entwässerung des Deichhinterlandes. Dazu dient ein ca. 200 ha großes Speicherbecken, in das bei Bedarf überschüssiges Wasser aus dem Binnenland abgepumpt wird, z. B. bei Überschwemmungen durch Sturmfluten.

Zum Ausgleich für die durch die Deichvorverlegung hervorgerufenen Flächenverluste wurde das ca. 680 ha große Naturschutzgebiet Leyhörn ausgewiesen. Es befindet sich innerhalb der neu errichteten westlichen Deichnase und besteht aus dem Speicherbecken und umgebenden Flächen. Im Speicherbecken sollen sich sowohl Salz- als auch Süßwasserarten etablieren. Auch außerhalb dieser künstlich errichteten Halbinsel wurden Ausgleichsmaßnahmen vorgenommen. Beispielsweise wurde der Sommerpolder Hauener Hooge geöffnet, um die Entstehung von Salzwiesen zu fördern und so diejenigen Salzwiesen zu ersetzen, die durch die neue Bedeichung zerstört wurden. ${ }^{34}$ Das Naturschutzgebiet Leyhörn ist generell ein wichtiger Brut- und Rastplatz für viele Vogelarten. Allerdings sind laut NABU manche Naturschutzziele nicht erreicht worden: Die Ansiedlung von Salzwasserarten wird durch das ins Speicherbecken eingeleitete Binnenwasser und den Schluss

\footnotetext{
31 Vgl. CPSL (2005), S. 33 f.

32 Vgl. ebd., S. 17 ff.

33 Vgl. Kramer u. Rohde (1992), S. 231.

$34 \mathrm{Vgl}$. NLWKN:

www.nlwkn.niedersachsen.de/hochwasser_kuestenschutz/kuestenschutz/ausgewaehlte_projekte/kuestenschutzprojekt_leybucht/43552.html (Abruf: März 2013).
} 
der Sielklappen und Schleusentore erschwert, sodass anstelle von Watvögeln wie der Säbelschnäbler Singvögel wie die Blaumeise das Gebiet besiedeln. ${ }^{35}$

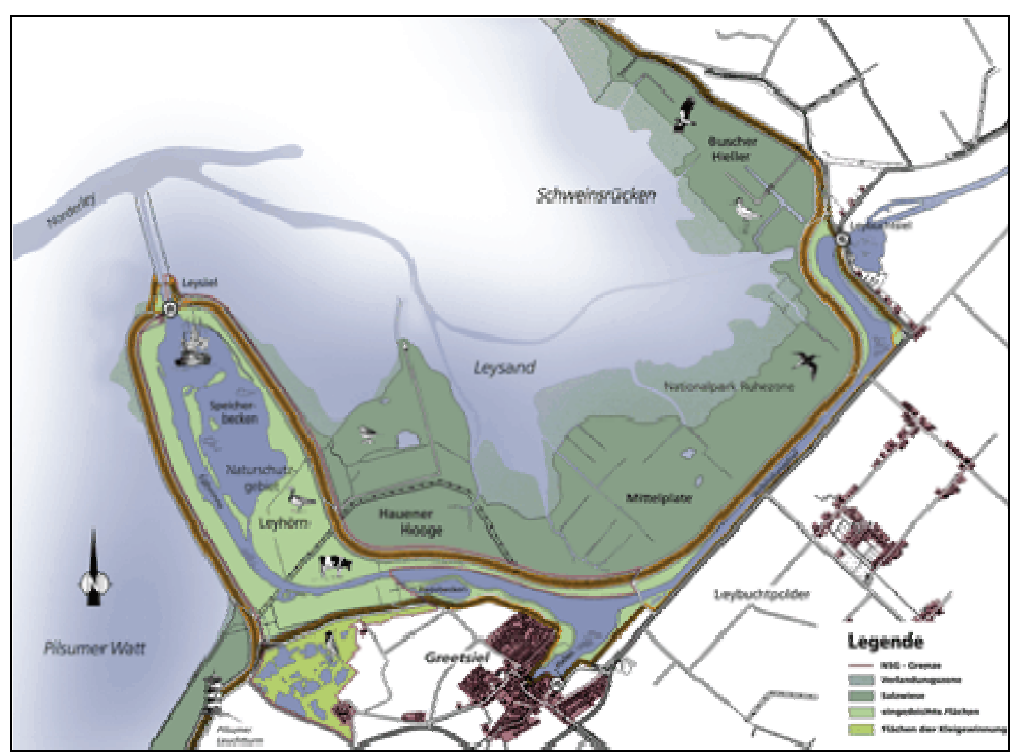

Abb. 2: Die Küstenschutzmaßnahme Leybucht nach der Fertigstellung. ${ }^{36}$

\subsection{Folgen des Deichbaus}

Der Deichbau brachte auch neue Risiken mit sich. Durch die Eindeichung des Vorlandes erhöhte sich der Sturmflutpegel und entwickelte somit eine größere Zerstörungskraft als bei einer ungehinderten Ausbreitung der Flut über das ungeschützte Land. Deshalb können die stärkeren Sturmfluten seit dem 13. Jahrhundert als anthropogen verursacht angesehen werden. ${ }^{37}$ Außerdem musste das Wasser bei Sturmfluten nun auf Buchten und Flussmündungen ausweichen; durch den verstärkten Druck auf die dortigen Deiche brachen diese häufiger als die Seedeiche.

Die fruchtbaren Böden der Küstenregion führten trotz der Gefahren, die das Meer mit sich brachte, zu einer flächendeckenden Besiedlung. Das Marschland konnte jedoch erst nach Eindeichung und Entwässerung genutzt werden. ${ }^{38}$ Der Deichbau wurde also nicht nur als Schutz-, sondern auch als Landgewinnungsmaßnahme eingesetzt, sodass die zerrissene Nordseeküste, die von vielen kleinen Inseln, Einbrüchen und Prielen unterbrochen war, nach und nach einen relativ

\footnotetext{
35 Vgl. NABU: www.nabu.de/nabu/nh/jahrgang2006/heft4/05694.html (Abruf: März 2013).

${ }^{36}$ NLWKN:

www.nlwkn.niedersachsen.de/hochwasser_kuestenschutz/kuestenschutz/ausgewaehlteprojekte/kuestenschutzprojekt_leybucht/sperrwerk_leysiel/38898.html (Abruf: März 2013).

37 Vgl. Meier (2005), S. 87.

38 Vgl. ebd., S 86.
} 
regelmäßigen und „glatten“ Küstenverlauf bekam. ${ }^{39}$ Unterstützend zu den natürlichen Verlandungsprozessen in Buchten, die aufgrund ihrer Breite bereits einen abgeschwächten Wellengang und eine geringere Tidenströmung aufweisen, wurden und werden Buhnen und Lahnungen als Erosionsschutz und zur Förderung der Sedimentation von Schwebpartikeln eingesetzt. Nach ausreichendem Anwachsen des Vorlandes konnte es eingedeicht werden. ${ }^{40}$ Insgesamt belief sich der Landverlust seit dem 14. Jahrhundert auf ca. $400 \mathrm{~km}^{2}$; dies konnte bis heute durch einen Landgewinn von ungefähr der gleichen Größe ausgeglichen werden. ${ }^{41}$

\subsection{Inszenierungen der Küste}

Bei der Benennung des Störtebekerdeichs berief man sich auf den der Sage nach im 14. Jahrhundert lebenden Freibeuter Klaus Störtebeker, ${ }^{42}$ der im ostfriesischen Marienhafe Unterschlupf gesucht haben soll. Mit dem Rückgriff auf diesen sagenumwobenen mittelalterlichen Piraten wurde an eine tradierte, noch heute in Ostfriesland lebendige Legende angeknüpft, was sicher nicht zuletzt auch in identifikatorischer Absicht geschah. Ob der Name Störtebeker zugleich auch für Widerständigkeit steht, die sein Handeln einst auszeichnete, und welche nun in analoger Symbolik auszeichnen soll, als Bollwerk gegen die Gewalten des Meeres, mag dahingestellt bleiben.

Der Kampf mit der Natur gehört zur Geschichte der Nordseeküste, er ist Teil ihrer Identität. Denkmäler für die Auf-See-Gebliebenen, für Sturmfluten und namenlose Opfer erinnern daran. Sie sind „küstenspezifische Aktualisierungen der eigenen Vergangenheit. “43 Diese tragen zu einer regionalen Identitätsbildung bei. ${ }^{44}$ Das „Sichtbarmachen“ der eigenen Vergangenheit stärkt den Zusammenhalt und das „Wir-Gefühl“; es entsteht ein „lokales Selbstbewusstsein“45.

Veranschaulicht werden diese Interpretationsmöglichkeiten in den beiden Denkmälern am Störtebekerdeich, die jeweils zum Bauende der Deiche 1950 (Abb. 3) und 2000 (Abb. 4) errichtet wurden. Innerhalb von 50 Jahren entstanden zwei Denkmäler am gleichen Ort. Ihre Existenz spiegelt die Kurzlebigkeit und den kontinuierlichen Wandel der Küste wider. Die Denkmäler erinnern nicht nur an die Veränderung der Küstengestalt; sie sind als in der Landschaft stehende Monumente selbst Teil davon. Im Gegensatz zu den meisten Denkmälern erinnern diese nicht an ein einmaliges Ereignis, sondern an das wiederholte Bemühen, den Ein-

\footnotetext{
39 Vgl. Kramer u. Rohde. (1992), S. 210.

${ }^{40}$ Vgl. Rapsch et al. (2006), S. 39 f.

${ }^{41}$ Vgl. Homeier (1992), zitiert nach Kramer u. Rohde (1992), S. 211.

42 Vgl. Planet Wissen:

www.planet-wissen.de/politik_geschichte/verbrechen/piraten/portraet.jsp (Abruf: September 2013).

43 Vgl. Fischer et al. (2007), S. 12.

${ }^{44}$ Vgl. Schmidt-Lauber (2007), S. 185, 207.

45 Vgl. ebd., S. 208.
} 
fluss des Meeres auf die Küste gering zu halten, und unterstreichen somit auch die ständige Veränderung der Küstenlandschaft.
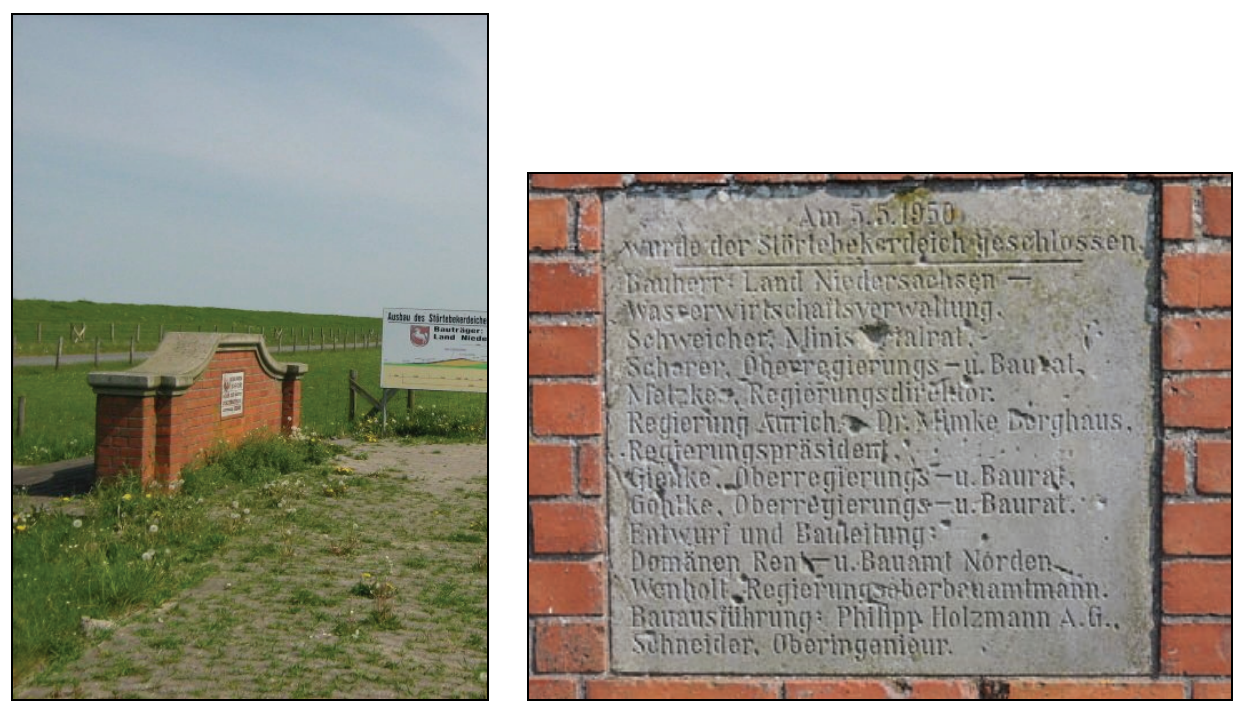

Abb. 3: Das Denkmal am alten Deich (links); Denkmalplatte im Denkmal am alten Deich (rechts). ${ }^{46}$

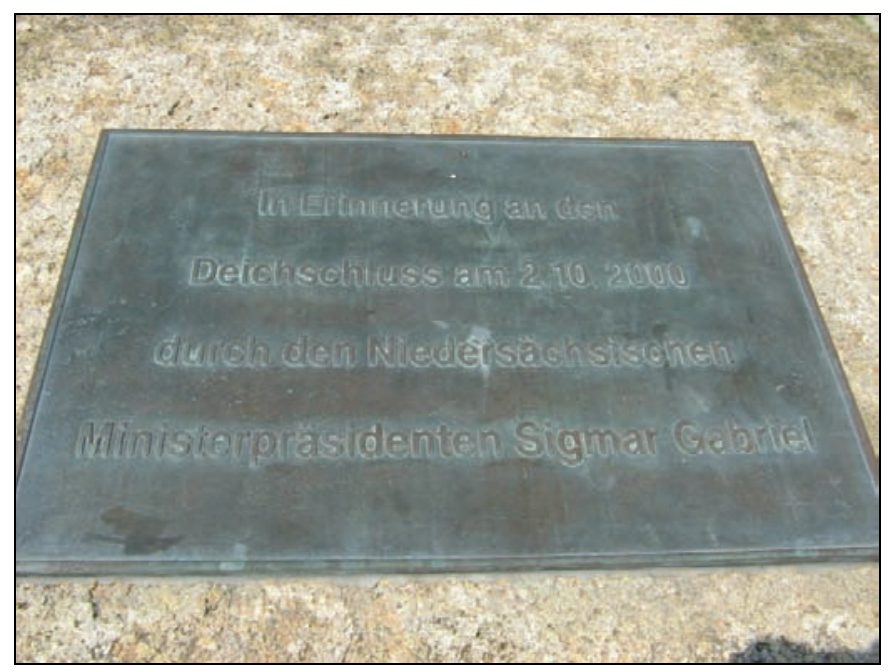

Abb. 4: Denkmalplatte am neuen Deich.

${ }^{46}$ www.ferienwohnungen-juergen-mueller.de/cpg132/displayimage.php?album $=8 \&$ pos $=6$. 


\section{Fazit}

Die Nordseeküste war in ihrer Gestalt schon immer einem Wandel unterworfen. In dem Wechselspiel aus Landgewinn und Landverlust nahmen sowohl der Mensch als auch die Natur wichtige Rollen ein. Während die Küstenbewohner versuchten ihren Lebensraum gegenüber dem Meer zu behaupten und ihm Fläche abzugewinnen, wurden immer wieder Landflächen vom Wasser überspült und besonders durch Sturmfluten wieder dem Meer zugeführt. Das Beispiel des Störtebekerdeichs zeigt die gegenseitige Beeinflussung von Mensch und Meer und die damit einhergehenden Veränderungen. So stehen die Denkmäler an der neuen sowie der alten Deichlinie nicht einfach nur für die technische Fertigstellung dieser Bauwerke, sondern gleichzeitig für die wechselvolle Geschichte der Leybucht und der Nordseeküste. Besonders die Tatsache, dass zwei Denkmäler für nur einen Deich existieren, macht auf die ständigen Veränderungen im Küstenbereich aufmerksam. Während der Mensch jedoch nur äußerliche Spuren an der Küstengestalt hinterließ, verursachte die Natur bei den Menschen auch innerliche Reaktionen in Bezug auf ihren Glauben und ihre Wahrnehmung und rief unterschiedliche Rezeptionen hervor. Die Ebenen, auf denen die Nordseeküste im Allgemeinen und der Störtebekerdeich im Besonderen als Schauplatz der Umweltgeschichte betrachtet werden können, sind also vielfältig. Der Mensch hat dabei entscheidend an der Küstengestalt mitgewirkt. Nicht umsonst heißt es in dem lateinischen Sprichwort Deus mare, friso litora fecit: Gott schuf das Meer, der Friese die Küste. ${ }^{47}$

\section{Literatur}

Allemeyer ML (2006) „Kein Deich ohne Land!“ - Lebenswelten einer Küstengesellschaft in der Frühen Neuzeit. Vandenhoeck \& Ruprecht, Göttingen.

Behre K-E (1987) Meeresspiegelbewegungen und Siedlungsgeschichte in den Nordseemarschen. Heinz Holzberg Verlag, Oldenburg.

CPSL (2005) Coastal Protection and Sea Level Rise - Solutions for sustainable coastal protection in the Wadden Sea Region. Wadden Sea Ecosystem No. 21. Common Wadden Sea Secretariat, Trilateral Working Group on Coastal Protection and Sea Level Rise (CPSL), Wilhelmshaven, Gemany.

Egidius H (2003) Sturmfluten - Tod und Verderben an der Nordseeküste von Flandern bis Jütland. Concept-Center-Verlag, Varel.

Fischer N, Müller-Wusterwitz S, Schmidt-Lauber B (Hg.) (2007) Inszenierungen der Küste. Reimer, Berlin.

\footnotetext{
47 Übersetzung: Rieken (2005), S. 26.
} 
Jakubowski-Tiessen M (1992) Sturmflut 1717 - Die Bewältigung einer Naturkatastrophe in der Frühen Neuzeit. Oldenbourg Verlag, München.

Kramer J, Rohde H (1992) Historischer Küstenschutz: Deichbau, Inselschutz und Binnenentwässerung an Nord- und Ostsee. Wittwer, Stuttgart.

Meier D (2005) Land unter! Die Geschichte der Flutkatastrophen. Thorbecke, Ostfildern.

NABU: www.nabu.de (Abruf: März 2013).

Niedersächsischer Landesbetrieb für Wasserwirtschaft, Küsten- und Naturschutz (NLWKN). Küstenschutz-Projekt Leybucht. www.nlwkn.niedersachsen.de (Abruf: März 2013).

Homepage der Stadt Norden: www.norden.de (Abruf: März 2013).

Pelc O (2010) Katastrophen in Norddeutschland - Vorbeugung, Bewältigung und Nachwirkungen vom Mittelalter bis ins 21. Jahrhundert. Wacholtz, Neumünster.

Planet Wissen: www. planet-wissen.de (Abruf: September 2013).

Rapsch H-J, Niemeyer HD, Peters KH (2006) Wider den Blanken Hans: der Kampf an der Nordseeküste um Land und Leben. Wachholtz, Neumünster.

Rieken B (2005) Nordsee ist Mordsee - Sturmfluten und ihre Bedeutung für die Mentalitätsgeschichte der Friesen. Waxmann, Münster. 



\title{
Salziges Lüneburg
}

\author{
Katharina Stephan
}

\section{Einleitung}

„Kalkberg, Solquell und Wasserstraßen, [...] - in der Tat ein Dreiklang, dem über die poetische Form ,Mons, Fons, Pons` hinaus die sinnigste Bedeutung innewohnt, wenn es gelten soll, die schöpferischen Lebensbedingungen Lüneburgs ganz knapp zu umreißen. “1

Die Stadt Lüneburg mit ihren etwas über 72.000 Einwohnern liegt am Unterlauf der Illmenau etwa $50 \mathrm{~km}$ südöstlich von Hamburg. Ihr unterirdischer Salzvorrat und ihre für den Handel günstige Lage bescherten Lüneburg einen frühen Wohlstand. Da die Stadtentwicklung wie die Zahnräder eines Uhrwerks mit der Saline gekoppelt war, besteht Lüneburgs altes Salzwerk heute immer noch als Industriedenkmal und es ist ohne Zweifel ein umweltgeschichtlicher Erinnerungsort. Wie die Geschichte Lüneburgs durch den Rohstoff Salz geprägt wurde, hat umgekehrt die menschliche Wirtschaftsweise ihre Spuren in der Umwelt hinterlassen. ${ }^{2}$ Die Lüneburger Heide ist ein Paradebeispiel einer Kulturlandschaft. Ohne Jahrhunderte lange Nutzung wäre dort heute Wald anstatt Heide vorzufinden. ${ }^{3}$ Menschen formen ihre Umgebung nach ihren Vorstellungen, erschaffen bewusst oder unbewusst durch ihre wirklichkeitsändernden Handlungen neue „Weltbilder“. ${ }^{4}$ Die

\footnotetext{
1 Vgl. Reinecke (1977), S. 8 (vlg. Abb. 5).

2 Vgl. Cordes (1997), S. 49.

3 Siemann u. Freytag (2003), S. 17.

${ }^{4}$ Herrmann (2013), S. 1.
} 
Wechselwirkungen zwischen Mensch und Umwelt zu verstehen, ist Ziel der Umweltgeschichte. ${ }^{5}$ Bei der Erforschung von Lüneburgs Geschichte wird eine solche Ambivalenz zwischen Mensch und Natur deutlich. Die Entdeckung des unterirdischen Salzstocks hatte Folgen für die Landschaftsentwicklung der Umgebung und ist untrennbar mit der Lebens- und Wirtschaftsweise der Bewohner der Stadt verknüpft. Von wo aus man auch immer auf den geschichtlichen Pfaden Lüneburgs wandeln möchte, es kann stets einer Salzspur gefolgt werden, die sich wie ein weiBer Faden durch die Entwicklung der Stadt zieht.

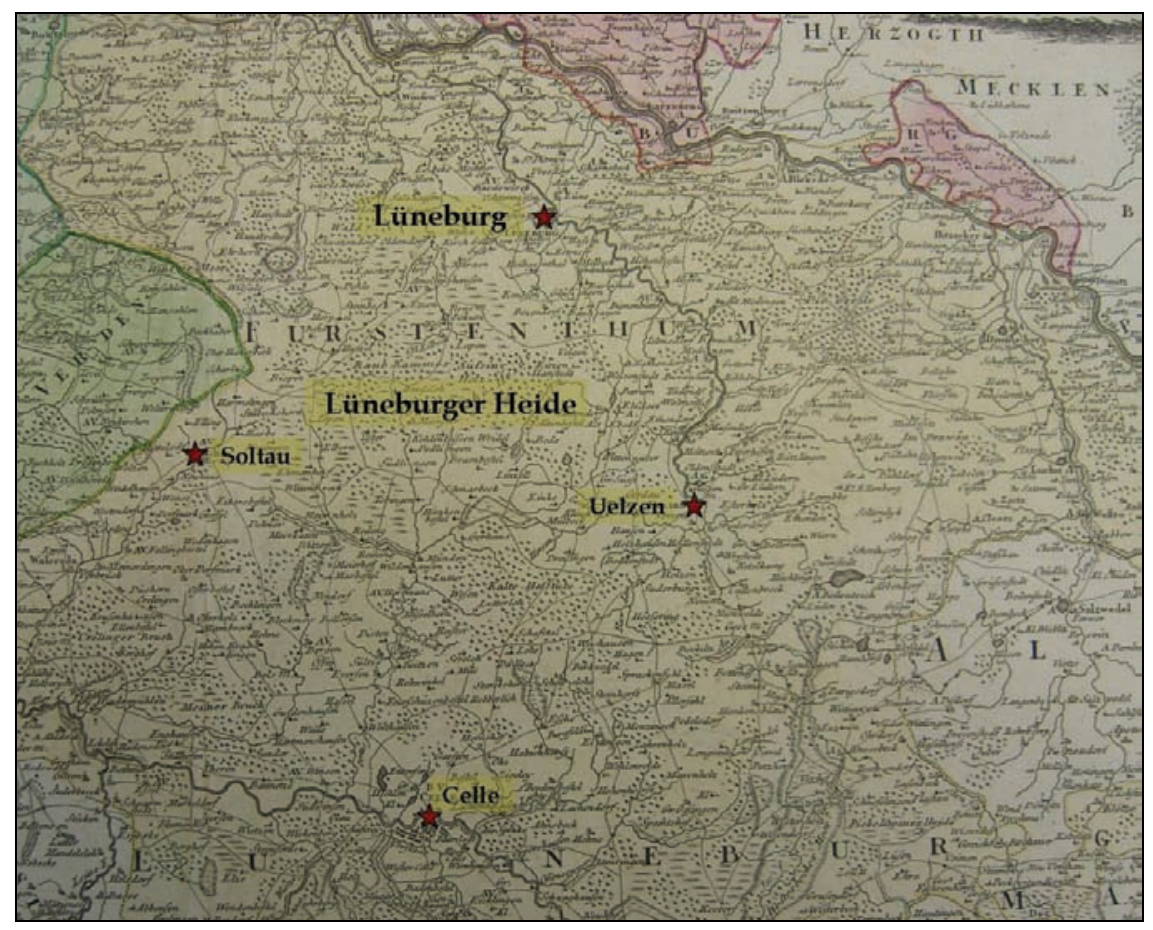

Abb. 1: Geographische Lage Lüneburgs, 1786 (Karte: SUB Göttingen, MAPP 7625, leicht verändert).

\section{Das weiße Gold}

„Das kostbarste aller Edelsteine ist das Salz“, schrieb der Chemiker Justus Liebig (1803 bis 1873). Dieses weiße Mineral ist nicht allein ein lebenswichtiger Stoff, sondern hat in früheren Jahrhunderten zu städtischem Wohlstand geführt. Lüneburg verdankte seinen heute immer noch sichtbaren Reichtum diesem Boden-

\footnotetext{
${ }^{5}$ Brüggemeier (2004), S. 66; Siemann u. Freytag (2003), S. 13.
} 
schatz. ${ }^{6}$ Das Erscheinungsbild der Stadt, das gesellschaftliche Leben und die ganze Politik waren geprägt und beherrscht durch das Salzvorkommen rund um den Kalkberg. ${ }^{7}$

Um das kostbare Gut Salz wurden zu früheren Zeiten sogar Kriege geführt; heute ist es nahezu allen zugänglich. Das Geschäft mit dem Salz war in alten Zeiten so lohnend, dass Heinrich der Löwe im Jahre 1156 die alte Isarbrücke im bayerischen Freising zerstören ließ, um sich am florierenden Salzhandel beteiligen zu können. So musste das in Bad Reichenhall abgebaute Salz von da an die Brücke in seiner Stadt München passieren und die dafür zu zahlenden Mauteinnahmen trugen zu Münchens Reichtum und seiner späteren Bedeutung bei. ${ }^{8}$ Salz war so kostbar, dass Beamte und Soldaten für ihre Dienste gelegentlich damit entlohnt wurden. Seit 600 n. Chr. werden immer wieder Salzschiffe auf Rhein, Donau und Mosel erwähnt. ${ }^{9}$ Allerdings ist der Salzhandel nicht kontinuierlich zurückzuverfolgen, die Nachweise für Halle an der Saale und weiter südlich gelegene Zentren brechen in der römischen Kaiserzeit ab. Seine Wiederaufnahme wird auf das frühe Mittelalter datiert, der genaue Zeitpunkt aber liegt im Dunkeln. ${ }^{10}$ Für Mittel- und Nordeuropa ist bekannt, dass sich seit dem frühen und hohen Mittelalter drei Salzgewinnungszentren herausbildeten - die Ostalpen (mit Reichenhall, Hallstatt, Hallein, Hall/T.), „das obere Seilletal in Lothringen“ (mit Vic, Moyenvic, Marsal) und „das Elbe-Saale-Gebiet" (mit Halle/S. und Lüneburg).11

Da Lüneburg im Zweiten Weltkrieg weitgehend unzerstört blieb und die Fassaden der Häuser in den 1950er und 1960er Jahren restauriert wurden, lässt sich noch der frühere Reichtum der Stadt durch den Salzhandel an den prachtvollen Giebelhäusern erkennen. Die heutige Bedeutung von Salz reicht nicht mehr ansatzweise an diejenige heran, die es noch im Mittelalter hatte. Zwar war Salz auch da ein viel genutztes Gewürz, aber bedeutender war sein Gebrauch als Konservierungsmittel. Zu Zeiten, in denen Kühlschränke noch nicht existierten, konnten so Fleisch und Fisch haltbar gemacht und Lebensmittelvorräte angelegt werden. Zusätzlich war es möglich, Handel mit diesen Waren zu betreiben und das Salz wurde zur wirtschaftlichen Grundlage vieler Händler im Mittelalter. Um $1 \mathrm{~kg}$ Fleisch zu konservieren, wurden z. B. 100 g Salz benötigt. ${ }^{12}$

\footnotetext{
${ }^{6}$ Kahle (1983), S. 6; Lehmann-Brune u. Petersen (2010), S. 12.

${ }^{7}$ Kahle (1983), S. 5; Kühlborn (2005), S. 265.

8 Reichlmayr (2013), S. 15.

9 Vgl. Witthöft (2010), S. 7.

10 Vgl. ebd.

11 Ebd., S. 7 f.

12 Pump u. Pump (2009), S. 6.
} 


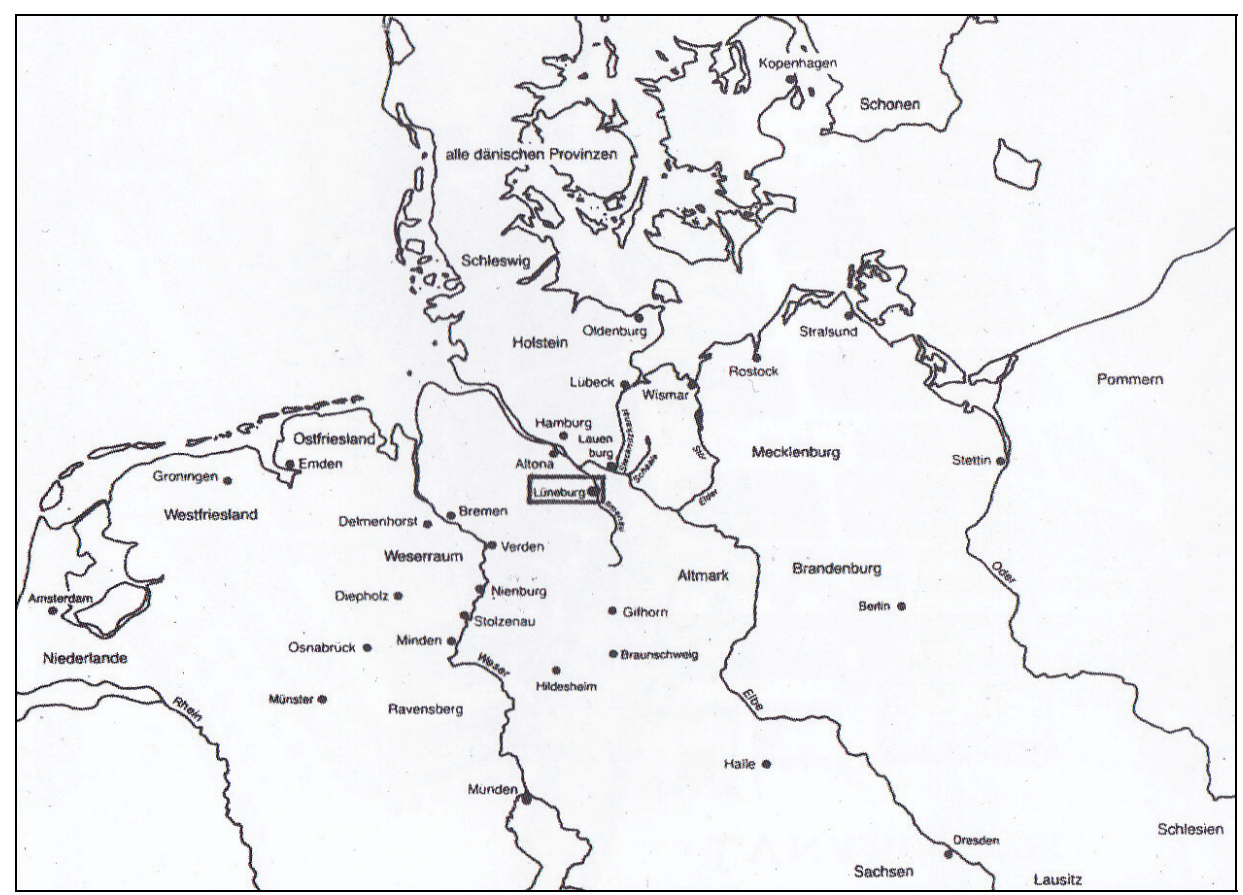

Abb. 2: Absatzmärkte des Lüneburger Salzes, 1385-1840 (Witthöft 2010, Tafel 3).

\section{Aus der Geschichte Lüneburgs}

In den Annalen des Fränkischen Reiches ist verzeichnet, dass Karl der Große im Jahre 795 an einem Ort gewesen sei, der Hliuni genannt wurde und in der Nähe der Elbe gelegen haben soll. Etymologisch gesehen bildet Hliuni den ersten Teil des Namens Lüneburg. Er lässt sich etwa mit Zufluchtsort oder Schutzburg übersetzen. ${ }^{13}$ Historisch gesichert ist Lüneburgs Existenz aber erst durch die erste urkundliche Erwähnung vom 13. August $956 .{ }^{14} \mathrm{Zu}$ dem Zeitpunkt waren bereits das Kloster St. Michaelis auf dem Kalkberg vorhanden und die Saline entdeckt. König Otto I. verlieh diesem Kloster das Privileg, den erwirtschafteten Salzzoll zu erhalten. Davon ausgehend wird ein Bestehen der Saline schon für das 9. Jahrhundert vermutet, da ein solch verliehenes Diplom einen größeren wirtschaftlichen Erfolg voraussetzt, der über den reinen Bedarf des Klosters und der Burgsiedlung hinausgeht. ${ }^{15}$

\footnotetext{
${ }_{13}$ Reinhardt (1989), S. 56.

14 Volger (1956), S. 7.

${ }^{15}$ Reinhardt (1989), S. 56.
} 


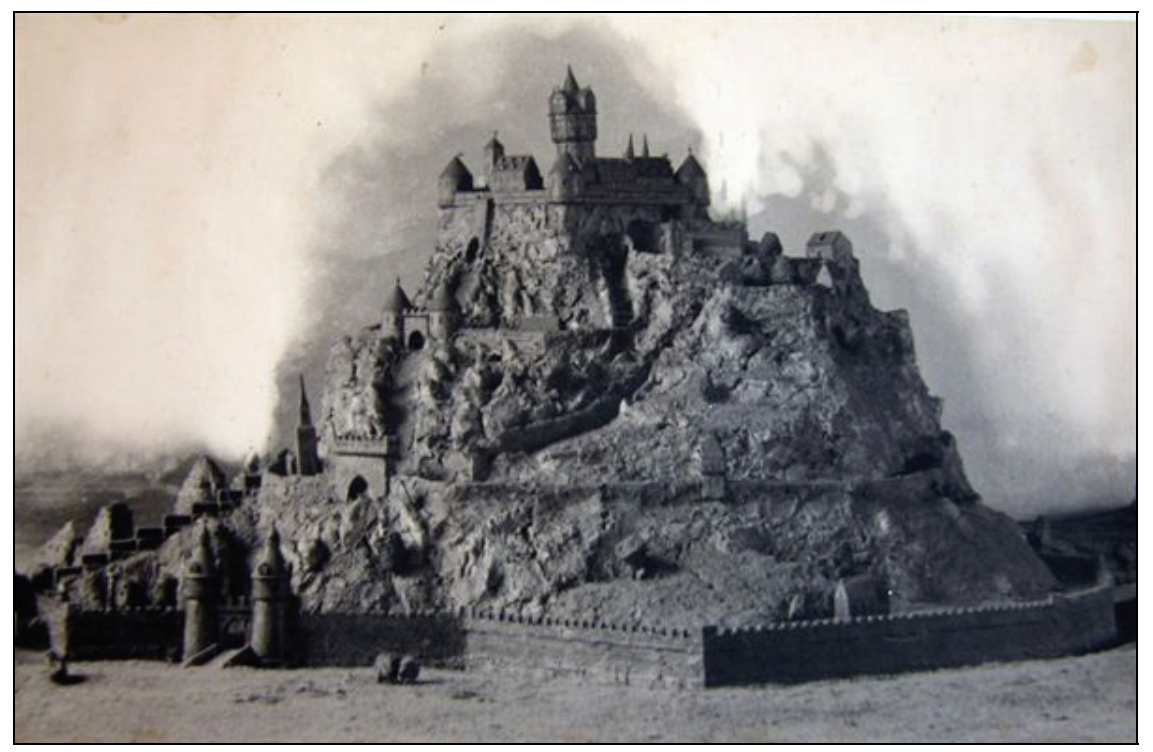

Abb. 3: Historische Darstellung des Kalkbergs. ${ }^{16}$

\subsection{Mons, Pons, Fons}

Die Entwicklung der Stadt basiert auf dem Zusammenschluss dreier UrSiedlungen: Mons, Pons und Fons, die jeweils einen Stadtteil kennzeichnen. Mons, der Kalkberg (Marktviertel), war früher eine leicht zu verteidigende Zufluchtsstätte für die Bevölkerung und wurde zur Gewinnung von Baumaterialien inzwischen nahezu vollständig abgetragen. Pons, die Brücke über die Ilmenau oder, wie der Lüneburger Geschichtsschreiber Wilhelm Reinecke formuliert, die Wasserstraße (Sandviertel / heute Platz am Sande), machte Lüneburgs günstige Verkehrslage aus und somit entwickelte sich dort ein Handels- und Stapelplatz. Fons (Sülzviertel), die Solequelle; ihre Grundlage war der Salzstock, der sich mit einem Durchmesser von $1 \mathrm{~km}$ rund um den Kalkberg erstreckte und eine Tiefe von 4.000-5.000 m aufwies. ${ }^{17}$

\footnotetext{
${ }^{16}$ www.lueneburg.de/Portaldata/1/Resources/stlg_dateien/stlg_bilder/stadtgeschichte/hohe Aufloesung/Kalkbergbs_ha.jpg (Stand: 22.07.2013).

17 Reinecke (1977), S. 8; Kahle (1983), S. 2.
} 


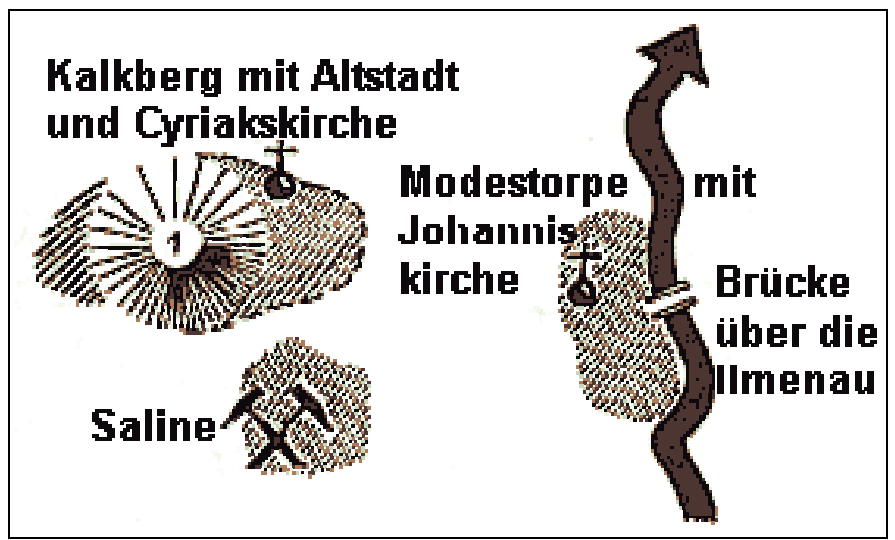

Abb. 4: Lüneburg um 1000 n. Chr. ${ }^{18}$

Später bildete sich zwischen Marktplatz, Salinenviertel und Sandviertel die Hafensiedlung (Wasserviertel) aus. Ende des 12. Jahrhunderts wurde Lüneburg durch Wall und Graben befestigt und bestand Jahrhunderte lang auf der gleichen Grundfläche. Erst im Zuge der Industrialisierung im 19. Jahrhundert wurde die Stadtfläche Lüneburgs ausgeweitet, aber bis heute ist der frühere Aufbau der Stadt mit seinen drei Ur-Siedlungen erkennbar. Nach der Zerstörung des in der Nähe gelegenen älteren und anfänglich bedeutenderen Bardowicks durch Heinrich den Löwen gewann Lüneburg eine vorherrschende Stellung. ${ }^{19}$

\subsection{Stadtentwicklung}

Die Salzgewinnung bestimmte spätestens seit dem 12. Jahrhundert das Leben in und um die Stadt. ${ }^{20} \mathrm{Zu}$ dem Zeitpunkt bildete das von seinen Stadtmauern umgebene Lüneburg eine geschlossene, wehrhafte Einheit. Das typische Erkennungszeichen, eine über der Stadt erhobene Dampfwolke, war schon aus der Ferne ersichtlich. ${ }^{21}$ Die Saline, die sich zwischen Sülzwiese und Kalkberg befand, war selbst mit dicken Mauern umgeben und hatte ihr Haupttor am Lambertiplatz.

\footnotetext{
${ }^{18}$ www.luene-info.de/fuerstmu/fuerstge.html (Stand: 25.07.2013).

19 Kahle (1983), S. 3.

${ }^{20}$ Witthöft (2011), S. 333 u. 341.

${ }^{21}$ Lamschus (1989), S. 83.
} 


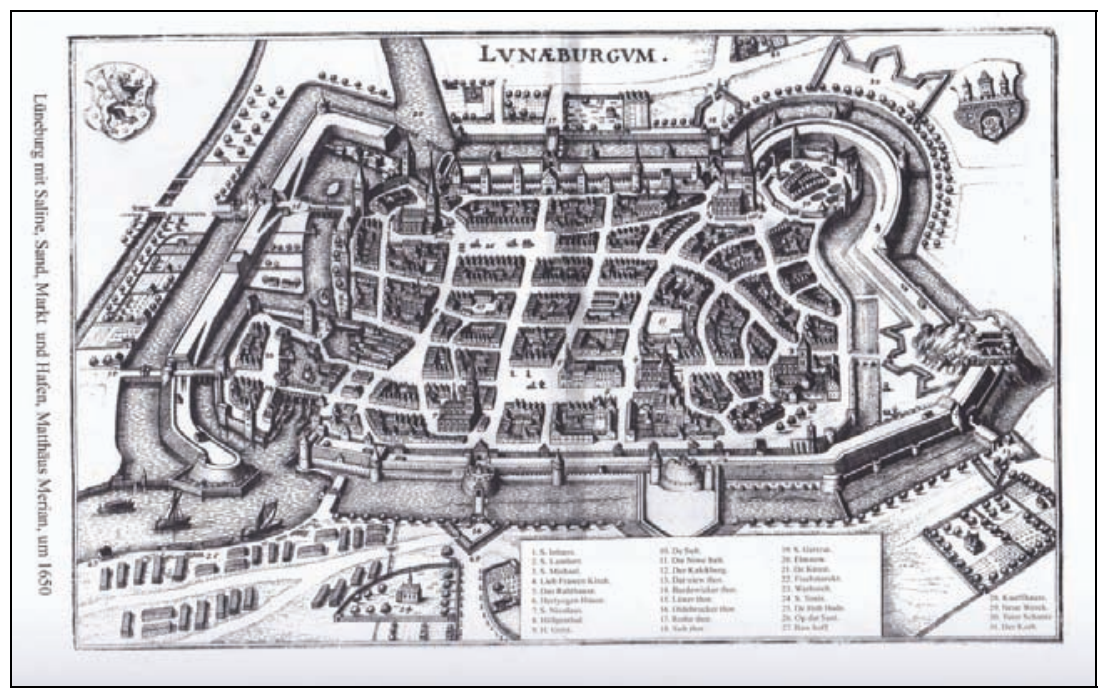

Abb. 5: Lüneburg um 1650 (Witthöft 2010: Die Lüneburger Saline, Tafel 4).

Durch die günstige Lage und Monopolstellung im Salzhandel für den norddeutschen Raum wurde Lüneburg Ende des 14. Jahrhunderts Mitglied der Hanse und gehörte zum wendischen Quartier, das unter der Führung Lübecks stand. Lüneburg war Produktionsstätte und Lübeck der Exporthafen; das erwies sich als eine hervorragende, wirtschaftliche Verbindung. ${ }^{22}$ Anders als Hansestädte wie Hamburg, Bremen oder Lübeck hatte Lüneburg durch seinen Wohlstand eine ,an die Reichsunmittelbarkeit grenzende Selbstständigkeit". ${ }^{23}$ Der Stadtrat, der von zwei Bürgermeistern geleitet wurde, hatte volle Gerichtsbarkeit über alle Einwohner; er schloss Verträge mit anderen Städten und Ländern und war befähigt Truppen aufzustellen. Gewählt wurden die Bürgermeister durch den Rat, der lange Zeit nur aus den Sülfmeistern bestand; sie betrieben die Siedehütten in der Saline. Diese angesehenen Männer hatten die Verantwortung in der Saline, weshalb ihnen auch eine Verantwortung für die Stadt selbst zuteilwerden konnte. ${ }^{24}$ Da diese Art der Stadtregierung auf Dauer zu Konflikten mit den übrigen städtischen Gewerben führte, nahm die Selbstständigkeit der Stadt eine von den Bürgern verursachte Rückläufigkeit an, die von den Auswirkungen des Dreißigjährigen Krieges zusätzlich beeinflusst wurde. Die aufkommenden absolutistischen Fürstenstaaten im 17. und 18. Jahrhundert ließen Lüneburg schließlich wieder zu einer mittleren Landstadt mit weniger großem politischem Einfluss absinken. ${ }^{25}$

\footnotetext{
22 Reinhardt (1989), S. 59.

${ }^{23}$ Kahle (1983), S. 3; vgl. auch Reinecke (1977).

${ }^{24}$ Kahle (1983), S. 5; Kühlborn (2005), S. 265.

${ }^{25}$ Kahle (1983), S. 5 f.
} 


\subsection{Die Saline}

Die Salzgewinnungsanlage Lüneburgs zählte im Mittelalter zu den bedeutendsten Salinen in Mitteleuropa und gehörte bis ins 16. Jahrhundert zu den größten industriellen Unternehmen. Ihre mittelalterlichen Betriebsstrukturen wurden erst Ende des 18. Jahrhunderts durch eine weitreichende Reform verändert. ${ }^{26}$ In der Saline wurde die Sole bergmännisch erschlossen, an die Erdoberfläche befördert, in die Siedehäuser eingeleitet und dort in Bleipfannen gesiedet. Das Zentrum der Saline war der von 54 Siedehütten umgebene Sod (= Salzbrunnen). ${ }^{27}$ Über seiner Öffnung war das Brunnenhaus errichtet, das „die Küntje“ genannt wurde. Von dort wurde die gesättigte Sole in die einzelnen Siedehütten über ein Leitungssystem, die Wege, verteilt. ${ }^{28}$ In jeder Siedehütte gab es je vier Siedepfannen, die auf gemauerte Herde aufgesetzt wurden und die aus den sich unter dem Haus befindlichen Solevorräten versorgt wurden. ${ }^{29}$ Dazu wurde die Sole mit Eimern an die Oberfläche befördert und von dort aus auf die Pfannen, unter denen ständiges Feuer brannte, verteilt..$^{30}$ Jeweils zwei Hütten waren mit der Längsseite aneinander gebaut und konnten so über einen gemeinsamen Gang, den Gunch, betreten werden. ${ }^{31}$ Damit die stetige Holzzufuhr gewährleistet werden konnte, waren die Hütten halb unterirdisch angelegt, um das Brennholz aus dem am Giebel angebauten Holzschuppen leicht in die Siederäume werfen zu können. ${ }^{32}$ Da die Siedehäuser sowohl aus Holz als auch sehr eng beieinander gebaut waren und einen großen Holzvorrat an ihren Eingängen hatten, war das Salinengelände stark brandgefährdet. Statistisch gesehen brannte es ungefähr einmal in zehn Jahren vollständig ab. ${ }^{33}$ In einer Siedehütte wurden in Tag- und Nachtschichten jeweils fünf Personen, drei Männer und zwei Frauen, beschäftigt. Insgesamt bot die Saline etwas mehr als 300 Menschen Arbeit. ${ }^{34}$

Da die Salzgewinnung das ganze Jahr über betrieben wurde, machte sich sehr schnell der hohe Holzverbrauch bemerkbar. Damit wurde die Brennholzbeschaffung zu einer der wichtigsten Aufgaben der Sülfmeister. Diese mussten jede Holzfuhre selbst vom Holzlieferanten auf den verschiedenen Ankaufplätzen der Stadt erwerben. Die Beschaffung des benötigten Brennholzes wurde zu einem großen Problem der Stadt. Um den Handel sowohl mit Holz als auch Salz effektiver zu betreiben, wurden in der Stadt ein Kanal und ein Kran am heutigen Stint gebaut.

\footnotetext{
${ }^{26}$ Emons u. Walter (1988), S. 127.

${ }^{27}$ Lamschus (1989), S. 83 u. 87; Emons u. Walter (1988), S. 129.

${ }^{28}$ Vgl. Witthöft (2010), S. 44.

${ }^{29}$ Emons u. Walter (1988), S. 128.

${ }^{30}$ Kahle (1983), S. 13.

${ }^{31}$ Ebd.; Runne (2009), S. 124.

32 Kahle (1983), S. 13; Emons u. Walter (1988), S. 128 f.

${ }^{33}$ Emons u. Walter (1988), S. 128.

${ }^{34}$ Kahle (1983), S. 14.
} 
Noch heute ist der alte Kran zu sehen und gilt inzwischen als eins der Wahrzeichen Lüneburgs. ${ }^{35}$

\subsection{Die Lüneburger Heide}

Die Kulturlandschaft Lüneburger Heide ist unter anderem durch den hohen Bedarf an Holz und infolgedessen den starken Holzeinschlag großflächig entwaldet worden. ${ }^{36}$ Der große Holzbedarf im Mittelalter führte in ganz Mitteleuropa zu tiefgreifenden Landschaftsveränderungen. ${ }^{37}$ Die Lüneburger Heide ist geprägt durch spärliche Besiedlung, überwiegend magere, teils trockene und anmoorigfeuchte Heideböden sowie intensive Landnutzung. ${ }^{38}$ Archäologische Funde und die Erforschung der Vegetationsentwicklung in der Lüneburger Heide lassen an der Vermutung, dass diese Kulturlandschaft allein durch den hohen Holzbedarf für die Salzgewinnung in der Lüneburger Saline entstanden sei, zweifeln. ${ }^{39}$ Aus überlieferten Aufzeichnungen ist bekannt, dass ein großer Teil des Brennholzes für die Saline über den Wasserweg, vorwiegend aus Mecklenburg und Lauenburg, über die Elbe bezogen wurde. ${ }^{40}$ Allerdings ist der Holzbedarf in Lüneburg immer stärker angestiegen und war zumindest ein Faktor, der für die rigorose Reduzierung der Waldbestände rund um Lüneburg mitverantwortlich war. ${ }^{41}$

Schon seit dem Beginn des Mittelalters ist eine Intensivierung der Landwirtschaft durch Dauerbesiedlungen und die Einführung des Lehensystems zu verzeichnen. Jahrhunderte lang wurde der Bedarf an Stallstreu und organischer Düngung für die Felder durch Laubrechen in den Wäldern gedeckt. Damit wurden dem Waldboden sämtliche Nährstoffe, Humus und der Verdunstungsschutz durch die Streudecke entzogen und die Bodenfruchtbarkeit stark herabgesetzt. Zusätzlich wurde das Weidevieh in die weniger dichten Wälder getrieben. Die sogenannten Waldweiden entstanden und trugen durch den Verbiss der nachwachsenden Baumsprösslinge zur Lichtung der Wälder bei. Eine natürliche Regeneration war nicht möglich, sodass sich in der Lüneburger Heide die Heidebauernwirtschaft entwickelte. ${ }^{42} \mathrm{Be}$ sonders in der ersten Hälfte des 19. Jahrhunderts sank der Waldanteil durch die starke landwirtschaftliche Nutzung nochmals drastisch. ${ }^{43}$ Durch frühzeitige Schutzbemühungen konnte die aus der Heidebauernwirtschaft entstandene Kultur-

\footnotetext{
${ }^{35}$ Lamschus (1988), S. 95 f.; Brosius (1984), S. 14.

36 Brosius (1984), S. 16.

${ }^{37}$ Ebd., S. 10.

${ }^{38}$ Cordes (1997), S. 73.

${ }^{39}$ Ebd., S. 49.

${ }^{40}$ Kahle (1983), S. 16.

41 Vgl. Brosius (1984), S. 13.

42 Cordes (1997), S. 57.

${ }^{43}$ Ebd., S. 113.
} 
landschaft als Naturschutzgebiet Lüneburger Heide mit mehr als 3.000 ha Fläche erhalten werden. ${ }^{44}$

\subsection{Das Ende der Salzgewinnung}

1980 endete schließlich die Salzproduktion in Lüneburg und die Saline wurde nach 1.000-jährigem Bestehen geschlossen. ${ }^{45}$ Schon seit dem frühen 17. Jahrhundert waren die Strukturen in der Saline nicht mehr dem technischen Fortschritt gewachsen und konnten deshalb nicht mit den staatlichen Salinen mithalten. Somit zeichnete sich ein deutlicher Produktionsrückgang ab. Nach und nach verlor Lüneburg seine Monopolstellung im Salzhandel, nicht zuletzt verursacht durch den zunehmenden Handel mit Meersalzen aus Frankreich, Portugal, Schottland oder England und den Bau bzw. Ausbau umliegender Salinenbetriebe. 46 Obwohl das Lüneburger Salz über Jahrhunderte hinweg wegen seiner besonderen Reinheit und seiner großen, gut ausgebildeten Kristalle sehr geschätzt wurde, musste die mittelalterliche Salzmanufaktur reorganisiert werden, um ihr Bestehen weiterhin zu sichern. Das energische Eingreifen der Landesherren in der Zeit von 1798 bis 1802 führte zu dieser notwendigen Veränderung. Die 54 Siedehäuser wurden abgerissen und modernere an ihrer Stelle errichtet. ${ }^{47}$ Begünstigt durch die Kontinentalsperre Napoleons konnte die neu organisierte Saline vorerst wieder aufblühen. Nach 1815 verschärfte sich der Kampf um die Absatzmärkte wieder und die Saline musste ständig um ihr Fortbestehen bangen. 1852 sollte die wirtschaftliche Basis der Saline durch den Bau einer Chemiefabrik auf dem Salinengelände gestärkt werden. Damit wurden zusätzlich Soda, Chlorkalk, Schwefelsäure, Salzsäure und Glaubersalze produziert. ${ }^{48}$ Schließlich erholte sich die Saline wirtschaftlich und erfuhr 1920 einen erneuten Aufschwung. Erst als in den 1970er Jahren die Salzerzeugung durch die steigenden Energiekosten und die verringerte Nachfrage nur noch wenig Gewinn erzielte, musste die Saline 1980 geschlossen werden. ${ }^{49}$

Die Auswirkungen des Salzabbaus sind insbesondere im historischen Viertel Lüneburgs zwischen Saline (heute Salzmuseum) und Kalkberg zu sehen. Da sich in diesem Bereich mit vermehrtem Abtragen des Salzes durch immer besser werdende technische Geräte ab etwa 1830 die Erdoberfläche um mehrere Meter absenkte, rutschten auch die sich dort befindlichen Häuser nach, verloren teilweise ihre Stabilität und mussten abgerissen werden. Vom Sande bis zum Ende der Grapengießerstraße, lässt sich das Ausmaß der Absenkungen deutlich erkennen. Eine durch die Absenkung entstandene Mulde zieht sich von dort ausgehend bis zum Lamber-

\footnotetext{
${ }^{44}$ Cordes (1997), S. 49.

45 Reinhardt (1989), S. 65.

46 Witthöft (2010), S. 20; Reinhardt (1989), S. 60.

47 Emons u. Walter (1988), S. 129.

48 Reinhardt (1989), S. 63.

${ }^{49}$ Emons u. Walter (1988), S. 131.
} 
tiplatz hin. Da die Senkungen noch nicht zum Stillstand gekommen sind, werden seit 1946 an 240 Messpunkten alle zwei Jahre eventuelle Veränderungen überprüft. An einigen historischen Gebäuden, die trotz der Absenkung vor einem Abriss gerettet werden konnten, sind die Spuren ihrer Geschichte noch ersichtlich.

\section{$4 \quad$ Fazit}

Der Salzabbau und -handel machte Lüneburg zu einer ganz besonderen Stadt, die durch ihr Erscheinungsbild auch heute noch an glorreiche Jahrhunderte erinnert. In die alte Saline ist inzwischen das „Deutsche Salzmuseum“ eingezogen. Sie ist dadurch zu einem wichtigen Erinnerungsort der Geschichte Lüneburgs geworden. Hier wird deutlich, wie sehr die Stadt durch das Salzvorkommen geprägt wurde. Dieser damals kostbare Rohstoff lieferte die Grundlage für ihren wirtschaftlichen Aufstieg: Die ökonomische Entwicklung Lüneburgs hatte wiederum Einfluss auf die umgebenden Landschaft. Landschaft wird somit nicht nur durch momentan vorherrschende Gegebenheiten geformt, sondern vor allem durch Einwirkungen, denen sie in der Vergangenheit ausgesetzt war. ${ }^{50}$ Die Lüneburger Heide ist ein solches Zeugnis intensiver menschlicher und tierischer Nutzung. Das 1.000-jährige Bestehen der Saline hat die Stadt erst zu dem gemacht, was sie heute ist; sie dient nun als lehrreiches Industriedenkmal, ohne das es auch die Lüneburger Heide, wie wir sie heute kennen, nicht geben würde.

\section{Literatur}

Brosius D (1984) Die Lüneburger Heide. Schriftenreihe der Niedersächsischen Landeszentrale für politische Bildung: Landschaften Niedersachsens und ihre Probleme 3. Niedersächsische Landeszentrale für politische Bildung, Hannover.

Brüggemeier F-J (2004) Natur und kulturelle Deutungsmuster. Die

Kulturwissenschaft menschlicher Umwelten. In: F. Jaeger, J. Rüsen (Hg.)

Handbuch der Kulturwissenschaften. Metzlar, Stuttgart, S. 65-78.

Cordes H (1997) Naturschutzgebiet Lüneburger Heide. Geschichte - Ökologie Naturschutz. Schriftenreihe des Vereins Naturschutzpark e.V. Hauschild, Bremen.

Emons H-H, Walter H-H (1988) Alte Salinen in Mitteleuropa. Zur Geschichte der Siedesalzerzeugung vom Mittelalter bis zur Gegenwart. Deutscher Verlag für Grundstoffindustrie, Leipzig.

Herrmann B (2013) Umweltgeschichte. Eine Einführung in Grundbegriffe. Springer, Berlin, Heidelberg.

${ }^{50}$ Siemann u. Freytag (2003), S. 18. 
Kahle E (1983) Die Organisation der Saline Lüneburg. Ein Beispiel für die Aufgaben- und Situationsgebundenheit organisatorischer Regelungen.

Arbeitsberichte. Hochschule Lüneburg, Lüneburg.

Kühlborn M (2005) Aspekte zum archäologischen Nachweis verschiedener sozialer Gruppen des Mittelalters und der Frühen Neuzeit. In: M. Meinhardt, A. Ranft (Hg.) Die Sozialstruktur und Sozialtopographie vorindustrieller Städte. Beiträge eines Workshops am Institut für Geschichte der Martin-Luther-Universität HalleWittenberg am 27. und 28. Januar 2000. Akademie Verlag, Berlin, S. 263-279.

Lamschus C (1989) Die Bergwerke der Saline Lüneburg. Arbeit und Technik in Mittelalter und Neuzeit. In: C. Lamschus (Hg.) Salz-Arbeit-Technik. Produktion und Distribution in Mittelalter und Früher Neuzeit. Deutsches Salzmuseum, Lüneburg, S. 83-92.

Lamschus H (1988) Komm mit nach Lüneburg. Eine Stadtgeschichte nicht nur für Kinder. Edition Alte Stadt, Lüneburg.

Lehmann-Brune M, Petersen HGF (2010) Historische Handelsrouten. Books on Demand $\mathrm{GmbH}$, Norderstedt.

Pump R, Pump G (2009) Die Alte Salzstrasse. Von Lüneburg nach Lübeck. Husum, Husum.

Reichlmayr G (2013) Geschichte der Stadt München. Sutton, Erfurt.

Reinecke W (1977) Geschichte der Stadt Lüneburg, Bd. 1. Nachdruck der Ausgabe Lüneburg 1933. Heine-Buchhandlung Neubauer, Lüneburg.

Reinhardt U (1989) Lüneburg - Stadt auf dem Salz. In: C. Lamschus (Hg.) SalzArbeit-Technik. Produktion und Distribution in Mittelalter und Früher Neuzeit. Deutsches Salzmuseum, Lüneburg, S. 56-68.

Runne H (2009) Urkunden des Mittelalters. Für Bienenbüttel und seine Ortsteile. Books on Demand, Norderstedt.

Siemann W, Freytag N (2003) Umwelt - eine geschichtswissenschaftliche

Grundkategorie. In: W. Siemann, N. Freytag (Hg.) Umweltgeschichte. Themen und Perspektiven. C.H. Beck, München, S. 7-20.

Volger WF (1956) Die Lüneburger Sülze. Hoppe \& Co, Lüneburg.

Witthöft H (2010) Die Lüneburger Saline. Salz in Nordeuropa und der Hanse vom 12.-19. Jahrhundert. Eine Wirtschafts- und Kulturgeschichte langer Dauer. Verlag Marie Leidorf, Rahden.

Witthöft H (2011) Vom Umgang mit Zahl und Zeit, Maß, Gewicht und Geld. Lüneburg und seine Saline im Mittelalter. In: R. Holbach, M. Pauly (Hg.) Städtische Wirtschaft im Mittelalter. Festschrift für Franz Irsigler zum 70. Geburtstag. Böhlau, Köln, S. 333-353. 


\title{
Die Reichserntedankfeste am Bückeberg - Volksgemeinschaft an der Weser
}

\author{
Ann-Kathrin Mogge
}

\section{Einleitung}

Feste und nationale Feiern können als paradigmatische Orte für Regime angesehen werden, um ihre Ideologie mit Anhänger_innen und Gegner_innen zu kommunizieren - das Dritte Reich bildet hier keine Ausnahme. Die Feste des NS-Staates waren janusköpfige Inszenierungen von Verführung und Anbiederung, aber auch Gewalt und Ausschluss. In diesem Beitrag wird am Beispiel der Reichserntedankfeste und der damit verknüpften „Blut und Boden“-Ideologie eine umweltgeschichtliche Perspektive auf die Festkultur eingenommen.

Das Regime des Nationalsozialismus versuchte mal mit mehr, mal mit weniger Erfolg Feiertage und Feste ideologisch aufzuladen oder neu zu schaffen. So ist das erste große Fest im neuen Staat am 1. Mai 1933 der „Tag der nationalen Arbeit“, der als Staatsakt auf dem Tempelhofer Feld begangen wurde. Ein weiterer Festakt im Dritten Reich, der wichtigste, waren die Reichsparteitage der NSDAP, die ab 1933 für je eine Woche Anfang September in Nürnberg stattfanden.

Um auch die Bäuer_innen an den neuen Staat zu binden, okkupierten die Nationalsozialist_innen ab 1933 den Erntedank-Sonntag, ein relativ schwach im christlichen Festkalender verankertes Fest, da es sich als einziges auf das Naturjahr bezieht und nicht mit dem Christusmythos im Zusammenhang steht. ${ }^{1}$ Das zentrale

\footnotetext{
1 Vgl. Liersch (2009), S. 27. Helmut Liersch weist darauf hin, dass eine Okkupation von (religiösen) Festen kein genuin nationalsozialistisches Phänomen ist, sondern seit tausenden Jahren dokumentiert
} 
Ann-Kathrin Mogge

Erntedankfest auf dem Bückeberg war das drittgrößte Fest im NS-Staat und wurde schnell zu einer der beliebtesten Feierlichkeiten in der Zeit vor 1939, weil es geschickt an älteres kirchliches und ländliches Brauchtum anknüpfte. Es soll im Folgenden im Zusammenhang mit der nationalsozialistischen Vorkriegspolitik genauer betrachtet werden.

\section{Das Erntedankfest auf dem Bückeberg}

Nach Geertz und van Gennep zeichnen sich Rituale, zu denen auch die hier behandelten Feste zu rechnen sind, durch ihren außeralltäglichen Charakter aus, sind Orte symbolischen Handelns (Geertz), gleichzeitig auch Medium der Zustimmung zur Welt, was implizit Nonkonformes ausschließt. Turner begreift Rituale als Ereignisse, die Wendepunkte einer Gesellschaft begleiten, danach würden sie zur bloßen Inszenierung. Dem folgt Freitag, der die Feste des Jahres 1933 als ,gesellschaftlichen Passageritus“ beschreibt, ${ }^{2}$ eine große, die gesamte Gesellschaft (also auch jene, die als nonkonform gelesen wurden) fassende Liminalität. Die Weimarer Republik war überwunden, die Zukunft Deutschlands schien durch Hitlers Versprechungen von nationaler Größe, Einheit und Gemeinschaft vorgezeichnet.

\subsection{Planung und Vorbereitung des Festaktes}

Die deutsche Bevölkerung erfuhr im Sommer 1933 aus der Tagespresse, dass ein großes „Deutsches Erntedankfest“ für den Herbst des Jahres anstünde, welches in der Folge jährlich wiederholt werden sollte. Im Zentrum dieser Feierlichkeiten sollte das deutsche Bauerntum stehen, das ,an diesem Tage in seltener Geschlossenheit nicht nur ein machtvolles Bekenntnis zum neuen Reich ablegen, sondern auch seine Bedeutung als Volksernährer vor aller Augen führen“" werde. ${ }^{3} \mathrm{Am}$ 1. Oktober 1933 sollte der „Reichsnährstand“ durch diesen Staatsakt in die Volksgemeinschaft eingegliedert werden.

Die Idee für das Fest geht auf Joseph Goebbels’ Propagandaministerium zurück, das in der Folge auch mit der Planung und Umsetzung betraut war. Landwirtschaftsminister und Reichsbauernführer Richard Walther Darré war zu keinem Zeitpunkt in die Organisation der Feierlichkeiten eingebunden und erschien lediglich als Redner.

Ursprünglich wurden als Ort für den Festakt die Weserwiesen bei Hoya von einer Gesandtschaft des Propagandaministeriums ausgewählt. Diese waren jedoch schlecht in die Infrastruktur eingebunden. Bei einem Besuch Hamelns entdeckte die Delegation um Regierungsrat und Reichshauptstellenleiter für Großkundge-

ist. Darüber hinaus hätten bereits in der Reformationszeit in einigen Gemeinden Erntedank-Sonntage stattgefunden.

${ }^{2}$ Freitag (1997), S. 16.

${ }^{3}$ Deister- und Weserzeitung vom 13.7.1933, zitiert nach Gelderblom (2002), S. 23. 
bungen Leopold Gutterer den südlich der Stadt gelegenen Bückeberg. Dieser schien genügend Platz für die erwarteten 300.000 Besucher_innen zu bieten, war mit Bahnverbindungen gut zu erreichen und das Gelände war in Domänenbesitz, stand der Regierung also kostenlos zur Verfügung. Außerdem lag es ebenfalls an der Weser und in Niedersachsen, welches den Nationalsozialist_innen als bäuerliches Kernland galt mit dem Strom, der von der Quelle bis zur Mündung durch deutsches Land fließt. ${ }^{4}$

In der Öffentlichkeit wurde die Wahl für den Bückeberg ideologisch kommuniziert. Am 16. September 1933 meldete das Propagandaministerium, dass am 1. Oktober auf dem Bückeberg das erste Reichserntedankfest gefeiert werden sollte. In der Folge wurde die Region mythisch überhöht. Die eher pragmatische Standortwahl wurde verschwiegen und die Weserlandschaft um Hameln stattdessen zur „Schicksalstätte deutscher Geschichte“ verklärt:

\begin{abstract}
„In der hügeligen und bergigen Weserlandschaft zeichnet sich der Bückeberg durch seine bevorzugte Lage aus. Am Fusse des Berges fließt die Weser, der deutscheste aller Ströme, vorüber. Nordwestlich sehen wir zwischen den Bergen die sagenumwobene Rattenfängerstadt Hameln liegen. Im Westen schauen wir in das fruchtbare Hummetal; dort steht in dem Orte Dehrenberg der Stammhof der Ahnen Horst Wessels. Ganz hinten im Norden thront majestätisch der Süntel, der durch die erbitterten Kämpfe unserer Vorfahren unter Widukind gegen die Heere Karls des Großen bekannt geworden ist; heute ist er dazu ausersehen, das Ehrenmal für Horst Wessel zu tragen. Nach der Sage soll der Herzog Widukind in dem Turmhause des Schlosses der Domäne Ohsen sich längere Zeit verborgen gehalten haben. So ist das Land um den Bückeberg ein Land reicher Geschichte und ist oft eine Schicksalstätte deutscher Geschichte gewesen. “5
\end{abstract}

Albert Speer wurde mit der Gestaltung des Festplatzes beauftragt, die Vorgabe von Goebbels lautete auf ein bäuerliches Volksfest bisher unbekannter Größenordnung in freier, möglichst unberübrter Landschaft. Anders als auf dem Reichsparteitagsgelände war die Inszenierung betont einfach zu halten, Speer sah für den sich ähnlich einer Theatertribüne neigenden Berghang eine große Holztribüne am oberen Ende vor, die Ehrengäste und Diplomaten vorbehalten war und den Erntealtar beherbergte. Am unteren Ende des Geländes, Richtung des Flusses, ließ Speer eine hölzerne Redner_innentribüne in Form einer Pyramide errichten; beide Tribünen waren über den etwa $600 \mathrm{~m}$ langen erhöht angelegten „Führerweg“ verbunden, der längs über das etwa 300 m x 600 m große Areal verlief und Hitler bei seinem „Weg durchs Volk“ gut sichtbar machen sollte. Das Gelände wurde von etwa tausend aus unbearbeiteten Holzstämmen geschlagenen Fahnenmasten umschlossen - so

\footnotetext{
${ }^{4}$ Vgl. Gelderblom (2010), S. 21.

${ }^{5}$ Karl Keese in den Heimatblättern der Schaumburger Zeitung vom 25.9.1937, zitiert nach Gelderblom (2002), S. 25.
} 
entstand eine sakrale Raumsituation ähnlich eines Kirchenraumes, in der die nationalsozialistische Liturgie gefeiert wurde.

Nach dem Erfolg des 1. Oktober 1933, an dem laut offiziellen Zahlen eine halbe Million Menschen an den Bückeberg pilgerten, ernannte Goebbels den Ort Ende des Jahres zur Reichsthingstätte und gab bekannt, dass von nun an das Reichserntedankfest jährlich am Bückeberg gefeiert werde. Im Frühjahr 1934 errichtete der Reichsarbeitsdienst drei ständige Lager im Wald oberhalb des Festplatzes, in denen bis zu 800 Männer an der Instandhaltung und dem Ausbau des Geländes arbeiteten, obwohl sich das $180.000 \mathrm{~m}^{2}$ große Areal bereits 1933 als zu klein erwiesen hatte. Die Neigung des Berges wurde für die Nutzung als Tribüne für die Massen optimiert und das Gelände vergrößert, Wasserleitungen wurden über den Platz ebenso wie eine Drainage und $15 \mathrm{~km}$ Stromkabel verlegt - Goebbels nutzte die modernsten Medien der Zeit für die Übertragung des Festes und so sollte es dem Rundfunk möglich sein, live vom „Führerweg“ zu berichten. Für die Anreise der Menschenmassen wurden Kolonnenwege gebaut, riesige Zeltstädte errichtet und Pontonbrücken überspannten die Weser. Das Schienennetz der Reichsbahn wurde erweitert und in Tündern wurde wegen des Festes gar der gesamte Bahnhof nach Süden verlegt. ${ }^{6}$

Speer machte 1934 einen neuen Plan für das Gelände, das nun Reichsthingplatz war, welcher Elemente deutlich monumentalerer Architektur enthielt, etwa die Errichtung eines Erdwalles rings um das Gelände (Abb. 1). Diese wurden jedoch nie realisiert, obwohl die Männer des Reichsarbeitsdienstes mit Unterstützung lokaler Facharbeiter bis 1937 daran arbeiteten.

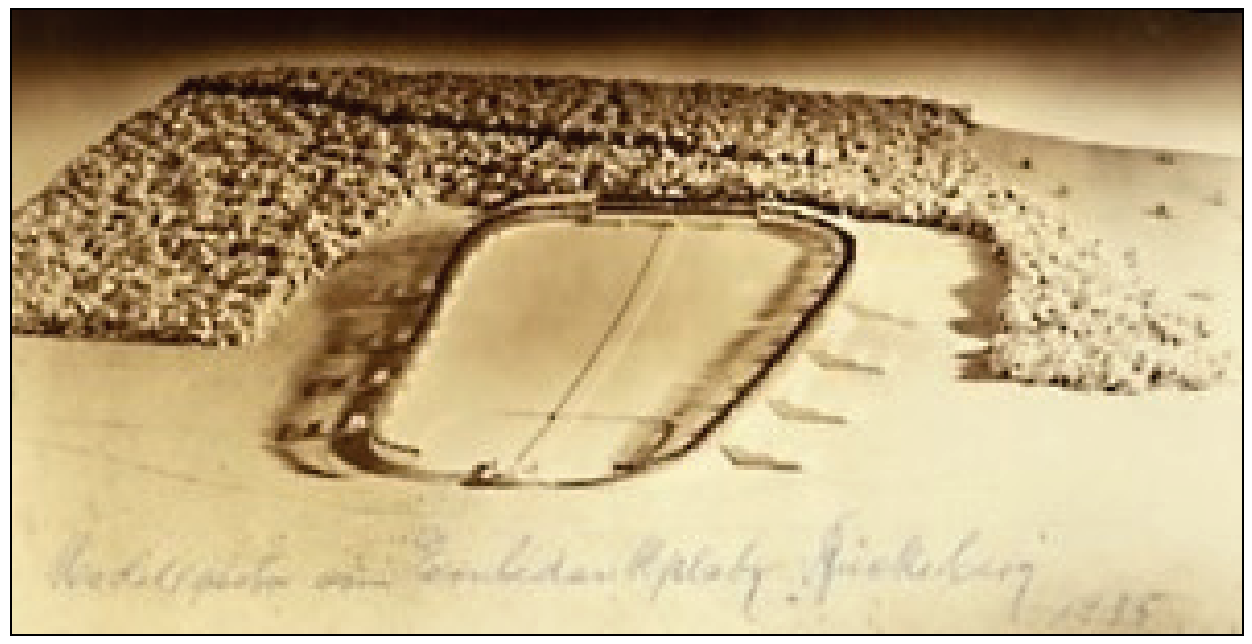

Abb. 1: Der Plan Albert Speers für die Gestaltung der Reichsthingstätte (Sammlung Gelderblom).

${ }^{6}$ Ebd., S. 31. 


\subsection{Der Staatsakt auf dem Bückeberg}

$\mathrm{Zu}$ den Feierlichkeiten reisten „Volksgenoss_innen“ aus dem gesamten Reichsgebiet an, bäuerliche Gruppen oft in regionaler Tracht. Obwohl es ein Fest des Landvolkes werden sollte, lud das Regime ausdrücklich die gesamte „Volksgemeinschaft" ein - räumliche und soziale Grenzen sollten überwunden werden ${ }^{7}$ und so lautete das Motto des ersten Festes auch „Stadt und Land - Hand in Hand“. Dieser Leitsatz sollte alte oftmals noch aus den Jahren des Kaiserreiches stammende Gräben zwischen ländlicher und urbaner Interessensvertretung schließen. Die Ernährungskrise und die darauf folgende „Zwangswirtschaft“ und spätere Kriegsniederlage verstärkten diese Hostilität noch: „(t)he rural world went to war in the optimistic belief that it was the central pillar of the German ,model of development'. This idea was soon brushed aside by the spectre of famine, the black market and defeat." ${ }^{8} \mathrm{Zu}$ dem gekränkten Standesgefühl kamen ökonomische Schwierigkeiten, gerade für kleine bäuerliche Betriebe, und stagnierende Löhne im Agrarsektor. ${ }^{9}$ Die Betonung der Notwendigkeit bäuerlicher Arbeit für die Nation und die Gemeinschaft, ebenso wie der wiederholte Rekurs auf den deutschen Boden, den Bäuer_innen bestellten, sollten diese Spannungen, so der Wunsch des Regimes, nivellieren.

Über die Hälfte der Besucher_innen des Bückeberges waren Frauen und ein Großteil der Menschen kam aus der Region um Hameln - dort fanden im Gegensatz zum übrigen Reichsgebiet keine Erntedank-Sonntage statt, um dem Bückeberg-Fest keine Konkurrenz zu machen. ${ }^{10}$ Die Menschen nahmen oftmals mehrtägige Anreisen in Kauf, um ihren Führer zu erleben. Die Reise in Wagenkolonnen, mit der Bahn oder zu Fuß sollte bereits das Gemeinschaftsgefühl der Festteilnehmer stärken, die ab $1935^{11}$ am Festtag ab 6 Uhr morgens über die Kolonnenwege, in Reihen von je sechs Menschen, auf das Gelände marschierten.

Dieser Aufmarsch nahm mehrere Stunden ein und war selbst Teil der großen Inszenierung. Die bereits auf dem Platz wartenden Menschen wurden von Tanzund Trachtengruppen sowie Massenchören und von Marschmusik der Wehrmacht unterhalten; Reichsarbeitsdienstler zeigten Turnübungen. Außerdem konnten Festteilnehmer_innen sich an den am Rande des Platzes errichteten Buden stärken Alkohol war untersagt, Bier bildete jedoch eine Ausnahme. Dies lässt vermuten,

\footnotetext{
7 Inge Marszolek spricht in diesem Zusammenhang vom (geglückten) Versuch des Regimes, ein „emotionales Vergemeinschaftungserlebnis“ zu inszenieren, das in der Folge die Volksgemeinschaft begründen sollte, vgl. Marszolek (2010), S. 67.

${ }^{8}$ Corni (1990), S. 3.

${ }^{9}$ Corni weist für die direkte Nachkriegszeit einen Anstieg der Fragmentierung bäuerlicher Betriebe nach, demnach gab es annähernd 3 Millionen Kleinstbetriebe mit weniger als 2 ha Nutzfläche, diese hatten einen Anteil von 4,2\% an der gesamten Abaufläche. Vgl. ebd., S. 7.

${ }^{10}$ Vgl. Gelderblom (2002), S. 36.

$11 \mathrm{Zu}$ jedem Erntedankfest wurde ein Programm erarbeitet, das sich je stark ähnelte. Der größte Unterschied war die Verlegung der Veranstaltung aus den Abendstunden (1933) erst auf den Nachmittag (1934) und dann auf den Mittag (ab 1935).
} 
dass die Erntedankfeste oftmals einen feuchtfröhlichen Abschluss fanden, der in der Festtheorie als orgiastisch beschrieben wird. ${ }^{12}$

Ab 10 Uhr sah das Programm auf dem „Führerweg“ den Aufmarsch von etwa 3.000 ausgewählten Bäuer_innen in Tracht aus dem gesamten Reichsgebiet vor. Sie standen im Weiteren am „Führerweg“ Spalier, hinter ihnen eine Reihe SS-Männer, die für die Sicherheit auf dem Platz verantwortlich waren. Den Trachtengruppen folgten SA-Standarten und weitere Uniformierte, ab 11 Uhr die Prominenz des NS-Staats, die den Platz um die Redner_innentribüne füllte und die nahende Ankunft Adolf Hitlers ankündigte. Hitlers Tag widmete sich ganz der Bäuer_innenschaft, ab 12 Uhr war er am Bückeberg, danach begrüßte er in der „Reichsbauernstadt" Goslar die Delegierten des „Reichsbauerntages“.

Bei der Ankunft des Führers wurden 21 Schuss Salut abgefeuert, Hitler begrüßte eine Ehrenkompanie der Reichswehr, dann begann er seinen „Weg durchs Volk“. Fotografien belegen die frenetische Begeisterung der Zuschauenden, immer wieder durchbrachen Kinder und Frauen das doppelte Spalier aus SS und Bäuerinnen und Bauern, um Hitler anzufassen. Hitler, der „Mann aus dem Volk“, steigt empor und geht ihm als Führer voran. Auch für ihn liegt in dieser Inszenierung auf dem Mittelweg ein entscheidendes Moment des Festes: „Wo ist der Staatsmann, wo ist das Staatsoberhaupt, das so durch sein Volk gehen kann, wie ich durch euch hindurchgehe?"13 Im Anschluss bekam Hitler von einem in Tracht gekleideten Paar auf der Ehrentribüne die Erntegaben überreicht - dies markierte die Abkehr von der christlichen Tradition, den Erntealtar im Gottesdienst dem Schöpfergott zu überreichen. ${ }^{14}$

Da die punktuellen, betont volkstümlich gehaltenen, Inszenierungen von Musik, Tracht und Sport auf dem riesigen Areal keine rechte Wirkung entfalten konnten, wurden sie ab 1935, nachdem Hitler auch die letzten Bestimmungen des Versailler Vertrages gebrochen hatte, zunehmend zugunsten militärischer Vorführungen der Wehrmacht im extra zu diesem Zwecke errichteten „Bückedorf“ abgelöst. Diese folgten den offiziellen Begrüßungen und Hitler und seine Entourage beobachteten sie von der Ehrentribüne; die Festteilnehmer_innen müssen sich auf dem Festgelände wie auf einem Feldherrenhügel gefühlt haben. ${ }^{15}$ Die Wehrmacht bot Panzer, Artillerie, Luftwaffe und riesige Truppenkontingente auf, 1937 über 10.000 Mann und alle zur Verfügung stehenden Waffengattungen. Im Anschluss an diese Übung ging das Dorf in Flammen auf.

\footnotetext{
12 Vgl. Freitag (1997), S. 14.

${ }^{13}$ Hitlers Bückeberg-Rede 1935, nach Deister- und Weserzeitung vom 7.10.1935, zitiert nach Geldberblom (2002), S. 46.

14 Vgl. Spurensuche Harzregion e.V. (2009), S. 10.

15 Vgl. Gelderblom (2002), S. 49.
} 


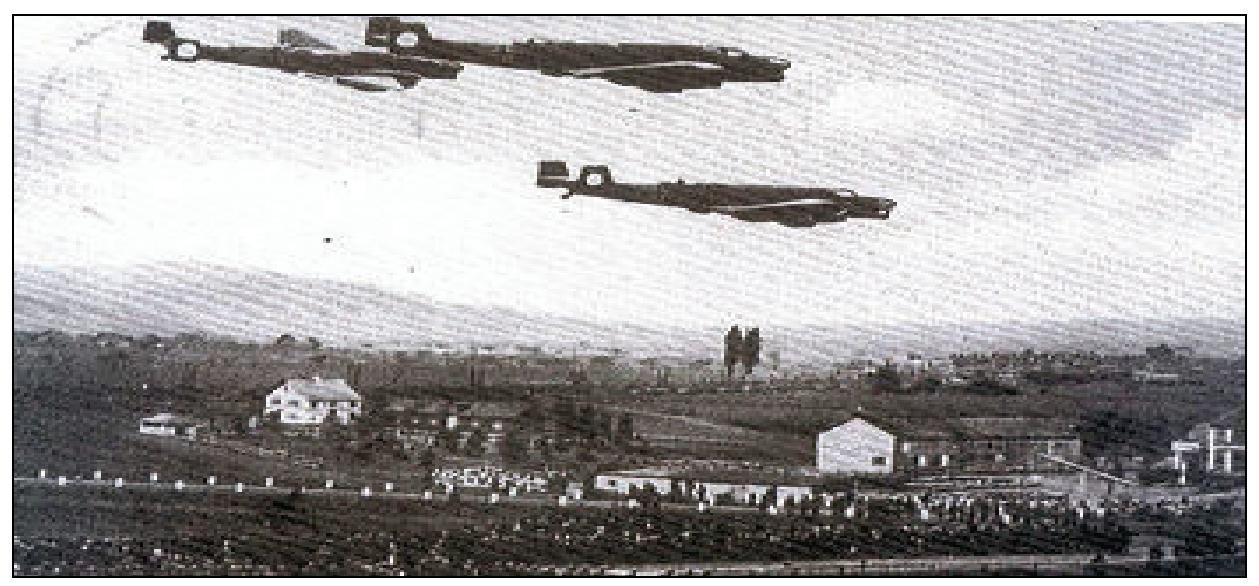

Abb. 2: Bomber der Luftwaffe über dem Bückedorf (Postkarte, wahrscheinlich 1937, Sammlung Gelderblom).

Im Anschluss an die Vorführung schritt Hitler den „Führerweg“ wieder hinab und hielt auf der Redner_innentribüne vor seiner eben entflammten Anhänger_innenschaft eine etwa dreißigminütige Rede, die immer wieder von begeisterten Zwischenrufen unterbrochen wurde.

Es folgten Reden weiterer Repräsentant_innen des Staates, Reichsbauernführer Darré verkündete so beispielsweise 1933, dass der „Reichsnährstand“ sich in Niedersachsen niederlassen werde und gab außerdem das Reichserbhofgesetz bekannt, das von der Regierung am 29. September verabschiedet worden war und Teilung und Überschuldung kleiner bäuerlicher Betriebe verhindern sollte. In seiner Rede ließ er die Erbhöfe zur Konkretisierung der „Blut und Boden“-Ideologie werden, ${ }^{16}$ Bäuer_innen wurden zu einem „biologische(n) Kollektiv“, „(d)er Bauer wurde zum entindividualisierten Repräsentanten des,Volkskörpers“ gemacht“"17, der aus ,deutscher Erde“ das „deutsche Volk“ nährte.

Nach diesem Teil folgten das gemeinsame Singen des Deutschlandliedes und des Horst-Wessel-Liedes; damit war das offizielle Fest beendet. Viele Besucher reisten im direkten Anschluss wieder ab, andere besuchten die von der KdF in umliegenden Dörfern veranstalteten Volksfeste.

\subsection{Das Ende der Reichserntedankfeste auf dem Bückeberg}

Die militärischen Übungen und unverhohlene Kriegspropaganda der Feste ab 1934 stimmten die „Volksgemeinschaft“ bereits auf die Kriegspläne des Regimes ein das Flammenende des Bückedorfes mag symptomatisch für das Ende des Festes stehen, das trotz seiner offiziellen Steifheit und (para-)militärischer Omnipräsenz

\footnotetext{
16 Vgl. Bensch (1995), S. 25.

${ }^{17}$ Mai (2002), S. 50.
} 
der Wehrmacht, SA und SS, auch Raum für scheinbar ausgelassenes Gemeinschaftserlebnis bot.

Das Propagandaministerium sagte am 30. September 1938, zwei Tage vor dem Termin, das Fest wegen „Transportmittel-Inanspruchnahme“ ab. Am selben Tag schloss Hitler mit Vertreter_innen von Großbritannien, Italien und Frankreich das „Münchner Abkommen“, das die Abgabe des Sudetenlandes an das Deutsche Reich vorsah. Die Sonderzüge, die in den Vorjahren nach Hameln gerollt waren und 1937 bis zu 1,2 Millionen Besucher_innen zum Reichserntedankfest gebracht hatten, rollten 1938 Richtung tschechoslowakischer Grenze und waren mit Soldaten belegt. Nach dem deutschen Überfall auf Polen 1939 wurde kein zentrales Erntedankfest mehr begangen, doch lokal wurde weitergefeiert. 1941 fand das Fest in Hameln mit 10.000 Teilnehmer_innen in der Halle der Domag statt. ${ }^{18}$

\subsection{Das Gelände am Bückeberg nach 1945}

Am Bückeberg fand 1937 die letzte Erntedankfeier statt, doch auch im Krieg und nach Kriegsende wurde das Fest weiterhin in der gesamten Bundesrepublik begangen. Ähnlich anderer Stätten der NS-Herrschaft und -Verfolgung im gesamten Bundesgebiet setzte eine Auseinandersetzung mit dem Gelände am Bückeberg erst in den 1980ern ein, nachdem die lokalen Gemeinden bereits Teile des Berges bebaut hatten und Pläne erstellten, den gesamten Hügel als Bauland zu erschließen. Dies führte zu einer gestörten Überlieferungssituation. Bei dem Reichserntedankfestgelände handelt es sich nicht um einen Ort von Verfolgung und Verbrechen, sondern einen selbstaffirmativen Ort der NS-Diktatur - er verweist auf die „Voroder Parallelgeschichte“ der Verfolgung und steht in seiner scheinbaren „Normalität ${ }^{\text {“ }}$ in mittelbarem Bezug zu Orten des Leidens. ${ }^{19}$

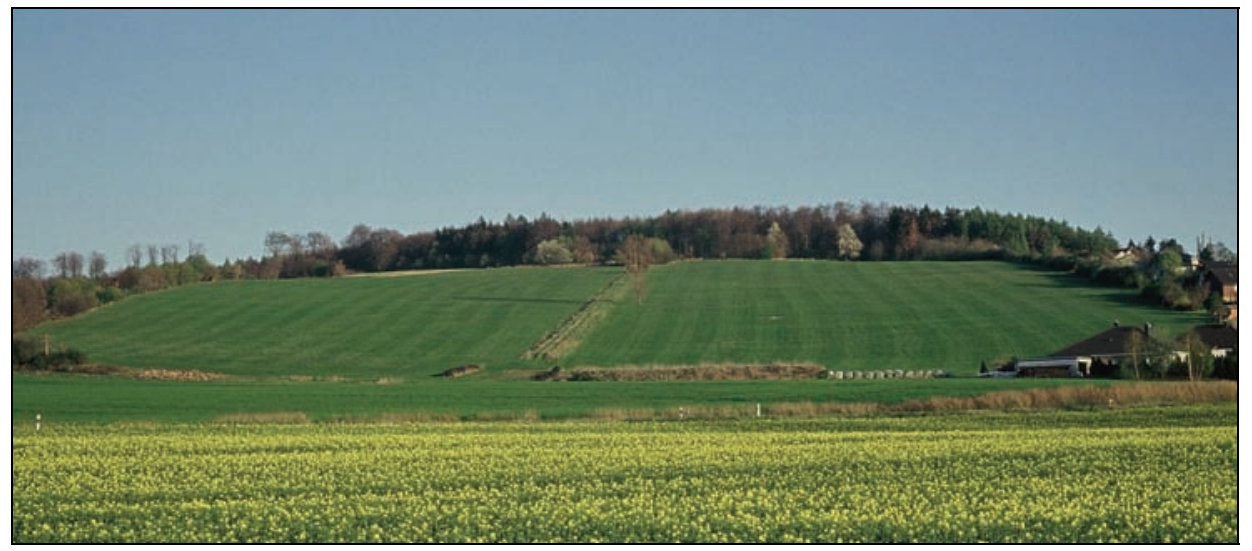

Abb. 3: Heutige Ansicht des ehemaligen Festgeländes (Sammlung Gelderblom 2010).

\footnotetext{
18 Bensch (1995), S. 54.

${ }^{19}$ Vgl. Marszolek (2010), S. 66.
} 
Das Land Niedersachsen hat 2011 beschlossen, das ehemalige Gelände der Reichserntedankfeste zum Baudenkmal zu erklären, da es sich um eine der wenigen NSRepräsentativanlagen handelt, die heute noch im Gelände erkennbar sind (Abb. 3). Die didaktische Gestaltung des Geländes ist dabei noch unklar, nicht jedoch, dass es sich bei der zu schaffenden Einrichtung um eine Dokumentations- und keine Gedenkstätte handeln wird.

\section{Umweltgeschichtliche Betrachtung}

Durch die beschriebene „schrittweise Militarisierung“ wird das Reichserntedankfest auch zum Seismographen der Hinwendung des NS-Regimes zur Aufrüstungsund Kriegspolitik. Die ursprünglich im Fokus stehende Zielgruppe der ländlichen Bevölkerung erlebte in der Folge einen Bedeutungsverlust, ${ }^{20}$ der mit der politischen Kaltstellung ihrer Repräsentant_innen, wie etwa Darré, einherging.

Seit den 1920er Jahren entwickelte Darré die bereits seit der Kriegszeit populäre Idee von „Blut“ und „Boden“21 als Naturkonstanten. Gegen den Vorwurf, er hänge einer unzeitgemäßen Agrarromantik an, verwehrte er sich stets. ${ }^{22}$ Bauerntum war bei ihm Weltanschauung. Zentrale Kategorien seiner fluiden Theorie waren „ein Siedlertum“, das das Land urbar mache und zu dem Darré die Germanen und diesen übergeordnet die „nordische Rasse“ zählte und dem gegenüber das „Nomadentum“, zu dem Darré Jüd_innen zählte. Als nomadisch sozialisierte Gemeinschaft konnten diese per definitionem keine Bäuer_innen sein oder werden, zumal der Begriff „Bauer“ mit dem Reichserbhofgesetz ab 1933 zu einer Art Ehrentitel wurde, den man sich beim Regime erst verdienen musste. ${ }^{23}$

Die deutschen Bäuer_innen stammten einer urtümlichen Gemeinschaft von „Freibauern“ ab, die von Generation zu Generation auf einem Hof, dem Erbhof, lebten und mit ihrer „Scholle“ verwurzelt seien.24 Diese Erdverbundenheit sei charakteristisch für die „nordische Rasse“ und auch die Planer des Reichserntedankfestes um Albert Speer suchten dieser imaginierten Harmonie zwischen den

\footnotetext{
${ }^{20}$ Vgl. Knoch (2010), S. 73.

21 Das Begriffspaar „Blut“ und „Boden“ tauchte zuerst 1917 in Oswalt Sprenglers „Untergang des Abendlandes" auf und wurde in der Belletristik der Zwischenkriegsjahre in der Folge beinahe inflationär von völkisch-nationalen Autoren benutzt. Die Begriffe wurden von Darré auf der im Juni 1930 von Alfred Rosenbergs „Kampfbund für deutsche Kultur“ initiierten ersten Reichstagung in Weimar in die Ideologie des Nationalsozialismus eingeführt. Der Titel seiner Rede lautete „Blut und Boden als Grundlage des Dritten Reiches“. Vgl. Bensch (1995), S. 25.

${ }^{22}$ Darrés Mitarbeiter im Reichsministerium für Ernährung und Landwirtschaft (RMEuL) galten vielen Zeitgenossen, vielleicht auch wegen ihres auffallend jungen Alters, als Romantiker, die von wirtschaftspolitischen Fragestellungen der Landwirtschaft wenig wissen wollten. Vgl. Mai (2002), S. $53 \mathrm{f}$.

${ }^{23}$ Ebd., S. 51. Das REG machte die Bauern, so Mais These, zur Basis der rassischen „Aufartung“. Zeugnis über die Erbgesundheit und Nachweis über die arischen Vorfahren väterlicher- sowie mütterlicherseits bis zum Stichtag 01.01.1800 waren deshalb sowohl für Neusiedler als auch Erben der vom NS-Regime besonders geschützten Erbhöfe obligatorisch.

${ }^{24}$ Vgl. Bensch (1995), S. 15.
} 
Deutschen und der Natur in ihrer Landschaftsplanung gerecht zu werden; diese sah vor, das Gelände möglichst unberührt, also nicht von der Zivilisation erfasst, wirken zu lassen. ${ }^{25}$

Zivilisation ist für Darré Stadt, Individualismus und Abkehr. Die Stadt kultiviere im Menschen die schlechten, ,ungermanischen“ und nomadischen Anlagen - seine Stadtkritik ist eine biologistische. Bäuer_innen stünden ,in der Moderne gegen die Moderne“. ${ }^{26}$ Bäuer_in ist für ihn aber nicht jeder Mensch, der landwirtschaftlicher Tätigkeit nachgeht. Er unterscheidet zwischen dem_der Landwirt_in, der zum Zwecke des Gelderwerbs Land bestellt und das Land so zur Ware werden lässt und dem_der Bäuer_in, der diese Tätigkeit ,als eine Aufgabe an seinem Geschlecht betrachtet.“27 Der NS-Staat wies dem „Reichsnährstand“ die bereits im Namen konkret werdende Aufgabe zu, das deutsche Volk, besonders in Kriegszeiten, von der Scholle zu ernähren, um die 1918 gemachten Erfahrungen zu verhindern, die letztlich zur Spaltung der „Gemeinschaft“ geführt hätten. In der „Anbauschlacht“ sollte der „Bauernsoldat“ seinen Dienst als „Kämpfer“ gegen den Bolschewismus und „Schützer“ seiner Scholle tun. ${ }^{28}$ Hitler sollte für die Bäuer_innen der „erste Bauer im Staat“ sein, auch er nur um das Wohl des heimatlichen „Blutes“ und „Bodens“ bemüht - politische Zeugnisse dieser Ideologie sind die Saarabstimmung 1935, der Anschluss Österreichs und die Besetzung des Sudetenlandes 1938. Boden als „deutsch“ zu imaginieren, auch dies wird hier deutlich, war vor allem eine intellektuelle und emotionale Transferleistung, die Herstellung einer kulturellen Konstruktion. Und die deutsche Ostpolitik, die stark vom Ideal „deutscher Bäuer-

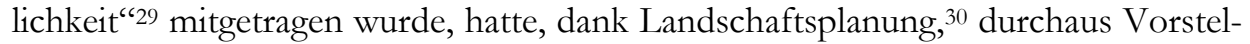
lungen davon, russische Weiten für deutsche Siedler_innen „heimatlich“ zu gestalten. Robert Gradmann, der als geistiger Vater eines „Urlandschafts“-Konzeptes gilt, auf das sich später einer der vordersten Naturschützer im NS, Walther Schoenichen, berufen sollte, erteilt der Vorstellung einer deutschen oder germanischen „Urlandschaft“ aber bereits 1932 eine deutliche Absage - vielmehr, und dies ist als schöpferische Leistung zu verstehen, handele es sich um eine deutsche „Kulturlandschaft". 31

Auf dem Bückeberg wurde 1933 in einer verteilten Broschüre zum ersten Mal der „nationalsozialistische Staatsgedanke“ mit „Blut und Boden“ identifiziert und

\footnotetext{
$25 \mathrm{Vgl}$. Wolschke-Buhlmann (2010), S. 46.

26 Bensch (1995), S. 44.

27 Ebd., S. 42.

28 Vgl. Marszolek (2010), S. 69.

29 Bensch (1995), S. 14.

30 Diese Planungen sollten für die lokale Bevölkerung desaströse, oftmals tödliche, Konsequenzen haben, mussten doch ganze Landstriche für die Umgestaltung erst entvölkert werden. Hier gingen Landschaftsplanung und NS-Expansion eine verbrecherische Verbindung ein. Vgl. Radkau (2003), S. 52 .

$31 \mathrm{Vgl}$. Fischer (2003), S. 185 f.
} 
Hitler ${ }^{32}$ zum „Vorkämpfer des Staatsgedankens von Blut und Boden“ ernannt. ${ }^{33}$ Radkau merkt an, dass sich Hitler bereits in seiner Schrift „Mein Kampf“ als „Vollstrecker der Natur“ (in (sozial-)darwinistischer Lesart, Anm. A.M.), begreift. ${ }^{34}$ Das „Blut“ bestimmt über die Zugehörigkeit zur „Volksgemeinschaft“, es „setzt alle ökonomischen, politischen und sozialen Bestimmungen von Gesellschaft auBer Kraft, so daß (sic) die sich vom Blut her legitimierende Ordnung zur einzig ,wahren“ Bestimmung von Gesellschaftlichkeit wird.“35 Diese Definition erlaubt sowohl den Ausschluss all jener Deutschen, die dem „Blut“ oder der aus ihm resultierenden Gemeinschaft vorgeblich schaden als auch die aggressive Vernichtung alles als „,blutsfremd“ Gelesenem.

Diese Exklusion findet im kollektiven Gefühlsrausch der Erntedankfeste am Bückeberg in der Rhetorik und Inszenierung des scheinbar GermanischUrtümlichen ihren festen Platz. Das Fest für die Landbevölkerung, die stets im Spannungsverhältnis zwischen Fortschritt und Antimoderne stand und bis heute steht, wandelte sich ebenso wie seine Adressat_innen. Den Bäuer_innen sollte über die militärischen Darbietungen, die die Moderne aufs Land brachten, ebenso wie allen anderen Besucher_innen, die je eigene Rolle im Krieg und der „Kriegsgemeinschaft" affektiv vermittelt werden. An dieser hatte sich scheinbar seit 1914 praktisch nicht viel geändert - doch der politische Rahmen hatte es und mit ihm die Ideologie, die die bäuerliche Lebenswelt nun von der Peripherie ins Zentrum rückte, zum Hort deutscher Heimat- und Blutpflege und somit deutscher Zukunft machte.

Der Einschätzung, dass die primäre Zielgruppe der Feste ab etwa 1935 an Bedeutung verlor, kann ich nicht folgen: 1933 hatte das Reichserntedankfest zum Ziel, Bäuer_innen in der Volksgemeinschaft zu verankern und die, auch von Darré betriebene, Spaltung zwischen Stadt und Land zu ebnen. Die Beliebtheit des Festes ist Ausdruck für den Erfolg. Das Zielpublikum war jedoch stets die gesamte Volksgemeinschaft - nur mit ihr konnte das NS-Regime gemeinschaftlich Krieg führen. Die Reichserntedankfeste legten dafür in breiten Bevölkerungsgruppen einen wichtigen Grundstein.

\footnotetext{
32 Farquharson merkt indes an, dass Hitlers Interesse an der ländlichen Bevölkerung stets von vorrangig strategischem Denken geleitet war, waren sie ihm doch auf dem Weg zur Machterlangung und -konsolidierung von nutzen. Gleiches lasse sich vom Gros der NSDAP-Parteiführung sagen, die "bourgeois" sozialisiert seien und mit abfällig-romantischem Blick auf das Landleben schauten. Vgl. Farquharson (1976), S. 3 f. Dieses tendenziell niedrige Interesse an der Landbevölkerung, auch auf der Ebene der Exekutive, wurde bereits im 1920 verabschiedeten Grundsatzprogramm der NSDAP evident. Lediglich Punkt 17 behandelt dabei Fragen der Landwirtschaft und des Bodens. Allgemein heißt es dort, Bodenspekulation sei abzustellen und eine „unseren nationalen Bedürfnissen angepasste Bodenreform" durchzuführen. Gerade letztere Forderung wurde zugunsten der östlichen Großgrundbesitzer (die keine Erbhofbauern waren) aber still behandelt. Erste Forderung wurde im April 1928 konkretisiert - es handele sich hierbei um jüdische Spekulanten.

33 Vgl. Bensch (1995), S. 25.

${ }^{34}$ Radkau (2003), S. 44.

35 Bensch (1995), S. 57.
} 


\section{Literatur}

Bensch M (1995) Die „Blut und Boden“-Ideologie: Ein dritter Weg der Moderne. Beiträge zur Kulturgeschichte der Natur 2, Eisl, Berlin.

Corni G (1990) Hitler and the Peasants: Agrarian Policy of the Third Reich 19301939. Berg, New York u. a.

Farquharson JE (1976) The Plough and the Swastika: The NSDAP and Agriculture in Germany 1928-45. SAGE Studies in 20th Century History 5, Sage, London.

Fischer L (2003) Die „Urlandschaft“ und ihr Schutz. In: J. Radkau, F. Uekötter (Hg.) Naturschutz und Nationalsozialismus. Campus, Frankfurt am Main, S. 183-207.

Freitag W (1997) Der Führermythos im Fest: Feuerwerk, NS-Liturgie, Dissens und „100\% KdF-Stimmung“ In: W. Freitag (Hg.) Das Dritte Reich im Fest.

Führermythos, Feierlaune und Verweigerung in Westfalen 1933-1945, Verlag für Regionalgeschichte, Bielefeld, S. 11-79.

Gelderblom B (2002) Die Reichserntedankfeste auf dem Bückeberg 1933-1937. Ein Volk dankt seinem Verführer. In: G. Biegel, O. Wulf (Hg.) Ein Volk dankt seinem (Ver)Führer: Die Reichserntedankfeste auf dem Bückeberg 1933-1937. Veröffentlichungen des Braunschweigischen Landesmuseums 102, Braunschweig, S. 19-63.

Gelderblom B (2010) Das Reichserntedankfest als emotional hoch aufgeladenes Event. In: S. Winghart (Hg.) Die Reichserntedankfeste auf dem Bückeberg bei Hameln: Diskussion über eine zentrale Stätte nationalsozialistischer Selbstinszenierung. Arbeitshefte zur Denkmalpflege in Niedersachsen 36, Niemeyer, Hameln, S. 20-29.

Knoch H (2010) Zusammenfassung. In: S. Winghart (Hg.) Die

Reichserntedankfeste auf dem Bückeberg bei Hameln. Diskussion über eine zentrale Stätte nationalsozialistischer Selbstinszenierung. Arbeitshefte zur Denkmalpflege in Niedersachsen 36, Niemeyer, Hameln, S. 72-76.

Liersch H (2009) Das Erntdankfest als Einfallstor für die religiöse Überhöhung des ,Führers'. In: Spurensuche Harzregion e.V. (Hg.) Erntedank und „Blut und Boden": Bückeberg/Hameln und Goslar 1933 bis 1938. NS-Rassekult und die Widerrede von Kirchengemeinden. Papierflieger, Clausthal-Zellerfeld, S. 27-32.

Mai U (2002) „,Rasse und Raum“: Agrarpolitik, Sozial- und Raumplanung im NSStaat. Schöningh, Paderborn.

Marszolek I (2010) Der Bückeberg - ein heterotoper Erinnerungsort. In: S.

Winghart (Hg.) Die Reichserntedankfeste auf dem Bückeberg bei Hameln:

Diskussion über eine zentrale Stätte nationalsozialistischer Selbstinszenierung. 
Arbeitshefte zur Denkmalpflege in Niedersachsen 36, Niemeyer, Hameln, S. 66-72.

Radkau J (2003) Naturschutz und Nationalsozialismus - wo ist das Problem?. In: J.

Radkau, F. Uekötter (Hg.) Naturschutz und Nationalsozialismus. Campus, Frankfurt am Main, S. 41-54.

Spurensuche Harzregion e.V. (Hg.) (2009) Erntdank und „Blut und Boden”:

Bückeberg/Hameln und Goslar 1933 bis 1938. NS-Rassekult und die

Widerrede von Kirchengemeinden. Papierflieger, Clausthal-Zellerfeld.

Wolschke-Buhlmann J (2010) Zur manipulativen Gestaltung von Landschaft - Der

Bückeberg im Kontext einschlägiger Anlagen der NS-Diktatur. In: S. Winghart (Hg.) Die Reichserntedankfeste auf dem Bückeberg bei Hameln: Diskussion über eine zentrale Stätte nationalsozialistischer Selbstinszenierung. Arbeitshefte zur Denkmalpflege in Niedersachsen 36, Niemeyer, Hameln, S. 42-57. 



\title{
Bergwerk Rammelsberg, Altstadt von Goslar und Oberharzer Wasserwirtschaft. Weltkulturerbe und Kulturlandschaft
}

\author{
Manuela Armenat
}

\section{Einleitung}

Bei der UNESCO Generalkonferenz im Jahr 1972 wurde das Ziel formuliert, Kultur- und Naturdenkmäler von außergewöhnlicher, weltweiter Bedeutung unter Schutz zu stellen und zu erhalten. ${ }^{1}$ Auch in Niedersachsen gibt es einige besonders herausragende Kultur- und Naturdenkmäler. ${ }^{2}$ So die Welterbestätte „Bergwerk Rammelsberg, Altstadt von Goslar und Oberharzer Wasserwirtschaft". Bereits im Jahr 1992 wurden das Erzbergwerk Rammelsberg und die Altstadt von Goslar zum UNESCO-Weltkulturerbe erklärt. Das Erzbergwerk Rammelsberg, welches etwa zwei Kilometer südlich der Goslarer Altstadt gelegen ist, wurde im Jahr 1988 aufgrund der Erschöpfung der Lagerstätte geschlossen. Die nach archäologischen Erkenntnissen mehr als 1.000-jährige Geschichte des Rammelsberger Bergbaus ist eines der bedeutendsten montanen Zeugnisse seiner Art. Mit der Aufnahme des

\footnotetext{
${ }^{1}$ Vgl. Hönes (2009a).

2 Im Jahr 1985 erhielten die 1.000-jährige Kirche St. Michaelis und der Dom zu Hildesheim den UNESCO-Weltkulturerbe Status. Ihr folgte das Denkmalensemble „Bergwerk Rammelsberg und Altstadt von Goslar“" im Jahr 1992. Erst 2009 wurde das erste Weltnaturerbe in Niedersachsen ernannt - das Wattenmeer (mit Schleswig-Holstein und Bereichen in den Niederlanden). Im Jahr 2010 wurde die Welterbestätte „Bergwerk Rammelsberg und Altstadt von Goslar“ um die „Oberharzer Wasserwirtschaft" erweitert. Die bisher letzte ernannte Weltkulturerbestätte in Niedersachsen ist das Fagus-Werk in Alfeld, welches im Jahr 2011 in die UNESCO Liste aufgenommen wurde.
} 
Manuela Armenat

historischen Stadtkerns von Goslar in den Antrag stellte man den Gesamtkontext dieser Montanregion deutlicher heraus. ${ }^{3}$ Im Jahr 2010 wurde die Welterbestätte um die „Oberharzer Wasserwirtschaft" ${ }^{* 4}$ konsequent erweitert. Damit wurde das größte, weit verzweigte Energieversorgungssystem, aber auch das Zisterzienserkloster Walkenried und einzigartige Schachtanlagen, wie beispielsweise der OttiliaeSchacht (Clausthal-Zellerfeld), der Knesebeck-Schacht (Bad Grund) oder die Fahrkunst in der Grube Samson (St. Andreasberg), zum Weltkulturerbe ernannt.

Die Denkmale des Harzer Bergbaus sind nicht nur für Niedersachsen von besonders herausragender Bedeutung, sondern zählen zu den wertvollsten Kulturerbestätten Deutschlands und weltweit, da sie eine Geschichte der Mensch-UmweltInteraktionen sichtbar und greifbar machen, die über Jahrtausende reichte. Der Naturraum Harz wurde zu einer Kulturlandschaft Harz, in der sich die gesellschaftlichen, ökonomischen und kulturell-ästhetischen Anforderungen des Menschen aus der Vergangenheit und Gegenwart widerspiegeln. ${ }^{5}$ Die Übergänge zwischen Kultur und Natur sind in der Landschaft ablesbar, so finden sich auch im Nationalpark Harz ${ }^{6}$ kulturhistorische Relikte, die eben diese heute attraktive Kulturlandschaft mit ihren Fichten- und Buchenwäldern oder den Mooren mit prägten und durch neue gesellschaftliche Bedürfnisse wieder überprägt werden. Im Folgenden kann diese Geschichte der sich auf über $200 \mathrm{~km}^{2}$ ausdehnenden Welterbestätte nicht en détail nachgezeichnet werden, vielmehr soll hier schlaglichtartig die Entwicklung des Rammelsberger Bergbaus und der Stadt Goslar dargestellt werden. Dabei lassen sich immer wieder Verbindungen zu den Elementen der Oberharzer Wasserwirtschaft nachzeichnen.

\section{Erze, Wald und Wasser - Naturräumliche Gegebenheiten}

Das etwa zwei Kilometer südöstlich der Altstadt von Goslar gelegene Erzbergwerk Rammelsberg wurde am 30. Juni 1988 stillgelegt. ${ }^{7}$ Die Lagerstätte umfasste ursprünglich etwa 30 Millionen Tonnen Blei-, Zink- und Kupfererze sowie geringe Mengen Silber. Es zählte damit zu den größten seiner Art. Nach mehr als 1.000jähriger Abbautätigkeit, die sich zugleich deutlich in der Stadt Goslar widerspiegelt, hat sich eine Vielzahl von Bergbaudenkmalen und mittelalterliche Stadtbaukunst

\footnotetext{
${ }^{3}$ Roseneck (1992), S. 6.

${ }^{4}$ Vgl. dazu beispielsweise Schmidt (2012); Teicke (2011); Balck (2000).

${ }^{5}$ Vgl. zum Begriff und zur Definition von „Kulturlandschaft“: Burggraaff (1996), S. 10-11.

${ }^{6}$ Der Nationalpark Harz umfasst heute insgesamt 24.703 Hektar Fläche. Davon liegen etwa 15.800 Hektar in Niedersachsen und etwa 8.900 Hektar in Sachsen-Anhalt. Der zu den größten Waldnationalparken in Deutschland zählende Nationalpark Harz wurde 2003 auch international von der Weltnaturschutzorganisation IUCN anerkannt. Die Flächen sind derzeit in drei Zonen eingeteilt: 1) Naturdynamikzone, mit aktuell $52 \%$ der Gesamtfläche, 2) Naturentwicklungszone, mit aktuell $47 \%$ der Gesamtfläche und 3) Nutzungszone, die aktuell etwa $1 \%$ der Gesamtfläche ausmacht. Letzteres sind Flächen mit kulturhistorischer Bedeutung, wie Bergwiesen, Schwermetallrasen oder sie sind für die Erholung und Bildung wichtig. Vgl. www.nationalpark-harz.de (Abruf: 07.06.2013).

${ }^{7}$ Spier (1988), S. 5.
} 
erhalten. ${ }^{8}$ Möglicherweise lassen sich zudem in den nächsten Jahren weitere wissenschaftliche Belege finden, die die derzeitigen Vermutungen bestätigen, dass erste Abbautätigkeiten in der Bronzezeit und damit bereits vor etwa 3.000 Jahren erfolgten. ${ }^{9}$ Die naturräumlichen Voraussetzungen, aber auch die gesellschaftlichen Veränderungen und technischen Entwicklungen beförderten die Bergbautätigkeit und den Landschaftswandel am Rammelsberg.

Die Rammelsberger Buntmetallerz-Lagerstätte gehört zu den so genannten SEDEX Lagerstätten, die submarin - synsedimentär - exhalativ entstanden. Das heißt, dass sie durch den Austritt von heißen, mineralhaltigen hydrothermalen Lösungen auf dem Meeresgrund des Goslarer Troges gebildet wurden. Die beiden Erzlinsen (Altes und Neues Lager) sedimentierten im unteren Mitteldevon - vor etwa 390 Millionen Jahren. Etwa 50 Millionen Jahre später - im Karbon - wurde die Lagerstätte zusammen mit dem Harz durch Auffaltungen stark deformiert und metamorphisiert. Zudem wurden die beiden Erzlinsen überkippt und dadurch in ihre heutige Schräglage von etwa $45^{\circ}$ gebracht. Die enormen Faltungsvorgänge vollzogen sich im gesamten mitteleuropäischen Raum, sie gehören zur so genannten Variszischen Orogenese. ${ }^{10}$

Durch die oberflächliche Verwitterung wurde mit der Zeit der Ausbiss des Alten Lagers auf etwa 500 Meter Länge sichtbar. ${ }^{11}$ Die chemische Zusammensetzung der stark sulfidischen und schwermetallreichen Lagerstätte ermöglichte es wahrscheinlich nur Flechten und Moosen, auf diesem Boden zu gedeihen. ${ }^{12}$ Das Neue Lager, welches erst 1859 durch das weitere Auffahren eines alten Stollens entdeckt wurde, trat nicht über Tage aus. ${ }^{13}$

Eine weitere wesentliche Voraussetzung für den aufblühenden Bergbau am Rammelsberg war der Wald. Das Holz war nicht nur wichtig als Brennstoff und Baumaterial für Betriebsgebäude und Wohnhäuser, sondern auch für den Bergbau. Dieser benötigte große Mengen Holz für die Sicherung der Gruben, den Bau von technischen Anlagen sowie für die Verhüttungsprozesse. ${ }^{14} \mathrm{Da}$ das Holz und die Holzkohle, die zunächst aus den Wäldern am Harzrand gewonnen wurden, im Zuge der Ausweitung des Verhüttungswesens und steigender Bevölkerungszahlen

\footnotetext{
8 Roseneck (1992), S. 7 f.

${ }^{9}$ So belegten archäologische Grabungen bei Düna am Südharz, dass am Rammelsberg bereits um 300 n. Chr. Bergbautätigkeit stattfand. Des Weiteren gibt es Hinweise auf Verhüttungsaktivitäten in der Eisenzeit (800 v.Chr. - Chr. Geb.) durch die geochemische Analyse der Schwermetallanreichungen in der Erdfallsenke „Silberhohl“ bei Seesen. Siehe Hettwer (1999). Weitere Blei-Isotopen-Analysen an bronzenen Schmuckscheiben geben außerdem Hinweise darauf, dass wahrscheinlich bereits in der Bronzezeit (1800-800 v. Chr.) Erzabbau am Rammelsberg betrieben wurde.

Siehe www.rammelsberg-blog.de/2012/02/altbackenes-aus-der-geruechtekueche-das-jahr-968/. Siehe auch www.welt.de/kultur/history/article13588223/3000-Jahre-alte-Muellkippe-bei-Goslarentdeckt.html (Abruf: 07.06.2013).

${ }^{10}$ Kraume (1955), S. 297 ff.; Deicke (2000), S. 43 f.

11 Roseneck (1992), S. 16 sowie Czyppul u. Küntzel (2005), S. 17.

12 Ebd.

${ }^{13}$ Roseneck (1992), S. 10, 16.

${ }^{14}$ Vgl. Bartels et al. (2007), S. 58 f.
} 
Manuela Armenat

lokal immer knapper wurde, mussten die Köhlerei und der Holzabbau in die Wälder des Harzes verlagert werden. Mit dem erhöhten Energiebedarf der zahlreichen Harzer Gruben, aber auch der Weidewirtschaft zur Versorgung der Bergleute, wurde die vorherige, naturbedingte Bewaldung zu wesentlichen Teilen durch die Fichte abgelöst. ${ }^{15}$ Nach paläoökologischen Erkenntnissen dürfte der Harz bis ins frühe Mittelalter ein Laubdunkelwald, dominiert von Buche (Fagus sylvatica) und Ahorn (Acer), gewesen sein. Die Harzränder, wie bei Goslar, waren durch Laubmischwälder aus Eiche (Quercus), Buche (Fagus sylvatica), Ahorn (Acer), Erle (Alnus), Birke (Betula) und Linde (Tilia) geprägt. ${ }^{16}$

Die gute Versorgung mit ausreichend Wasser war eine weitere Voraussetzung für die Entwicklung der Bergbautätigkeit, wie dies eindrücklich an der Oberharzer Wasserwirtschaft, aber auch am Rammelsberg verdeutlich werden kann. Nicht nur als zweiter Energieträger neben dem Holz, sondern auch für die Siedlungsentwicklung und den Abtransport von Schadstoffen kommt dem Wasser eine besondere Bedeutung zu. Am nordwestlichen Harzrand bei Goslar nutzte man die Nebengewässer der Oker für den Bergbau. Bereits der Name des Baches Abzucht, welcher im oberen Wintertal entspringt und oberhalb des Erzbergwerkes Rammelsberg im Herzberger Teich künstlich aufgestaut wird, deutet auf dessen Rolle beim Abbau des Rammelsberger Erzes hin. ${ }^{17}$ Das Wasser der Abzucht trieb nicht nur die Wasserräder für den Bergbau an und wurde zur Erzwäsche verwendet, es lieferte auch die Energie für den Betrieb von Mühlen, Walkereien und Sägewerken in Goslar. ${ }^{18}$ Da das Wasser der Abzucht stark verunreinigt war, ${ }^{19}$ gewann man das Trink- und Brauwasser aus dem Bach Gose. ${ }^{20}$

Nach Bartels et al. (2007) bildeten diese naturräumlichen Potenziale die Grundlage für die Entwicklung einer frühen Gewerbelandschaft im nordwestlichen Harz. ${ }^{21}$ Spätestens seit dem ausgehenden Frühmittelalter ist diese Entwicklung auch für die anderen Teile des Harzes nachweisbar. Die größeren Siedlungen lagen zu dieser Zeit noch vorrangig an den Harzrändern, aber die Aufbereitung und Verhüttung erfolgte nun vermehrt in der Nähe des Energie- und Bauträgers Holz. ${ }^{22}$ So finden sich Schlackenreste aus der Verhüttung von Rammelsberger

\footnotetext{
15 Bartels et al. (2007), S. 59 f.

16 Hillebrecht (2000), S. 85.

17 Adelung (1793), S. 141 und Nds. Landesbetrieb für Wasserwirtschaft und Küsten- und Naturschutz (NLWKN) (2002), S. 29 f.

18 Auch heute noch finden sich in der Altstadt von Goslar alte Mühlenanlagen, die die historische Wassernutzung belegen.

19 Viele der früheren Schwermetallablagerungen der Harzer Gewässer lassen sich in den Sedimenten nachweisen. Siehe dazu beispielsweise Lindorfer (1997). Siehe auch Deicke (2000), S. 80 f. Das Wasser der Abzucht ist auch heute noch stark von Schwermetallen belastet. Siehe dazu NLWKN (2002), S. 116.

${ }^{20}$ Entsprechend gibt es heute noch die Gose Brauerei, die auch Führungen zur Brauereigeschichte anbietet. www.brauhaus-goslar.de (Abruf: 07.06.2013).

${ }^{21}$ Bartels et al. (2007), S. 65.

22 Ebd., S. 66. Vgl. auch Ließmann (1997).
} 
Erzen in der gesamten Harzregion. ${ }^{23}$ Siedlungen wie Goslar erlebten einen deutlichen Bevölkerungszuwachs und entwickelten sich zu Handels- und Machtzentren. Die Auf- und Abschwünge des Bergbaus zeichneten sich auch in der Stadtentwicklung $\mathrm{ab}$.

\section{Die Stadt Goslar - Von der Kaiserpfalz zum Weltkulturerbe}

Mit über 1.500 besonders gut erhaltenen Fachwerkhäusern und dem Profanbau Kaiserpfalz, stellt die Altstadt von Goslar ein bedeutendes UNESCO Weltkulturerbe dar. In der Struktur der Goslarer Altstadt, den verschiedenen Baustilen der Epochen, zeichnet sich nicht nur die Geschichte einer Stadt, sondern auch die Bergbaugeschichte des nordwestlichen Harzrandes und im Besonderen des Rammelsberger Bergbaus ab. Ihre Entwicklung soll im Folgenden dargelegt werden.

\subsection{Von den Anfängen}

Bereits vor dem Einsetzen der schriftlichen Überlieferung zu Goslar - ab dem 10. Jahrhundert - wurde die Gegend bereits durch Menschen in der Mittel- und Jungsteinzeit (ca. 5.000 v. Chr.) genutzt. So belegen Funde die Anwesenheit von Jägern und Sammlern in der Region. ${ }^{24}$ Spätestens seit der Bronzezeit (2.200 bis 800 v. Chr.) war das Harzvorland vermutlich kontinuierlich besiedelt. ${ }^{25}$

Mit der Eroberung der Sachsenlande durch den Karolingerkönig Karl den Großen (747/48-814) vollzog sich nicht nur eine Aneignung von Grund und Boden, sondern auch ein Zugriff auf die etablierten Handelswege. Eines der damals erzeugten und gehandelten Produkte waren Messingwaren. Deren Kupferanteil stammte aus dem Gebiet des heutigen Marsberg und aus dem Harz, wie archäologische Funde zur frühen Kupfergewinnung aus Rammelsberger Erz belegen. ${ }^{26}$ Die karolingische Expansion und eine Münzreform belebten die Wirtschaft und den Handel. Insbesondere das Metallhandwerk und die Metallgewinnung profitierten von diesen Veränderungen. ${ }^{27}$ Bartels et al. (2007) konstatieren, dass die Sachsenkriege (772-805), neben der Unterwerfung und Missionierung der Sachsen, den Zugriff auf und die Kontrolle über Rohstoffe und Produktionsstätten des Sachsenlandes zum Ziel hatten. Dazu gehörte wohl auch der Harzraum mit seinen Erzen und deren Verhüttung. ${ }^{28}$ In den folgenden Jahrhunderten bis zum Ausgang des 13.

\footnotetext{
${ }^{23}$ Deicke (2003), S. 3.

24 Grunewald (2000), S. 56 f. sowie Czyppul u. Küntzel (2005), S. 14, 16.

25 Siehe dazu Bartels et al. (2007), S. 68 f. So fanden sich endbronzezeitliche Artefakte bei Bad Harzburg. Auch der Fund eines Bronzearmrings oberhalb der heutigen Innerstetalsperre und die kettenartige Verbreitung von bronzezeitlichen Hügelgräbern deuten auf eine rege Nutzung des Harzvorlandes und Oberharzes hin.

${ }^{26}$ Bartels et al. (2007), S. 72 f.

27 Ebd., S. 74.

${ }^{28}$ Ebd.
} 
Jahrhunderts wurde der Harz zu einer ,wichtigen, zeitweilig sogar die zentrale Kernlandschaft des deutschen Reiches“29.

\subsection{Die Zeit der Kaiserpfalz (1009-1253)}

Auf einem kleinen Plateau am Fuß des Rammelsberges entstand im 10. Jahrhundert ein Bergdorf, an dessen Rand der Kaiser Heinrich II. (973/78-1024) zu Beginn des 11. Jahrhunderts eine Pfalz anlegte. Sie löste damit die im Harzvorland gelegene Pfalz Werla als Herrschaftssitz ab. ${ }^{30}$ Die heute noch erhaltene und restaurierte Goslarer Kaiserpfalz (siehe Abb. 1) wurde unter dem Salier Kaiser Konrad II. (um 990-1039) und seinem Sohn Heinrich III. (1017-1056) errichtet. ${ }^{31}$ Die Feier religiöser Festtage, aber auch die rege Regierungstätigkeit in Goslar sowie das Ansinnen sich territorial und politisch auf sächsischem Gebiet ${ }^{32} \mathrm{zu}$ etablieren, haben Müllers (2007) Ansicht zufolge, den festen und vergrößerten Ausbau der Pfalz unterstützt. ${ }^{33}$

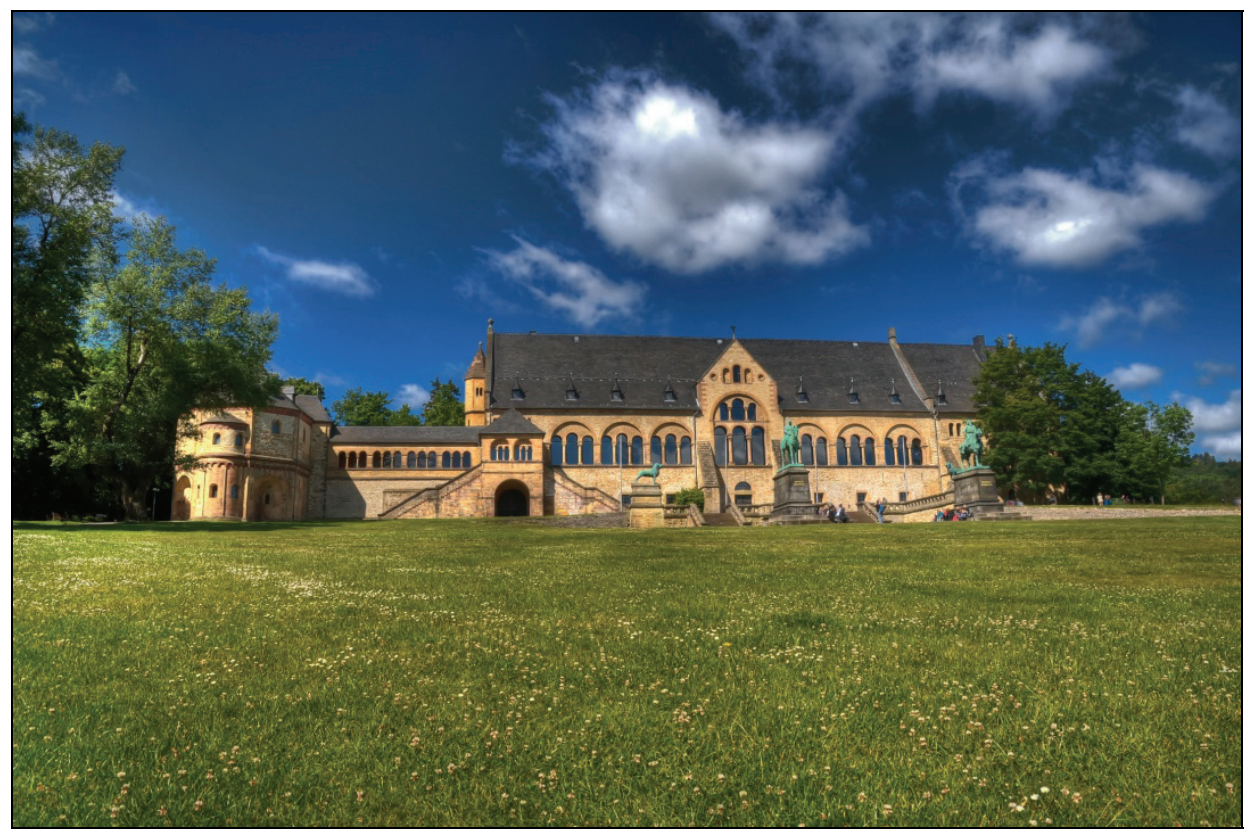

Abb. 1: Kaiserpfalz Stadt Goslar (GOSLAR Marketing GmbH/ Stefan Schiefer). ${ }^{34}$

\footnotetext{
${ }^{29}$ Jordan (1977), S. 164, zitiert in Bartels et al. (2007), S. 75.

${ }^{30}$ Roseneck (1992), S. 11 und Czypull u. Küntzel (2005), S. 30. Vgl. auch Müller (2007), S. 10 f.

${ }^{31}$ Roseneck (1992), S. 11

${ }^{32}$ Sächsisches Gebiet meint hier Altsachsen bzw. das Stammesherzogtum Sachsen.

33 Müller (2007), S. 12 f.

${ }^{34}$ Mit freundlicher Genehmigung von GOSLAR Marketing GmbH.
} 
Nach einer Neuordnung des Münzwesens verlagerten sich Ende des 9. Jahrhunderts die Prägestätten von Magdeburg in den Harzraum und nach Goslar, wo die Prägetätigkeit ab 1069 schriftlich belegt ist. Zeitgleich wuchs Goslar rasch zu einer Stadt heran, deren Entwicklung wahrscheinlich positiv durch den Handel in Richtung Ostsee befördert wurde. ${ }^{35}$

Während das Bergdorf spätestens im 12./13. Jahrhundert verödete, ging der Ausbau des Ortes Goslar voran. ${ }^{36}$ Das Gemeinwesen der Stadt war wahrscheinlich schon früh ausgebildet und der Bau von schützenden Wällen und Palisaden führte zu einem verstärkten Zuzug der BewohnerInnen aus den umliegenden Dörfern. ${ }^{37}$ Die wirtschaftliche Grundlage bildeten der Rammelsberger Bergbau und der Handel mit den abgebauten Erzen. ${ }^{38}$ Zum Beginn des 12. Jahrhunderts wuchsen die, bis dahin räumlich noch sehr voneinander abgegrenzten Stadtbereiche der weltlichen und religiösen Bezirke stärker zusammen. ${ }^{39}$

Mit dem Bau der Pfalz wurde Goslar zum wichtigen Knotenpunkt der mittelalterlichen Montanwirtschaft und bildete ein Zentrum der königlich-kaiserlichen Macht. ${ }^{40}$ Dies zeigte sich auch in der Etablierung eines Verwaltungsbezirks, der die königlichen Güter und die Besitzstände in und um Goslar zusammen legte und unter der Kontrolle eines königlichen Reichsvogtes stand. ${ }^{41}$ Diese Aufgabe übernahm in Goslar der spätere Bischof Benno, ein enger Vertrauter Heinrich des III. und Heinrich des IV. (1050-1106).42

Die zu verwaltenden Güter waren sehr ergiebig. Dazu trug vor allem das florierende Montanwesen bei, welches sich nicht nur auf die Gewinnung und Produktion der Metalle allein beschränkte, sondern auch Gebühren für Wald- und Wassernutzung umfasste. So entwickelte sich Goslar zu einem attraktiven Ort für die deutschen Könige, die teils über Monate in der Pfalz verweilten. ${ }^{43}$ Erst mit dem Tod des Kaisers Friedrich I. Barbarossa (1151-1190) verlor die Pfalz Goslar an Bedeutung. ${ }^{44}$ In seiner Zeit, beim Reichstag von Roncaglia 1158, wurden die Regalrechte festgelegt, darunter auch das Bergregal, welches dem König die finanzielle Mitnutzung sowie ein Verleihungsrecht zusprach. Damit wurde auch die Weggabe königlicher Besitzrechte ermöglicht, die - wie am Rammelsberg - an andere Eigner übertragen wurden. ${ }^{45}$ Der Verband der neuen Eigner war mit besonderen Rechten

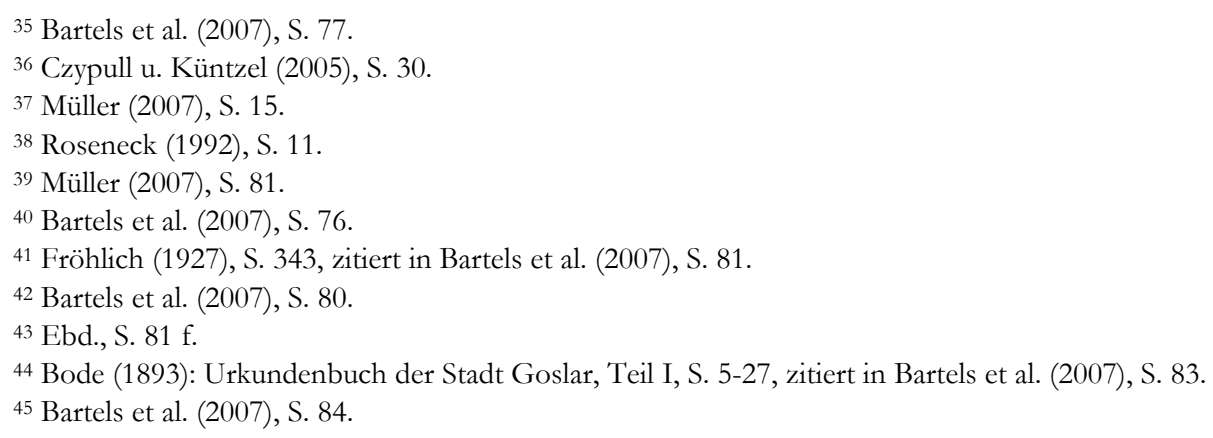


verbunden, aber auch zur Übernahme wesentlicher Gemeinschaftsaufgaben verpflichtet. ${ }^{46}$

In der Folgezeit erlangte das heute ebenfalls zur Welterbestätte gehörende „Kloster Walkenried ${ }^{47}$, weltliche und kirchliche Einrichtungen sowie Goslarer Ritter- und Patriziergeschlechter großen Einfluss im Montanwesen des ganzen westlichen Harzes"48. Goslar stellte dabei zwar das Zentrum der Macht- und Prachtentfaltung dar, vernetzte aber vor allem die im ganzen Revier verteilten Montanareale des nordwestlichen Harzraumes. ${ }^{49}$

\subsection{Das „Bürgerliche Mittelalter“ (1219-1523)}

Um den Einfluss und Besitz der Stadt Goslar im Montanwesen zu mehren, bemühte sich der Goslarer Rat Ende des 13. Jahrhunderts um den Erwerb von Hüttenstätten. ${ }^{50}$ Im Jahre 1290 eröffnete sich für den Rat der Stadt eine Möglichkeit. Mit dem Erwerb der Reichsvogtei Goslar wurde Goslar zu einer freien Reichsstadt. Der Rat der Stadt besaß nun die uneingeschränkte Handelsfreiheit. ${ }^{51}$

Diese Entwicklung setzte sich mit dem Abschwung des Bergbaus um 1300 fort. Zu dieser Zeit gelang es den bürgerlichen Familien der Stadt Goslar, in die bestehende Korporation von Montanen und Silvanen einzusteigen und weiter an Macht und Kontrolle zu gewinnen. ${ }^{52}$ Der Status als „freie Stadt“ und der wachsende Einfluss auf das Montanwesen beflügelte das „Selbstbewusstsein des Goslarer Bürgertums“"53. Es begann die Zeit des „bürgerlichen Mittelalters“. Nach Bartels et al. (2007) zielten die politischen Bestrebungen der Stadt und ihres Rates darauf ab, einen Stadtstaat Goslar entstehen zu lassen, der den gesamten nordwestlichen Harzraum umfassen sollte. ${ }^{54}$ Im 15. Jahrhundert zeigten sich in Goslar aber auch, wie andernorts, vielgestaltige Krisen. Das Schwinden der kaiserlichen Macht verursachte ein Machtvakuum, welches durch neue territoriale Kräfte gefüllt wurde. Zudem erforderte die Zeit des Raubrittertums eine stärkere Außenverteidigung der Stadt, was sich in dem Bau von Schutzanlagen und der Gründung einer Bürgerwehr widerspiegelt. ${ }^{55}$

\footnotetext{
46 Bartels et al. (2007), S. 86.

47 Seit 2010 gehört das 1127 gestiftete Zisterzienserkloster zum UNESCO-Weltkulturerbe Oberharzer Wasserwirtschaft. Der jahrhundertelangen, engen Verflechtung der Zisterziensermönche mit dem Bergbau im Harz wird damit Rechnung getragen. Weitere Informationen z. B. unter www.klosterwalkenried.de (Abruf: 07.06.2013).

48 Bartels et al. (2007), S. 93.

49 Ebd.

50 Ebd., S. 94.

51 Titz-Matuszak (ca. 2000), S. 1.

52 Bartels et al. (2007), S. 94 f.

53 Ebd., S. 98.

54 Ebd.

55 Titz-Matuszak (ca. 2000), S. 1.
} 


\subsection{Der Konflikt mit Heinrich dem Jüngeren und der Riechenberger Vertrag (1523-1552)}

Die Bemühungen die eigene Vormachtstellung im Montanwesen zu halten, sollten im 16. Jahrhundert zu einem Konflikt mit den Braunschweiger Herzögen führen, deren Interesse der Entwicklung eines frühmodernen Territorialstaates galt. Die Konkurrenz um die Verfügungsgewalt über Hütten, Wälder und Bergwerke eskalierte 1526/27, als der Herzog Heinrich der Jüngere (1485-1568) seine verpfändeten Besitztümer einforderte. Dazu gehörten zunächst die Harzwälder, die er durch das Begleichen der Pfandsummen zurück erlangte. Die Abhängigkeit von Holzlieferungen aus dem nun wieder fürstlichen Waldbesitz und die zunehmende Konkurrenz zum Rammelsberg befeuerte den Konflikt, der 1527 in eine militärische Auseinandersetzung mit der Stadt Goslar mündete. Erst der Riechenberger Vertrag aus dem Jahr 1552 löste die Streitigkeiten. Die Verfügungsgewalt über das Montanwesen ging nun ganz an das Herzogtum, nur die Anteile am Rammelsberger Bergbau verblieben in städtischer Hand. Damit wurde, so Bartels et al. (2007), die Vormachtstellung der Stadt Goslar (siehe Abb. 2) im nordwestlichen Harz unterbunden und das Montanwesen unter eine zentrale und einheitliche Organisation und Leitung gestellt. Dieser Einschnitt sollte sich in den folgenden Jahrhunderten positiv auf die Entwicklung des welfischen Territorialstaates, aber auch auf das Montanwesen im Nordwestharz auswirken. ${ }^{56}$ Unter dem Nachfolger Heinrichs des Jüngeren, seinem Sohn Herzog Julius von Braunschweig-Wolfenbüttel (1528-1589) prosperierten die Bergwerke und Hütten..$^{57}$

Diese Entwicklung war allerdings von nicht allzu langer Dauer. Die wirtschaftlichen und technischen Herausforderungen, zunehmende politische und gesellschaftliche Spannungen bis hin zu kriegerischen Auseinandersetzungen sowie Verschiebungen in den Machtverhältnissen in Europa sollten im 17. Jahrhundert zu einem deutlichen Abschwung im Montanwesen führen. ${ }^{58}$ Der Dreißigjährige Krieg (1618-1648) hinterließ im Falle Goslars zwar nicht eine zerstörte Stadt, hatte aber immense finanzielle Belastungen und Verschuldungen zur Folge. Auch der Siebenjährige Krieg (1756-1763) wirkte sich vor allem für die städtischen Finanzen nachteilig aus. Hinzu traten hohe Kosten zum Wiederaufbau nach zwei verheerenden Stadtbränden (1728 und 1780). ${ }^{59}$

\footnotetext{
56 Bartels et al. (2007), S. 101; Bartels (2000b), S. 141 ff.

57 Bartels (2000b), S. 143 f.

58 Ebd.

59 Titz-Matuszak (1997), S. 1.
} 


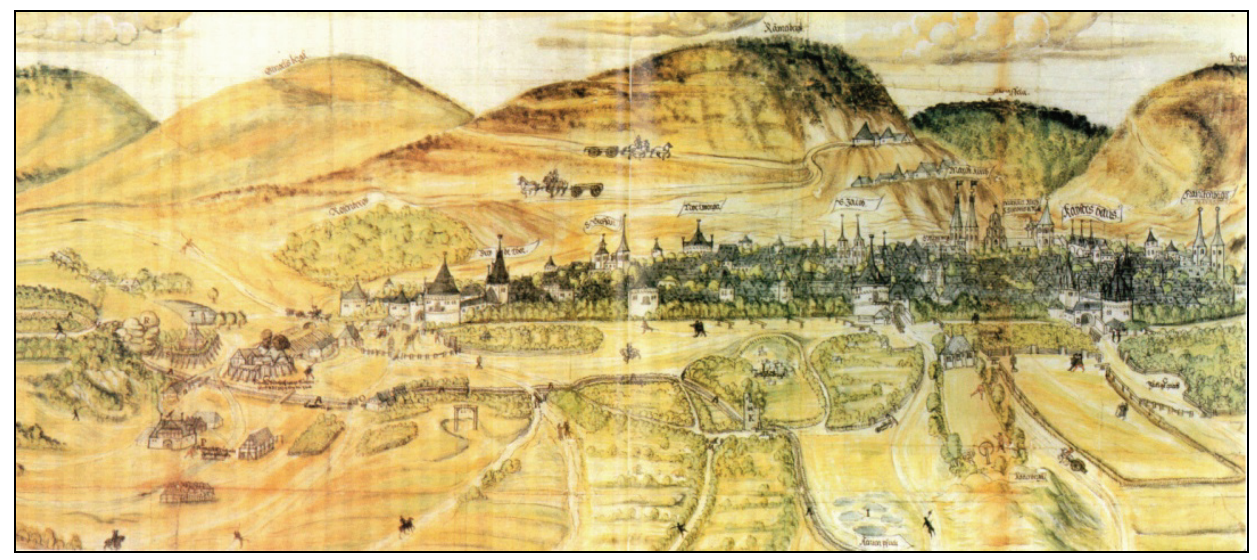

Abb. 2: Max Silken, Stadtansicht von Goslar 1547 (Ausschnitt). Im Hintergrund der Rammelsberg mit Bergbauanlagen (Witthöft (2000), S. 124). ${ }^{60}$

\subsection{Goslar in der Folgezeit}

Nach Titz-Matuszak (1997) waren das 17. und 18. Jahrhundert eine Zeit „des wirtschaftlichen Niedergangs" ${ }^{61}$. Um den neuen Anforderungen gerecht zu werden, bedurfte es weit reichender Veränderungen. So verlor die Stadt Goslar beispielsweise Anfang des 19. Jahrhunderts (1803) ihre Reichsfreiheit. Damit wurde sie zu einer Landstadt ohne spezielle Funktionen. Diese Entwicklung stellte ein enormes Potential für notwendig gewordene Stadtreformen dar. ${ }^{62}$ Für Heinrich Heine, der 1824 auf seiner „Harzreise“ Goslar aufsuchte, waren Veränderungen dringend notwendig. Anstelle einer - in seinen Augen - stattlichen Stadt, erwartete ihn ,ein Nest mit meistens schmalen, labyrinthisch krummen Straßen, allwo mittendurch ein kleines Wasser, wahrscheinlich die Gose, fließt, verfallen und dumpfig, und ein Pflaster, so holprig wie Berliner Hexameter." ${ }^{\prime \prime 3}$

Die Goslarer Wirtschaft, die zwischen einerseits Bemühungen zum Freihandel und andererseits konservativer Innungsbindung pendelte, war weiterhin stark vom Bergbau geprägt. Die Entdeckung des Neuen Lagers und technische Entwicklungen ließen die Erzförderung stetig steigen. Neben dem Bergbau waren vor allem das Handwerk, der Mühlenbetrieb, der Handel z. B. mit Metall und die mittelständische Chemieindustrie von Bedeutung für das wirtschaftliche Leben der Stadt, die über fünfzig Jahre (1815-1866) in die Wirtschaftspolitik des Königreichs Hannover eingebunden sein sollte. ${ }^{64}$

\footnotetext{
${ }^{60}$ Original aus: Bachmann, M; Marx, H \& Wächtler, E (Hg.)(1990): Der Silberne Boden. Kunst und Bergbau in Sachsen. Leipzig, Abb. 4, Kat.-Nr. 431.

61 Titz-Matuszak (1997), S. 1.

62 Deininger u. Lange (1998), S. 1.

${ }^{63}$ Heine (1825).

${ }^{64}$ Deininger u. Lange (1998), S. 1 f.
} 
In der zweiten Hälfte des 19. Jahrhunderts wurde die Kaiserpfalz restauriert, zu Teilen neu aufgebaut und als Nationaldenkmal stilisiert. ${ }^{65}$ Die Stadt entwickelte sich, dank experimentierfreudiger Anwohner, zu einem Kur- und Pensionsort. Mit der Machtübernahme der Nationalsozialisten wurde Goslar 1936 zur „Reichsbauernstadt“ ernannt. Die jährlichen ideologisierten Zeremonien der „Reichsbauerntage“ (1934-1938), fanden vor der geschichtsträchtigen Kaiserpfalz statt. ${ }^{6}$ Der Rammelsberger Bergbau und die Unterharzer Hüttenwerke G.m.b.H. sowie die chemische Fabrik Gebr. Borchers A.G./H.C. Starck in Goslar zählten während des Dritten Reichs zu den rüstungsrelevanten Industrien, in denen zahlreiche Zwangsarbeiter beschäftigt waren. ${ }^{67}$

Nach 1945 wurde Goslar zu einer Stadt in Grenzlage, welches Nachteile, aber auch Vorteile, wie die finanzielle Unterstützung durch die Zonenrandförderung, mit sich brachte. Die besondere historische Bausubstanz der Altstadt (siehe Abb. 3) und die Einzigartigkeit des 1988 geschlossenen Rammelsberger Bergwerkes waren entscheidende Gründe zur Aufnahme in die Weltkulturerbeliste.

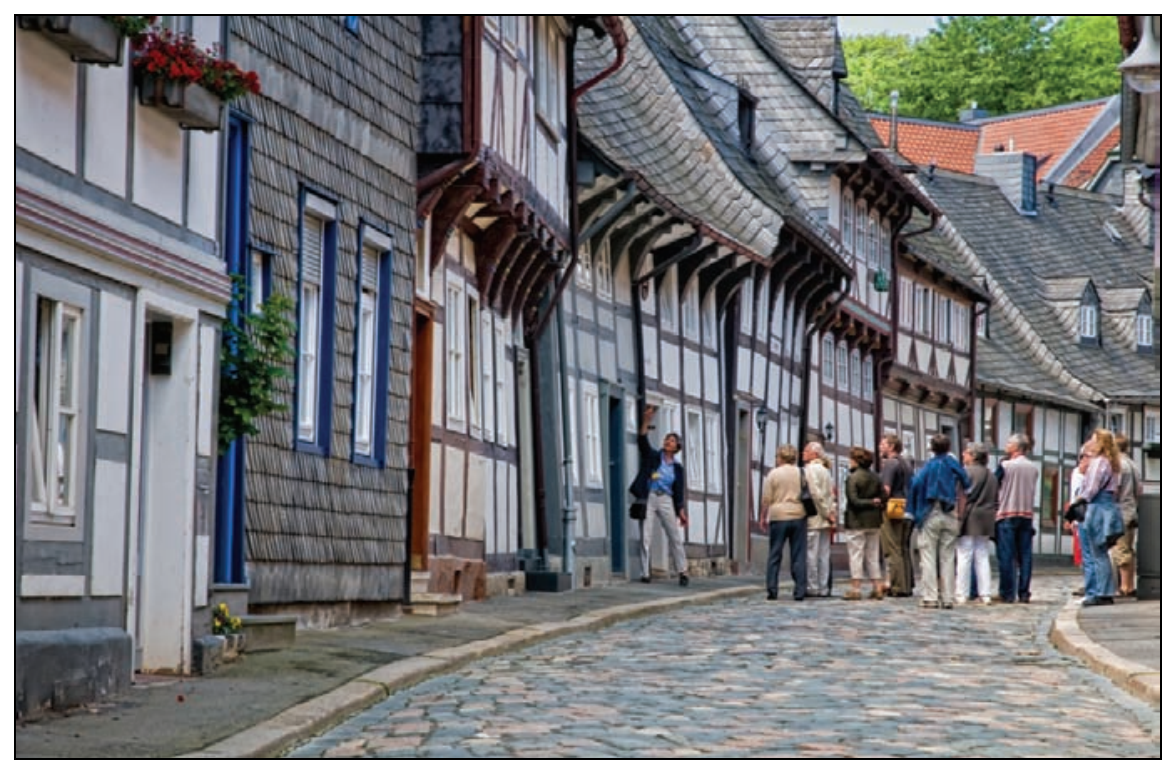

Abb. 3: Altstadt von Goslar. Diese alten Gassen und Häuser sind heute restauriert und für die Nachwelt erhalten (GOSLAR Marketing GmbH/ Stefan Schiefer). ${ }^{68}$

\footnotetext{
${ }^{65}$ Deininger u. Lange (1998), S. 2.

${ }^{66}$ Siehe de.wikipedia.org/wiki/Goslar (Abruf: 07.06.2013). Weiterführende Literatur: Schyga (1999).

${ }^{67}$ Vgl. Bartels (1988), S. 62.

${ }^{68}$ Mit freundlicher Genehmigung von GOSLAR Marketing GmbH.
} 


\section{Das Erzbergwerk Rammelsberg - 1000 Jahre Montanhistorie}

Mit einer mehr als 1.000-jährigen Montangeschichte gehört der Rammelsberg zu einem der bedeutendsten und einzigartigsten Industriedenkmäler in Europa, aber auch weltweit. Im Folgenden wird die Geschichte schlaglichtartig dargestellt und die Bedeutung im Kontext von Mensch-Umwelt-Interaktionen sowie der technischen Entwicklungen beleuchtet.

\subsection{Von den Anfängen bis ins späte Mittelalter}

Wie bereits dargelegt wurde, bedarf die frühe Geschichte des Erzbergbaus am Rammelsberg noch einiger Forschungen. Nach Bartels (1988) erfolgte die erste Blütephase des Rammelsberger Bergbaus zwischen etwa 970 und 1235. Nicht nur die Otto-Adelheid-Pfennige, die möglicherweise auch in Goslar geprägt wurden, belegen eine rege Handelstätigkeit seit dem ausgehenden 10. Jahrhundert, auch die Verwendung von großen Mengen Rammelsberger Kupfer in den niedersächsischen Erzgießereien ist für die Zeit zwischen dem 10. und 13. Jahrhundert bekannt. ${ }^{69}$ Ein Zeugnis für das Aufblühen des Bergbaus und den Übergang vom übertägigen zum untertägigen Bergbau ist der noch heute zugängliche älteste erhaltene Wasserlösungsstollen in Europa - der „Rathstiefsten Stollen“ am Rammelsberg -, der zur Mitte des 12. Jahrhunderts in Handarbeit aufgefahren wurde. ${ }^{70}$

Für die Zeit zwischen dem Ende des 13. bis zur Mitte des 15. Jahrhunderts ist eine Phase des Rückgangs zu konstatieren. Die zunehmend schwierige Wasserhaltung, unzureichende Technik, zur Neige gehende Kupferreserven, das Einstürzen von Gruben und schwere Pestepedemien (1347 bis 1352) brachten den Erzabbau am Rammelsberg fast zum Erliegen. ${ }^{71}$ Die Krise betraf auch den Oberharz mit seinen ergiebigen Gangerzen. Chronisten aus dem 16. Jahrhundert, wie der Pastor Hardanus Hake ${ }^{72}$, deuteten diesen bergbaulichen Niedergang als Teil der Strafe Gottes, die in engem Zusammenhang mit der Pest stehen würde. Dies ist nicht von der Hand zu weisen, so vermuten auch Bartels et al. (2007), dass die steigenden Lohn- und Produktionskosten im Montanwesen die wirtschaftliche Krise mit beförderten. ${ }^{73}$

Durch die erfolgreichen Bemühungen des Goslarer Rates, den Bergbau mehr zu koordinieren und zu reglementieren sowie durch die Anwendung neuer Technologien und dem allgemeinen Aufschwung im europäischen Montanwesen, erlebte die Erzförderung seit der zweiten Hälfte des 15. Jahrhunderts ein erneutes Wachstum. Die durchschnittliche Jahresfördermenge am Rammelsberg lag bei

\footnotetext{
${ }^{69}$ Bartels (1988), S. 13. Zur Stadtgeschichte vgl. Müller (2007), S. 8 f.

${ }^{70}$ Bartels (1988), S. 13.

${ }^{71}$ Bartels et al. (2007), S. 188 ff., S. 201 und Bartels (1988), S. 15.

72 Weiterführende Literatur Denker (1911).

${ }^{73}$ Bartels et al. (2007), S. 202.
} 
etwa 30.000 Tonnen. ${ }^{74}$ Von besonderer Bedeutung war dabei die umfangreiche Bleiproduktion. ${ }^{75}$

\subsection{In der Frühen Neuzeit}

Mit dem Ende des Siebenjährigen Krieges (1756-1763) setzte ein erneuter Aufschwung ein. Durch Modernisierung des Bergbaus im unter- und obertägigen Betrieb gelang es, unter der Leitung des Oberbergmeisters Johann Christoph Roeder $^{76}$, die Produktion deutlich zu steigern. Er ordnete die Verfüllung ausgeerzter Hohlräume an, um weiteren Grubenzusammenbrüchen entgegen zu wirken, ließ eine „Tagesförderstrecke“ auffahren und die Wasserkraftanlagen erneuern und umgestalten. ${ }^{77}$ So verdreifachte sich unter seiner Riege das Fassungsvolumen des bereits 1561 angelegten Herzberger Teiches durch die Erhöhung der Dammkrone im Jahre 1769 von 25.000 Kubikmeter auf etwa 71.000 Kubikmeter (vgl. Abb. 4). ${ }^{78}$

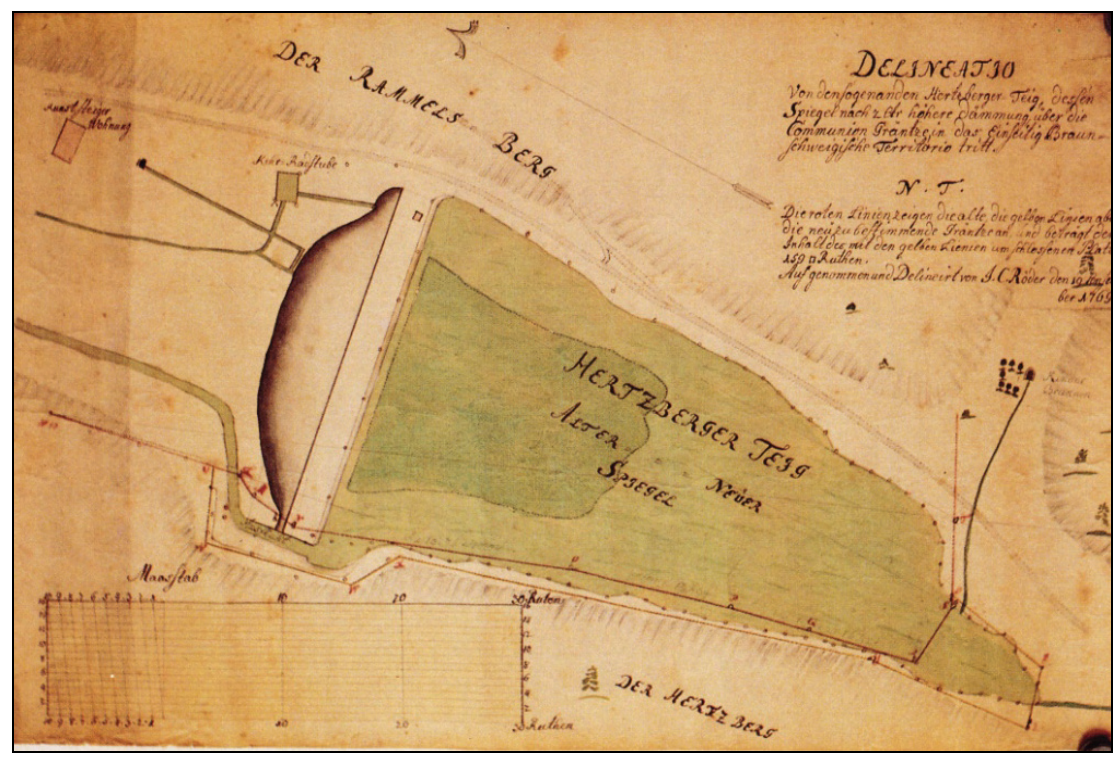

Abb. 4: Zeichnung des Herzberger Teichs vom Oberbergmeister am Rammelsberg Roeder. Karte von 1769 mit Darstellung des Stauvolumens vor und nach der Dammerhöhung (Hillebrand, W (1988), S. 13, Preussag AG Metall, Goslar: Rißarchiv B164, Maßstab ca 1:940).

\footnotetext{
${ }^{74}$ Bartels (1988), S. 15 und Bartels (2000a), S. 110. Vgl. auch Bartels et al. (2007), S. 206 ff.

75 Bartels et al. (2007), S. 201.

${ }^{76}$ Johann Christoph Roeder (1730-1810) war von 1863 bis 1810 Oberbergmeister am Rammelsberg.

${ }_{77}$ Bartels (1988), S. 26 f.

${ }^{78}$ Ebd., S. 26; Spier (1988), S. 8 f.
} 
Manuela Armenat

Ein von Roeder ausgeklügeltes, untertägiges Kehr- und Kunstradsystem nutzte ab 1805 das Aufschlagwasser sowohl zur Erzförderung als auch zur Wasserhaltung. ${ }^{79}$ Diese Anlagen waren Meisterleistungen der Ingenieurskunst. ${ }^{80}$ Die Erneuerung der Wasserkraftanlagen, das Abteufen neuer Schächte und das Auffahren der Tageförderstrecke ermöglichte - trotz einer bedeutenden Brandkatastrophe im Jahr 1800 eine Steigerung der Erzförderung auf durchschnittlich 15.000 Tonnen im Jahr. ${ }^{81}$

\subsection{Das 19. Jahrhundert}

Die gesellschaftlichen Entwicklungen, mit den Napoleonischen Kriegen (18001815) und der einhergehenden wirtschaftlichen Depression, führten auch am Rammelsberg zu Produktionsstockungen, sinkenden Erträgen und Arbeitslosigkeit.82 Hinzu traten Engpässe in der Holzversorgung, nach Bartels (1988) gab es schwere Wurmfraßschäden und Windbrüche um die Jahrhundertwende, die die Holzerträge minderten. ${ }^{83}$ Der Einsatz von Steinkohle im Hüttenbetrieb - seit etwa 1830 - kennzeichnet einen wesentlichen weiteren Schritt zu industriellen Verfahren. Die Fördermenge stieg wieder kontinuierlich an und lag um 1830 bei fast 17.200 Tonnen im Jahr. ${ }^{84}$ Der Prozess der Modernisierung des Berg- und Hüttenwesens, aber auch die Entwicklungen im Maschinenbau waren kein kontinuierlicher Prozess, aber ab etwa 1830 vollzog sich dieser in einer neuen Intensität und Geschwindigkeit. ${ }^{85}$

Die schwere Missernte von 1846 und die Wirtschaftkrise in dem darauf folgenden Jahr, führte auch am Rammelsberg zu einem deutlichen Rückgang der Produktion. ${ }^{86}$ Dies zeigt zugleich, wie stark die Gesamtwirtschaft noch vom Agrarsektor geprägt wurde. ${ }^{87}$ Die positive Entwicklung und Investitionen in den industriellen Sektor in den Folgejahren wurden am Rammelsberg durch die Exploration und Entdeckung des Neuen Lagers im Jahr 1859 begleitet. Die rasche ErschlieBung des Lagers fiel in die Zeit eines immensen Wachstums. Die Industrie übernahm eine wichtig Rolle als Wirtschaftssektor, allen voran die Montan- und Eisenindustrie. Nicht nur die Kohleförderung verzeichnete enorme Zuwächse auch der Abbau der Erze, wie am Rammelsberg. Innerhalb von etwa 30 Jahren verdreifachte sich die geförderte Menge von 21.000 Tonnen Erz im Jahr 1869 auf etwa 60.000

\footnotetext{
${ }^{79}$ Spier (1988), S. 8, 22 ff.

80 Bartels (1988), S. 26.

81 Ebd., S. 27.

82 Ebd. Vgl. außerdem zur Geschichte der Industrialisierung zum Beispiel: Nipperdey (1998), S. 181 f.

83 Dies kann auch ein Hinweis auf Monokulturen sein.

${ }^{84}$ Bartels (1988), S. 27 f.

85 Nipperdey (1998), S. 195.

86 Bartels (1988), S. 27 f. Nach einer Erholungsphase Anfang der 1850er Jahre drückte die Weltwirtschaftskrise 1856/57 die Produktionsmengen am Rammelsberg deutlich nach unten.

87 Nipperdey (1998), S. 197.
} 
Tonnen im Jahr 1897.88 Diese Steigerung wurde auch durch den vermehrten Einsatz von Druckluftbohrmaschinen ab 1876 ermöglicht. Die Maschinen ersetzten das zum Teil gefährliche Feuersetzen und damit die bis dahin bestehende älteste Technik zum Abbau des festen Gesteins. ${ }^{89}$

Mit dem Ende des Deutschen Krieges von 1866 verlor das Königreich Hannover seinen Machtanspruch an Preußen. Somit gingen auch die Grubenanteile des Rammelsberges von Hannover an Preußen über. Preußen gehörten nun 4/7 des Bergwerks, die restlichen 3/7 verblieben weiterhin im Besitz von Braunschweig. Durch einen Staatsvertrag zwischen Preußen und Braunschweig im Jahre 1874 wurde der Rammelsberg der preußischen Landeshoheit unterstellt und war somit nun auch den preußischen Berggesetzen unterstellt. Die Bergordnung des Herzogs Heinrich des Jüngeren von 1555 verlor damit ihre Gültigkeit. ${ }^{90}$

\subsection{Das 20. Jahrhundert}

\section{Anfang des 20. Jahrhunderts}

Die Mechanisierung und Elektrifizierung im Rammelsberger Bergbau setzte sich zum Beginn des 20. Jahrhunderts fort. In den Jahren 1905/06 begann man mit dem Bau einer elektrischen Betriebszentrale, die 1909/10 erweitert wurde und die alten Wasserkrafträder zur Wasserhaltung ablöste. Ebenfalls in diese Zeit fällt die Abteufung eines Neuen Schachtes, dem Richtschacht, der bis in etwa 300 Meter Tiefe unterhalb der Tagesförderstrecke reicht. Auch über Tage erfolgten weitere Neubauten und Modernisierungen. Neben der Betriebszentrale entstanden eine Erzsieberei mit Klaubeanlage und ein neues Zechenhaus. Trotz des Ersten Weltkrieges erfolgte die Erzförderung weiterhin auf dem maximalen Niveau. Für die Umbaumaßnahmen, zur Modernisierung und für die Weiterentwicklung des Betriebes wurden während des Krieges auch kriegsgefangene Zwangsarbeiter eingesetzt. Sie bauten die sechs Kilometer lange Schmalspur-Werksbahn-Trasse vom Rammelsberg nach Oker. ${ }^{91}$

Um den Anforderungen des jungen 20. Jahrhunderts gerecht zu werden, entschloss sich der preußische Staat im Dezember 1923, durch die Gründung einer Aktiengesellschaft, den Bergwerks- und Hüttenbetrieb nunmehr nach privatwirtschaftlichen Grundsätzen zu führen. Im Zuge der Gründung der „Preußische Bergwerks- und Hütten-Aktiengesellschaft" wurde der Erzbergbau am Rammelsberg neu strukturiert. ${ }^{92}$ Die Erze wurden in den Hütten der Unterharzer Berg- und Hüttenwerke weiter verarbeitet. ${ }^{93}$ Bis etwa Juli 1930 stieg die Erzfördermenge an

\footnotetext{
88 Bartels (1988), S. 29. Vgl. zur allgemeinen Entwicklung Nipperdey (1998), S. 198.

89 Bartels (1988), S. 29.

${ }^{90}$ Ebd. Noch bis 1820 lag der Rammelsberger Bergbau zu Teilen im Besitz der Stadt Goslar. Diese trat die Rechte aber an die Kommunionsverwaltung ab.

91 Bartels (1988), S. 30 f.

92 Ebd., S. 37.

93 Ebd., S. 40.
} 
(vgl. Abb. 5), sie wurde durch zahlreiche Maßnahmen der Rationalisierung im Bergbaubetrieb flankiert. Dazu zählten beispielsweise die Elektrifizierung und die verbesserte Strecken- und Schachtförderung. ${ }^{94}$

Förderungsmenge Roherz Rammelsberg [t/a]

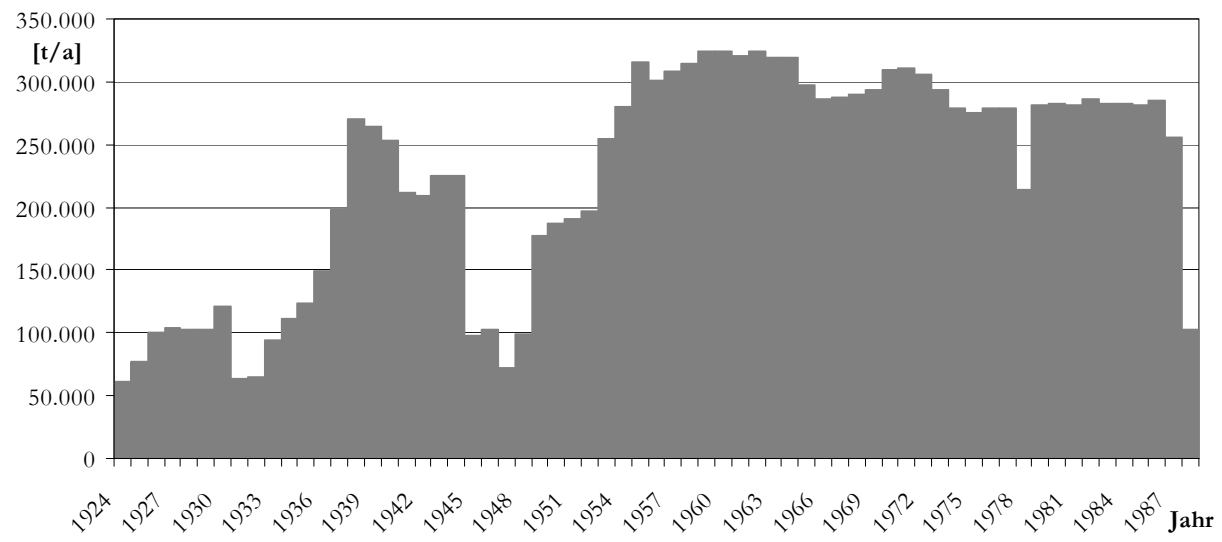

Abb. 5: Förderungsmenge des Erzbergwerks Rammelsberg 1927 bis Ende Juni 1988. Eigene Darstellung. Zahlen nach Bartels (1988), S. 124.

\section{Weltwirtschaftskrise und Zweiter Weltkrieg}

Mit der Weltwirtschaftskrise und der zurückgehenden Metallnachfrage musste auch am Rammelsberg die jährliche Förderrate drastisch reduziert werden, was zugleich mit Massenentlassungen und Kurzarbeit einherging. Der Tiefpunkt wurde 1932 erreicht. Eine in Erwägung gezogene Schließung des Betriebes stand mit der Machtergreifung der Nationalsozialisten im Jahr 1933 nicht mehr zur Debatte. ${ }^{95}$ Mit Hilfe von Subventionen und Prämien für die Förderung und Verhüttung der Rammelsberger Erze sollten die Ziele der wirtschaftlichen Autarkie und Remilitarisierung, die in den Zweiten Weltkrieg münden sollte, erreicht werden. Die großen Finanzspritzen ermöglichten es den nationalsozialistischen Machthabern zugleich, sich in fast allen Bereichen des Bergbaus mit ihrer Ideologie durchzusetzen. Hinzu kam, dass 1935 das „Rammelsbergprojekt“ beschlossen wurde. ${ }^{96}$

Mit der erfolgreichen Anwendung des Flotationsverfahrens bei der Erzaufbereitung, besonders für die Erzeugung von Zink, stiegen die Aussichten auf eine deutliche Steigerung der Metallproduktion, um etwa 180 Prozent. Entsprechend sollte eine neue Aufbereitungsanlage am Rammelsberg entstehen. Neben einer Steigerung der Erzförderung beinhaltete das Projekt den Ausbau der Unterharzer Berg- und Hüttenwerke und den Neubau einer Zinkhütte. Alle Maßnahmen dien-

\footnotetext{
94 Bartels (1988), S. 44.

95 Ebd., S. 46.

96 Ebd., S. 48 f.
} 
ten dem nationalsozialistischen Regime zugleich zur Schaffung von Arbeitsplätzen. ${ }^{97}$ Die im November 1937 vollständig betriebsbereiten Neuanlagen (siehe Abb. 6) am Rammelsberg wurden durch den Zechenbaumeister Fritz Schupp (1896-1974) entworfen, der ebenfalls die Schachtanlage der Zeche Zollverein konstruiert hatte. ${ }^{98}$

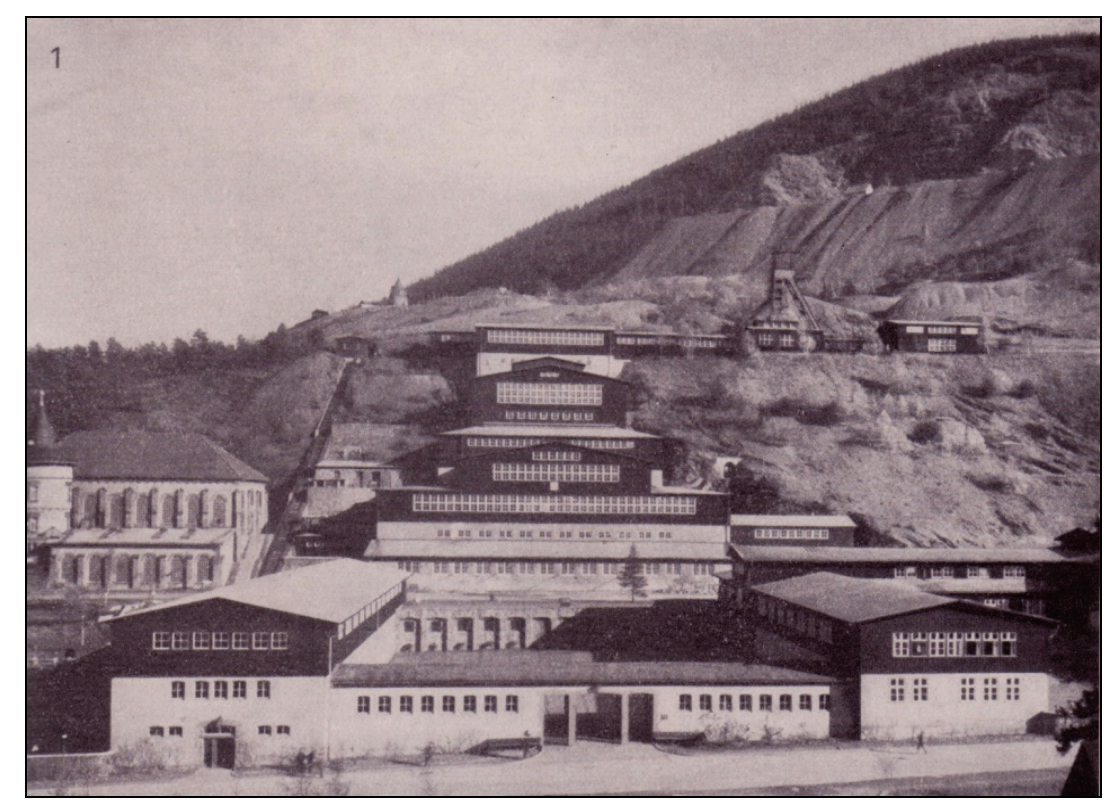

Abb. 6: Tagesanlagen des Erzbergwerks (Kraume (1955), Tafel 3).

Zugleich wurde im Rahmen des kriegswichtigen „Rammelsbergprojektes“ ein neuer Hauptschacht abgeteuft. ${ }^{99}$ Die Maßnahmen führten zur gewünschten Produktionssteigerung. Im Jahr 1938 überschritt man das ursprünglich geplante Fördermengenziel von 250.000 Tonnen pro Jahr um 20.000 Tonnen. In den folgenden Jahren sollte die Förderung weiter erhöht werden, allerdings führte der Beginn des Zweiten Weltkrieges zu einem leichten Rückgang (vgl. Abb. 5). ${ }^{100}$

Mit Kriegsbeginn wurde fast ein Fünftel der Rammelsberger Bergleute und Angestellten zum Kriegsdienst eingezogen. Durch den Einsatz von oberschlesischen Bergleuten und Bergjungleuten ${ }^{101}$ sollten die fehlenden Arbeitskräfte zunächst ersetzt werden. Mit dem Voranschreiten der Kriegshandlungen manifestier-

\footnotetext{
97 Bartels (1988), S. 50 f.

98 Ebd., S. 55.

99 Ebd., S. 58.

100 Ebd., S. 60.

101 In Ausbildung befindliche Belegschaft. Vgl. ebd., S. 61.
} 
te sich jedoch der Mangel an Bergleuten. ${ }^{102}$ Um dies aufzufangen und weiterhin auch für die Kriegsmaschinerie zu produzieren, wurden ab 1942 bis zu 400 Kriegsgefangene zur Zwangsarbeit am Rammelsberg herangezogen. ${ }^{103}$ Der Krieg hatte aber nicht nur Auswirkungen auf die Zahl der Arbeitskräfte und den Einsatz von Zwangsarbeitern, auch die Versorgungslage mit Nahrung, Kleidung, Wohnraum, Ersatzteilen für den Bergbaubetrieb etc. verschlechterte sich dramatisch. So konstatiert Bartels (1988), dass die gesamte Rammelsberger Anlage sich in einem kritischen Zustand befand. Mit dem Sieg der alliierten Truppen 1945 wurde der Betrieb zunächst eingestellt. ${ }^{104}$

\section{Die Zeit nach dem Zweiten Weltkrieg}

In der Nachkriegszeit bis 1948 nahm die Förderquote trotz einer Zunahme der Belegschaft weiter ab. Grund hierfür war nach Bartels (1988) der bereits genannte kritische Gesamtzustand der Bergbauanlagen. In den Jahren 1949/50 erholte sich der Betrieb und die Produktion konnte wieder in vollem Umfang aufgenommen werden. ${ }^{105}$ Diese Entwicklung setzte sich in den Jahren des beginnenden „Wirtschaftswunders" fort. Die steigenden Metallpreise auf dem internationalen Markt, befördert durch den Koreakrieg, ließen die Produktion am Rammelsberg in den Jahren von 1951 bis 1955 deutlich steigen. Der parallel zum Abbau betriebene Versuch auch das bisher unattraktive Armerz wirtschaftlich aufzubereiten, erwies sich als erfolgreich und sicherte dem Rammelsberger Bergbau in der Metallwirtschaftskrise (1957 bis 1959) mit das Überleben. ${ }^{106}$ In den Jahren der Krise erzielte das Erzbergwerk die höchsten Produktionszahlen seiner Geschichte mit etwa 320.000 Tonnen pro Jahr, stieß aber an seine Kapazitätsgrenzen. Auch in den nachfolgenden Jahren der schwankenden Metallpreise konnte sich das Rammelsberger Werk auf dem Markt behaupten. Zuträglich waren dabei neben einer möglichst effizienten Förderung und Aufbereitung der Roherze, Rationalisierungsmaßnahmen sowie Maßnahmen zur Modernisierung, um wettbewerbsfähig zu bleiben. ${ }^{107}$

Ab 1965 stabilisierten sich die Metallmärkte, die Produktion wurde etwas zurückgefahren. Zeitgleich analysierte man die Bauwürdigkeit des Kupferkniests, dessen Abbau aber, trotz der guten Marktpreislage, nicht wirtschaftlich hätte betrieben werden können. Die Suche nach neuen oder abbauwürdigen Erzvorkommen blieb erfolglos. ${ }^{108} \mathrm{Um}$ dennoch die Produktionsleistung zu halten, trieb man die Rationalisierung und den Einsatz neuer Techniken voran, wobei letztere

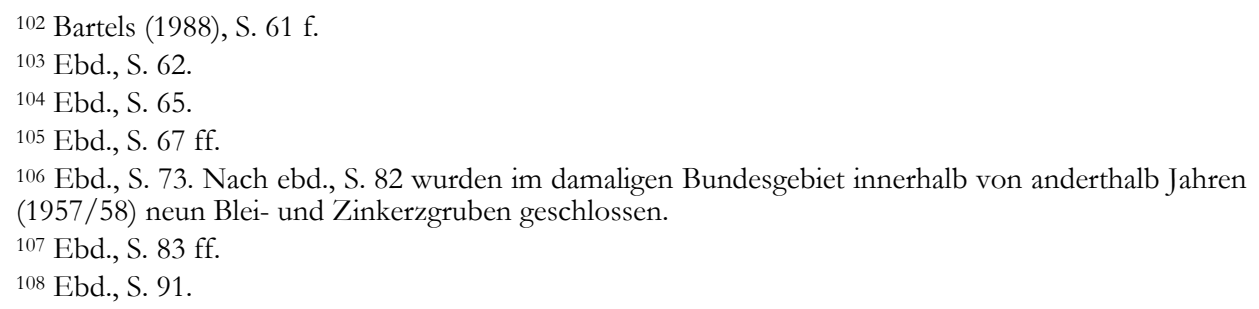


zugleich die Fortsetzung des Kammerbaus ermöglichen sollte. ${ }^{109}$ Diese Mechanisierung des Untertagebetriebs führte zudem zu einer deutlichen Verbesserung der Arbeitssicherheit. Im Jahr 1978 musste im Zuge einer weltweiten Metallkrise, durch einen rapiden Preisverfall von Zink, die Produktion im Erzbergwerk Rammelsberg zurückgefahren werden. Mit Kurzarbeit wurde die Krise überstanden, die sich bereits 1979 wieder legte. ${ }^{110}$

In den Folgejahren wurde der Betrieb weiter rationalisiert und der wirtschaftlich positive Trend setzte sich zunächst bis etwa 1985 fort. Zu dieser Zeit bahnte sich ein erneuter Verfall der Metallpreise an. Grund hierfür war eine weltweite Überproduktion. Mit der absehbaren Erschöpfung der Vorräte des Neuen Lagers beschloss die Preussag AG, die seit 1967 alleiniger Eigentümer des Erzbergwerks Rammelsberg war, 1986 die Einstellung des Abbaus. Seit dem 30. Juni 1988 stehen die Anlagen nun still. ${ }^{111}$ Das 1992 zum Weltkulturerbe ernannte Erzbergwerk, stellt heute die universelle Bedeutung des mehr als 1000-jährigen Bergbaus heraus und verknüpft sie mit der Entwicklung der Kulturlandschaft Harz. ${ }^{112}$

\section{Die Montanlandschaft Rammelsberg}

Die über Jahrhunderte erfolgten Veränderungen und Entwicklungen des Bergbaus lassen sich auch heute noch in der Stadt, im Bergwerk und in der Kulturlandschaft Harz ablesen. Zu der Vielzahl von sichtbaren Relikten zählen neben dem Erzbergwerk selbst beispielsweise der Herzberger Teich, der seit den 1920ern zugleich als Waldbad genutzt wurde, die mittelalterliche Bergspalte am Ramseck (siehe Abb. 7) oder die alten Erzabfuhrwege (Abb. 8).

Daneben prägen vor allem auch die alten Steinbrüche und Blockschutthalden den Anblick sowie die Flora und Fauna am Rammelsberg. Das heute etwa 18,5 Hektar große Naturschutzgebiet „Blockschutthalden am Rammelsberg“, welches im November 1983 unter Schutz gestellt wurde, ist dafür beispielhaft. An diesem extremen Standort, dessen taubes und zum Teil schwermetallhaltiges Gestein nur für einige Organismen einen Lebensraum bietet, finden sich als Pionierpflanzen 66 Flechtenarten, von denen 24 auf der Roten Liste stehen. Eine, die Flechte Lecidea ullrichii, ist sogar weltweit einzigartig. ${ }^{113} \mathrm{Um}$ die natürliche Sukzession und damit die Verdrängung des einzigartigen Flechtenbestandes zu unterbinden, wurden 1999

\footnotetext{
109 Bartels (1988), S. 95.

110 Ebd., S. 102 f.

111 Ebd., S. 109.

112 Czypull u. Küntzel (2005), S. 43.

113 Nds. Landesbetrieb für Wasserwirtschaft, Küsten- und Naturschutz (NLWKN), siehe www.nlwkn.niedersachsen.de/portal/live.php?navigation_id=8062\&article_id $=43079 \& \_p s m a n d=26$ (Abruf: 07.06.2013).
} 
am Kommunions-Steinbruch die aufkommenden jungen Gehölze als landschaftpflegerische Maßnahme entfernt. ${ }^{114}$

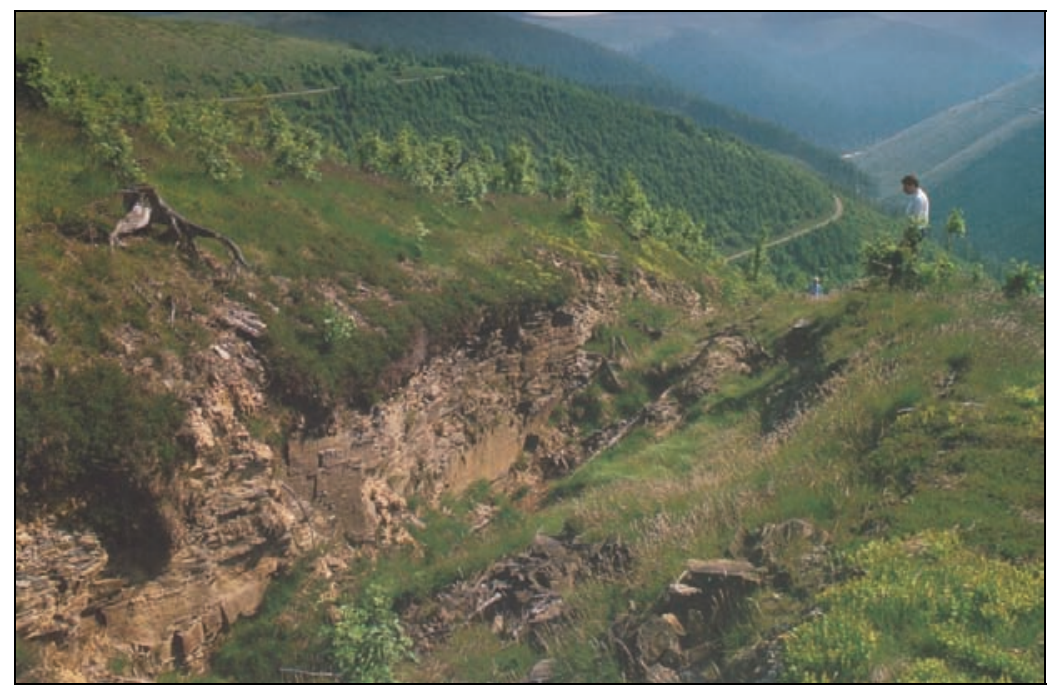

Abb. 7: „Bergspalte oberhalb des Ramseck-Felsvorsprungs“ (Foto: K. Pfeiffer, Wida 15.6.1986. In: Spier (1988), S. 19).

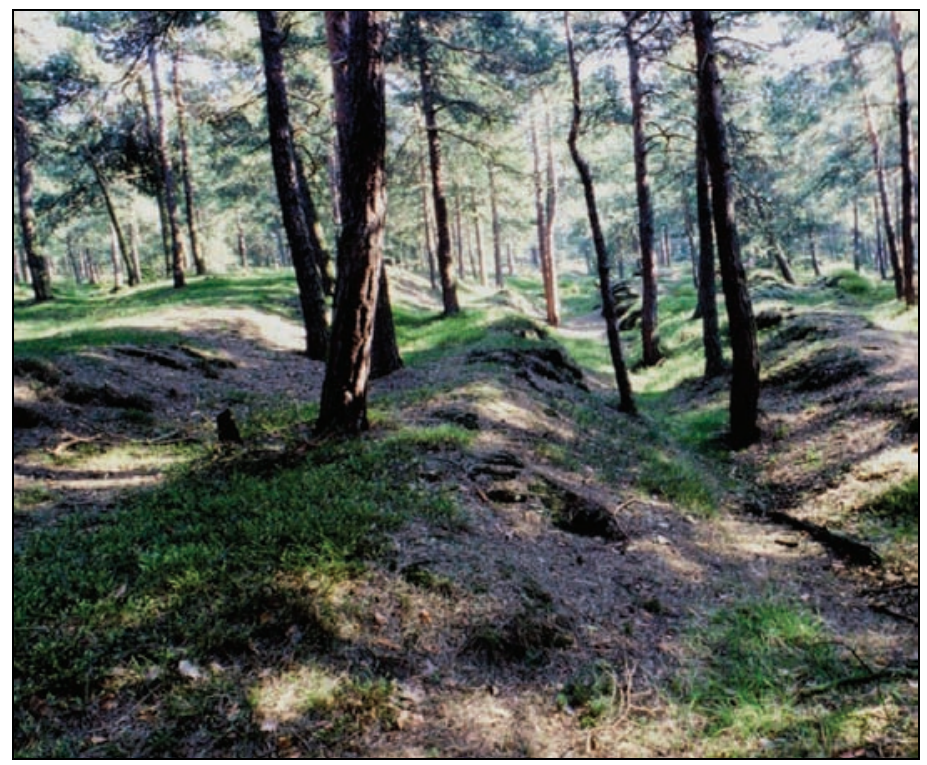

Abb. 8: Erztransportwege am Rammelsberg (Dettmer (2006), S. 56).

\footnotetext{
${ }^{114}$ Siehe www.natur-und-umwelthilfe-goslar.de/natur-spezial.html, Artikel: Holste: Die Rammelsberger Flechten (Abruf: 07.06.2013).
} 
Ein weiteres Relikt des tiefgreifenden Kulturlandschaftswandels am Rammelsberg sind die umliegenden Wälder. Hier vollzogen sich über die Jahrhunderte deutliche Veränderungen in der Baumartenzusammensetzung und Bestandsstruktur, aufgrund eines steigenden Bedarfs an Brenn- und Bauholz, aber auch für neue Flächennutzungen. Bereits seit dem 8. Jahrhundert war der Waldanteil deutlich zurückgegangen. Seit dem 12. Jahrhundert fand um Goslar ein großflächiger Rückgang von „natürlichem“ Wald statt, der kleinflächig durch Sekundärwald mit Eberesche (Sorbus aucuparia), Birke (Betula), Zitterpappel (Populus tremula) und Haselnuss (Corylus avellana) ersetzt wurde. Hohlwege, die beispielsweise dem Transport von Holz dienten und nach Goslar führten, sind noch heute im Gelände erkennbar. ${ }^{115}$

Im 16. und 17. Jahrhundert war der Wald bei Goslar und dem Rammelsberg weitgehend zurückgedrängt. So dominierten kahle Flächen mit geringem Pflanzenbewuchs die Landschaft. ${ }^{116}$ Nur einige der umgebenden Anhöhen waren mit kleinräumigen Wäldern bestanden. Zum Schutz kleiner Baumbestände vor Rodung wurden im 16. Jahrhundert Wallgräben um die Bestände angelegt. Ansätze einer planmäßigen Forstwirtschaft gab es unter dem Herzog Heinrich und seinem Sohn Julius, die verordneten: „Die Menge des nutzbaren Holzes soll von fürstlichen Beamten geschätzt, zu stark beanspruchte Gehölze aus der Nutzung genommen werden." 117

Im 18. bis Anfang des 19. Jahrhunderts kulminierte die Waldzerstörung. Zudem behinderte der Viehtrieb auf die Flächen den Aufwuchs. An einigen Standorten breitete sich langsam die Fichte aus. ${ }^{118}$ Förderlich für einen Bewuchs der jahrhundertelang befahrenen Hohlwege zu den Schachtanlagen waren die Roederschen Reformen und die Verlegung der Schächte auf Talniveau. Ab 1877 begann unter dem Oberförster Reuß eine planmäßige Aufforstung. ${ }^{119}$ Die Stadt Goslar selbst prägte und prägt den Hangfuss des Rammelsbergs.

Über die Jahrhunderte entwickelte sich eine abwechslungsreiche Kulturlandschaft aus wertvollen Naturräumen und Industrierelikten (siehe Abb. 9), deren Vergangenheit sich nicht nur in Schriften und Büchern nachlesen lässt, sondern manifest in der Region entdeckbar und erlebbar ist und dies nicht nur über- sondern auch untertage, wie beispielsweise im Erzbergwerk Rammelsberg.

Die Harzlandschaft ist eine einzigartige Montanlandschaft, geprägt nicht nur von den Bergwerken, sondern ebenso von den dazugehörigen Anlagen. Zu ihnen zählen auch die wasserwirtschaftlichen Anlagen im Oberharz mit ihren vielzähligen Teichen, Stauseen, Wassergräben und Wasserkraftanlagen sowie einem komplexen System von Schächten und Stollen, das zum Antrieb von Pumpen und Förderma-

\footnotetext{
115 Czypull u. Küntzel (2005), S. 31.

116 Ebd., S. 37.

117 Ebd.

118 Ebd., S. 40.

119 Ebd., S. 42.
} 
schinen diente und heute zur Erzeugung von elektrischer Energie noch Verwendung findet.120 Die Welterbestätte „Bergwerk Rammelsberg, Altstadt von Goslar und Oberharzer Wasserwirtschaft" eröffnet den Blick in ein komplexes System von Mensch und Umwelt Interaktionen und deren Manifestation in der Landschaft.

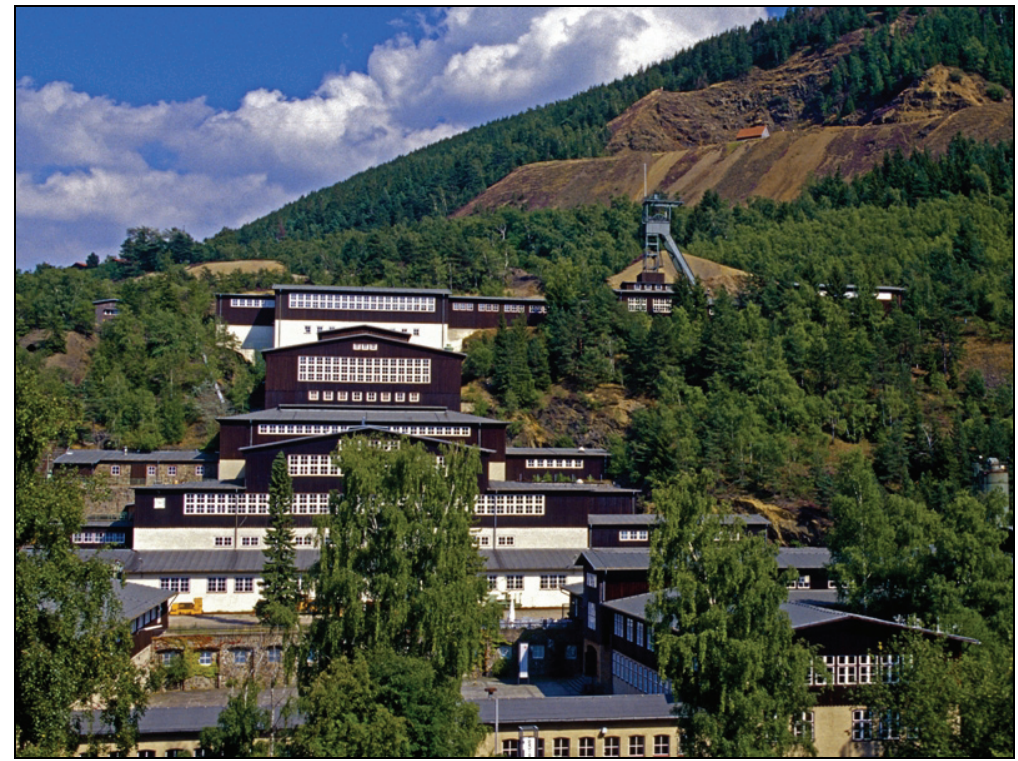

Abb. 9: Erzbergwerk Rammelsberg in Goslar (GOSLAR Marketing GmbH). ${ }^{121}$

\section{Industriekultur und Industrienatur - Zwei Seiten einer Medaille}

Die Ernennung zur UNESCO-Weltkulturerbestätte „Bergwerk Rammelsberg, die Altstadt von Goslar und die Oberharzer Wasserwirtschaft“ zeugt von ihrer besonderen Bedeutung als weltweit einzigartiges, materielles und immaterielles Kulturerbe, aber auch Naturerbe, wenn wir sie in Verbindung mit der Kulturlandschaft, die sich heute beispielsweise auch in den Naturschutzgebieten und dem Nationalpark entdecken lässt, betrachten.

Der mehr als 1.000-jährige Bergbau am Rammelsberg hinterließ nicht nur sichtbare Spuren am und im Berg, sondern auch in der eng mit seiner Entwicklung verbundenen Stadt Goslar. Die Regierungs-, Handels- und Wohnstätte zeichnete das Auf und Ab im Montanwesen und den wechselnden politischen Machtverhältnissen nach. Der Reichtum aus dem Bergbau, Handel und Handwerk spiegelte sich in den zahlreichen Kirchen und wertvollen Bauwerken, bis hin zur Kaiserpfalz und

${ }^{120}$ Vgl. hierzu auch Bartels (200b), S. 145. Siehe auch Abhandlung von Döring (1996), S. 24-34.

121 Mit freundlicher Genehmigung von GOSLAR Marketing GmbH. 
zeigt sich zugleich in dem umgebenden Naturraum. Nach Willerding (2000) ist es daher besonders wichtig, „dass sich das Wissen von der Verknüpfung ökonomischer Strukturen mit ihren ökologischen Konsequenzen ebenso durchsetzt wie die Erkenntnis von der historischen Bedingtheit des heutigen Lebens. " 122

Das Ziel den Harz „ganzheitlich“ zu erforschen wie es Bartels et al. (2007) formulierte, erfordert die Zusammenschau von gesellschaftlichen und naturräumlichen Veränderungen. Die Betrachtung dieser Interaktionen zwischen Mensch und naturaler Umwelt kann durch die Verwendung verschiedener umwelthistorischer Archive, beispielsweise von Sedimenten und Pollen, Bodenarchiven, Bergbaurelikten, Infrastrukturen, Akten und Urkunden oder Knochenmaterial ${ }^{123}$ rekonstruiert werden. Für den Harz als Montanregion besteht hier noch reichlich Forschungsbedarf.

Die weltweite Bedeutung dieser Montanregion impliziert eine notwendige Integration von Industriekultur und Industrienatur, von Kulturerbe im Sinne von Denkmälern, Ensembles und Stätten, die zugleich als „gemeinsame Werke von Natur und Mensch und damit Kulturlandschaften"124 angesprochen werden können. Der Harz zieht alljährlich eine Vielzahl von Kulturinteressierten, Erholungssuchenden und Sportbegeisterten an. ${ }^{125}$ Ziel der Touristen sind die heute als schützenswert erachteten Naturräume, die scheinbar ursprünglich sind, wie im Bereich des Nationalparks Harz, aber auch die zahlreichen historischen Bergbaustätten und Ortschaften, die in der Landschaft Harz ihre deutlichen Spuren hinterließen, wie dies exemplarisch für Goslar am Rammelsberg in diesem Beitrag dargelegt wurde. Industriekultur und Industrienatur laden zur Entdeckungsreise dieser einzigartigen Montanregion ein.

\section{Literatur}

Adelung (1793) Grammatisch-kritisches Wörterbuch der Hochdeutschen Mundart, Band 1. Leipzig 1793.

Balck F (2000) Zur Nutzung der Wasserkraft. In: Ch. Segers-Glocke (Hg.) Auf den Spuren einer frühen Industrielandschaft. Naturraum - Mensch - Umwelt im Harz. Niemeyer, Hameln, S. 87-95.

\footnotetext{
122 Willerding (2000), S. 105.

${ }^{123}$ Vgl. beispielsweise Schutkowski et al. (2000a), S. 70-71. Sowie Schutkowski et al. (2000b), S. 96-99.

${ }^{124}$ Hönes (2009a), S. 113.

125 So zeigen sich für den Harz in Niedersachen und den Harz und Harzrand in Sachsen-Anhalt stetig steigende Ankunfts- und Übernachtungszahlen für die Jahre 2008 bis 2012. Etwas different zeigen sich die Werte für den Südharz in Thüringen. Siehe Zahlen nach: Statistisches Bundesamt (2009/2010/2011/2012): Binnenhandel, Gastgewerbe, Tourismus. Ergebnisse der Monatserhebung im Tourismus. Winterhalbjahr 2008/2009, Sommerhalbjahr 2009 Winterhalbjahr 2009/2010, Sommerhalbjahr 2010, Winterhalbjahr 2010/2011, Sommerhalbjahr 2011, Winterhalbjahr 2011/2012, Sommerhalbjahr 2012. In: Fachserie 6 Reihe 7.1. Statistisches Bundesamt, Wiesbaden.
} 
Bartels Ch (1988) Das Erzbergwerk Rammelsberg. Die Betriebsgeschichte von 1924 bis 1988 mit einer lagerstättenkundlichen Einführung sowie einem Abriß der älteren Bergbaugeschichte. Preussag AG Metall, Goslar.

Bartels Ch (2000a) Der Bergbau - Ein Überblick. In: Ch. Segers-Glocke (Hg.) Auf den Spuren einer frühen Industrielandschaft. Naturraum - Mensch - Umwelt im Harz. Niemeyer, Hameln, S. 106-111.

Bartels Ch (2000b) Die Metalle an der Wende zur Neuzeit. In: Ch. Segers-Glocke (Hg.) Auf den Spuren einer frühen Industrielandschaft. Naturraum - Mensch Umwelt im Harz. Niemeyer, Hameln, S. 140-145.

Bartels Ch, Fessner M, Klappauf L, Linke AF (2007) Kupfer, Blei und Silber aus dem Goslarer Rammelsberg von den Anfängen bis 1620. Die Entwicklung des Hüttenwesens von den frühmittelalterlichen Schmelzplätzen im Wald bis zur Metallerzeugung in großem Maßstab am Beginn des 17. Jahrhunderts nach den archäologischen und schriftlichen Quellen. Montanregion Harz, Bd. 8, Deutsches Bergbau-Museum Bochum. Dt. Bergbau-Museum, Bochum.

Burggraaff P (1996) Der Begriff „Kulturlandschaft“ und die Aufgabe der „Kulturlandschaftspflege“" aus der Sicht der Angewandten Historischen Geographie. In: Natur- und Landschaftskunde, H. 32, S. 10-12.

Czyppul B, Küntzel Th (2005) Durch Land und Zeit. Bilder und Texte zum Wandel des Landschaftsbildes seit der Eiszeit am Beispiel von Rammelsberg und Goslar, Seeburger See, Wesertal bei Corvey. In: Landschaftsverband Südniedersachsen, Heimat- und Geschichtsverein für Landkreis und Stadt Holzminden (Hg.) Reihe „Bilder und Texte aus Südniedersachsen“, Bd. 3, Verlag Mitzkat.

Deicke M (2000) Geologie und Erzlagerstätten des Harzes. In: Ch. Segers-Glocke (Hg.) Auf den Spuren einer frühen Industrielandschaft. Naturraum - Mensch Umwelt im Harz. Niemeyer, Hameln, S. 42-46.

Deicke M (2003) Erdfallablagerungen des südlichen Harzvorlandes - Archive der Umweltgeschichte der letzten Jahrtausende. Diss. Georg-August-Universität Göttingen, Göttingen.

Deicke M, Ruppert H (2000) Frühe Metallgewinnung und Umweltbelastung im Harz - Umweltgeochemische Aspekte. In: Ch. Segers-Glocke (Hg.) Auf den Spuren einer frühen Industrielandschaft. Naturraum - Mensch - Umwelt im Harz. Niemeyer, Hameln, S. 78-82.

Deininger F, Lange HG (1998) Das 19. Jahrhundert. In: Geschichtsverein Goslar (Hg.) Quellen zur Geschichte der Stadt Goslar, H. 3. Geschichtsverein, Goslar.

Denker H (1911) Die Bergchronik des Hardanus Hake, Pastors zu Wildenmann, Wernigerode. 
Dettmer H-G (2006) Bergbauspuren auf Schritt und Tritt. 30 Gründe den Rammelsberg zu erwandern. Rammelsberger Bergbaumuseum, Goslar.

Döring M (1996) Die Wasserkraftwerke im Samsonschaft in St. Andreasberg/Harz. In: Wasserkraft \& Energie 3, 96, S. 24-34.

Grunewald L (2000) Der Oberharz und sein unmittelbares Vorland. Ein Abriss der Siedlungsgeschichte vor dem Einsetzen der schriftlichen Überlieferungen im 8. Jahrhundert n. Chr. In: Ch. Segers-Glocke (Hg.) Auf den Spuren einer frühen Industrielandschaft. Naturraum - Mensch - Umwelt im Harz. Niemeyer, Hameln, S. 55-63.

Heine H (1825) Die Harzreise. 1824. In: Heine, Heinrich (1825/1972): Werke und Briefe in zehn Bänden. Band 3, Berlin und Weimar. www.zeno.org/Literatur/M/Heine,+Heinrich/Reisebilder+und+Reisebriefe/R eisebilder.+Erster+Teil/Die+Harzreise.+1824. Erstdruck in: Der Gesellschafter oder Blätter für Herz und Geist (Berlin), 9. Jg., Januar/Februar 1825.

Hettwer K (1999) Stoffbestand und Schwermetall-Anomalien eines Moorprofils der Erfallsenke „Silberhohl“ bei Seesen (Westharz). Geol. Diplomarbeit. Universität Göttingen.

Hillebrand W (1988) 1000 Jahre Bergbau am Rammelsberg bei Goslar. Sonderausstellung der Stadt Goslar im Zusammenwirken mit der Preussag AG Metall, Goslar, und dem Verein Rammelsberger Bergbaumuseum Goslar/Harz e.V. im Goslarer Museum 25. Juni bis 21. August 1988. Goslarer Museum, Goslar.

Hillebrecht M-L (2000) Der Wald als Energielieferant für das Berg- und Hüttenwesen. In: Ch. Segers-Glocke (Hg.) Auf den Spuren einer frühen Industrielandschaft. Naturraum - Mensch - Umwelt im Harz. Niemeyer, Hameln, S. 8386.

Hönes E-R (2009a) Internationaler Kulturgüter-, Denkmal- und Welterbeschutz. Schriftenreihe des Deutschen Nationalkomitees für Denkmalschutz, Bd. 74.

Kraume E (1955) Die Erzlager des Rammelsberges bei Goslar. In: Monographien der Deutschen Blei-Zink-Erzlagerstätten Bd. 4 = Beih. Geol. Jb. 18. Dietrich , Hannover, Göttingen.

Ließmann W (1997) Historischer Bergbau im Harz: ein Kurzführer. Springer Verlag, Berlin, Heidelberg, New York.

Lindorfer H (1997) Relikte ehemaliger Metallgewinnung als Quelle von Schwermetall-Belastungen in rezenten Überflutungssedimenten des niedersächsischen Harzvorlandes. Unveröffentl. Diplomarbeit. Georg-August-Universität Göttingen.

Müller G (2007) Goslar vom 10. bis zum frühen 12. Jahrhundert - Die Zeit der sächsischen und salischen Herrscher. In: Geschichtsverein Goslar (Hg.) Quel- 
len zur Geschichte der Stadt Goslar, H. 6. Übersetzung lateinischer Urkunden: Dr. Armin Theuerkauf. Geschichtsverein, Goslar.

Nipperdey Th (1998) Deutsche Geschichte. 1800-1866 Bürgerwelt und starker Staat. C.H. Beck, München.

Nds. Landesbetrieb für Wasserwirtschaft und Küsten- und Naturschutz (NLWKN) (2002) Gewässergütebericht. Oker.

Roseneck R (1992) Der Rammelsberg - Ein Dokument der Bergbaugeschichte. Niedersächsisches Landesverwaltungsamt - Institut für Denkmalpflege. Niemeyer, Hameln.

Schmidt M (2012) WasserWanderWege. Ein Führer durch das Oberharzer Wasserregal - UNESCO-Welterbe. 4. Aufl. Papierflieger, Clausthal-Zellerfeld.

Schutkowski H, Fabig A, Herrmann B (2000a) Nahrung und Subsistenz der Goslarer Hüttenleute anhand anthropologischer Untersuchungen. In: Ch. SegersGlocke (Hg.) Auf den Spuren einer frühen Industrielandschaft. Naturraum Mensch - Umwelt im Harz. Niemeyer, Hameln, S. 70-71.

Schutkowski H, Fabig A, Herrmann B (2000b) Schwermetallbelastung bei Goslarer Hüttenleuten des 18. Jahrhunderts. In: Ch. Segers-Glocke (Hg.) Auf den Spuren einer frühen Industrielandschaft. Naturraum - Mensch - Umwelt im Harz. Niemeyer, Hameln, S. 96-99.

Segers-Glocke Ch (Hg.) Auf den Spuren einer frühen Industrielandschaft. Naturraum - Mensch - Umwelt im Harz. Niemeyer, Hameln.

Spier H (1988) Historischer Rammelsberg. Ein Führer durch die erhalten gebliebenen über- und untertätigen historischen Rammelsberger Bergbauanlagen und die Besonderheiten der Rammelsberger Vitriole. Verlag G. Pfeiffer, Wieda/Harz und Hagenberg-Verlag, Hornburg.

Statistisches Bundesamt (2009/2010/2011/2012) Binnenhandel, Gastgewerbe, Tourismus. Ergebnisse der Monatserhebung im Tourismus. Winterhalbjahr 2008/2009, Sommerhalbjahr 2009 Winterhalbjahr 2009/2010, Sommerhalbjahr 2010, Winterhalbjahr 2010/2011, Sommerhalbjahr 2011, Winterhalbjahr 2011/2012, Sommerhalbjahr 2012. In: Fachserie 6 Reihe 7.1. Statistisches Bundesamt, Wiesbaden.

Teicke J (2011) UNESCO-Welterbe Oberharzer Wasserwirtschaft: das Oberharzer Wasserregal; das bedeutendste vorindustrielle Energiegewinnungs- und Energieversorgungssystem der Welt. Hildesheim: Harzwasserwerke (Kulturdenkmal Oberharzer Wasserregal).

Titz-Matuszak I (1997) Quelle zur Alltagsgeschichte im 17. und 18. Jahrhundert. In: Geschichtsverein Goslar (Hg.) Quellen zur Geschichte der Stadt Goslar, H. 2. Geschichtsverein, Goslar. 
Titz-Matuszak I (ca. 2000) Goslar im 15. Jahrhundert. In: Geschichtsverein Goslar (Hg.) Quellen zur Geschichte der Stadt Goslar, H. 4. Geschichtsverein, Goslar.

Willerding U (2000) Landschaft - Ernährung - Entwicklung der Vegetation. Zusammenfassung und Ausblick. In: Ch. Segers-Glocke (Hg.) Auf den Spuren einer frühen Industrielandschaft. Naturraum - Mensch - Umwelt im Harz. Niemeyer, Hameln, S. 103-105.

Witthöft H (2000) Die Rolle der Metalle in der Geschichte des frühen und hohen Mittelalters. In: Ch. Segers-Glocke (Hg.) Auf den Spuren einer frühen Industrielandschaft. Naturraum - Mensch - Umwelt im Harz. Niemeyer, Hameln, S. 121-128.

\section{Internetquellen}

www.unesco-welterbe.de/de/unesco-welterbestaetten

www.reiseland-niedersachsen.de/unesco-welterbe

www.harzinfo.de/kultur/unesco-welterbe-im-harz.html

www.harzwasserwerke.de/index2.html?ohwr.html haupt

www.kloster-walkenried.de

www.harzregion.de/news.php

www.nationalpark-harz.de

www.rammelsberg.de

www.rammelsberg-blog.de/2012/02/altbackenes-aus-der-geruechtekueche-dasjahr-968

www.welt.de/kultur/history/article13588223/3000-Jahre-alte-Muellkippe-bei-

Goslar-entdeckt.html

www.goslar.de

de.wikipedia.org/wiki/Goslar

www.brauhaus-goslar.de

de.wikipedia.org/wiki/Reichsbauernstadt

www.natur-und-umwelthilfe-goslar.de/natur-spezial.html

www.nlwkn.niedersachsen.de/portal/live.php?navigation_id=8062\&article_id=43

079\&_psmand $=26$ 



\title{
„Aes rarum“ - Zur Bedeutung des Silberbergbaus in der Oberharzer Stadt Sankt Andreasberg
}

\author{
Franziska Völkel
}

\section{Einleitung}

„Der Reichthum der Andreasberger Gänge besteht (...) in der so großen Edelkeit der Erze“" In diesem Auszug aus der Abhandlung „Bemerkungen über den Harz“ von dem Montanwissenschaftler Johann Carl Freiesleben ${ }^{2}$ aus dem Jahr 1795 kommt zum Ausdruck, dass Sankt Andreasberg reichhaltige und wertvolle Erzvorkommen besaß und der dortige Bergbau schnell zu einem Objekt der Wissenschaft wurde. Vor allem das Vorhandensein des Edelmetalls Silber und seiner chemischen Verbindungen hatte in der Bevölkerung eine hohe Bedeutung, da der Abbau dieser Erze in vielerlei Hinsicht nutzbar gemacht werden konnte. Der Silberbergbau ließ diese Stadt sowie die gesamte Oberharzer Region seit dem 16. Jahrhundert zu einem der führenden Zentren der Erzgewinnung in Mitteleuropa aufsteigen.

Es lassen sich an diesem Punkt die Fragen stellen, welche Umweltbedingungen im Harz und in diesem Fall explizit in Sankt Andreasberg gegeben waren und wie diese sich auf die regionale menschliche Geschichte auswirkten. Wie wurden die naturräumlichen Gegebenheiten wahrgenommen und gedeutet? Ferner bleibt zu fragen, wie die Menschen die natürlichen Ressourcen erschlossen und genutzt

\footnotetext{
${ }^{1}$ Freiesleben (1795), S. 322.

2 Johann Carl Freiesleben $(* 1774, \dagger 1846)$ entstammte einer Freiberger Bergbaufamilie und arbeitete später selbst als Berghauptmann und Montanwissenschaftler. Er war mit Alexander von Humboldt befreundet und verfasste zahlreiche Schriften zu naturwissenschaftlichen Themen (N.N. (2008), S. 18-19).
} 
haben. Inwiefern wurde des Weiteren der Zugang zu ihnen gesellschaftlich geregelt?

Ziel dieser Arbeit soll es daher sein, herauszufinden, welche Wechselwirkungen zwischen der Natur und den Menschen in dieser Region existierten. In diesem Zusammenhang ist auf die Entwicklung des Bergbaus und ausdrücklich auf politische, wirtschaftliche und kulturelle Faktoren der Nutzungsgeschichte einzugehen, mit der Beantwortung der Frage, welche Folgen anthropogene Eingriffe in die Umwelt hatten und wie diese Veränderungen auf die menschlichen Lebensverhältnisse zurückwirkten. Übergeordnet lässt sich die These aufstellen, dass Umweltbedingungen substantiell das menschliche Handeln beeinflussen. ${ }^{3}$ In einem dialektischen Prozess greift der Mensch ferner in die Umwelt ein und beeinflusst somit wiederum seine Lebenswelt.

Es bleibt festzuhalten, dass sich die Schwerpunktsetzung dieser Arbeit aus dem Interesse an den besonderen natürlichen Zuständen sowie an der zentralen Bedeutung des Bergbaus im Harz ergibt. Zunächst sollen nun wichtige Rahmenbedingungen des Montanwesens in diesem Gebiet geklärt und der Stellenwert des Edelmetalls Silber umrissen werden. Die Untersuchung der Entwicklung des Bergbaus in Sankt Andreasberg stellt den Hauptpunkt dar. Dabei wird auf die Quelle von Johann Carl Freiesleben rekurriert, um die Wahrnehmungs- und Deutungsperspektive damals lebender Menschen bezüglich umwelthistorisch relevanter Gegebenheiten aufzuzeigen. Nach einem kurzen Exkurs zum historischen und gegenwärtigen Tourismus im Harz soll letztlich in einem Fazit auf ein fundiertes Ergebnis bezüglich der Fragen gelangt werden.

\section{Bergbau im Harz}

\subsection{Allgemeine Hintergrundinformationen}

Der Harz ist ein deutsches Mittelgebirge, welches sehr reich an Erzvorkommen ist und somit als eine metallogenetische Provinz ${ }^{4}$ bezeichnet werden kann. In dieser Region gibt es eine große Anzahl an Lagerstätten mit bestimmten Metallen wie Blei, Zink, Kupfer, Antimon und Silber. Der Beginn des Abbaus von solchen Erzen ist in vor- und frühgeschichtliche Zeit zu datieren, als der Harz schon von Menschen bewohnt wurde. Im frühen und hohen Mittelalter wurde in diesem Gebiet vor allem Kupfer, aber auch Silber und Blei abgebaut. Durch den Handel mit diesen Waren konnte sich die Gegend um den Harz, vor allem um Goslar, als ein wichtiges mittelalterliches Zentrum des Bergbaus etablieren.

Da sich diese Arbeit explizit mit der Oberharzer Region beschäftigt, sollen zunächst die geographischen Bedingungen umrissen werden. Der Begriff Oberharz

\footnotetext{
${ }^{3}$ Angelehnt an Siemann u. Freytag (2003), S. 7-20.

${ }^{4}$ Ließmann (2002), S. 6.
} 
bezeichnet den nordwestlichen Teil des Harzes ${ }^{5}$ und somit die Region um die Bergstädte Bad Grund, Wildemann, Lauthental, Clausthal-Zellerfeld, Altenau und Sankt Andreasberg im heutigen Bundesland Niedersachsen. Vor allem Sankt Andreasberg war durch seine wertvollen Mineralienarten und reichhaltigen Silbervorkommen berühmt. Für die Untersuchung des Silberbergbaus in dieser Stadt ist es zunächst nötig, die naturwissenschaftlichen Hintergründe sowie die kulturellen Konnotationen dieses Edelmetalls zu erörtern.

\subsection{Silber - das ,glantzig Ertz“}

In einem Auszug aus einer Betriebsakte einer Sankt Andreasberger Grube um 1720 wird deutlich, dass ,glantzige Ertze worinn zu zeithen sich etwas von gediegen Silber (...) spühren laße"6 über die Jahrhunderte in den Bergbauschächten gefunden und abgebaut wurden. Es kommt zum Vorschein, dass Silber schon immer von weitreichender gesellschaftlicher Bedeutung war.

Das chemische Element Argentum, wie es in der lateinischen Sprache lautet, ist ein Schwermetall, welches in sogenannten Gängen, also in ,steil stehende[n], mit Mineralen bzw. Erzen gefüllte[n] Bruchspalte[n]“7, auftritt (Abb. 1 und 2). Im Sankt Andreasberger Revier waren neben Silber insbesondere die Erze Blei, Zink und Kupfer in solchen Gängen zu finden. Die genannten Metalle kamen meist nicht gediegen (also rein) vor, sondern fast immer in Verbindungen. ${ }^{8}$ Im Oberharz galt vor allem das Bleisulfid, oder auch Bleiglanz genannt, als einer der wichtigsten Silberträger. ${ }^{9}$

Seit dem Altertum stellte Silber ein wichtiges Münz- und Schmuckmetall dar. Ferner wurde es unter anderem auch zur Herstellung von Spiegeln benutzt. Der Wert dieses Edelmetalls ergab sich demnach nicht zuletzt durch seine Eigenschaften wie Härte, Glanz, Farbe, Formbarkeit und Seltenheit. Der Abbau von Silber war für die Menschen somit von vielfältigem Nutzen.

\footnotetext{
${ }^{5}$ Bartels (1992), S. 20.

${ }^{6}$ Ließmann (2001), S. 38.

7 Klähn (2009), S. 14.

${ }^{8}$ Ebd.

${ }^{9}$ Ebd.
} 


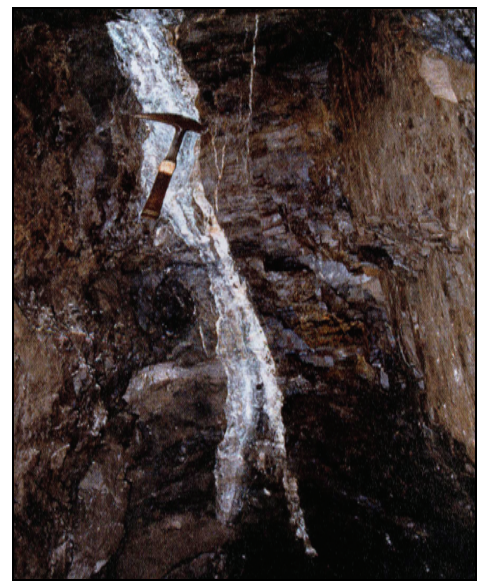

Abb. 1: Silbererzgang in der Grube Samson (Klähn 2009, S. 16).

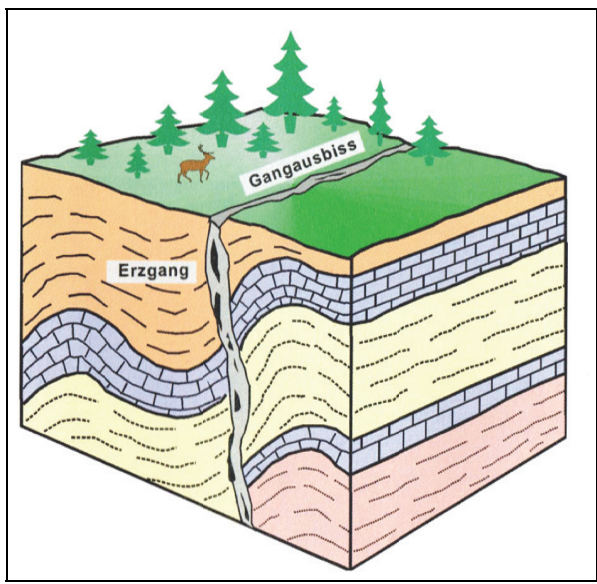

Abb. 2: Steil stehender Erzgang durchschneidet die Gesteinsschichten (Klähn 2009, S. 16).

\section{Silberbergbau in Sankt Andreasberg}

\subsection{Anfänge des Bergbaus}

Eine Urkunde belegt, dass um 1487 im Gebiet des späteren Sankt Andreasberg Erz geschürft wurde. ${ }^{10} \mathrm{Im}$ Jahre 1520 wurde dann in dieser Gegend ein Gang mit wertvollen Erzen gefunden, wodurch die Landesherren aus dem Grafengeschlecht Honstein zur Förderung des Abbaus dieser Ressourcen angeregt wurden. Sie besaBen das „Bergregal“, das heißt die Hoheits- und Verfügungsrechte über Bodenschätze. In dieser Zeit waren große Teile des Oberharzes kaum oder nicht bewohnt, da die klimatisch unwirtlichen Bedingungen, wie beispielsweise zu kurze Vegetationsphasen, hohe Niederschlagsraten und niedrige Lufttemperaturen, ${ }^{11}$ kaum Anreize zum Siedeln gaben. Aus diesem Grund erließen die Landesherren „Bergfreiheiten“, wodurch Bergmänner in das gräfliche Gebiet kommen und die gefundenen Gänge bestmöglich ausschöpfen sollten. Die Bergfreiheiten brachten für die Bergleute Vergünstigungen, wie freies Siedlungsrecht, kommunale Selbstverwaltung, freie Nutzung der Wasserkraft, Befreiung von Fron- und Hofdiensten, freie Holzung in den herrschaftlichen Wäldern zur Gewinnung von Schacht-, Bauund Brennholz sowie Steuerfreiheit. ${ }^{12}$ Im Gegenzug musste der Zehnte an den Herrn abgeleistet werden. Während die Bergfreiheiten einen materiellen Anreiz für die Abbautätigkeiten oder für Investitionen schufen, regelten die Bergordnungen,

\footnotetext{
10 Niemann (1991), S. 1.

11 Steinsiek (1999), S. 26.

12 Klähn (2009), S. 22.
} 
wie beispielsweise von 1528, die technischen, betriebswirtschaftlichen und arbeitsrechtlichen Bestimmungen. ${ }^{13}$

Die Kunde von neuen Erzfunden im Sankt Andreasberger Revier breitete sich schnell in anderen bergbaulich aktiven Gegenden wie dem Erzgebirge oder dem Mansfelder Land aus. Es dauerte nicht lange, bis Bergleute aus diesen Gebieten in den Harz kamen, um nach Erz zu schürfen. In dieser Zeit investierten Gewerken ${ }^{14}$, besonders aus dem Hanseraum sowie aus der sächsischen Bergbauregion, in Sankt Andreasberger Gruben. ${ }^{15}$ Wenn das Bergwerk viel Gewinn ausschüttete, bekamen die Investoren ihre Dividende. In sogenannten „Bergzetteln“ wurde Auskunft über die aktuelle Wirtschaftslage der jeweiligen Gruben gegeben.

Bis um 1550 konnte das Erz in Sankt Andreasberg häufig von Tage aus gewonnen werden. Der Bergmann nahm den Abbau dort auf, wo die Erzgänge an der Erdoberfläche austraten. Durch das Aushauen von Stollen und Schächten wurde auf Erzvorkommen in tieferen Erdschichten zugearbeitet. Das Herstellen von Hohlräumen im festen Gebirge war äußerst mühevoll und die Bergleute kamen nur sehr langsam voran. ${ }^{16} \mathrm{Im}$ 16. und frühen 17. Jahrhundert wurden für die Arbeit fast ausschließlich Schlägel und Eisen verwendet, die die Symbole dieses Berufszweiges waren. Eine weitere Methode zur Erzgewinnung war das Feuersetzen, bei dem die Abbaufront stark erhitzt wurde. Dieses Vorgehen verursachte das Entstehen von Rissen im Gestein, wodurch es leichter abgebaut werden konnte. ${ }^{17}$

Die Erze wurden nach ihrem Abbau mit technischen Geräten wie den Haspelwinden oder mit Maschinen, die durch tierische Muskelkraft betrieben wurden, zu Tage gefördert. In tieferen Gruben konnte das Erz nur mit Förderanlagen emporgehoben werden, die mit Wasserrädern betrieben wurden. Die Wasserräder dienten auch als Motoren zum Antrieb von anderen Maschinen, die zum Beispiel in den Aufbereitungsanlagen oder in den Hütten zu finden waren. Sie wurden des Weiteren neben Wasserlösungsstollen zur Entwässerung des Schachtes eingesetzt, indem sie bestimmte Pumpentechniken antrieben.

Nach der Gewinnung und Förderung wurde das Material aufbereitet, denn das Roherz war zu unrein, um daraus Metall zu schmelzen. ${ }^{18}$ Schließlich wurde der gewonnene Stoff verhüttet und weiterverarbeitet.

\footnotetext{
${ }^{13}$ Regenhardt (1978), S. 12.

${ }^{14}$ Der Begriff Gewerke bezeichnet ein Bergwerksunternehmen mit verkäuflichen Anteilen.

${ }^{15}$ Dennert (1960), S. 22.

16 Ließmann (2002), S. 25.

17 Ebd., S. 28.

18 Klähn (2009), S. 68.
} 


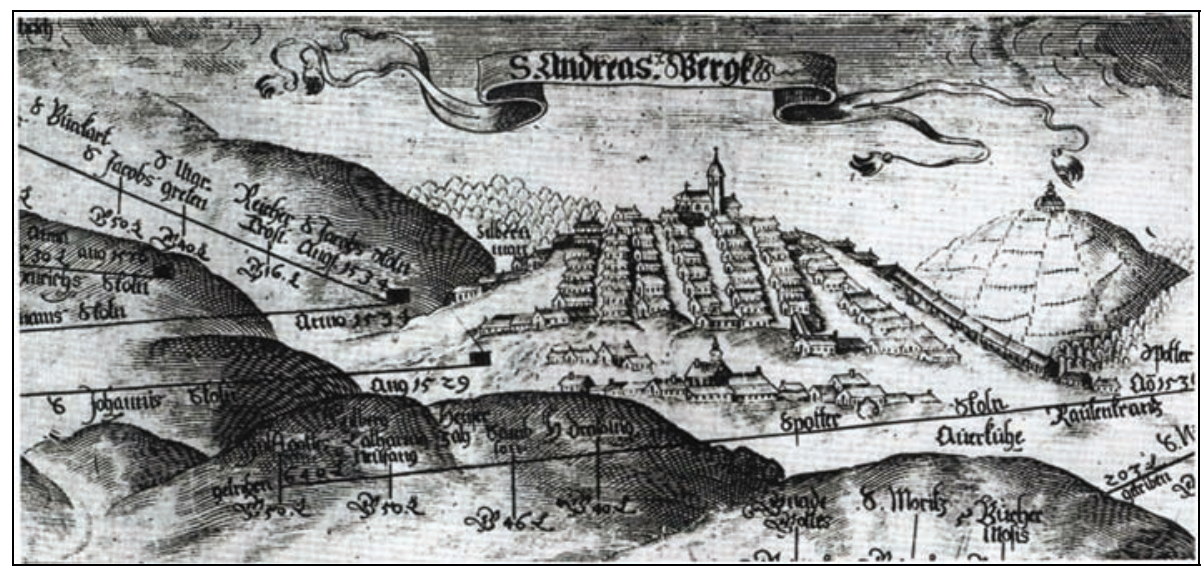

Abb. 3: Sankt Andreasberg und seine Gruben, Stich um 1600 (Klähn 2009, S. 5).

Nach der ersten Blütezeit um die Mitte des 16. Jahrhunderts war die Landschaft „durchwühlt" ${ }^{\text {"19 }}$. In dieser Zeit weist der Gelehrte Georg Agricola auf ökologische und gesundheitliche Schäden durch den Bergbau hin ${ }^{20}$ und greift damit die antike Bergbaukritik auf. Schon seit dem Altertum wurde die Ausbeutung der als „Mutter" stilisierten Erde und damit einhergehend die Zerstörung fruchtbaren Landes, die Übernutzung der Wälder und die Verschmutzung der Gewässer angeklagt. ${ }^{21}$

Ende des 16. Jahrhunderts traten in Sankt Andreasberg weitere Probleme auf: Viele Schächte hatten bereits eine Tiefe von circa 80 Metern erreicht. ${ }^{22}$ Das weitere Vordringen in die Erde wurde durch immer stärker werdendes Grundwasser sowie durch das Fehlen größerer Stollen verhindert. Die Gewinne ließen nach und viele Gruben schlossen. Zahlreiche Bergleute wanderten daraufhin ab. An dieser Stelle wird deutlich, dass ökonomisches Handeln substantiell von der Umwelt abhängig ist. Im Zeitraum von 1610-1624 kam es zum fast vollständigen Erliegen des Bergbaus. Der in dieser Zeit wütende Dreißigjährige Krieg behinderte des Weiteren die wirtschaftliche Wiederaufnahme der Gruben. ${ }^{23}$ Erst um 1660 wurde der Bergbau in Sankt Andreasberg wieder angekurbelt, worauf im nun folgenden Punkt näher eingegangen werden soll.

\footnotetext{
${ }^{19}$ Klähn (2009), S. 27.

${ }^{20}$ Grams (1992), S. 214.

21 Winiwarter u. Knoll (2007), S. 273.

22 Klähn (2009), S. 29.

${ }^{23}$ Dennert (1960), S. 22.
} 


\subsection{Bergbau im 17. und 18. Jahrhundert}

Der Bergbau im westlichen Oberharz erholte sich allmählich durch verschiedene Methoden seitens des Landesherrn, der Stadtverwaltung und privater Investoren. ${ }^{24}$ Im Jahr 1672 wurde beispielsweise das Direktorialprinzip eingeführt, welches für eine straffe Verwaltung im Montanwesen sorgte und einer Bergbehörde die alleinige Betriebsführung der verschuldeten Gruben überließ. ${ }^{25}$ Zum Ende des 17. Jahrhunderts konnte zum ersten Mal wieder eine Ausbeute in einem Sankt Andreasberger Bergwerk verzeichnet werden.

Im Zeitraum von 1690-1730 erlebte das Sankt Andreasberger Revier eine zweite Blütezeit, die nicht zuletzt durch technische Verbesserungen im Bergbau hervorgerufen wurde. Seit 1691 war der sogenannte Grünhirscher Stollen im Bau, der viele kleinere Stollen ablöste und zahlreiche Erzgruben entwässerte. Er wurde später durch den tiefer gelegenen Sieberstollen ersetzt.

In den nächsten Jahrzehnten wurde unter anderem die Betriebswasserversorgung verbessert, indem ein komplexes Wasserkraftnetz aus Staudeichen, Gräben, unterirdischen Wasserläufen, Wasserrädern und Radstuben ${ }^{26}$ angelegt wurde. Die wohl für Sankt Andreasberg wichtigsten Elemente dieser Oberharzer Wasserwirtschaft waren der Rehberger Graben (Abb. 4) und der Oderteich (Abb. 5): „Dem Wasserbedürfnis der Andreasberger Gruben, wird mittelst des Rehberger Grabens aus einem der größten Bergwerksteiche abgeholfen. Dieser Teich ist der berühmte Oderteich, (...) der [der] größte und ansehnlichste Teich am ganzen Harze ist" ${ }^{\text {" } 27}$. Saisonale oder witterungsbedingte Änderungen konnten durch dieses ausgefeilte System ausgeglichen werden.28 Am Beispiel der Oberharzer Wasserwirtschaft werden die dialektischen Prozesse im Bergbau deutlich: Einerseits musste das Wasser abfließen können, damit die Grube nicht versickerte. Andererseits waren die bergbaulichen Tätigkeiten von diesem flüssigen Element abhängig, da durch die Wasserräder die Maschinen in der Grube, den Aufbereitungsanlagen und den Hütten angetrieben wurden.

\footnotetext{
${ }^{24}$ Klähn (2009), S. 29.

${ }^{25}$ Ließmann (2001), S. 33.

26 Wilgeroth (2006), S. 241.

${ }^{27}$ Freiesleben (1795), S. 354.

${ }^{28}$ Steinsiek (1999), S. 71.
} 


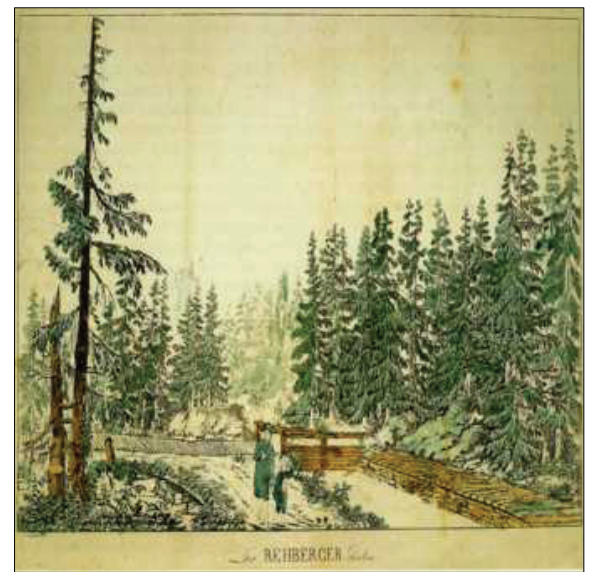

Abb. 4: Rehberger Graben, kolorierte Radierung um 1800 (Juranek 1999, S. 253).

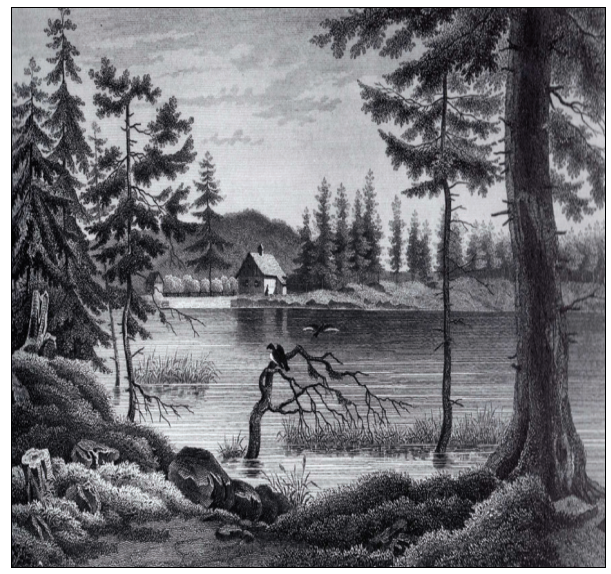

Abb. 5: Oderteich, Stahlstich um 1840 (Juranek 1999, S. 45).

Neben der Ressource Wasser besaß auch Holz eine essentielle Relevanz im komplexen technischen Netz des Bergbaus. Das Holz war unter anderem wichtig für den Schacht- und Stollenbau sowie für das Befeuern der Hüttengebläse. Durch einen umfangreich betriebenen Bergbau wurde der Wald übernutzt. Aus diesem Grund wurde um 1730 begonnen, die Berge des Harzes mit der schnellwachsenden Flachlandfichte aufzuforsten. ${ }^{29}$ Durch den Anbau von Monokulturen entstanden in den nächsten Jahrzehnten ökologische Veränderungen, die beispielsweise zu Kalamitäten führten.

Neben diesen Umweltproblemen kamen in den 1760er Jahren finanzielle Schwierigkeiten im Sankt Andreasberger Bergbau auf, was nicht zuletzt durch eine allgemeine Wirtschaftskrise während des Siebenjährigen Krieges bedingt war. Nach dieser ökonomischen Tiefphase nahm die Silberproduktion um 1770 wieder sehr schnell zu. Zum Ende des 18. Jahrhunderts war der Sankt Andreasberger Bergbau wieder auf einem Höhepunkt.

In dieser Zeit besuchten viele Gelehrte den Harz und auch die Stadt Sankt Andreasberg, wie beispielsweise Johann Wolfgang von Goethe oder Carl Johann von Freiesleben. Die Gruben des Andreasberger Reviers wurden zu einem Gegenstand der Wissenschaft, da in ihnen sehr wertvolle und einzigartige Silbermineralien zu finden waren, worauf im folgenden Abschnitt eingegangen wird.

${ }^{29}$ Klähn (2009), S. 53. 


\subsection{Das „mineralogische Schatzkästchen“}

Die Sankt Andreasberger Lagerstätten sind in Hinblick auf ihre Mineralien international berühmt und werden in der Literatur oft mit dem Titel „mineralogische Schatzkästchen des Harzes " ${ }^{30}$ versehen. Das Vorhandensein kostbarer und seltener Silberverbindungen veranlasste den Montanwissenschaftler Freiesleben, Ende des 18. Jahrhunderts die Sankt Andreasberger Gruben zu befahren und zu untersuchen. Die Grube Samson stach mit ihrem Hauptzug heraus, denn dieser war „einer der edelsten und reichsten Gänge “31. In seinen Ausführungen bemerkt Freiesleben, dass das Silber dort in „mancherley (zum Theil sehr fabelhaften und abentheuerlichen) Formen, (...) theils für sich allein, theils in Verbindung “32 vorgekommen sei. Ferner listet er das in großen Teilen zu findende „Rothgiltigerz"33 auf. Das sehr silberhaltige dunkle Rotgültigerz wird aufgrund seiner tiefroten Farbe heute auch als Pyrargyrit bezeichnet. ${ }^{34} \mathrm{Zu}$ späterer Zeit wurden weitere außergewöhnliche Silbermineralien in Sankt Andreasberg entdeckt. Der Samsonit stellt beispielsweise mit seinen Silber-, Antimon-, Mangan- und Schwefelelementen eine ungewöhnliche chemische Verbindung dar. ${ }^{35}$ Dieser Stoff wurde erstmals in der Grube Samson gefunden, wodurch er seinen Namen erhielt. Er ist eines der weltweit seltensten Silbermineralien. ${ }^{36}$

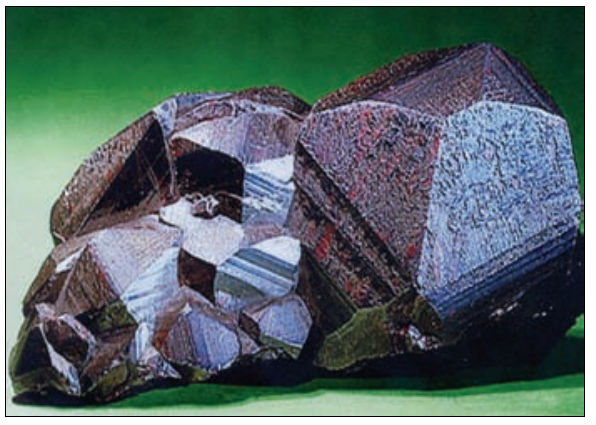

Abb. 5: Rotgültigerz (geomuseum.tu-clausthal.de).

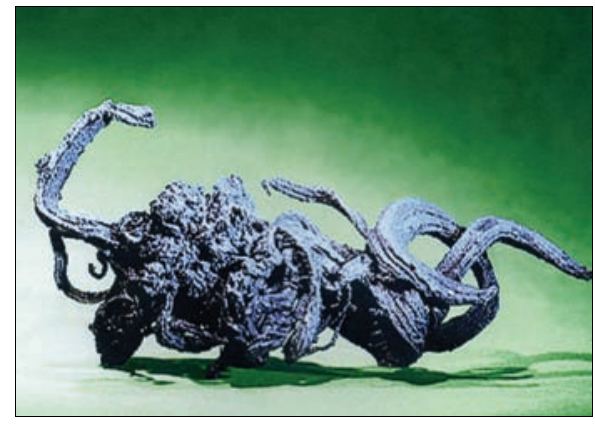

Abb. 6: gediegen Silber (geomuseum.tu-clausthal.de).

Freiesleben berichtet ferner von einem gewissen „Buttermilcherz“. Er führt eine Quelle von 1617 an, die der Stadtpfarrer Johann Funcken verfasste und die von diesem Phänomen Auskunft gab:

\footnotetext{
${ }^{30}$ Klähn (2009), S. 17.

${ }^{31}$ Freiesleben (1795) (Bd. 2), S. 217.

32 Ebd., S. 230.

33 Ebd., S. 232.

34 Ließmann (2002), S. 8.

${ }^{35}$ Klähn (2009), S. 17.

${ }^{36}$ Ebd.
} 
„Aes rarum et friabile wie man es nennt, mild Erz, das mit Händen hat können zerrieben und zusammen geballt werden, war weiß in der Gruben, wenn es aber an die Luft kam, wards blau und mild, wie ein Thon doch von Silber reich (...) die Arbeiter, wenn sie ausgefahren, Schue und Strümpfe haben waschen müßen, und ist von demselben Schlamme Silber gemacht worden" ${ }^{\text {"37. }}$.

In diesem Bericht ist von einem weißen, flüssigen Material die Rede, das aus dem Ganghohlraum geschöpft werden konnte. Aufgrund des hohen Silberanteils wurde es von den Schuhen und Strümpfen der Bergarbeiter abgewaschen und weiterverarbeitet. Unter einigen Gelehrten wurde dieser Stoff für reines, flüssiges Silber gehalten. ${ }^{38}$ Freiesleben negiert diese Ansicht und beruft sich auf eine zeitgenössische Untersuchung, die aussagt, dass das „Buttermilcherz" eine besondere Form von Silberchlorid darstelle. Diese chemische Verbindung wurde damals auch als „Hornerz" bezeichnet. ${ }^{39}$ Nach heutiger Forschung steht fest, dass vor rund 200 Jahren schon sehr genaue Ergebnisse erzielt wurden. Der heute als Chlorargyrit bezeichnete Stoff kann mit Tonmineralien die oben beschriebenen Ausformungen bilden. Die Verfärbung an der Luft kam durch eine chemische Reaktion zustande.

An dem Beispiel des „Buttermilcherzes“ wird deutlich, wie Menschen in verschiedenen Zeitabschnitten Umwelterscheinungen unterschiedlich wahrgenommen und interpretiert haben. Während dieses Phänomen um 1600 von dem Stadtpfarrer als außergewöhnlich konnotiert wird, deutet der Wissenschaftler Freiesleben Ende des 18. Jahrhunderts diese Erscheinung mit einem rationalen Naturverständnis, was aufzeigt, dass sich die Aneignungen, Klassifizierungen und Deutungen von Umweltbedingungen in den jeweiligen historischen und gesellschaftlichen Kontext einfügen. ${ }^{40}$

\subsection{Niedergang des Bergbaus}

Die reichen und wertvollen Erzfunde bescherten Sankt Andreasberg vor allem um 1800 einen wirtschaftlichen Aufschwung. Im Zeitraum von 1807-1827 war in diesem Revier die höchste Silberproduktion zu verzeichnen. ${ }^{41}$ Ab den 1830er Jahren sank aber die Ausbeute trotz technischer Neuerungen. Die hohen Gewinnungskosten und die teuren Untersuchungsarbeiten verhinderten bei gleichzeitig sinkendem Silberpreis eine günstige wirtschaftliche Entwicklung des Bergbauwesens. ${ }^{42}$ In den folgenden Jahrzehnten wurde immer weniger Silber abgebaut, sodass viele Gruben schlossen. Im Jahr 1910 wurde das letzte Bergwerk in Sankt Andreasberg eingestellt.

\footnotetext{
${ }^{37}$ Freiesleben (1795) (Bd. 2), S. 239.

38 Ebd., S. 240.

${ }^{39}$ Bischof (o. J.).

40 Siemann u. Freytag (2003), S. 18.

${ }^{41}$ Liessmann (2001), S. 56.

42 Ebd., S. 63.
} 


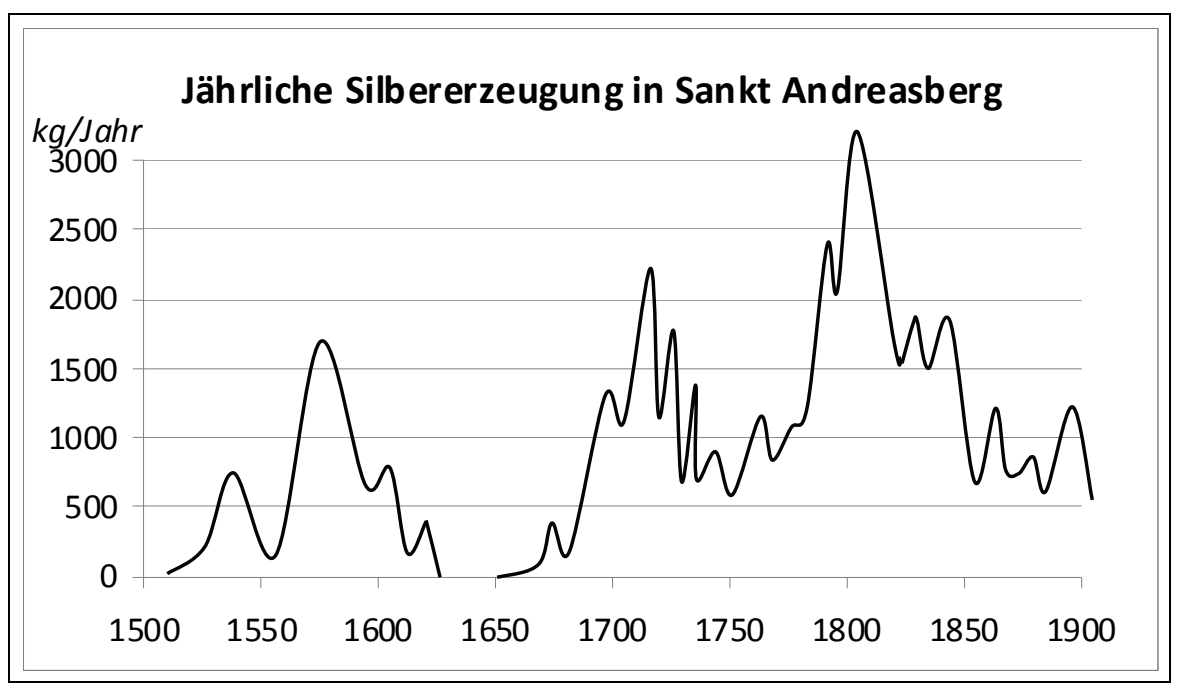

Abb. 7: Diagramm: Silberproduktion in Andreasberg (in Anlehnung an Klähn 2009, S. 36).

In dem folgenden Gedicht von Weidemeier Farchtr aus dem Jahr $1989^{43}$ kommt der Verfall und Niedergang des Bergbaus in Sankt Andreasberg zum Ausdruck:

Der Berggeist lebt

Alles steht heute verlassen da,

Was einst von Silber schwer.

Verfallene Schächt ${ }^{`}$ sind ringsumher,

Vor Ort ist's tot und leer.

Doch manchmal, wenn der Sturmwind heult,

In Finstren Neumondnächten,

Der Berggeist um die Felsen steicht,

Dann rührt sich's in den Schächten.

Dann gehn die alten Knappen um

Wie in vergangenen Tagen,

Die Silberglanz und Gültigerz

Aus unseren Bergen gegraben.

Und aus der Tiefe dringen ans Ohr,

Seltsam verhaltene Weisen,

Das nun schon lang vergessene Lied

Von Schlägel und von Eisen.

${ }^{43}$ Ließmann (2007), S. 151. 
In diesem schaurig anmutenden Gedicht wird aufgezeigt, dass nur noch die gespenstischen „Knappen“ das bedeutende Silber und Rotgültigerz in den verlassenen Bergwerken abbauen. Es wird aber auch deutlich, dass der Bergbau in der Erinnerung und Tradition der in dieser Region lebenden Menschen nach wie vor präsent ist, was sich auch im Tourismus niederschlägt.

\section{Tourismus}

Im 18. und 19. Jahrhundert gehörten zahlreiche Mitglieder der Bildungseliten, wie der erwähnte Montanwissenschaftler Freiesleben, zu den zahlreichen Besuchern des Oberharzes und der Bergstädte. Das romantische Naturerlebnis an der Harzreise trat hinter das akademische Interesse an den naturräumlichen Besonderheiten und an den technischen Leistungen des Bergbaubetriebs in dieser Gegend zurück. ${ }^{44}$ Aktuell ist der Harz und auch Sankt Andreasberg als Naherholungsgebiet ein beliebtes touristisches Ausflugsziel. Die jüngste Aufwertung erfuhr der Harz im Jahr 2006 bei seiner Ernennung zum Nationalpark.

Die vielfältigen Museen stellen einen weiteren Touristenmagneten im Harz dar. Die Musealisierung des historischen Bergbaus und der Alltagskultur ${ }^{45}$ kommt vor allem in der Grube Samson ${ }^{46}$ zum Ausdruck. Sie wurde im 16. Jahrhundert angelegt und war eines der bedeutendsten Bergwerke im Sankt Andreasberger Revier. Diese Grube beherbergte für einige Zeit den längsten Schacht der Welt ${ }^{47}$ und warf bis in das Jahr 1910 Silber ab. Der Samson umfasst heute neben dem Museum auch ein Besucherbergwerk. Die Anlage besteht unter anderem aus einem vollständig erhaltenen Grubenensemble, dem Pochwerksgebäude und einem Zechenhaus. ${ }^{48}$ Weiterhin befindet sich dort die wohl letzte voll funktionsfähige Fahrkunst, die im Jahr 1837 eingebaut wurde. ${ }^{49}$ Die Grube Samson ist mit ihrem Wassersystem letztlich ein Element der im frühen 18. Jahrhundert geschaffenen Oberharzer Wasserwirtschaft und somit ein Teil des UNESCO-Weltkulturerbes.

\footnotetext{
${ }^{44}$ Laufer (2010), S. 51.

45 Ebd., S. 17.

46 Der Name leitet sich nach aller Wahrscheinlichkeit vom alttestamentarischen Richter Samson ab. Solche religiös konnotierten Namen dienten vor allem der mentalen Bekräftigung und Unterstützung der Bergleute.

47 Um 1850 war der Samson mit 791 Metern einer der tiefsten Schächte der Welt.

48 Klähn (2009), S. 6.

${ }^{49}$ Ebd.
} 


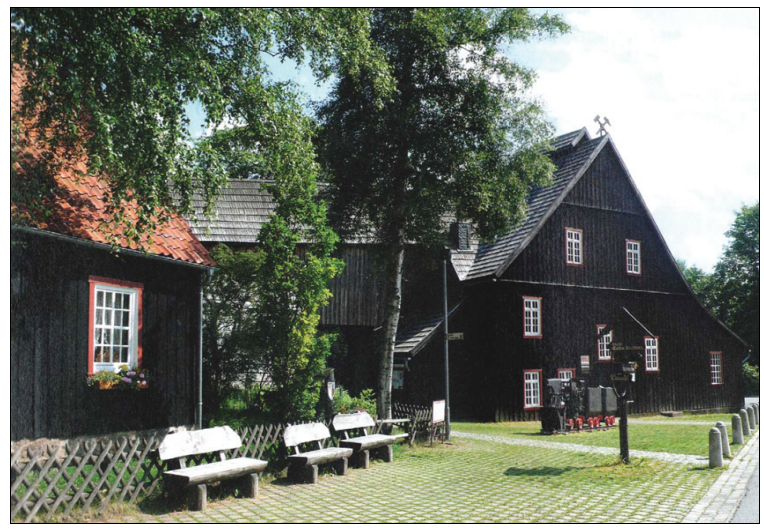

Abb. 8: Außengelände der Grube Samson (Klähn 2009, S. 60).

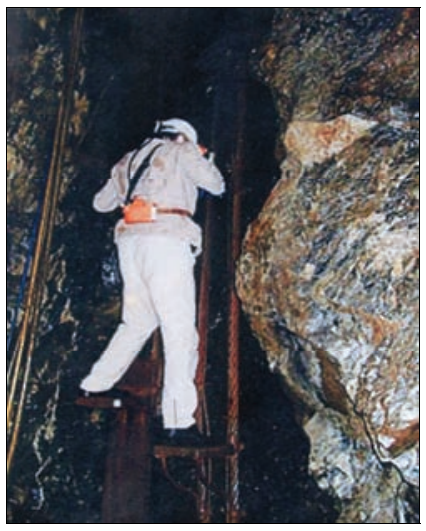

Abb. 9: Fahrkunst im Samson (harz-netz.com).

\section{$5 \quad$ Fazit}

Zusammenfassend lässt sich nach der Untersuchung der Entwicklung des Silberbergbaus in Sankt Andreasberg feststellen, dass die natürlichen Gegebenheiten und explizit die wertvollen und reichen Erzlagerstätten den Menschen erst den Anreiz gaben, in dieser klimatisch unwirtlichen Region zu siedeln. Der Abbau der Bodenschätze wurde zu verschiedenen Zeiten und in unterschiedlichen gesellschaftlichen Kontexten einerseits als wohlbringend gepriesen oder andererseits als Raub an der personifizierten „Mutter Erde“ angesehen. Mit der Nutzung der natürlichen Ressourcen waren demnach politische, wirtschaftliche und kulturelle Vorstellungen und Prozesse verbunden.

Die Umweltbedingungen setzten den Rahmen für politische Herrschaft. Beispielsweise sicherten die Erzvorkommen herrschaftliches Kapital und Prestige. Andererseits veränderten politische Konstellationen auch ökologische Gegebenheiten. Die Bergfreiheiten gaben zum Beispiel Anreize zum Abbau der Erze, sodass die mineralischen Rohstoffe vermehrt erschlossen und genutzt wurden, was weitere Auswirkungen auf die Umwelt hatte.

Die Nutzungsgeschichte ist vor allem im Kontext der Ökonomie zu sehen. An den Hoch- und Tiefphasen im Bergbauwesen wird deutlich, dass wirtschaftliches Handeln von den Umweltbedingungen abhängig ist. Die zeitweise geringe Anzahl an Erzfunden, die nicht mehr zu beherrschenden Schachttiefen sowie der Mangel an Aufschlagwasser für die Betriebswasserversorgung der Gruben zeigen nur einige Beispiele von Problemen auf. Das wirtschaftliche Agieren des Menschen wirkte im Gegenzug auch auf die Umwelt ein. Durch anthropogene Eingriffe in die Natur entstanden ökologische Veränderungen. Das Bergbauwesen rief im Oberharzer Gebiet teilweise schwerwiegende Umweltschäden hervor. Die Wälder wurden durch die Entnahme des Holzes, welches für den Bergbau in großen Mengen be- 
nötigt wurde, stark belastet. Durch die Aufforstung wurde das ehemalige Laubwaldgebiet in einen Nadelwald umgewandelt. Der Anbau von Monokulturen hatte unter anderem den Rückgang der biologischen Diversität und das vermehrte Risiko von Kalamitäten zur Folge.

Eine weitere Gefährdung des lokalen Ökosystems stellten beispielsweise Schadstoffemissionen aus dem Rauch der Hütten dar. Neben Schwermetallionen und Schwefel gelangten große Mengen Arsen in die Luft und kontaminierten den Boden, das Wasser und die Vegetation. Diese Umweltbelastungen wirkten auf den Menschen zurück, da der Kontakt mit diesen Stoffen gesundheitsgefährdend war. Insgesamt ist zu verzeichnen, dass durch die Siedlung der Menschen und durch die Bewirtschaftung des Landes eine bestimmte Flora und Fauna entstanden ist. Die Folgen der Montanwirtschaft zeigen deutlich auf, inwiefern der Mensch und die Umwelt in einer dynamischen Wechselbeziehung stehen.

Die Veränderungen in der Landschaft ließen im Laufe der Jahrhunderte die aktuell gängige Erscheinung vom Harz entstehen. Der heutige Zustand wird oft als „,natürlich“ angesehen, doch erst durch anthropogene Eingriffe wurde dieses gegenwärtige Bild hervorgebracht. Der Harz ist zu einer Kulturlandschaft geworden, denn der Mensch hat sich seine Umwelt angeeignet und gestaltet, was letztlich auf die Identität dieser Region wirkt und somit auch den Tourismus sichert.

\section{Literatur}

Bartels C (1992) Vom frühneuzeitlichen Montangewerbe zur Bergbauindustrie. Erzbergbau im Oberharz 1635-1866. Dt. Bergbaumuseum, Bochum.

Bischof W (o. J.) Das historische Buttermilcherz von Sankt Andreasberg. www.harz-mineralien.de/Das\%20historische\%20Buttermilcherz.htm (29.09.2012).

Dennert H (1960) Bergbau und Hüttenwesen im Harz vom 16. bis zum 19. Jahrhundert. Pieper, Clausthal-Zellerfeld.

Freiesleben JC (1795) Bemerkungen über den Harz. (2 Bde.). Schäferische Buchhandlung, Leipzig.

Grams W (1992) Karl Philipp Moritz. Eine Untersuchung zum Naturbegriff zwischen Aufklärung und Romantik. Westdt. Verl., Opladen.

Klähn J (2009) Sankt Andreasberge über Tage und unter Tage. Ein Leitfaden zur Geschichte der Bergstadt und ihrer Umgebung. Harzdruckerei Wernigerode $\mathrm{GmbH}$, Sankt Andreasberg.

Laufer J (2010) Lebenswelten und Lebenswege in den Oberharzer Bergstädten. Alltag und soziale Verhältnisse des Bergvolks im 19. Jahrhundert. Hahn, Hannover. 
Ließmann W (2007) Historischer Bergbau im Harz. Ein Kurzführer. 2. Aufl. Springer, Berlin.

Ließmann W (2002) Der Bergbau am Beerberg bei Sankt Andreasberg. Ein (Wander-) Führer durch „Auswendigen Grubenzug“ sowie Anlagen des Lehrbergwerks Grube Roter Bär. Mecke, Duderstadt.

Ließmann W (2001) Zur Betriebsgeschichte der Grube Samson von 1661 bis 1866. In: Sankt Andreasberger Verein für Geschichte und Altertumskunde (Hg.) 50 Jahre Bergwerksmuseum Grube Samson. Selbstverl., Sankt Andreasberg, S. 2978.

Niemann HW (1991) Die Geschichte des Bergbaus in St. Andreasberg. Pieper, Clausthal-Zellerfeld.

N.N. (2008) Johann Carl Freiesleben. In: Mansfeld. Geschichte und Geschichten 9, S. 18-19.

Regenhardt HO (1978) Menschen im Produktionsprozess. Bergarbeiter im Erzbergbau vom 16. bis 20. Jahrhundert. Pieper, Clausthal-Zellerfeld.

Siemann W, Freytag N (2003) Umwelt. Eine geschichtswissenschaftliche Grundkategorie. In: W. Siemann (Hg.) Umweltgeschichte. Themen und Perspektiven. Beck München, S. 7-20.

Steinsiek PM (1999) Nachhaltigkeit auf Zeit. Waldschutz im Westharz vor 1800. Waxmann, Münster.

Winiwarter V, Knoll M (2007) Umweltgeschichte. Eine Einführung. Böhlau, Köln.

Wilgeroth CO (2006) Die Oberharzer Wasserwirtschaft in der Frühen Neuzeit (16.-19. Jahrhundert). In: Graduiertenkolleg 1024 Interdisziplinäre Umweltgeschichte. Werkstattbericht Schauplätze der Umweltgeschichte. Universitätsverlag, Göttingen, S. 241-254. 



\title{
Die Pferdezucht im Solling und ihre Auswirkung auf die Kulturlandschaft und Siedlungsstruktur des Ortes Neuhaus
}

\author{
Detlef Creydt \& Tina Creydt
}

\section{Einleitung}

Im allgemeinen Bewusstsein ist der Solling noch immer eng verknüpft mit der Pferdezucht. Bis heute ist Hunnesrück die einzige Hengstaufzuchtstation des Landes Niedersachen. Das Bild von edlen Hannoveranern oder Trakehnern, die auf lichten Sollingweiden grasen, war und ist ein beliebtes Motiv für Postkarten und Synonym für das Sollingidyll. Dies gilt besonders für die Sollingortschaft Neuhaus. Hier hat der Gestütsbetrieb baulich das Ortsbild stark geprägt und die die Weiden umgebenden Mauern sind charakteristisch für die Umgebung. Vielzählige Flurnamen deuten auf die lange Tradition der Pferdezucht hin.

Der folgende Aufsatz möchte aufzeigen, wie bedeutend die landesherrschaftliche Pferdezucht für Neuhaus war und wie sie die Ortschaft und Umgebung prägte. Welche Bedingungen waren es, die diesen Ort für die Pferdezucht prädestinierten? Wie wurde in die Landschaft eingegriffen, um sie hierfür zu optimieren? Welche siedlungsgeschichtlichen Aspekte in Verbindung mit der Pferdezucht spielten für die Entwicklung des Ortes eine Rolle? Was ist geblieben von der Pferdezucht?

Das Gestüt Neuhaus gehörte im Laufe der Zeit zu den großen norddeutschen Gestüten, welche die Pferdezucht im heutigen Niedersachsen mit bestimmten. Am Beispiel Neuhaus wird deutlich, dass das Schicksal des Gestüts mit dem jeweiligen Landesherrn eng verbunden war. Die Grenze zwischen Braunschweig-Wolfenbüttel und Calenberg-Göttingen bzw. Hannover führte genau durch die Ortschaft. 
Nördliche Flurnamen mit Bezug zur Pferdezucht lassen sich nur in der frühen braunschweigischen Zeit finden. Ab dem 18. Jahrhundert spielte sich die Pferdezucht lediglich im südlichen hannoverschen Teil des Ortes ab. Für das Gesamtverständnis folgt ein historischer Abriss über die Pferdezucht in der Sollingregion. Im Anschluss steht die Betrachtung der Pferdezucht im Bezug auf Neuhaus.

Ein Exkurs über die Rettung der Trakehner nach dem Zweiten Weltkrieg soll die Bedeutung der Sollinggestüte für die neuere Zeit belegen, fand hier doch die ostpreußische Trakehnerzucht eine neue Heimat. ${ }^{1}$

\section{Pferdezucht im Solling}

Im Solling standen den Landesherren eigene Flächen zur Verfügung, die landwirtschaftlich nicht genutzt wurden, für die Weidehaltung von Pferden aber ideal waren. Die größten Weideflächen lagen um den heutigen Ort Neuhaus zentral im Solling (Abb. 1). Die dazu gehörenden Sollinggestüte befanden sich zum einen in Neuhaus selbst, anfänglich aber auch in dem etwa sieben Kilometer südlich liegenden Nienover, und zum anderen auf der ca. 15 Kilometer entfernt am Sollingrand bei Dassel gelegenen Erichsburg und im nahgelegenen Relliehausen. Später gesellte sich als weiteres Gestüt Hunnesrück hinzu, das direkt an die Erichsburg angrenzt. Die Sollinggestüte standen immer miteinander in Beziehung und dienten der jeweiligen Landesherrschaft dazu, ihren Bedarf an Reit-, Kutsch- und Militärpferden zu decken.

\subsection{Erste Belege für die Pferdezucht im Solling}

Die Pferdezucht im Solling hat eine lange Tradition. Erste gesicherte Überlieferungen finden sich aus der Zeit des Braunschweiger Herzogs Erich I. (1495-1540). Die Weiden um Neuhaus an der Dölme und oberen Ahle sowie am Tepkenbach mit den sich anschließenden oberen Derenthaler Wiesen ermöglichten eine erfolgreiche Zucht. Das Angebot an Futterpflanzen war für Pferde optimal. Herzog Erich I. besaß Gestüte für Reitpferde auf der Erichsburg, in Nienover sowie in Relliehausen. Hier wurden die Stuten aufgezogen, während die Hengstfohlen auf das nördlich von Nienover liegende Weidegebiet bei Neuhaus gebracht wurden. 1540, am Ende seiner Regierungszeit, werden insgesamt 38 Stuten mit 23 Stutfohlen für die Erichsburg, Relliehausen und Nienover sowie acht Hengste und 41 Hengstfohlen für Neuhaus genannt. ${ }^{2}$ Nach dem Tod des Herzogs übernahm seine Witwe, Herzogin Elisabeth, die Regierungsgeschäfte für ihren minderjährigen Sohn. Sie verkleinerte die Pferdezucht und verkaufte einige Pferde. Aus den überlieferten Unterlagen erfahren wir auch etwas über die gezüchteten Pferde. Es ist

\footnotetext{
${ }^{1}$ Heling (1962), S. 102 f.; Schilke (1974), S. 144 f.

${ }^{2}$ Weise (1989), S. 46.
} 
von „Grauen Sollingern“ die Rede. Da dies augenscheinlich kein Eigenname war, können wir zu diesem Zeitpunkt von einem eigenen Pferdeschlag im Solling ausgehen. Was genau diesen Pferdeschlag auszeichnete, ist allerdings nicht überliefert. Da es in der zweiten Hälfte des 16. Jahrhunderts vor allem darum ging, gute Reitpferde für kriegerische Auseinandersetzungen zur Verfügung zu haben, ist anzunehmen, dass auch der „Graue Sollinger“ diese Anforderungen erfüllte. ${ }^{3}$

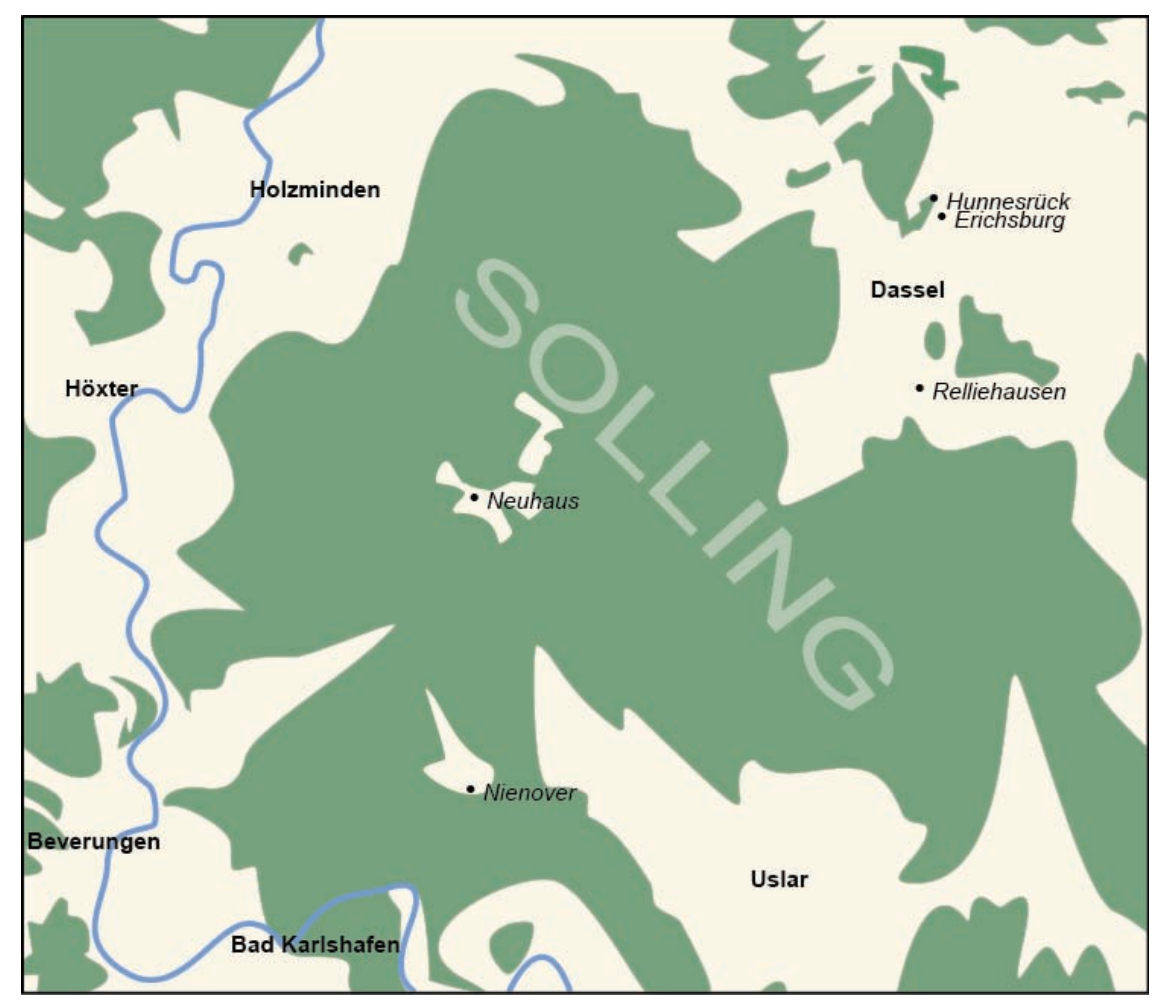

Abb. 1: Karte des Solling mit den Gestütsstandorten Neuhaus, Nienover, Erichsburg, Hunnesrück und Relliehausen (Creydt).

\subsection{Die Dezentralisierung der Pferdezucht}

Unter Herzog Erich II. (1540-1584) fand eine Dezentralisierung der Zucht statt. Neben den drei Gestüten wurden dezentrale Stallanlagen, sogenannte Marställe errichtet. Sie befanden sich auf den braunschweigischen Ämtern Fürstenberg, Allersheim, Forst, Wickensen und Greene am und im Solling. Zu dieser Zeit kam den Ämtern eine immer größere Bedeutung in der Pferdezucht zu. Auf dem Marstall in Fürstenberg standen beispielsweise 45 Stuten, fünf Wilde (junge Stuten) sowie 16

${ }^{3}$ Weise (1989), S. 46. 
Hengst- und neun Stutfohlen. Im Sommer waren die Pferde auf den Weiden und kamen nur im Winter in den Stall. Marstaller und Pferdehirten waren für die Tiere verantwortlich. ${ }^{4}$

Einen guten Einblick in diese Form der Pferdehaltung gibt eine Bestallungsurkunde des Marstallers Hans Kleinschmidt aus dem Jahre 1587. Die Urkunde benennt ihn zum ,wildenmarstaller Erichsburgischen theils, auch vor unsern förster unter unsere ußlersche forst daselbst" ${ }^{\text {"5 }}$. Seine Aufgaben bestanden darin, ,uff unsere wilden am Solling fleissig acht haben“, damit „dieselbe woll geweidet, gehütet und gewartet werden." "Dazu sollte er von seinem Wohnsitz in Bodenfelde aus in den Solling reiten, sie begutachten, ob sie gut gehütet wurden, der Hengst gut erzogen und für die Mutterfohlen zum Nutzen des Herzogs alles Menschenmögliche getan wurde. Für seine Dienste bekam er zusätzlich zum Gehalt als Deputat Getreide für sich und sein Pferd, zwei Stoppelschweine, Sommer- und Winterkleider (Uniform) und als besondere Wertschätzung einen abgabefreien Krug in Bodenfelde. Dafür musste er als Marstaller auf seine Kosten für kriegerische Auseinandersetzungen gerüstet sein: mit einem blanken Harnisch mit Rüstung, drei kurzen Rohren (Pistolen), einem langen Rohr (Gewehr) samt Kugeln und einer Saufeder (Abb. 2). ${ }^{7}$

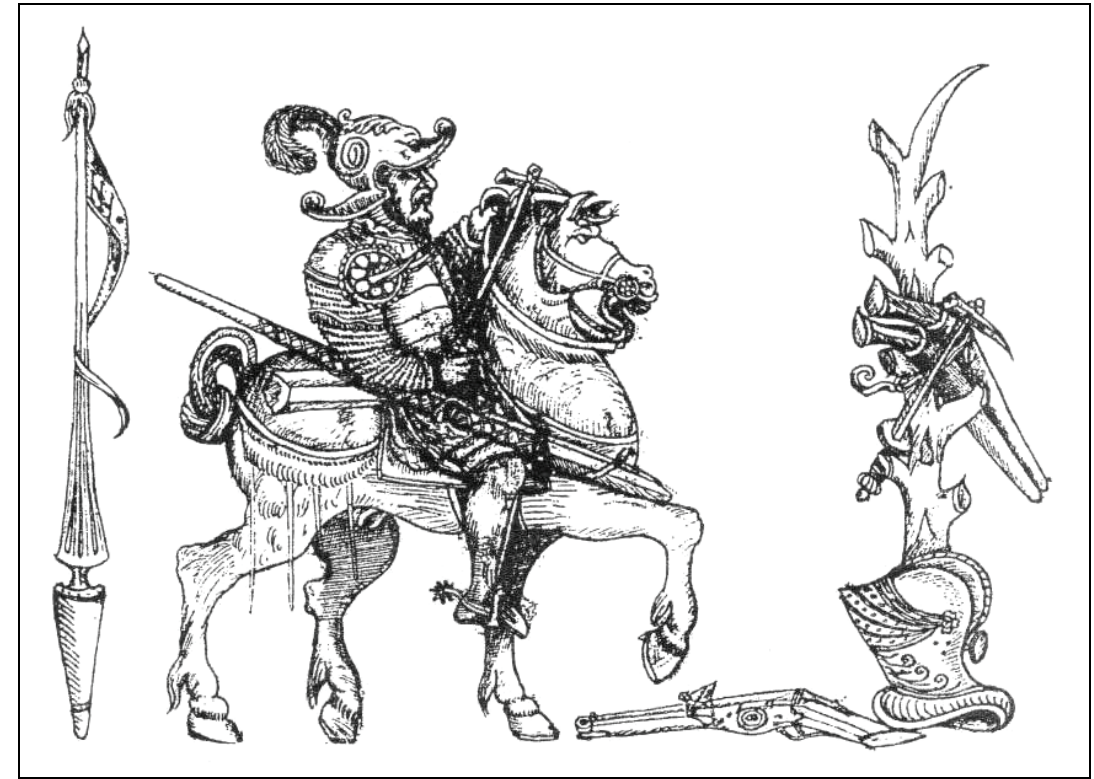

Abb. 2: Marstallern vorgeschriebene Ausrüstung (StAW 50 Slg 1034).

\footnotetext{
${ }^{4}$ Fürstenberger Erbregister von 1554, nach Bloß (1975).

5 Tacke (1957), S. 13.

${ }^{6}$ Ebd., S. 13.

${ }^{7}$ Ebd., S. 13-16.
} 
Die Pferdezucht im braunschweigischen Solling kam während des Dreißigjährigen Krieges zum Erliegen. Mit Fortschreiten des Krieges wurden immer mehr Pferde von regulären Truppen, die durch den Solling zogen, requiriert oder fielen Marodeuren in die Hände. 1632 wurden noch die wertvollsten Pferde von Nienover nach Einbeck gebracht, wo man sie hinter hohen Mauern als gesichert ansah. Aber Graf von Pappenheim erzwang die Kapitulation der Stadt und requirierte auch diese noch verbliebenden Reitpferde für sich. ${ }^{8}$

Seit dieser Zeit scheint im braunschweigischen Nordteil des Sollings keine Pferdezucht mehr betrieben worden zu sein. Auf den Weiden standen nun statt der Pferde Kühe.

\subsection{Wiederbelebung der Pferdezucht nach dem Dreißigjährigen Krieg}

Im südlich gelegenen Herrschaftsbereich des Herzogs von Calenberg-Göttingen kam erneut der Wunsch auf, Pferde zu züchten. 1665 wurde das Gestüt Nienover als Nienover-Neuhaus wiederbelebt. Die Gestütsgebäude wurden wiederum bezogen und die Ställe mit Pferden bestückt. Bereits 1677 konnte der zuständige Hirte dem Herzog vermelden, dass die Herde nun auf 69 Häupter angewachsen sei. ${ }^{9}$

Unter Ernst August, Herzog von Braunschweig-Calenberg (1679-1714), ging 1692 das Herzogtum Calenberg-Göttingen in Personalunion in das Kurfürstentum Hannover auf. Ernst August setzte die Pferdezucht fort. Sein Nachfolger, Georg I. (1714-1727), baute sie weiter aus. Georg II. (1727-1760) wiederum vernachlässigte das Gestütswesen im Solling und gründete stattdessen 1734 das Landgestüt Celle. Als dann Georg III. (1760-1806) die Regierung antrat, veränderte sich das Interesse an den Sollinggestüten erneut grundlegend und gewann wieder an Bedeutung.

\subsection{Das 19. und 20. Jahrhundert}

Neben der Pferdezucht im Solling gab es zwei weitere wichtige Gestüte in Norddeutschland: Memsen bei Nienburg und Radbruch bei Lüneburg. Die Gestüte standen in enger Beziehung zu den Sollinggestüten. ${ }^{10}$ Im neu entstandenen Königreich Hannover erlebte die Pferdezucht einen enormen Aufschwung. Im Jahre 1800 wurde der Pferdehandel als ein „Hauptreichtum“ des Königreichs bezeichnet. Durch die Gestüte in Celle und Neuhaus sowie Memsen und Radbruch konnten jährlich über 6.000 Pferde exportiert werden. ${ }^{11}$

Während der napoleonischen Kriege gehörte sowohl der braunschweigische als auch der hannoversche Teil des Sollings zum französischen Königreich Westphalen. Der Export von Pferden kam in dieser Zeit fast völlig zum Erliegen. Erst nach

\footnotetext{
8 Weise (1989), S. 110.

9 Tacke (1955), S. 29 f.

${ }^{10}$ Köhler (1977), S. 57.

${ }^{11}$ Hutten-Czapski (1876), S. 202.
} 
dem Ende der westfälischen Herrschaft gewann der Export von Pferden unter dem hannoverschen König Georg IV. (1820-1830) wieder an Bedeutung. Die in der Zucht nun angestrebten Ziele galten einer Rasse, die für den Krieg, zur Jagd und zum Lastenziehen brauchbar sein sollte. Dies versuchte man durch die Einführung von englischen Vollblütern zu erreichen. ${ }^{2}$ Die Zahl der Hengste hatte sich von 1800 bis 1840 in den Landgestüten verdoppelt. Zwei Drittel der Beschäler stammten aus Neuhaus und Memsen oder vom königlichen Marstall in Hannover, ein Drittel waren Vollbluthengste, die meist aus England stammten. ${ }^{13}$

Nach der Annexion Hannovers durch Preußen 1866 nutzte das preußische Militär die günstigen Voraussetzungen im Solling. Den Preußen ging es vor allem um Remonten, Ersatzpferde für die verschiedenen Waffengattungen des Militärs. 539 Remonten wurden 1867/68 in Erichsburg, Hunnesrück und dem nur fünf Kilometer entfernten und 900 Hektar umfassenden Vorwerk Relliehausen sowie Neuhaus aufgezogen. In Spitzenzeiten waren es bis zu 1.000 Remonten. Das war der größte Zugewinn seit Bestehen der Sollinggestüte. Das Zuchtziel der hannoverschen Landespferdezucht war ein kräftiges, großes und starkes Pferd als Kutschschlag und Militärpferd. ${ }^{14}$

1920 wurde das Gestüt Hunnesrück dem Landesgestüt Celle unterstellt. Züchterisches Ziel war jetzt das Hannoversche Warmblutpferd, „das jede Arbeit in der Landwirtschaft verrichten konnte, aber auch so viel Blut, Nerv und Gang besaß, um als starkes Reit- und Wagenpferd Verwendung zu finden“. Das Gestüt Hunnesrück-Erichsburg sollte dabei als Hengstaufzuchtstation dienen. ${ }^{15}$ Nach Jahrgängen eingeteilt, wuchsen die Fohlen in Herden bis zum Herbst ihres dritten Lebensjahres heran. Von April bis Oktober standen sie auf den Sollingweiden. In der winterlichen Zeit fanden sie in den Laufställen ausreichende Bewegung im Freien. Mit 1 1/2 Jahren kamen die Hengstanwärter auf das Vorwerk Relliehausen, wo ebenfalls hervorragende Bergweiden für die Aufzucht vorhanden waren. Hier blieben sie für ein Jahr. ${ }^{16}$ Die Körkommission erschien in jedem Herbst und besichtigte die $2 \frac{1}{2}$ jährigen Hengstfohlen zusammen mit den Landstallmeistern. Nicht nur die ausgezeichneten Weiden mit ihrer optimalen Futterzusammensetzung, den für die Kondition wichtigen Hängen an den Bergen, dem Höhenklima sowie dem guten Wasser, sondern auch der sachgemäßen Haltung war es zu verdanken, dass am und im Solling aufwachsende Pferde sowohl die guten als auch die schlechten Anlagen offen zutage treten ließen, so dass die gewünschte züchterische Auslese optimal durchgeführt werden konnte. ${ }^{17}$

\footnotetext{
12 Hutten-Czapski (1876), S. 202; Tennecker (1842), S. 220.

13 Tennecker (1842), S. 220 f.; Bräuer (1901), S. 90.

14 Bräuer (1901), S. 87; nach Aufzeichnungen von Heinz Voss, ehemaliger Verwalter des Vorwerkes Relliehausen.

15 Plümer (1971), S. 79 u. 106; Köhler (1977), S. 69; Mirus (1981), S. 233.

16 Mündliche Auskunft von Karl Bartels, der die Deckstation in Erichsburg von 1959 bis 1982 leitete.

${ }^{17}$ Landgestüt Celle (1959), S. 34.
} 
1946 wurde das Landgestüt Celle mit dem Hengstaufzuchtgestüt HunnesrückErichsburg dem niedersächsischen Ministerium für Ernährung, Landwirtschaft und Forsten unterstellt. Hunnesrück trat außerdem die Nachfolge des ostpreußischen Trakehnergestüts an. Die auf der Flucht aus Ostpreußen versprengten Pferde wurden gesammelt und rund 50 Trakehner zogen in die Ställe ein. Sie wurden wie folgt auf die einzelnen Stationen verteilt: Erichsburg beinhaltete die Deckstation mit Stuten und Fohlen. In Hunnesrück standen die Junghengste. In Relliehausen waren Hannoveraner Junghengste untergebracht. In Neuhaus weideten im Sommer die Stuten. ${ }^{18}$

Um 1960 wurden die Pferde aus Relliehausen abgezogen. Das Vorwerk Relliehausen wurde 1966 von Hunnesrück abgetrennt. Es entstand eine eigenständige Domäne, die an die „Landwirtschaftliche Versuchsanstalt für Tierzucht der Universität Göttingen“ verpachtet wurde. ${ }^{19}$ Etwa ab 1968, nachdem sich durch den wachsenden Lebensstandard in der Bundesrepublik auch der Reitsport ausgeweitet hatte und zahlreiche Reitsportvereine entstanden, wurde eine breitere Basis der Hengstaufzüchter in Niedersachsen geschaffen. Waren bisher $50 \%$ des Hengstersatzes aus Hunnesrücker Beständen erfolgt, so wurde nun das Ankaufsverhältnis auf ca. 2/3 aus Privataufzucht und 1/3 auf Hengste aus Hunnesrück festgelegt. 1975 gab es 70 Hannoversche Hengstanwärter im Gestüt Hunnesrück. Aus ihnen rekrutierte sich zusammen mit privat aufgezogenen Pferden der Celler Hengstbestand, der jährlich zur Körung in Verden vorgeführt wurde. 1988 waren es noch $30 .{ }^{20}$ Heute weiden ein Hengstjahrgang von 50 Köpfen auf den Hunnesrücker Weiden und ein weiterer in gleicher Stärke auf den Neuhäuser Berghängen.

\section{Das Gestüt Neuhaus}

\subsection{Die Anfänge}

Erstmalige Erwähnung findet Neuhaus im 16. Jahrhundert als Weidefläche für die Hengstfohlen der Gestüte Nienover, Erichsburg und Relliehausen. Nach der Dezentralisierung der Pferdezucht unter dem braunschweigischen Herzog Erich II. (1546-1584) weideten in und um Neuhaus die Stuten der Marställe der SollingÄmter. Die jungen Stuten oder „Wilden“ der Ämter hielten sich im Frühjahr mit einem Schälhengst auf den Weiden und in den Brüchen um Neuhaus herum auf. Auch nachdem der Hengst nicht mehr bei ihnen war (ab Juni), blieben sie in den Hochlagen des Sollings - bis zum Beginn des Winters. Dann wurden sie auf die Ämter verteilt. ${ }^{21}$

\footnotetext{
18 Mündliche Auskunft von Karl Bartels.

${ }^{19}$ Mirus (1981), S. 172.

${ }^{20}$ Köhler (1977), S. 98; Dossenbach et al. (1977), S. 70 f.; Einbecker Morgenpost vom 2./3. Juli 1988.

${ }^{21} \mathrm{Bloß}(1975)$.
} 
Aus dieser Zeit stammen vermutlich viele der Flurnamen um Neuhaus herum, die in Verbindung zur Pferdezucht stehen: „Wildenbuchen“ oberhalb von Mühlenberg, „Pferdehude“ nördlich von Silberborn, „Pferdestall“ und „Pferdehalskopf“ nördlich von Neuhaus, „Fohlenplacken“, „Rosshagen“, „Wildenkielsgrund“, „Wildenkiel“" und „Wildenkielskopf“ westlich von Neuhaus. Diese Flurnamen liegen alle im ehemals braunschweigisch-wolfenbüttelschen Teil im Nordsolling.

Nach dem Dreißigjährigen Krieg wuchs die Bedeutung von Neuhaus für die Pferdezucht. Es war jetzt fester Bestandteil des Gestüts Nienover, was sich auch in dem Namen Nienover-Neuhaus widerspiegelt. Jetzt waren es wieder die südlich gelegenen Weiden im hannoverschen Teil des Sollings, die zur Weidehaltung genutzt wurden.

\subsection{Der Auf- und Ausbau in Neuhaus}

Das Gestüt Nienover-Neuhaus wurde zu Beginn des 18. Jahrhunderts von Ernst August, Kurfürst von Hannover, gründlich instand gesetzt und mit weiteren Gebäuden versehen. 1712-1714 errichtete er die „Alte Stutery“, einen Stall für Stuten im hannoverschen Ortsteil von Neuhaus. Sein Nachfolger, Georg I., führte sein Werk fort. Bereits unter Georg II. ging die Pferdezucht aber erneut zurück und 1755 lag das Gestüt Nienover-Neuhaus brach. Ein Glücksfall für Neuhaus war Georg III. Er besann sich auf die Pferdezucht im Solling und belebte das Gestüt wieder. Hierfür wurde ab 1760 die „Alte Stuterey“ ausgebessert, weitere Stallungen angelegt und die Weiden mit Palisaden und Gräben gesichert. Dann wurde eine große Anzahl von Fohlen nach Neuhaus gebracht. Der züchterische Erfolg muss sehr groß gewesen sein. Denn bereits 1774-1776 wurde das „Neue Gestüt“ errichtet (Abb. 3). Von vier Seiten wurde ein großer Innenhof (A) von Gebäuden umgeben. Das heutige „Haus des Gastes“ der Gemeinde Neuhaus auf der östlichen Seite war einst der Füllenstall (B). Das „Sekretärshaus“ (heute Sitz des Zweckverbands Solling-Vogler) befand sich auf der Nordseite (C). Daneben, in dem westlichen Teil waren Stuten untergebracht (D). Der Innenhof, der sogenannte „Laufhof“", diente als Auslauf. Diese Anlage beherbergte 40 Mutterstuten mit ihren Fohlen. Hinzu kamen ein Magazin (E), ein Wiegenhaus (F) und ein Beschälerstall (G). Die „Stutennachtweide“ $(\mathrm{H})$ schloss sich südwestlich an. 


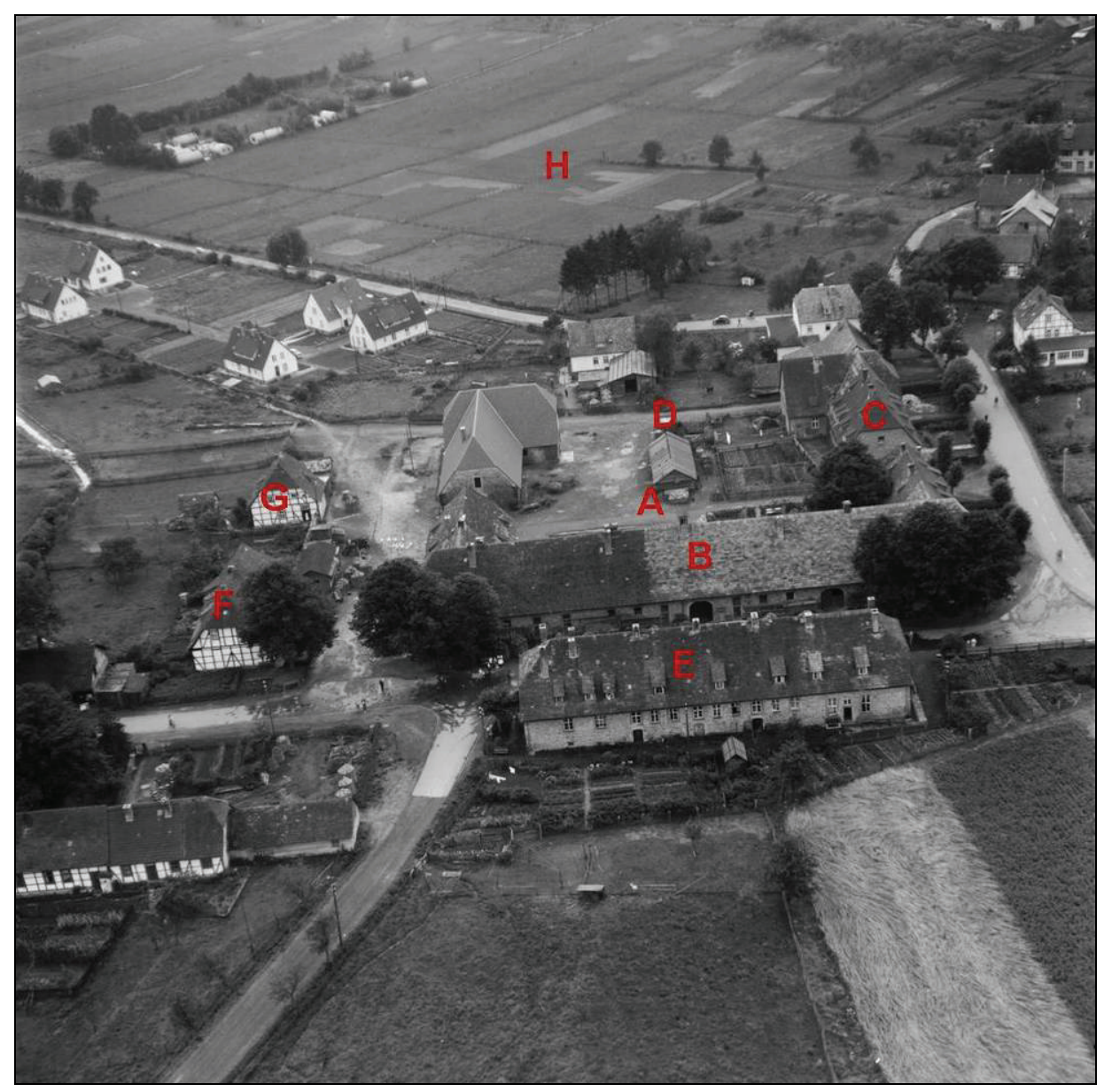

Abb. 3: Das Neue Gestüt 1956 (Stadtarchiv Holzminden).

An den Gestütsgebäuden findet man die Jahreszahlen 1774 und 1775, am Nebengebäude 1776. 1780 kamen Kapelle und Schule hinzu, während das heutige Schloss als damaliges Amtshaus erst 1791 gebaut wurde. In diesem Hauptgebäude waren die Wohnungen des Großstallmeisters und Gestütsverwalters untergebracht. Rechts und links angebaut waren Gebäude mit 42 Boxen, in denen Hengstfohlen aufgezogen wurden sowie zusätzlich Unterbringungsmöglichkeiten für Stallknechte, die nachts die Fohlen unter Beaufsichtigung halten mussten.

Links auf der nördlichen Seite befand sich ein alleinstehendes Gebäude für Kühe, Schweine und Geflügel. Der Hof wurde im Osten durch die nördlich liegende Wäscherei mit der dahinter liegenden Bäckerei abgeschlossen. Der Mittelbau mit großem Tor und einer darüber in Stein gemeißelten Feuerspritze verrät, dass es sich hier um das Spritzenhaus handelte. Es folgte in südlicher Richtung die 
Schmiede. Ein weiteres an der Straße liegendes Gebäude wurde im 20. Jahrhundert als Molkerei genutzt. Alle Gebäude sind heute noch vorhanden, sogar noch mit den eichenen Holzrollen an den Ecken des Innenhofes, die bei Gedränge der Fohlen Verletzungen vermeiden sollten. Über dem Tor auf der Rückseite des nördlich an das Hauptgebäude angebauten Stalles ist die Jahreszahl 1791 eingemeißelt. Waschkessel, Backofen und Schmiedeesse existieren heute noch, ebenso wie einige Ständer der Boxen in den Flügelbauten.

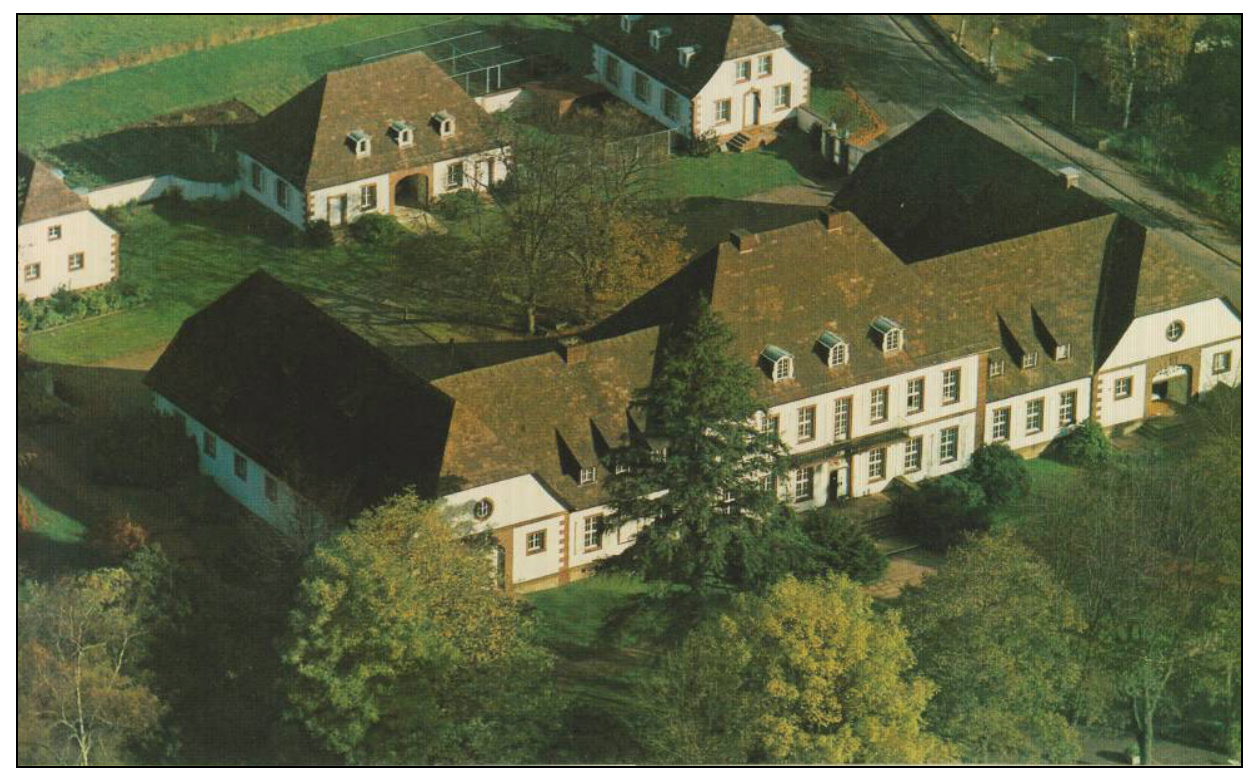

Abb. 4: Das ehemalige Amtshaus und heutige Schloss Neuhaus mit den Nebengebäuden, 1980 (Postkarte, Bildarchiv des Heimat- und Geschichtsvereins für Landkreis und Stadt Holzminden e.V.).

Diese ehemaligen Gestütsgebäude dominieren noch immer das Ortsbild von Neuhaus. Das alte Amtshaus, das heutige Schloss mit den vorgelagerten Parkanlagen (Abb. 4), das „Neue Gestüt“ mit den Ställen, Gestütshäusern und der Kapelle mit der alten Schule ergeben ein in sich geschlossenes Ensemble von Gebäuden, die etwa zur gleichen Zeit entstanden sind. Heute stellen sie den alten Kern des hannoverschen Teils des Ortes Neuhaus dar. Auch die Flur erhielt im 18. Jahrhundert die heutige Gliederung und vermutlich auch die dazu gehörigen Flurnamen, die alle im ehemals hannoverschen Teil des Sollings liegen: „Bruchweide“, auf der die „Alte Stuterey“ lag, „Nachtweide“, „Obere und untere Hengstweide“ und „Neuweide“. Der Flurname „Turmweide“ hängt vermutlich mit der französischen Telegrafenstation zusammen, die auf dem Moosberg stand und um 1810 betrieben 
wurde. ${ }^{22}$ Ende des 18. Jahrhunderts lieferte Neuhaus vor allem den Pferdenachwuchs für den königlichen Hof und stellte einen Großteil der Marstallbeschäler. ${ }^{23}$

\subsection{Die französische Zeit}

Als 1803 die Franzosen in den Solling kamen, versuchte Georg III. die Gestütspferde zu retten. Ein Teil wurde nach Mecklenburg transportiert, ein Teil verkauft und andere nach England eingeschifft. ${ }^{24}$ Nach Errichtung des Königreichs Westphalen 1807 besetzte der als König eingesetzte Jerome Bonaparte Neuhaus erneut mit brauchbaren und leistungsfähigen Zuchtpferden und verbesserte die Weiden ganz erheblich..$^{25}$ Jerome hob das zu dieser Zeit einzige noch verbliebene braunschweigische Gestüt „Harzburg“ auf und verfügte die Überführung nach Neuhaus. Über 100 Pferde wurden nun zusätzlich auf die Sollingweiden gestellt. ${ }^{26}$ 1811 besuchte Jerome neben der Spiegelglashütte in Amelith auch das Gestüt Neuhaus. Dafür wurde extra ein Weg angelegt, der für die königliche Kutsche geeignet war. Er ist heute noch weitgehend vorhanden und führt leicht geschwungen über die „Alte Schmacht“ in Richtung Neuhaus. ${ }^{27}$ Als sich 1813 das Ende des Königreichs Westphalen abzeichnete, wurde der Bestand in Neuhaus auf 100 Pferde reduziert und 28 Pferde nach Memsen abtransportiert. Um das Blut aufzufrischen, wurden Hengste und Stuten aus England importiert. ${ }^{28}$

\section{$3.4 \quad 1813-1843$}

Der Bestand wuchs schnell wieder an, und 1817 konnten die Marställe komplett durch die Pferde aus Neuhaus und Memsen versorgt werden. In Neuhaus gab es 775 Pferde der Reitrasse, von denen 568 Fohlen geboren wurden. ${ }^{29}$ Aus der nachfolgenden Zeit gibt es Aufzeichnungen, die Besonderheiten des Gestüts wiedergeben. So wirkte in Neuhaus von 1814-1839 der Förster und spätere Oberförster Johann Friedrich Georg, der ab 1824 ein Tagebuch führte. Hier vermerkte er, dass vor allem das königliche Gestüt mit seinen kostbaren Isabellen-Hengsten Leben in das Sollingdorf brachte. 16.000 Taler hätte jedes der von England herübergebrachten Tiere gekostet und viel Pflegepersonal wäre für sie nötig gewesen. Und beim Sollingdichter Heinrich Sohnrey kann man ergänzend dazu lesen, dass zusätzlich prachtvolle Schimmel nach Neuhaus gebracht und von Gestütsangestellten geführt worden seien. Diese wären in roter Uniform (der englischen Jagduniform, von

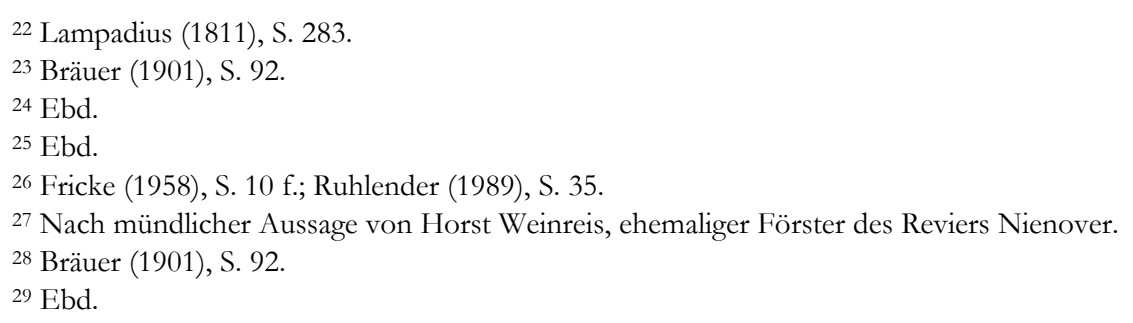


Einheimischen spöttisch „Affenjacke“ genannt) gekleidet gewesen, zur Freude von Jung und Alt. Als Georg zum Reitenden Förster (= Oberförster / Forstmeister) befördert wurde, bekam er aus dem Gestüt einen wertvollen Goldfuchs zum persönlichen Gebrauch von Herzog Adolf von Cambridge, dem Vizekönig von Hannover, geschenkt. Der Herzog weilte des Öfteren in Neuhaus, um zu jagen..$^{30}$

1833 wurde das Gestüt Memsen eingezogen und Neuhaus zum Hauptgestüt erhoben. Der Bestand war auf drei Hengste und 66 Zuchtstuten festgesetzt. Jedes Jahr mussten 23 bis 25 Remonten an die Marställe abgeliefert werden. ${ }^{31}$ Weitere Verbesserungen hielten Einzug. Es wurde jetzt bei schlechten Wetterverhältnissen zugefüttert und auch schützende Schuppen aufgebaut. Die Weiden wurden von Steinen abgelesen und mit hohen Mauern umgeben. ${ }^{32}$ Diese Maßnahmen gestalten bis heute die Kulturlandschaft um Neuhaus: weite Weiden, die von hohen Mauern umgeben sind und auf denen sich von Frühjahr bis Herbst edle Pferde tummeln (Abb. 5).

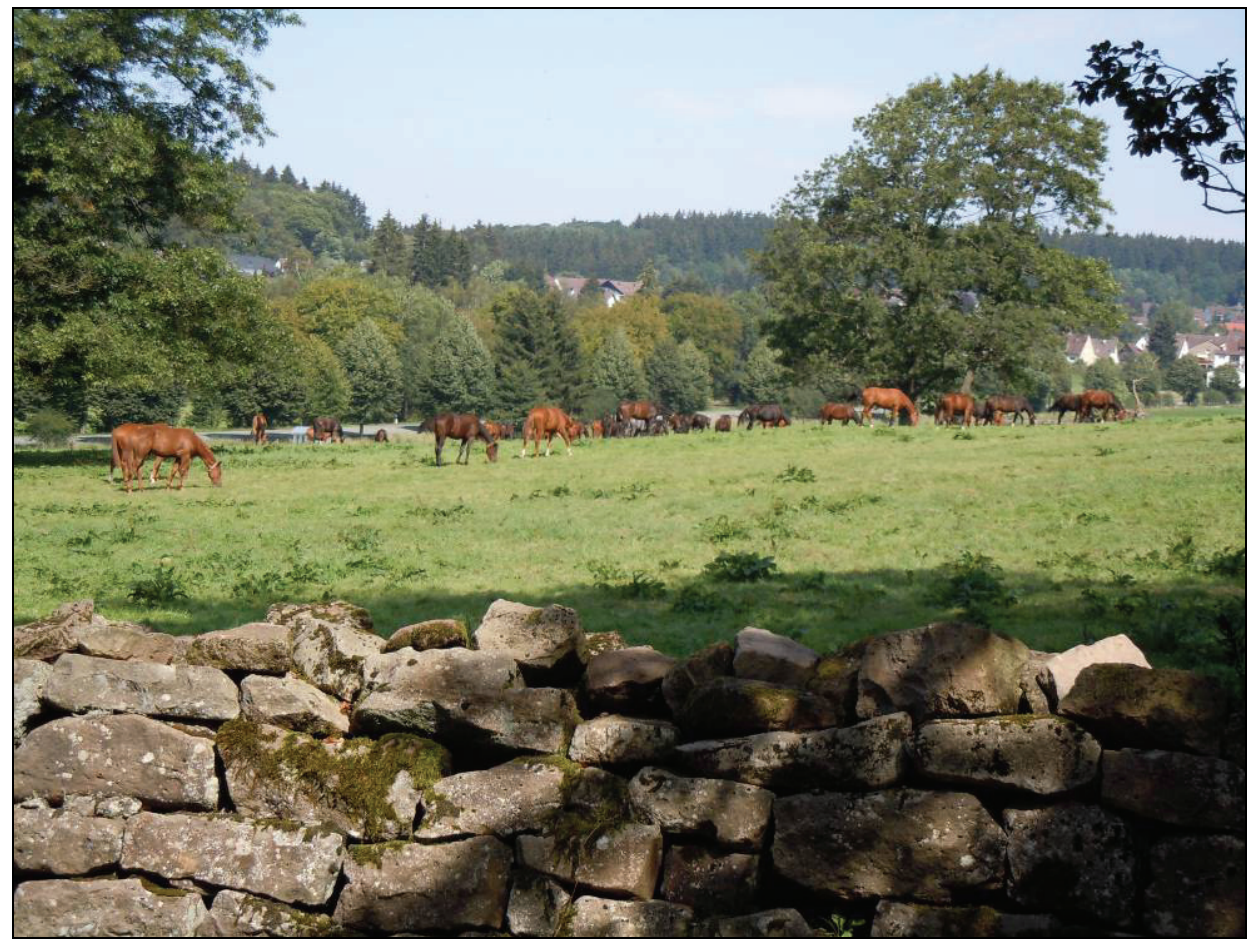

Abb 5: Die Nachtweide vor Neuhaus mit weidenden Hannoveranern und den typischen Mauereinfassungen (Detlef Creydt 2013).

\footnotetext{
${ }^{30}$ Georg (1953), S. 5.

31 Bräuer (1901), S. 92.

32 Fricke (1958), S. 11.
} 
Im Jahr 1843 fand die erste Ablieferung von Remonten statt. Die Pferde waren jedoch recht klein. Es wurden Untersuchungen angestellt, die ergaben, dass das raue Klima in Neuhaus zwar für die Zucht von Reitpferden tauge, für die Züchtung des Kutschschlages aber nachteilig sei. Deshalb wurden die Fohlen der Kutschrasse nach Memsen gebracht und dort aufgezogen. ${ }^{33}$ In Neuhaus züchtete man fortan nur noch den Reitschlag.

Im Jahrbuch für Pferdezucht findet sich 1842 ein Beitrag über das Gestüt Neuhaus. Dieser zeitgenössische Bericht gibt umfassend Auskunft über den seinerzeitigen Zustand des Gestüts. Die Weiden waren in sechs fast gleichgroße Abteilungen aufgeteilt und mit 1,60 Meter hohen Mauern umgeben. Der Autor berichtet, dass der ursprünglich öde Boden in den letzten 20 Jahren maßgeblich verbessert worden war, indem eine „unermeßliche Menge von Steinen“ abgelesen wurden und Dünger aufgebracht worden war. ${ }^{34}$ So seien nahrhafte Weiden und Wiesen entstanden. Zum Schutz gegen den Nordwind wurden Fichtengruppen angepflanzt, unter die sich die Pferde zukünftig bei schlechtem Wetter oder Hitze würden flüchten können. ${ }^{35}$ Die Gestütsgebäude lagen im Mittelpunkt der Anlage:

„Die Gebäude bilden zwei Höfe, wovon einer den Hengstfohlen, der andere den Zuchtstuten und Stutenfüllen gewidmet ist, eine Mauer von 7 Fuß Höhe scheidet diese Abtheilungen. Die Face ${ }^{36}$ eines dieser Höfe bildet das Hauptgebäude mit den Wohnungen des Großstallmeisters und des Gestüte-Chefs. Rechts und links liegen die Wohnungen einiger Stallknechte und communizieren mit Stallungen für Hengstfohlen, welche zusammen 42 Stände enthalten; jeder Stand ist $91 / 2$ Fuß ${ }^{37}$ lang, 5 Fuß breit. Auf einer andern Seite findet man die Stallungen für das Hornvieh, die Schweine und das Geflügel der Gestütebeamten; endlich die Schmiede, die Feuerspritzen und anderes Löschwerkzeug, das Waschhaus und die Bäckerei.“"38

Über die „Stüterei“ schrieb der Autor:

„Der zweite Hof bildet, gleich dem ersten, ein längliches Viereck und enthält die Wohnung des Tierarztes und des Aufsehers. Diese Wohnungen communizieren mit zwei Stallungen, deren jede 40 Stände von 9 Fuß 9 Zoll in's Geviert enthält, zum Aufenthalt für eine Mutterstute mit ihrem Füllen. Krippen und Raufen sind darin so angebracht, daß das Füllen mit seiner Mutter fressen kann.

Die Stallung der nicht trächtigen Mutterstuten und der Stutenfüllen von 2 bis 4 Jahren, enthält 73 Stände, jeden von 91/2 Fuß Länge und 4 Fuß Breite. In einem letzten

\footnotetext{
33 Bräuer (1901), S. 92.

34 Tennecker (1842), S. 218.

35 Ebd., S. 218. Auf der Nachtweide existieren solche Baumgruppen noch heute.

36 Vorderseite.

371 hannoverscher Fuß (seit 1837) = 12 Zoll = 0,292 Meter.

38 Tennecker (1842), S. 218 u. 219.
} 
Stall befinden sich 8 große Abtheilungen zur Wohnung für 40 entwöhnte Hengstfohlen.“39

Weiterhin erfahren wir, dass die Mutterstuten größtenteils in der zweiten Generation von Arabern aber auch von Persern und Engländern abstammten. Die Pferde waren rein braun, ohne jegliche weiße Abzeichen. ${ }^{40}$

\subsection{Die preußische Zeit}

Das Gestüt Neuhaus wurde 1867/68 nach der Annexion Hannovers durch PreuBen dem Remontedepot Hunnesrück zugeschlagen. Es war nun nur noch ein Vorwerk. 1900 lief der Pachtvertrag mit der Forstverwaltung aus. Das Vorwerk Neuhaus wurde als Remontedepot aufgegeben und dem staatlichen Forstamt unterstellt. In das leer stehende Amtshaus, mittlerweile zum Schloss umgebaut, zog nun die Oberförsterei. ${ }^{41}$ Die Gestütsgebäude wurden zu Wohnungen für 13 Waldarbeiterfamilien aus Schönhagen ausgebaut. Das 275 Hektar große Areal wurde anschließend z. T. auf der „Bruchweide“ und dem „Zweiten Berg“ unterhalb der „Turmweide“ aufgeforstet, z. T. an kuhhaltende Bauern verpachtet. ${ }^{42}$ Jetzt weideten Kühe statt edler Reitpferde im Solling. Die Sandsteintrockenmauern, die als Weideeinzäunung gedient hatten, wurden teilweise abgetragen und zum WaldstraBenbau verwendet. Heute stehen die noch vorhandenen Mauern unter Denkmalschutz.

\subsection{Neuhaus als Sommerweide}

Nachdem 1921 das Gestüt Hunnesrück dem Landesgestüt Celle unterstellt worden war, diente Neuhaus erneut als Sommerweide. Die Junghengste standen in Silberborn, die Stuten in Neuhaus. Die ein- und zweijährigen Stuten wurden auf die Hunnesrücker Weiden getrieben. Nach dem Zweiten Weltkrieg ging es mit der Zucht des Hannoverschen Warmblutpferdes wieder bergauf. Neuhaus diente weiterhin als Sommerweide. Nachdem Hunnesrück-Erichsburg die Nachfolge des ostpreußischen Gestüts Trakehnen angetreten hatte, wurde 1952 ein Vertrag mit der niedersächsischen Forstverwaltung geschlossen, so dass auch Neuhäuser Weiden für den Sommerauftrieb von Stuten und Fohlen genutzt werden konnten. Hannoveraner und Trakehner Pferde weideten jetzt gemeinsam in und um Neuhaus. ${ }^{43}$ Bundespräsident Heuss war es, der 1955 Neuhaus als die neue Heimat der Trakehner bestimmte. Er ließ zwei Ställe und ein Wohnhaus errichten, so dass die

\footnotetext{
39 Tennecker (1842), S. 219.

40 Ebd., S. 220.

41 Bräuer (1901), S. 90.

42 Ruhlender (1998), S. 80.

43 Mündliche Mitteilung von Friedrich Wegener, Gestütsleiter von Hunnesrück (1973 - 1987).
} 
Pferde auch im Winter in Neuhaus verbleiben konnten. Auch wenn die Deckstation in Erichsburg verblieb, hieß es dennoch ab dieser Zeit „Ostpreußengestüt Neuhaus".44

Heute ist Neuhaus immer noch Sommerweide der Hengstaufzuchtstation Hunnesrück. Jedes Jahr wird ein neuer Jahrgang Hannoveraner mit 50 Hengsten auf die Weiden von Neuhaus gestellt. Diese Kulisse hat letztendlich auch mit dafür gesorgt, dass im 20. Jahrhundert ein boomender Fremdenverkehr einsetzte, der den Ort wirtschaftlich und siedlungsmäßig stark geprägt hat. Es kam zu einer regen Bautätigkeit von Pensionen, Hotels und Gastwirtschaften. 1977 erreichte Neuhaus seinen Höhepunkt als „Staatlich heilklimatischer Kurort“ mit 186.823 Übernachtungen. ${ }^{45}$ Sicher ist, dass die Trakehner in Neuhaus ein fester Bestandteil der Fremdenverkehrswerbung seien. Vor allem Pferdefreunde würden Tagesausflüge zum Anlaß nehmen, diese Pferde zu besichtigen, so der Tägliche Anzeiger Holzminden im Oktober 1980.46 Der Bürgermeister Schwerdtfeger spricht von vielen Übernachtungsgästen, die nur wegen ,ihrer Trakehner“ nach Neuhaus kämen. ${ }^{47}$

In den 1980er Jahren ging der Fremdendverkehr stark zurück. Das lag sicher zum Teil am Abzug der Trakehner aber auch an veränderten Reisezielen und höheren Erwartungen an die Qualität der Unterkünfte. Außerdem kam noch hinzu, dass nach der Grenzöffnung zur ehemaligen DDR Berliner Gäste wegblieben, die bis dahin aufgrund der schnellen Erreichbarkeit einen Großteil der Übernachtungen ausgemacht hatten. Diese Faktoren zusammen bewirkten einen starken wirtschaftlichen Rückgang des Ortes.

\section{Exkurs: Rettung der Trakehner durch die Sollinggestüte}

Der Zweite Weltkrieg hätte fast das Ende der Trakehnerzucht bedeutet. Doch die Sollinggestüte - hier vor allem Hunnesrück mit seinen Vorwerken - konnten das Aussterben dieser traditionsreichen Pferderasse in Deutschland verhindern. War es doch in Neuhaus, wo Bundespräsident Theodor Heuss die neue Heimat der Trakehnerpferde sah.

\subsection{Ostpreußengestüt im Solling}

Von den rund 1.300 Beschälern und ca. 36.000 Zuchtbuchstuten aus Ost- und Westpreußen erreichten nur etwa 1.500 während und nach dem Zweiten Weltkrieg den Westen. Von ihnen standen letzten Endes nur noch 45 Deckhengste und 650

\footnotetext{
${ }^{44}$ Mündliche Mitteilung von Armin Lattke, ehemaliger Mitarbeiter des Staatshochbauamtes Northeim.

45 Ruhlender (1998), S. 152 u. 190.

46 Täglicher Anzeiger Holzminden (TAH) vom 25. Oktober 1980, S. 23.

47 TAH vom 30. Juli 1980, S. 19.
} 
Stuten zur Zucht zur Verfügung. ${ }^{48}$ Das Gestüt Hunnesrück und seine Vorwerke spielten bei der Rettung der Trakehner eine herausragende Rolle. Hier waren schon die Hengstanwärter des Jahrgangs 1943 sowie einige Stuten untergebracht worden, und hier begann parallel neben der schon beschriebenen Haltung der Hannoveraner zusätzlich die Zucht der Trakehner. Bereits 1946 standen 50 Stuten und vier Hengste zur Verfügung. ${ }^{49}$ Das nach dem Krieg neugegründete Land Niedersachsen unterstützte den im Westen neu entstandenen „Trakehner Verband“ bei der Gründung einer neuen Zuchtstätte. Das Land stellte Weiden in Hunnesrück und Relliehausen zur Verfügung sowie eine Deckstation in Erichsburg. Ab 1952 wurden auch die Weiden in Neuhaus genutzt. Als Bundespräsident Theodor Heuß 1955 Neuhaus einen Besuch abstattete und die Trakehner Herde besichtigte, beschloss er, dass ihnen hier eine neue Heimat geschaffen werden sollte. Daraufhin wurden zwei Ställe und ein Wohnhaus errichtet und hier das „Ostpreußengestüt Hunnesrück“ hinverlegt, das nunmehrige „Ostpreußengestüt Neuhaus“ (Abb. 6). 50

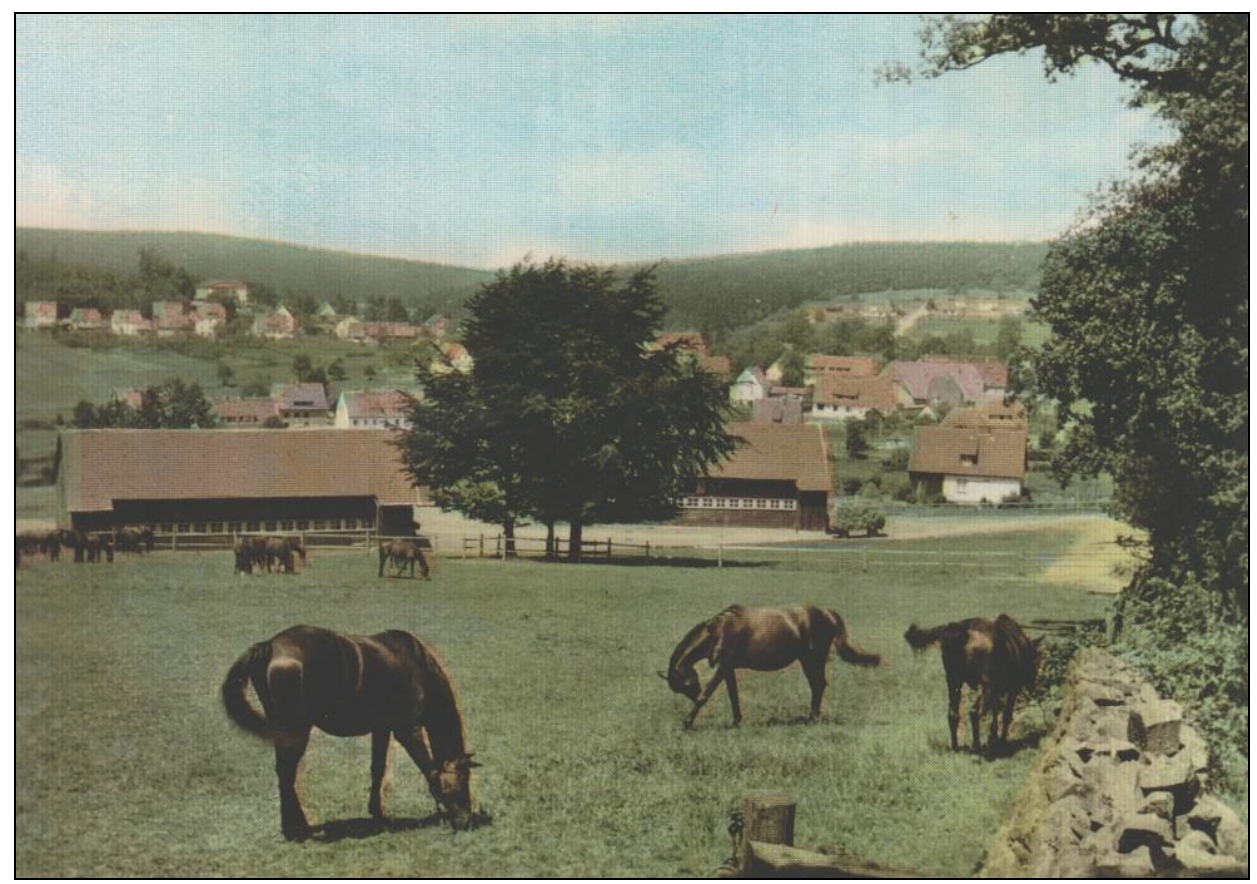

Abb. 6: Trakehner auf der Nachtweide mit dem „Ostpreußengestüt Neuhaus“, 1964 (Luftkurort Neuhaus, Bildserie, Bildarchiv des Heimat- und Geschichtsvereins für Landkreis und Stadt Holzminden e.V.).

\footnotetext{
48 Heck u. Schietinger (1986), S. 47.

${ }^{49}$ Köhler (1975), S. 23.

50 TAH vom 30. Juli 1980.
} 
Das Land Niedersachsen übernahm einen Teil der Kosten. Nach Gründung der Bundesrepublik Deutschland beteiligte sich ab 1948 auch der Bund zu fast gleichen Teilen an der Finanzierung. Damit war eine staatliche Absicherung erreicht. Mit diesen Voraussetzungen waren Hunnesrück und später Neuhaus die tragenden Säulen der Trakehnerzucht in Deutschland. Neuer Leiter des Gestüts wurde Ernst Ehlert, der schon in Trakehnen die Zucht geleitet hatte. Die Rettung der Trakehner in Deutschland ist weitgehend durch das Ostpreußengestüt Hunnesrück, später Neuhaus, möglich gewesen. ${ }^{51}$

Das Land Niedersachsen stellte dem Ostpreußengestüt Hunnesrück bzw. Neuhaus Trakehnerhengste für die in Erichsburg untergebrachten Stuten zur Verfügung. Das Augenmerk lag dabei auf der Zucht und Aufzucht von Beschälern. Dies wurde mit großem Erfolg umgesetzt. Bis Anfang der 70er Jahre konnten über 60 gekörte Hengste gezogen und größtenteils auch aufgezogen werden. Nach der Körung in Celle wurden die Hengste über ganz Deutschland verteilt. Die hohe Anzahl hat die Trakehnerzucht in Deutschland vor einem Mangel an Hengsten bewahrt und ein Überleben dieser Rasse bewirkt. ${ }^{52}$ Anfangs stellte das Landgestüt Celle die Hauptbeschäler zur Verfügung, aber Ende der 1960er Jahre war es dazu nicht mehr in der Lage. Der Verband musste selbst für Beschäler sorgen. Dabei bewies er wenig Geschick, da einige dieser Hengste durch Tod, Verletzung oder Deckunlust ausfielen. Hinzu kam, dass 1981 der Trakehnerverband mit dem Land Niedersachsen einen neuen Vertrag über das Ostpeußengestüt abschloss. Die Herde wurde daraufhin um zehn Pferde reduziert, was das Land veranlasste, den Zuschuss zu kürzen. Dies konnte der Verband finanziell nicht mehr auffangen und beschloss alle Pferde in Hunnesrück und Erichsburg zu verkaufen und das „Ostpreußengestüt Neuhaus“ per 30. Juni 1982 aufzulösen. ${ }^{53}$

\section{$5 \quad$ Fazit}

Die Pferdezucht um Neuhaus ist schon seit Mitte des 16. Jahrhunderts nachweisbar. Seit dieser Zeit haben bis auf einige Jahre ununterbrochen Pferde auf den umliegenden Hängen geweidet. Dies führte zu einer noch heute weitflächigen offenen Landschaft, die z. T. immer noch aus Pferdeweiden besteht. Markant und landschaftsprägend sind die bis zu zwei Meter hohen Buntsandsteinmauern, mit denen die Weiden eingefasst worden sind. Die heute noch vorhandenen Mauern weisen eine Länge von ca. 10 Kilometern auf und wurden unter Denkmalschutz gestellt.

Auf die lange Zeit der Nutzung der um Neuhaus herumliegenden Flächen weisen viele Flurnamen hin, die in Verbindung mit Begriffen für Pferde oder Weide stehen. Die im ehemaligen braunschweigischen Teil des Sollings vor Neuhaus vor-

\footnotetext{
51 Heling (1962), S. $101 \mathrm{f}$.

52 Schilke (1982), S. 199.

${ }^{53}$ Ebd., S. 200 ff.
} 
handenen Flurnamen sind als älter anzusehen als die im hannoverschen Teil. Die Siedlungsstruktur im ehemals hannoverschen Ortsteil von Neuhaus ist stark geprägt durch Gestütsbauten aus dem 18. Jahrhundert. Das heutige Schloss mit seinen Ställen und Nebengebäuden sowie das „Neue Gestüt“ mit dem heutigen „Haus des Gastes“ sowie einigen Dienstgebäuden, Kapelle und „Alte Schule“ ergeben ein noch weitgehend original erhaltenes Ensemble von Gebäuden gleicher Bauzeit. Die Landschaftsgestaltung und -nutzung hat dazu beigetragen, dass Neuhaus ein bedeutender Fremdenverkehrsort im Weserbergland im 20. Jahrhundert war. Das Bild der hellen und lichten Weiden mit edlen Hannoveranern ist immer noch ein aktuelles Postkartenmotiv.

\section{Literatur}

Bloß O (1975) Sollinger Heimatblätter. Beilage zum Täglichen Anzeiger Holzminden, Juli. Hüpke \& Sohn, Holzminden.

Bräuer C (1901) Die Gestüte des In- und Auslandes, Eine Beschreibung der bekanntesten Pferdezuchtanstalten der Haupt-, Land und Privatgestüte nebst Angaben ihrer Ziele und Erfolge. Schönfeld, Dresden.

Dossenbach M, Dossenbach HD, Köhler HJ (1977) Die großen Gestüte der Welt. Hallwag, Stuttgart.

Einbecker Morgenpost vom 2./3. Juli 1988. Rüttgerodt, Einbeck.

Fricke H (1958) Bilder aus der Geschichte von Neuhaus im Solling. Sohnrey, Neuhaus.

Heck H, Schietinger F (1986) Die berühmtesten Trakehner Deutschlands. Hengste, Stuten, Sportpferde ab 1945. Ahnert, Hannover.

Heling M (1962) Trakehnen. Das Hauptgestüt als Quell und Mittelpunkt der ostpreußischen Pferdezucht. BLV, München.

Hutten-Czapski M Graf v. (1974) Die Geschichte des Pferdes. Reprint [1876], Zentralantiquariat der DDR, Leipzig.

Köhler HJ (1975) Tempelhüter. Symbol der Trakehner Pferdezucht und des Landes Ostpreußen. Reich, Luzern.

Köhler HJ (1977) Hannoversche Pferde. Geschichte - Zucht - Erfolge. Reich, Luzern.

Lampadius WA (1811) Die Reise zu den sieben Schwestern am Rhein und an der Weser im Jahre 1810 in Briefen an einen Freund. Craz und Gerlach, Freyburg.

Landgestüt Celle (o. J.) Das Landgestüt Celle und die hannoversche Zucht. Celle. 
Mirus H (1981) Chronik der Stadt Dassel. Von der Grafschaft bis zur Gebietsreform 1974. Lax, Hildesheim.

Plümer E (1998) Der Landkreis Einbeck. Geschichte und Gegenwart. Börner, Einbeck.

Ruhlender O (1998) Neuhaus im Solling. Geschichte und Geschichten. Mitzkat, Holzminden.

Schilke F (1982) Trakehnerpferde einst und jetzt. 5. Aufl. BLV, München.

Täglicher Anzeiger Holzminden vom 30. Juli 1980 und 25. Oktober 1980. Hüpke \& Sohn, Holzminden.

Tacke E (1955) Zur Geschichte der „Stüterey am Solling“ (1665 - 1677). In: Northeimer Heimatblätter 1. Hahnwald, Northeim, S. 29-30.

Tacke E (1957) Die Bestallung des „,Wildenmarstellers und Holzförsters am Solling“, Hans Kleinschmidt, durch Herzog Julius von Braunschweig i. J. 1587. In:

Northeimer Heimatblätter 1. Hahnwald, Northeim, S. 13-16.

Tennecker S v. (1842) Jahrbuch für Pferdezucht, Pferdekenntniß, Pferdehandel, Pferdedressur und Roßarzneikunst auf das Jahr 1842. XVIII. Jg., Voigt, Weimar.

Weise E (1989) Geschichte von Schloss Nienover im Solling. Veröffentlichungen des Instituts für historische Landesforschung der Universität Göttingen. Lax, Hildesheim.

\section{Ungedruckte Quellen}

Georg B (1925) Familiengeschichte der Försterfamilie Georg. (Überarbeitete Fassung, maschinenschriftlich, 1953). 



\title{
Nutzungsgeschichte des Reinhardswaldes
}

\author{
Irina Kollo
}

\section{Einleitung}

„Vor ungefähr 700 Jahren lebte Graf Reinhard, dem alles Land zwischen Weser und Diemel gehörte. Er war ein besessener Spieler, doch war das Glück stets bei seinem Gegner, dem Bischof von Paderborn. Als der Graf wieder einmal verloren hatte, setzte er seine ganze Grafschaft aufs Spiel. Die Würfel fielen und er war ruiniert. So schnell gab sich Reinhard jedoch nicht geschlagen. Voller List fragte er den Bischof, ob es ihm vergönnt sei, noch eine letzte Aussaat und Ernte auf seinem Boden zu machen. Der Bischof war einverstanden. Aber was säte der Graf im Herbst? Nichts als Eicheln und Bucheckern! Die Dörfer ließ er niederbrennen und über die alten Hofstätten ging der Pflug. Im Frühjahr reckten sich die jungen Bäumchen, und es grünte talauf und talab. Als der Bischof im Herbst wiederkam, um seinen Besitz anzutreten, führte ihn der listige Graf hinaus in den Flur., Ihr seht ja, Herr Bischof, meine Ernte ist noch nicht so weit, Ihr müsst euch noch etwas gedulden“." ${ }^{\prime}$

Der Reinhardswald liegt in Nordhessen zwischen den Städten Kassel und Bad Karlshafen sowie Hannoversch Münden und Hofgeismar (Abb. 1). Im Norden und Osten wird er von der Weser begrenzt, im Südosten und Osten von der Fulda. Im Westen grenzt er an die Esse und im Nordwesten an die Diemel. Heute zieht der Reinhardswald mit dem „Urwald“ und dem Tierpark Sababurg jedes Jahr tausende Touristen an. 2005 haben allein 3.150 Besucher an Führungen im „Urwald

${ }^{1} \mathrm{Iba}(1998)$. 
Sababurg“ teilgenommen. ${ }^{2} \mathrm{Zu}$ vergangenen Zeiten entstanden in und um den Reinhardswald viele Sagen und Märchen. Wie schon die Gebrüder Grimm sehen auch heutige Autoren häufig etwas Magisches und Mystisches in diesem Wald. Steiner beschreibt seine Erfahrungen wie folgt: „Man geht zögernd, ein Rieseln im Nacken, die alten Götter scheinen nahe, wie im heiligen Hain. "3 Darüber hinaus wird die „malerische Schönheit“ des Waldes betont. ${ }^{4}$ Der frühere Waldzustand wird als vielfältig und undurchdringbar beschrieben. ${ }^{5}$ Es gab eine offene Waldgrenze, einen lockeren Übergang von Einzelbäumen zu einem lichten Wald, der mit der Entfernung zu Siedlungen und in schwer zugänglichen Teilen immer dichter wurde. Seit ca. 500 n. Chr. wurde der Wald von Menschen genutzt. In diesem Beitrag werden die ursprünglichen vier Nutzungsformen - die Jagd, der Holzschlag und der Vieheintrieb sowie die Rodung des Waldes, um landwirtschaftliche Flächen zu gewinnen - näher betrachtet.

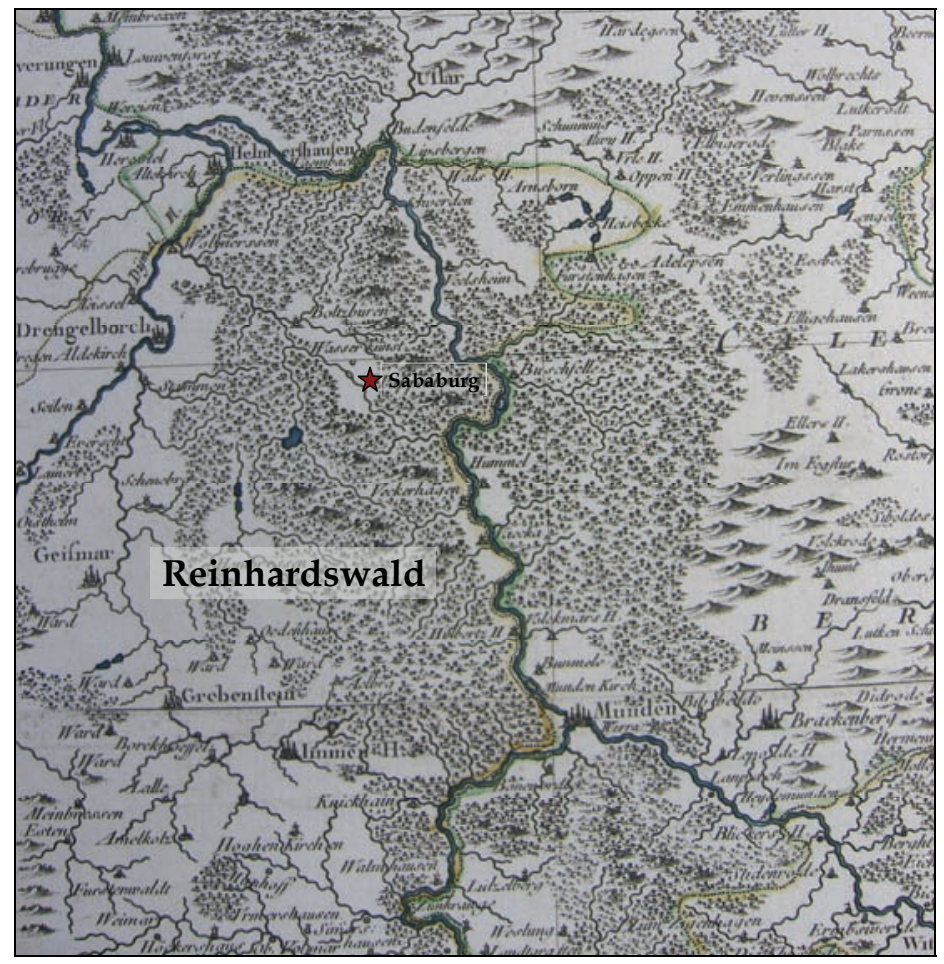

Abb. 1: Der Reinhardswald 1758 (Karte: SUB Göttingen, MAPP 7034, leicht verändert).

\footnotetext{
2 Piechocki u. Vogtmann (2006).

${ }^{3}$ Steiner (2002).

${ }^{4}$ Schumann (1994).

5 Tamm (2002).
} 


\section{Vom Hutewald zum Urwald}

\subsection{Hutewald}

Hutewälder sind Wälder, die als Weideplatz dienen. Da die Dreifelderwirtschaft nicht genügend Raum für Wiesen und Weiden bot, trieben die Bürger ihr Vieh im Sommer zur Mast in den Wald; im Winter sammelten sie trockenes Laub als Winterfutter und Stalleinstreu. 6 Diese Form der Bewirtschaftung beeinflusste den Wald in erheblichem Maße. Aufgrund des nährstoffarmen Futters mussten sehr große Flächen beweidet werden. ${ }^{7}$ Das Vieh lichtete den Waldboden weiträumig und verhinderte das Heranwachsen von jungen Trieben; Niederschläge und Sonne konnten ungehindert einfallen. Anstelle von Baumsprösslingen breiteten sich bodendeckende, weideresistente Pflanzen wie Heidekraut, Schlehe, Heckenrose und Wacholder aus. ${ }^{8}$ Auch die Holzqualität wurde beeinträchtigt, da junge Triebe älterer Bäume im Frühjahr geschädigt wurden und ungerade Wuchsformen entstanden. ${ }^{9}$ Zeitgenössische Bemerkungen verdeutlichen die negative Betrachtung der Waldweide vor dem Hintergrund der Holzproduktion:

„Die Hauptursache des Wälderverderbens findet man gewöhnlich im übertriebenen Weidegang und überhaupt in der Vernachlässigung der erforderlichen Waldhegung, wodurch der Nachwuchs junger Holzungen verhindert wird und wodurch der Wald mit der Zeit in eine Lichtung und endlich in eine Wüstung verwandelt werden muss. " ${ }^{10}$

Zwischen 1000 und 1350 n. Chr. wuchs die Bevölkerung und damit der Bedarf an Nahrung. Die Landesherren erlaubten jedoch keine Ausdehnung der Agrarflächen und eine damit verbundene Rodung von Teilen des Reinhardswaldes. Stattdessen wuchsen die Viehherden und rückten weiter in den Wald hinein. ${ }^{11}$

1532 erließ Philipp der Großmütige eine Forstordnung, die unter anderem bestimmte, dass Ziegen nur gehalten werden sollten, wenn man sich kein anderes Vieh leisten konnte, da diese den Wald besonders stark schädigten. ${ }^{12}$ Doch nicht nur die Bürger, auch die Landesherren nutzten die Waldweide. Die „Schweinemast" wurde in zwei Monaten im Herbst, zur Zeit der Eichel- und Bucheckernreife durchgeführt. Zu diesem Zweck wurden die Schweine der Umgebung vor der Schlachtung in den Reinhardswald getrieben. Dafür musste eine Gebühr an die Landesherren gezahlt werden. Diese Methode wurde im Laufe der Jahre immer besser kontrolliert, beispielsweise mit Brandzeichen, die die „mastberechtigten“

\footnotetext{
${ }^{6} \mathrm{Vgl}$. Koch (1998).

7 Rapp (2002a).

8 Schmidt (2002).

${ }^{9}$ Rapp (2002a).

${ }^{10}$ Hartig (1791).

11 Bonnemann (1984).

12 Vgl. Olischläger (2002).
} 
Schweine bekamen. ${ }^{13} 1571$ benannte eine Jagd- und Forstordnung bestimmte Gebiete zu hutefreien Zonen. Weitere Gesetze und Bestimmungen folgten, doch Hute und Holzinteressen ließen sich nicht vereinen. ${ }^{14}$ Brauchbares Holz wurde knapp, war jedoch zum Kochen und für den Hausbau lebensnotwendig. 1748 erließ Landgraf Wilhelm von Hessen das „Waldhute-Reglement vom Reinhardswalde". Jeder Stadt oder Gemeinde wurde eine bestimmte Fläche zur Hute zugewiesen. Außerdem wurden Viehart und -anzahl festgelegt. Ein Drittel des Waldes sollte geschont werden und wurde umzäunt. ${ }^{15} \mathrm{Um}$ dem Wald eine großflächige Verjüngung zu ermöglichen, sollten diese Flächen nach einiger Zeit gewechselt werden, was aber kaum umgesetzt wurde. ${ }^{16}$ In den genutzten Gebieten wurde der Baumbestand immer lichter und Holz wurde vom 18. zum 19. Jahrhundert immer knapper. Kriege lichteten den Wald durch Plünderei und große Feuer zusätzlich. ${ }^{17}$ Obwohl die Huteregeln immer strenger wurden und die Missachtung zu Strafen führte, wurden die Forstgesetze häufig gebrochen. Die Menschen im Reinhardswald waren arm und litten, wie auch ihr Vieh, häufig Hunger. Daher trieben sie das Vieh auch in gesperrte Gebiete und sammelten trotz Verbotes Früchte des Waldes wie Bucheckern. ${ }^{18} 1748$ wurden auf 100 ha Wald im Durchschnitt 47 Pferde, 90 Rinder, 298 Schafe, 11 Ziegen, 84 Schweine und 0,8 Esel gehalten. ${ }^{19} 1765$ wurde eine „Gesellschaft für Ackerbau“ gegründet, um die landwirtschaftliche Situation $\mathrm{zu}$ verbessern. ${ }^{20}$ Durch den Anbau von Futterklee auf den Brachflächen wurde zunehmend eine Stallfütterung des Viehes ermöglicht.

In der ersten Hälfte des 19. Jahrhunderts sollte die Waldweide zur Holzschonung vollständig abgeschafft werden. ${ }^{21}$ Im Reinhardswald wurde sie jedoch bis zum Ende des 19. Jahrhunderts praktiziert. Besonders die ärmere Bevölkerung, die nur wenig Land zur Verfügung hatte, nutzte den Wald weiterhin als Weideplatz. Im Gebiet des Forstamts Gahrenberg wurden noch bis $187596 \%$ der Rinder und $100 \%$ der Schafe in den Wald getrieben. ${ }^{22}$ Ortsbezeichnungen wie Kälberhute, Kuhberg, Melkplatz und Schweinseiche zeugen von dieser Nutzungsart. ${ }^{23}$ Erst als das Gebiet Ende des 19. Jahrhunderts preußisch wurde, konnte die Waldhute abgeschafft werden, indem neue Weide- und Ackerflächen gerodet und bereitgestellt wurden und Flächenverlust entschädigt wurde. ${ }^{24}$ Die Wälder wurden mit Fichte

\footnotetext{
13 Koch (1998).

14 Olischläger (2006).

15 Rapp (2002b).

16 Höfer (1947).

17 Rapp (2002b).

18 Olischläger (2006).

${ }^{19}$ Höfer (1947).

20 Olischläger (2006).

${ }^{21}$ Hasel (1985).

22 Höfer (1947).

23 Rapp (2002a).

24 Olischläger (2006).
} 
(Picea abies) und Buche (Fagus sylvatica) aufgeforstet. Heute heißt es im hessischen Forstgesetz ( $\mathbb{S} 21$ Forstliche Nebennutzung), dass Forstnebennutzungen (z. B. Streu- und Grasnutzung, Waldweide) nur so ausgeübt werden dürfen, dass „die ordnungsgemäße forstliche Bewirtschaftung nicht gefährdet wird“.

\subsection{Der „Urwald Sababurg“}

Der „Urwald Sababurg“ war das erste Naturschutzgebiet Hessens und ist eines der ältesten in Deutschland. Per Definition ist ein Urwald „ein von Menschen nicht kultivierter Wald mit reichhaltiger Fauna". ${ }^{25}$ Wie ein Hinweis im Eingangsbereich des „Urwalds Sababurg“ zeigt, entspricht der Wald dieser Definition nicht:

„Das Naturschutzgebiet ist kein Urwald im Sinne eines unberührten Naturwaldes. Es handelt sich vielmehr um forstlich nicht mehr genutzte Flächen, die aus einem ehemaligen Hutewald (Wald zum Hüten von Vieh) hervorgegangen sind.“

Aufgrund seines urtümlichen Erscheinungsbildes wurde die Bezeichnung trotzdem gewählt. Noch heute erscheint der Wald als typischer Hutewald: Kennzeichnend dafür sind Hutesteine und einzeln stehende Eichen (Quercus robur), Buchen und Hainbuchen (Carpinus betulus), die zum Teil ein sehr hohes Alter erreicht haben (Abb. 2). Die Baumkronen setzen tief an und sind sehr breit. Auch Borstgras (Nardus stricta) und Adlerfarn (Pteridium aquilinum) sind typisch für alte Hutewälder und können überall im Reinhardswald gefunden werden (Abb. 2). ${ }^{26}$

25 Zeit-Lexikon (2005).

${ }^{26}$ Schmidt (2006). 

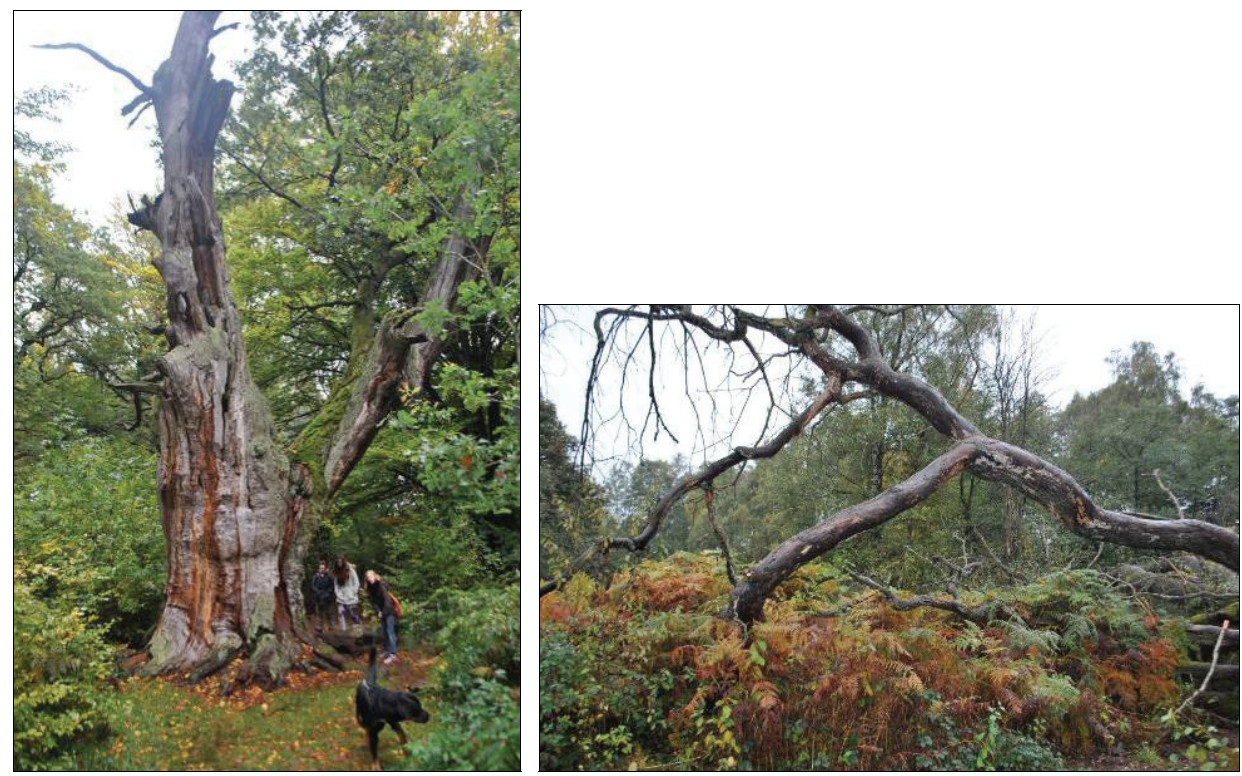

Abb. 2: Eichenstumpf im „Urwald“ (links), Adlerfarn im Herbst (rechts) (eigene Aufnahmen 2012).

Obwohl die Waldweide Ende des 19. Jahrhunderts abgeschafft wurde, befand sich der „Urwald“ weiterhin unter dem Einfluss von starkem Verbiss, da er von 1848 bis 1967 innerhalb eines umzäunten Wildschutzgebietes lag. ${ }^{27}$ Der Wald wurde somit als Hutewald „konserviert“. 1905 wurden 160 ha des Reinhardswaldes auf Wunsch des zur damaligen Zeit berühmten deutschen Kriegsmalers und Professors an der Kunstakademie Düsseldorf Theodor Rocholl aus der Nutzung genommen. ${ }^{28}$ Dieser hatte bereits als Schüler den Reinhardswald besucht und ihn immer wieder als Inspiration für seine Werke genutzt. Schon 1907 wurden auf Bestreben Rocholls und Hugo Conwentz', Leiter der 1906 eröffneten „Staatlichen Stelle für Naturdenkmalpflege in Preußen“"29, offiziell 61-66 ha des Waldes als „Malerreservat“ geschützt. ${ }^{30} 1908$ wurde das Schutzgebiet zum ersten Mal in der Fachliteratur erwähnt:

„Ein ausgedehntes Reservat wurde in neuester Zeit in der Oberförsterei Hombressen, Schutzbezirk Sababurg, Forstort Kuhberg [...] eingerichtet [...] da dieser Waldteil mit seinen reizvollen Baumformen nicht nur vielfach von Touristen, son-

\footnotetext{
27 Schmidt (2006).

28 Schumann (1994).

${ }^{29} \mathrm{BfN}(2006)$.

${ }^{30}$ Schmidt (2006).
} 
dern auch zu Studienzwecken von Malern [...] besucht wird, hat der Minister diese Fläche von 70 ha zur Erhaltung bestimmt. “31

1914 wurde die Fläche „naturwissenschaftlich inventarisiert“ und Fotografien und Abbildungen angefertigt. ${ }^{32}$ Die Größe des geschützten Gebietes variierte stark im Laufe der Jahre bis es seine jetzige Ausdehnung von 92 ha zugesprochen bekam. 1935 wurden mit dem Reichsnaturschutzgesetz erstmals deutschlandweit Gesetze zum Schutz der Natur erlassen. ${ }^{33}$ Der „Urwald Sababurg“, der als „echter deutscher Wald“ im Nationalsozialismus einen hohen Stellenwert einnahm, ${ }^{34}$ wurde mit der Anmerkung: „Der urwaldartige Bestand des Naturschutzgebietes ist eins der wertvollsten Naturschutzgebiete des Deutschen Reiches“" offiziell als Schutzgebiet aufgenommen..$^{35} 1933$ wurde vermutlich durch fahrlässige Wanderer ein Feuer verursacht, das starke Schäden im Schutzgebiet anrichtete und mehrere alte Buchen und Eichen zerstörte. ${ }^{36}$ Ungefähr 4 ha des Waldes waren betroffen. ${ }^{37}$ Jedoch fielen nicht alle Bäume dem Feuer vollständig zum Opfer. Noch heute kann man ausgebrannte Eichen und Bäume mit Brandspuren von damals sehen.

Trotz seines Naturschutzstatus' wird der Wald weiterhin von Menschen beeinflusst. Es findet Jagd, Pflanzenpflege und eine Strukturierung für den Tourismus statt. ${ }^{38}$ Jungwuchs wird gestattet und ist erwünscht. Bedrängt er jedoch die sehr alten Bäume, wird er entfernt, um diese zu erhalten. ${ }^{39}$ Der Urwald Sababurg kann also heute als Naturmuseum verstanden werden. Jedoch ist der Verfall der Altbäume nicht aufzuhalten (Abb. 3). Besonders Stürme, Blitze und Feuer, aber auch Umweltverschmutzung schaden den alternden Bäumen. Die Vorstellungen von Naturschutz haben sich in über 100 Jahren ebenfalls gewandelt. Zur Zeit der Gründung des Naturschutzgebietes stand vor allem das ästhetische Bild der alten Bäume im Vordergrund, heute hat ein hundertjähriges Naturschutzgebiet allein durch sein Alter einen hohen Wert für den Naturschutz, da es über so lange Zeit forstwirtschaftlich ungenutzt war. ${ }^{40}$

\footnotetext{
31 Schmidt (2006).

32 Ebd.

33 BfN (2006).

34 Vgl. Burmeister (2006).

35 Schmidt (2006).

36 Schumann (1994).

37 Rapp (2006).

38 Ebd.

39 Schumann (1994).

40 Schmidt (2006).
} 


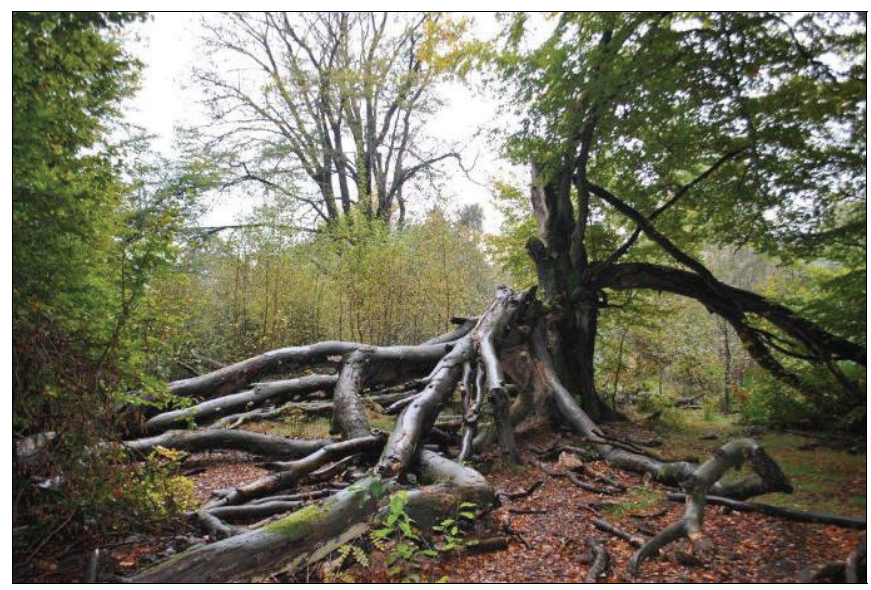

Abb. 3: Beschädigter Baum im „Urwald“ Sababurg (eigene Aufnahme 2012).

\section{Jagd und Tierpark}

\subsection{Jagd im Reinhardswald}

Der Reinhardswald war viele Jahrhunderte lang ein geschätztes Jagdgebiet. Seit dem Mittelalter war die Jagd ein Privileg der Landesherren; Bauern war das Tragen von Waffen sowie die Jagd im Allgemeinen verboten. ${ }^{41}$ Wilderei wurde mit Folter oder dem Tod bestraft. ${ }^{42}$ Der Adel war für die Bekämpfung von Raubtieren sowie die Minimierung von Wildschäden zuständig. Gleichzeitig konnte er für diesen Dienst sowie für die Nutzungsrechte Gegenleistungen in Form von Fron- und Jagddiensten verlangen. ${ }^{43}$ Beispielsweise waren bei Treibjagden viele Helfer notwendig und auch die Jagdhunde mussten von den Bürgern gehalten werden. ${ }^{44}$ Die Waldweide wirkte sich störend auf die Jagd aus, da die Viehherden mit dem Wild um Nahrung konkurrierten. Außerdem vertrieben die Hütehunde das Wild von den Weideflächen, sodass dort eine Jagd nicht möglich war. Aus diesen Gründen durften Haustiere in Teilen des Waldes nicht weiden; der Wildbestand stieg an und es kam zu vermehrten Wildschäden auf den Feldern. Die Bevölkerung begann sich zu wehren. Per Gesetz wurde die Jagdberechtigung im Juli 1848 auf die Gemeinden übertragen. Es folgte eine drastische Reduzierung des Wildes im Gebiet des Reinhardswaldes. ${ }^{45}$

\footnotetext{
${ }^{41}$ Rapp (2002b).

42 Koch (1998).

43 Bode u. Emmert (1998).

44 Koch (1998).

${ }^{45}$ Rapp (2002b).
} 


\subsection{Der Tierpark}

Landgraf Wilhelm II. begann 1490 inmitten des Reinhardswaldes aus der Ruine einer aus dem 14. Jahrhundert stammenden Burg das Jagdschloss Sababurg mit Gestüt zu errichten. 1492 war der Bau vollendet und sollte 1508 erweitert werden. Jedoch starb der Landgraf 1509 und der Bau wurde erst 1519 durch Philipp den Großmütigen vollendet, der dort neben den Pferden auch Rinder und Schafe züchtete und die Burg vor allem auch weiterhin als Jagdschloss nutzte. 1563 soll er „150 und mehr Säue" an einem Tag erlegt haben. ${ }^{46}$ Das Jagdschloss bot Platz für viele Besucher, mit denen Philipp Jagden und Turniere veranstaltete und ausgiebige Feste und Bälle feierte. ${ }^{47}$ Sein Sohn Landgraf Wilhelm IV. erweiterte das Schloss, legte Teiche an und errichtete 1571 am Fuß der Burg den privaten „Thiergarten“, der einen Umfang von $5 \mathrm{~km}$ hatte und von einer Dornenhecke umgeben war (Abb. 4). 20 Jahre später wurde die Dornenhecke durch eine $4 \mathrm{~m}$ hohe Steinmauer ersetzt. Mit dem Thiergarten sollte zunächst für den Fortbestand des Wildes gesorgt werden, da dieses durch Jagd und Waldausdünnung reduziert wurde. Neben einheimischen Arten wurden Damwild aus Dänemark, Gämsen aus den Alpen, Elche aus Schweden sowie Rentiere gehalten. ${ }^{48}$ Im Dreißigjährigen Krieg (16181648) wurde das Schloss feindlich besetzt und verwüstet. Es wurde 1651 von Landgraf Wilhelm VI. wiederhergestellt und von dessen Sohn Karl 1701 restauriert. Im Siebenjährigen Krieg (1756-1763) wurde die Burg erneut besetzt, danach aber von Friedrich II. wieder in Stand gesetzt und erneut als Jagdschloss verwendet. Auch im Tierpark selbst wurde gejagt. Bei der eingestellten Jagd trieb man, meist vor einem Fest, Wild in einen eingezäunten Bereich. Am Tag des Festes standen Männer in Ständen und das Wild wurde ihnen von Hunden oder Menschen direkt in die Sicht getrieben, sodass es mit einer Schusswaffe oder Saufeder erlegt werden konnte. Zur Durchführung von Parforcejagden wurden 1770 sechs Schneisen und ein Umlauf entlang der Tierparkmauer hinzugefügt. ${ }^{49}$ Am Ende des 18. Jahrhunderts stand das Schloss erneut leer und 1826 wurden Teile der Gemäuer abgerissen..$^{50}$

\footnotetext{
46 Rohde (2002).

${ }^{47}$ Ebd.

48 Rapp (2002b).

49 Ebd.

${ }^{50}$ Rohde (2002).
} 


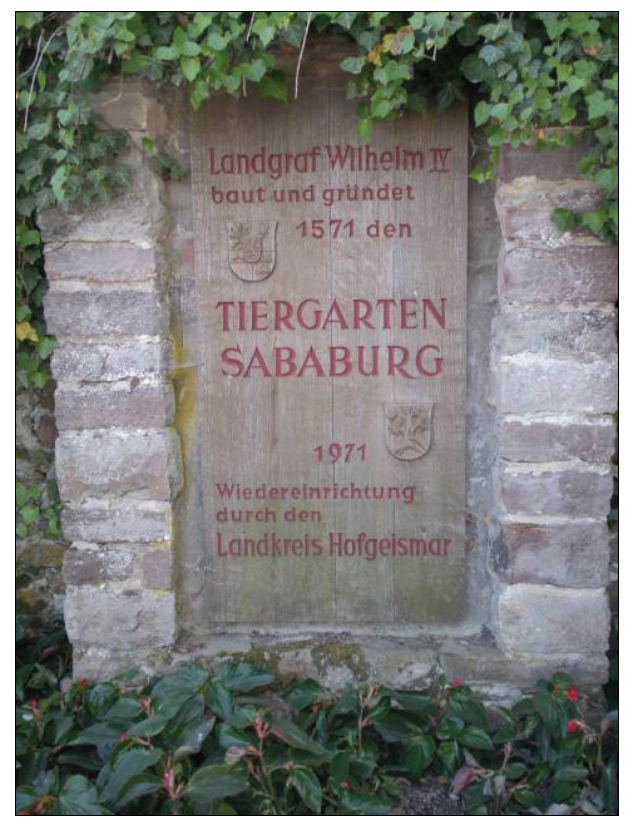

Abb. 4: Schild am Tierparkeingang (eigene Aufnahme 2012).

1957 wurde die Burg vom Land Hessen restauriert und für die Öffentlichkeit zugänglich gemacht. Die Außenmauer und die Aufteilung des heutigen Tierparks entsprechen noch der barocken Anlage. Das 1770 entstandene Rondell bildet seinen Mittelpunkt und die sechs Schneisen, heute mit großen Eichen bewachsene Alleen, führen sternförmig zur Außenmauer. Mit zwei weiteren Alleen teilen sie den Park in acht Bereiche, von denen sechs wiederum 10 bis 20 ha große Wildweiden darstellen. Heute beherbergt der Park verschiedene Hirscharten, um an die Zeiten der Landgrafen zu erinnern. Außerdem gibt es einen Urwildpark, der zur Erhaltung bedrohter heimischer Wildtierarten und Nutztierrassen wie dem Przewalski-Pferd und dem Heckrind beitragen soll. Der Haustierhof (Pickers Hof) zeigt traditionelle Haus- und Nutztierrassen. Des Weiteren verfügt der Park über Greifvögel, einen Kinderzoo und einige exotische Tierarten wie Affen und Kängurus. ${ }^{51}$

\section{$4 \quad$ Fazit}

Der Reinhardswald hat eine vielfältige Nutzungsgeschichte. Lange Zeit diente er den Menschen als Lebensgrundlage. Doch die Bewirtschaftung hat ihn grundlegend geprägt. Beispielhaft hierfür sind die Veränderungen im Waldbild durch die Nutzung als Hutewald und Jagdgebiet. Der alte Hutewald („Urwald Sababurg“`) ist

\footnotetext{
51 tierpark-sababurg.de
} 
heute ein Naturmuseum, das einen Blick in die Vergangenheit zulässt und touristisch erschlossen wurde. Er wird nicht mehr wie in vergangenen Zeiten zur Erhaltung der Lebensbedingungen, sondern zur Erholung und Inspiration genutzt. Der Wald kann auch noch zukünftigen Generationen zeigen, wie Gesellschaften ihre Umwelt beeinflussten und wie aus einem Hutewald zum Nutzen des Menschen ein „Urwald“ zum Schutz der Natur werden kann. Auch der Tierpark hat eine lange Geschichte. Entstanden aus Gründen der Wilderhaltung für die Jagd, dient er nun dem Schutz bedrohter Haus- und Wildtierarten sowie als Touristenattraktion.

\section{Literatur}

Bode W, Emmert E (1998) Jagdwende: Vom Edelhobby zum ökologischen Handwerk. 3. Aufl., C. H. Beck, München.

Bonnemann A (1984) Der Reinhardswald. Verlag der Weserbuchhandlung, Hann. Münden.

Bundesamt für Naturschutz (2006) Hintergrundinfo - 100 Jahre Naturschutz als Staatsaufgaben (www.bfn.de/fileadmin/MDB/documents/hintergrund _100_jahre.pdf).

Burmeister H (2006) Theodor Rocholl und die Eichen des „Urwaldes“ an der Sababurg - Motivationen einer Rettung. In: H. Rapp, M. Schmidt (Hg.)

Baumriesen und Adlerfarn - Der Urwald Sababurg im Reinhardswald. Euregio Verlag, Kassel.

Hartig G (1791) Anweisung zur Holzzucht für Förster, Marburg. Reprint (1991), Georg-Ludwig-Hartig-Stiftung, Wiesbaden.

Hasel K (1985) Forstgeschichte: Ein Grundriss für Studium und Praxis. Parey, Hamburg, Berlin.

Höfer R (1947) Reviergeschichte des Forstamtes Gahrenberg im Reinhardswald insbesondere seit 1750. Dissertation, Universität Göttingen.

Iba E (1998) Sagen und Geschichten aus Nordhessen. 7. Aufl., CW Niemeyer Buchverlage GmbH, Hameln.

Koch M (1998) Alltagsgeschichte der Waldnutzung im Kaufunger Wald und Reinhardswald 1550-1650. Magisterarbeit, Universität Göttingen.

Olischläger K (2002) Vom Bannforst zum Wald für alle Bürger. In: H. Rapp (Hg.) Reinhardswald - Eine Kulturgeschichte. Euregio Verlag, Kassel.

Olischläger K (2006) Vom „Kuhberg“ und der Waldhute. In: H. Rapp, M. Schmidt (Hg.) Baumriesen und Adlerfarn - Der Urwald Sababurg im Reinhardswald. Euregio Verlag, Kassel. 
Piechocki R, Vogtmann H (2006) Wildnis in Deutschland. In: H. Rapp, M. Schmidt (Hg.) Baumriesen und Adlerfarn - Der Urwald Sababurg im Reinhardswald. Euregio Verlag, Kassel.

Rapp H (2002a) Auf den Eichen wachsen die besten Schinken. In: H. Rapp (Hg.) Reinhardswald - Eine Kulturgeschichte. Euregio Verlag, Kassel.

Rapp H (2002b) Und immer wieder Jagd. In: H. Rapp (Hg.) Reinhardswald - Eine Kulturgeschichte. Euregio Verlag, Kassel.

Rapp H (2006) Der „Urwald“ heute. In: H. Rapp, M. Schmidt (Hg.), Baumriesen und Adlerfarn - Der Urwald Sababurg im Reinhardswald. Euregio Verlag, Kassel.

Rohde H (2002) Die Sababurg - Ihre Entstehung und Geschichte. Reprint, Sumpf, Hann. Münden.

Schmidt M (2006) Nur Adlerfarn und Pfeifengras? - Flora und Vegetation. In: H. Rapp, M. Schmidt (Hg.) Baumriesen und Adlerfarn - Der Urwald Sababurg im Reinhardswald. Euregio Verlag, Kassel.

Schumann G (1994) Der Urwald Sababurg. 3. Aufl., Verein für hessische Geschichte und Landeskunde e. V. 1834, Hofgeismar.

Steiner B (2002) Ein Schatzhaus zur Zeit und Unzeit - Der Reinhardswald als Geschichtslektion und Gesellschaftslabor. In: H. Rapp (Hg.) Reinhardswald Eine Kulturgeschichte. Euregio Verlag, Kassel.

Tamm J (2002) Heimat für Katz und Maus - Bedeutung des Reinhardswaldes für den Naturschutz. In: H. Rapp (Hg.) Reinhardswald - Eine Kulturgeschichte. Euregio Verlag, Kassel.

Zeit Lexikon (2005), Bd. 19. Hrsg. Zeit-Verlag, Gerd Bucerius GmbH \& Co.KG, Hamburg.

\section{Internetquellen}

www.tierpark-sababurg.de (Stand: 1.10.2012). 


\title{
Das Grüne Band Deutschland
}

\author{
Michael Unger
}

\section{Einleitung}

Fast 40 Jahre lang war Europa auf einer Länge von $12.500 \mathrm{~km}$ durch die politischen Grenzen des Eisernen Vorhangs getrennt. ${ }^{1}$ Besonders innerhalb Deutschlands machten sich die Auswirkungen bemerkbar; ehemals verbundene Gemeinden wurden durch unüberwindbare Mauern, Wachtürme und Sperrbereiche getrennt. In diesem Grenzstreifen konnten sich seltene Biotope bilden und gefährdete Tier- und Pflanzenarten neue Rückzugsgebiete erschließen. ${ }^{2}$ Mit der Öffnung der Grenze und der Wiedervereinigung Deutschlands wurde von Naturschützern beider ehemals getrennter Länder der Begriff Grünes Band Deutschland geschaffen und damit das erste gesamtdeutsche Naturschutzprojekt eingeleitet. Neben dem Schutz der Natur dient es heute auch als zeithistorisches Denkmal.

Im Folgenden wird die Entwicklung des Grünen Bandes und seine Bedeutung für den Umweltschutz sowie als Denkmal für die Geschichte des Kalten Krieges beleuchtet. Dabei möchte ich insbesondere auf die Gründe der Entstehung wie auch auf politische Probleme bei der Umsetzung des Naturschutzprojekts Grünes Band eingehen und einen kurzen Ausblick auf die zukünftige Entwicklung geben.

\footnotetext{
${ }^{1}$ www.goethe.de/ges/mol/del/pan/de9370906.htm, 21.03.2013.

2 Steinsiek u. Laufer (2012), S. 134.
} 


\section{Die Entstehung des Grünen Bandes}

Mit dem Begriff „Das Grüne Band Deutschlands“ (auch „Das Grüne Band“ oder „Grünes Band“) wird das erste gesamtdeutsche Naturschutzprojekt mehrerer deutscher Bundesländer des ehemaligen Ost- und Westdeutschlands zur Unterschutzstellung des Kerngebietes der früheren innerdeutschen Grenze bezeichnet.

Das Kerngebiet besteht aus einem 50-200 m breiten Geländestreifen ${ }^{3}$ zwischen dem Kolonnenweg der ehemaligen Grenzpatrouillen und der vorgelagerten eigentlichen innerdeutschen Staatsgrenze (Abb. 1). Zusammen mit einer Grenzlänge von $1.393 \mathrm{~km}$ ergibt sich daraus eine Kernfläche von insgesamt $176 \mathrm{~km}^{2}$. Entlang der Grenze auf Seiten der DDR gab es zusätzlich einen ca. $5 \mathrm{~km}$ breiten Schutzstreifen, ${ }^{4}$ welcher für die Bevölkerung gesperrt war und ausschließlich mit Sondergenehmigung betreten werden durfte. Daraus ergab sich neben dem Grenzkerngebiet eine weitere Sperrfläche von ca. $7.000 \mathrm{~km}^{2}$.

1952 trat die Bundesrepublik der Europäischen Verteidigungsgemeinschaft bei, woraufhin in der DDR die Befestigung der Grenze zwischen Ost- und Westdeutschland beschlossen wurde. ${ }^{5}$ Die für die Bevölkerung nun nicht mehr zugänglichen Grenzgebiete boten Tieren und Pflanzen für Jahrzehnte ein Refugium.

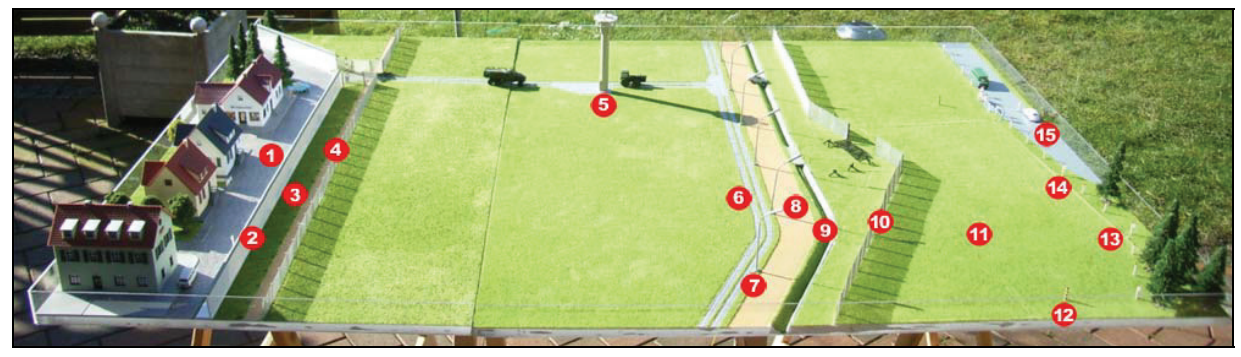

Abb. 1: Grenzmodell (1. DDR-Ortschaft, 2. Betonsperrmauer (Sichtschutz bei Ortschaften direkt an der Grenze), 3. Spurensicherungsstreifen K2 (2 m breit), 4. Grenzsignal- u. Sperrzaun II - Höhe $2 \mathrm{~m}$ (mit Unterkriechschutz, an einigen Abschnitten mit Hundelaufanlage), 5. BT-11 Beobachtungsturm Höhe 11 m, 6. Kolonnenweg, 7. Lichttrasse (bei Ortschaften oder schwierigen Geländeabschnitten), 8. Spurensicherungsstreifen K6 (6 m breit), 9. Kfz-Sperrgraben ( $3 \mathrm{~m}$ breit - 1,5 m tief), 10. Grenzzaun Höhe 3,3 m, 11. Vorgelagertes Hoheitsgebiet der DDR, 12. DDR-Grenzsäule - Höhe 1,8 bis 2,2 m , 13. DDR-Grenzstein , 14. Grenzpfahl weiß mit roter Kappe (Bayern: blaue Kappe) mit Warnschild „Halt Hier Grenze, Bundesgrenzschutz“, 15. Hoheitsgebiet der Bundesrepublik Deutschland). ${ }^{6}$

Ornithologische Feldbeobachtungen zeigten erstmals zu Beginn der 1970er Jahre, dass entlang der Grenze vermehrt seltene Vogelarten zu finden waren. Mitte der 70er Jahre wurden daraufhin gezielte und vergleichende Beobachtungen im Grenz-

\footnotetext{
${ }^{3}$ www.bund.net/themen_und_projekte/gruenes_band/geschichte_gruenes_band, 21.03.2013.

${ }^{4}$ BfN u. BUND (2002), S. 2.

${ }^{5}$ Ebd.

${ }^{6}$ www.informationsarchiv.de/galerie3.htm, 28.03.2013.
} 
gebiet nahe des oberfränkischen Steinachtals durchgeführt. Die Ergebnisse dieser Beobachtungen führten im Anschluss in den Jahren 1979 bis 1984 zu einer aufwändigen ornithologischen Rasterkartierung eines $1.005 \mathrm{~km}^{2}$ großen Landschaftsraumes im Grenzgebiet, darunter auch auf einem ca. $140 \mathrm{~km}$ langen Grenzstreifen auf Seiten der DDR. ${ }^{7}$ Hier wurde deutlich, welche Wirkung der Grenzstreifen auf die Entwicklung der Natur hatte. Seltene Vogelarten, die als gefährdet auf der Roten Liste der BRD geführt wurden, brüteten hier in ungewöhnlich hoher Dichte (Abb. 2). Kai Frobel, Geoökologe, späterer Mitbegründer und heutiger Leiter des Projekts Grünes Band Deutschland, ${ }^{8}$ beschäftigte sich seit 1975 mit der Vogelwelt entlang der Grenze und veröffentlichte 1981 einige Ergebnisse seiner Beobachtungen und der Rasterkartierung unter dem Titel „Letzter Zufluchtsort: Todesstreifen“ in der Zeitschrift „Vogelschutz“.

Frobel nahm bereits zu dieser Zeit Kontakt zu Vogelschützern in der DDR auf, wobei dies durch die Staatssicherheit der DDR akribisch beobachtet wurde. Heute ist erwiesen, dass mindestens drei der jugendlichen Vogelschützer, zu denen er Kontakt aufsuchte, informelle Mitarbeiter der Staatssicherheit waren. ${ }^{9}$ Man versuchte zu verhindern, dass die aufkommenden Umwelt- und Naturschutzbewegungen in der Bevölkerung der BRD ${ }^{10}$ (darunter die Gründung von Greenpeace Deutschland 198011) sowie die neuen politischen Diskussionen über Luftverschmutzung, Waldsterben und Atomkraft auch in der DDR populär wurden. Anfang der 1970er Jahre verfolgte die SED ein neues Programm, welches den beschleunigten Wohnungsbau und die Warenherstellung verbessern sollte, um die Massenbedürfnisse besser befriedigen zu können. Investitionen in den Umweltschutz, welcher die Industrie kontraproduktiv beeinflusst hätte, blieben aus, sodass aufgrund von katastrophalen Schäden an der Natur Umweltdaten der DDR ab 1982 als Verschlusssache galten. ${ }^{12}$

\footnotetext{
7 http:/ / umweltunderinnerung.de/index.php/kapitelseiten/oekologische-zeiten/96-das-gruene-band, 23.03.2013.

${ }^{8}$ www.bundesregierung.de/Content/DE/Artikel/20Jahre/2009-12-09-erstes-gesamtdeutschesnaturschutzprojekt.html, 23.03.2013.

${ }^{9}$ Gras (2009), S. 6.

${ }^{10}$ Bezakova (2009), S. 7.

11 Maute (2011), S. 18.

12 www.bundesregierung.de/Content/DE/Artikel/2012/11/2012-11-25-umweltbibliothek-ddr.html, 29.07.2013.
} 


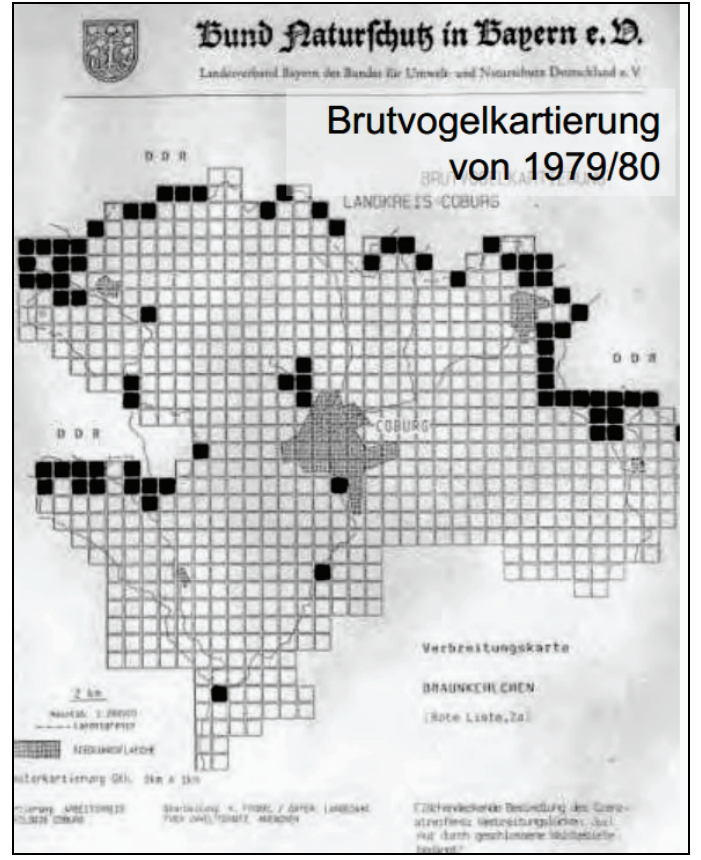

Abb 2: Brutvogelkartierung entlang der Grenze bei Cottbus (Grenzverlauf zur DDR im Norden, Osten und Westen, schwarze Karos: Nistplätze des gefährdeten Braunkehlchens) (Dieter Leupold, Projektkoordinator Grünes Band (2009) „Das Grüne Band- vom Eisernen Vorhang zur Lebenslinie Europas", BUND LV Sachsen-Anhalt e.V.).

Popularität bei der Bevölkerung der BRD erlangten die Entwicklungen der Natur entlang der Grenze durch die 1988 gezeigte Dokumentation des Biologen und Naturfilmers Heinz Sielmann „Tiere im Schatten der Grenze“. Sielmann engagierte sich nach Abschluss der Dreharbeiten auch weiter für den Erhalt der Natur im Grenzgebiet und sprach sich bereits zu dieser Zeit, vor der Öffnung der Grenze, für einen „Nationalpark von der Ostsee bis zum Bayerischen Wald“ aus. ${ }^{13} \mathrm{Nach}$ Öffnung der Grenze gründete er 1994 die Heinz-Sielmann-Stiftung, welche unter anderem versucht durch den Ankauf von ehemaligen Grenzflächen die dortigen Biotope zu erhalten.

Eine offizielle Kontaktaufnahme zu Naturschützern in der DDR, ursprünglich gedacht, um die akute Problematik des Waldsterbens zu behandeln, fand durch Prof. Dr. Hubert Weiger, dem damaligen Landesbeauftragten des Naturschutzes in Bayern während einer Delegationsreise Ende der 1980er Jahre statt. ${ }^{14}$ Neben der Kontaktaufnahme zu Prof. Dr. Harald Thomasius, damaliger Vorsitzender der Gesellschaft für Natur und Umwelt des Kulturbundes in der DDR, sammelte man 30 Adressen von Naturschützern aus der DDR zwecks einer möglichen zukünftigen Zusammenarbeit. ${ }^{15}$

\footnotetext{
${ }_{13}$ Der Elbländer, April 2010, S. 7.

$14 \mathrm{http}: / /$ umweltunderinnerung.de/index.php/kapitelseiten/oekologische-zeiten/96-das-grueneband, 22.03.2013.

$15 \mathrm{http}: / /$ umweltunderinnerung.de/index.php/kapitelseiten/oekologische-zeiten/96-das-grueneband, 22.03.2013.
} 
Nach Öffnung der Grenze wurden im Dezember 1989 Naturschützer zu einem Treffen nach Hof eingeladen, welches den Auftakt zur Bewahrung der Natur in den ehemaligen Grenzgebieten darstellte. Man erreichte 27 Personen aus der DDR. ${ }^{16}$ Die Veranstalter rechneten mit etwa 30-40 Teilnehmern aus Ost und West; tatsächlich erschienen sind jedoch 400 allein aus Ostdeutschland. ${ }^{17}$ Der Resolutionstext der Tagung wurde von den Teilnehmern einstimmig und ohne Enthaltung angenommen: ${ }^{18}$

\begin{abstract}
„Der Grenzstreifen zwischen der Bundesrepublik und der Deutschen Demokratischen Republik ist als grünes Band und ökologisches Rückgrat Mitteleuropas vorrangig zu sichern, d.h. es muss umgehend eine einstweilige Sicherstellung dieser Gebiete in der DDR und BRD erfolgen. Darüber hinaus sollen großflächige grenzüberschreitende Schutzgebiete errichtet oder miteinander vernetzt werden. Die Detailkonzeption sollte vom Institut für Landschaftsforschung und Naturschutz (IUN) und von der Bundesforschungsanstalt für Naturschutz und Landschaftsökologie (BFANL) durchgeführt werden. Bei der Detailkonzeption sind die Bedürfnisse der ortsansässigen Bevölkerung zu berücksichtigen. Diese Forderung ist keine nachträgliche Rechtfertigung der Grenze. “19
\end{abstract}

Die Verabschiedung der Resolution und die geplante Zusammenarbeit gilt heute als Geburtsstunde des grenzübergreifenden Naturschutzes in Deutschland. ${ }^{20}$ Auch der Begriff Grünes Band wurde auf diesem Treffen geprägt und beschreibt nach Kai Frobel, dem Initiator der Konferenz, neben dem Schutz der Natur auch die Grenze als lebendiges Denkmal:

„Das Grüne Band, als Tafelsilber der deutschen Einheit gefeiert, ist nicht nur das erste gesamtdeutsche Naturschutzprojekt, es ist ein lebendiges Denkmal der jüngeren deutschen Zeitgeschichte. Ein gemeinsames Naturerbe historischer Dimension, das für kommende Generationen erhalten werden muss. “21

\title{
3 Politische Verzögerungen und Probleme bei der Umsetzung
}

Trotz des einstimmigen Beschlusses zur Unterschutzstellung der Grenzgebiete war und ist die Umsetzung desselben nur langsam vorangeschritten. Das politische Interesse am Grünen Band schien bereits direkt nach Öffnung der Grenzen groß.

\footnotetext{
16 Gras (2009), S. 8.

${ }^{17}$ www.tagesspiegel.de/wissen/tierwelten/gruene-band-vom-todesstreifen-zurlebenslinie/1918086.html, 21.03.2013.

$18 \mathrm{http} / /$ / umweltunderinnerung.de/index.php/kapitelseiten/oekologische-zeiten/96-das-grueneband, 21.03.2013.

${ }^{19}$ Frobel et al. (2009).

${ }^{20} \mathrm{http} / /$ / umweltunderinnerung.de/index.php/kapitelseiten/oekologische-zeiten/96-das-grueneband, 22.03.2013.

${ }^{21}$ Frobel K (2009) Pressemitteilung BUND/BfN/Sielmann-Stiftung.
} 
Alfred Dick, bayerischer Staatsminister für Umweltfragen 1977-1990, betonte im Juli 1990: „Schutz der Natur im grenzüberschreitenden Bereich duldet keinen Aufschub."22 Die Flächen der ehemaligen Grenze waren nach der Grenzöffnung jedoch im Besitz der Bundesrepublik; die Ausweisung zum Naturschutzgebiet hingegen wird nach dem Grundgesetz durch die einzelnen Bundesländer durchgeführt. Eine gesetzliche Unterschutzstellung durch die Landesregierungen war unmittelbar nach Öffnung der Grenze somit nicht möglich. ${ }^{23}$ Die Bundesländer oder Naturschutzorganisationen konnten nur durch Ankauf die Umwelt im Grenzgebiet sichern. 1996 wurde vom Bundestag das Mauergrundstücksgesetz (MauerG) verabschiedet, nach welchem es ehemaligen Grundbesitzern bzw. deren Rechtsnachfahren ermöglicht wurde, ihre Flächen im Grenzgebiet zu $25 \%$ des aktuellen Marktwertes zurückzukaufen. ${ }^{24}$ In einem Schreiben an den BUND vom 19. Juni 1996 erklärte Dr. Angela Merkel, Bundesumweltministerin 1994-1998:

„[...] bitte ich zu beachten, dass dem Bund für das Naturschutzrecht nur die Rahmenkompetenz zusteht. Die Durchführung [...] obliegt den zuständigen Landesbehörden. Dazu zählt auch die Festsetzung von Schutzgebieten. Aus Sicht des Bundes ist es daher grundsätzlich nicht möglich, dass der Bund einen Rückerwerbsantrag aus Gründen des Naturschutzes unter Hinweis ,auf dringende eigene öffentliche Zwecke' ablehnt. [...] Insgesamt ist festzustellen, dass es durchaus ein Instrumentarium gibt, das die Bundesländer in die Lage versetzen kann, das Grüne Band in seiner Bedeutung für den Naturschutz zu erhalten. In welchem Umfang dieses Instrumentarium tatsächlich von den Ländern genutzt wird, liegt jedoch in deren Ermessensspielraum.“

Eine Unterschutzstellung der Flächen durch den Bund wurde somit abgelehnt und die Zuständigkeit den Ländern überlassen. Auch wurden besonders schützenswerte Flächen nicht zum Zwecke des Naturschutzes vom Verkauf ausgeschlossen. Bis 1997 wurden über 4.000 Rückkaufanträge von ehemaligen Eigentümern gestellt, welche noch bis 2003 bearbeitet werden sollten. ${ }^{25}$ In dieser Zeit war ein weiterer Erwerb - auch durch die Bundesländer - mit der Auflage verbunden, Flächen, zu denen ein Antrag eingegangen war, auch nachträglich kostengünstig wieder abzugeben. Hatte man also den vollen Preis gezahlt, drohten bei einer möglichen Abgabe große Verluste.

Jürgen Trittin, Bundesumweltminister zwischen 1998 und 2005, verkündete im Jahr 2000 auf einer Umweltministerkonferenz in Berlin, dass die verbliebenen Flächen kostenfrei den Bundesländern zwecks der Unterschutzstellung zur Verfügung gestellt werden sollen;26 im Widerspruch dazu, nur wenige Wochen später,

\footnotetext{
22 Frobel (2011), S. 3.

${ }^{23}$ www.nabu.de/nh/400/czybulka400.htm, 24.03.2013.

${ }^{24} \mathrm{http}$ // umweltunderinnerung.de/index.php/kapitelseiten/oekologische-zeiten/96-das-grueneband, 20.03.2013.

25 BfN u. BUND (2002), S. 7.

${ }^{26} \mathrm{Ebd}$.
} 
wurden die Flächen jedoch durch den Bundesfinanzminister Hans Eichel auf dem freien Grundstücksmarkt für den Verkauf freigegeben. ${ }^{27}$ Erst 2002 wurde in den Koalitionsvereinbarungen von SPD und Bündnis90/Grüne eine kostenfreie Abgabe der Flächen an die Bundesländer festgesetzt. Da jedoch viele Bundesländer die teilweise kostenintensiven notwendigen Pflegemaßnahmen der Flächen scheuten, kam es erst am 9. November 2008 durch Thüringen zur ersten Übernahme ehemaliger Grenzflächen durch ein Bundesland. ${ }^{28}$ Nach weiteren Verhandlungen wurde die Übertragung an die Bundesländer im Jahr 2010 abgeschlossen. ${ }^{29}$

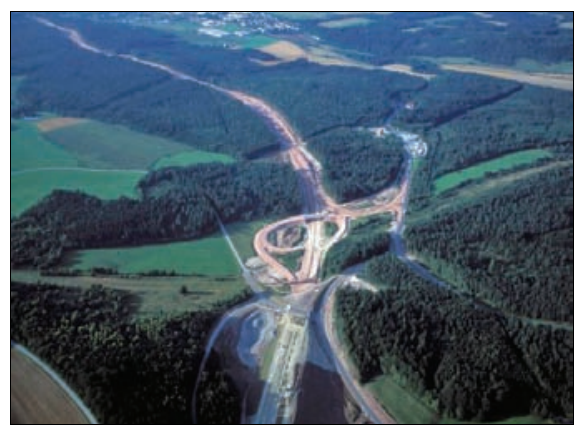

Abb. 3: Zerschneidung des Grünen Bandes durch den Ausbau der A73. ${ }^{31}$

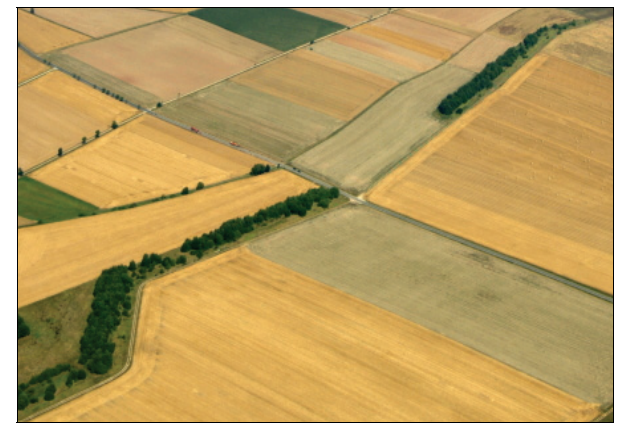

Abb. 4: Verlust durch Agrarnutzung. ${ }^{30}$

21 Jahre nach der Öffnung der Grenze waren durch die langen Verzögerungen bereits viele Grenzflächen durch den Infrastrukturausbau, die landwirtschaftliche Nutzung und die mangelnde Pflege in ihrer Eigenschaft als Biotopverbund verloren (Abb. 3 und 4). Der Verkauf der Flächen durch das Mauergrundstücksgesetz sowie auf dem freien Markt erschwert auch heute noch die Unterschutzstellung, ${ }^{32}$ da sich noch immer ca. ein Drittel der Flächen in Privatbesitz befinden. ${ }^{33}$

\section{Das Grüne Band als Naturschutzgebiet}

Während die meisten Teile Deutschlands durch intensive landwirtschaftliche Nutzung, Düngemitteleintrag, Waldwirtschaft sowie Infrastruktur- und Siedlungsbau

\footnotetext{
27 www.oekologische-bildungsstaette.de/absp/presse.htm, 21.03.2013.

28 Geidezis (2010), S. 6.

${ }^{29}$ www.bfn.de/0311_gruenes_band.html, 26.03.2013.

30 www.bfn.de/0311_gruenes_band.html, 20.03.2013.

31 www.bund.net/themen_und_projekte/gruenes_band/geschichte_gruenes_band/ erfolge_und_gefahren/(Foto: K. Leidorf), 22.03.2013.

32 www.goettinger-tageblatt.de/Nachrichten/Duderstadt/Uebersicht/Birkner-Gruenes-Band-kannnoch-scheitern, 24.03.2013.

33 BUND u. BfN (2012), S. 5.
} 
stark in ihrer natürlichen Entwicklung beeinträchtigt sind, konnten sich im Grenzgebiet seltene Biotoptypen bilden. Die Grenzkerngebiete wurden in unregelmäßigen mehrjährigen Abständen freigeschlagen, um die nötige Rundumsicht für die Grenzpatrouillen zu schaffen; ${ }^{34}$ dies unterstützte frühe Sukzessionsstadien bei der Entwicklung, förderte seltene Pionierwald- und Vorwaldstadien mit angrenzenden Waldgebieten, in denen Luchs und Wildkatzen zu finden sind, und schützte und unterstützte Grünlandflächen wie Ruderalflure, Magerrasen, Zwergstrauchheiden und seltene Wiesen und Weiden. ${ }^{35}$ Hier lassen sich unter anderem verschiedene Orchideenarten finden, die in vielen Teilen Deutschlands durch Trockenlegung von Feuchtwiesen, den Einsatz von Pestiziden und der künstlichen Düngung gefährdet sind. ${ }^{36}$ Aber auch naturnahe Fließgewässerbiotope profitierten von der Absperrung für den Menschen. Bäche und Flüsse entlang des Grünen Bandes wurden aufgrund der strikten Grenzziehung nicht begradigt und nicht für die Schifffahrt genutzt. Auch wurden keine Abwässer aus Haushalt, Industrie und Ackerbau in die Flüsse eingeleitet, wodurch streckenweise unberührte Bach- und Flusslandschaften mit natürlichen Uferzonen sowie Auewälder erhalten geblieben sind. In diesen meist klaren und unverschmutzten Gewässern haben sich auf saubere Gewässer angewiesene Arten wie Eisvogel, Grüne Keiljungfer, Fischotter oder Laubfrosch angesiedelt. ${ }^{37}$ Das Grenzgebiet zog sich auch durch Stillgewässer wie die seit dem Jahr 2000 als UNESCO Biosphärenreservat anerkannte Schaalseelandschaft südlich von Lübeck, ${ }^{38}$ entlang welcher seltene von Sauergräsern beherrschte Nasswiesen zu finden sind. ${ }^{39} 1.200$ bedrohte Tier- und Pflanzenarten wurden bisher im Grünen Band registriert (Stand 2007). ${ }^{40}$

\footnotetext{
34 BfN u. BUND (2002), S. 4.

35 www.bund.net/themen_und_projekte/gruenes_band/natur_am_gruenen_band/lebensraeume, 22.03.2013.

36 www.bund.net/themen_und_projekte/gruenes_band/natur_am_gruenen_band/pflanzen/, 26.03.2013.

37 www.bund.net/themen_und_projekte/gruenes_band/natur_am_gruenen_band/lebensraeume, 22.03.2013.

38 www.bund.net/themen_und_projekte/gruenes_band/natur_am_gruenen_band/lebensraeume, 23.03.2013.

${ }^{39}$ Schlumprecht et al. (2006), S. 23.

${ }^{40}$ www.dradio.de/dlf/sendungen/umwelt/1527491/, 20.03.2013.
} 

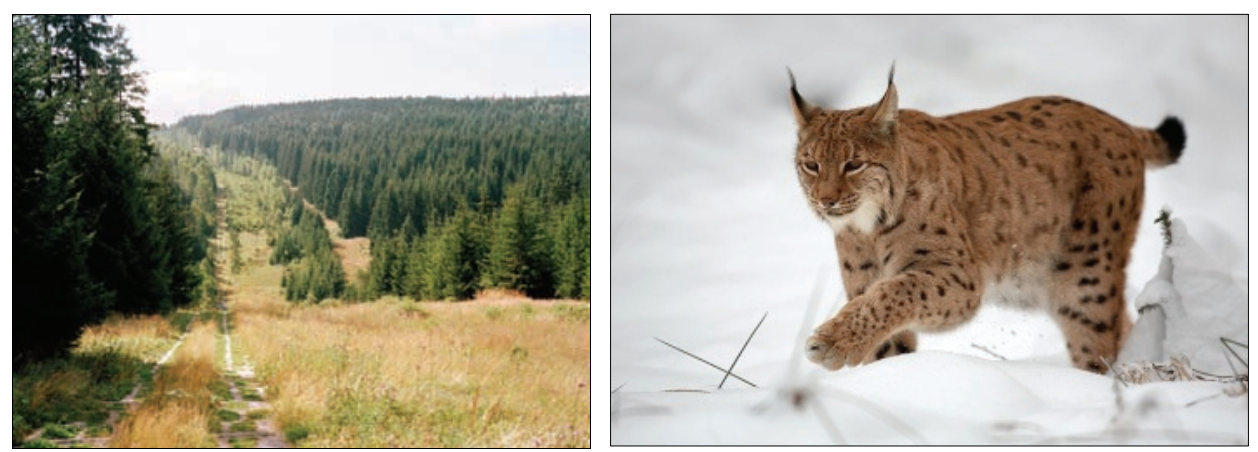

Abb. 5/6: Das Grüne Band im Harz bei Sorge. Seltene Tiere wie der Luchs nutzen die Biotope am Grünen Band. ${ }^{41}$

Das Grüne Band streift neun Bundesländer und bildet damit den längsten Waldund Offenlandbiotopverbund Deutschlands. Eine vom BfN, Bund Naturschutz in Bayern e.V. und BUND in den Jahren 2001 bis 2002 durchgeführte erneute Kartierung des Grünen Bandes bestätigt, wie wertvoll die Gebiete trotz der geringen flächenmäßigen Ausbreitung für den Naturschutz sind (Tab. 1).

Trotz der geringen Fläche von $176 \mathrm{~km}^{2}$, das entspricht ca. 0,028 \% der Gesamtfläche Deutschlands, spielt das Grüne Band eine wichtige Rolle beim Erhalt gefährdeter Tier- und Pflanzenarten. Wildkatzen besiedeln europäische Wälder bereits seit über 300.000 Jahren, ${ }^{42}$ galten in den meisten Teilen Deutschlands aber lange Zeit als ausgestorben, nur in waldreichen Gebieten wie dem Harz überlebten kleine Populationen. ${ }^{43}$ Die Tiere konnten das Grüne Band als Wanderkorridor nutzen, um in andere Waldgebiete zu gelangen, sodass es heute wieder mehrere Populationen gibt. 150 Naturschutzgebiete liegen an dem ehemaligen Grenzgebiet. ${ }^{44}$ Die Länge des Grünen Bandes erlaubt es scheuen Tieren, sich über weite Strecken hinweg ohne Kontakt zum Menschen zu bewegen und in andere Naturschutzgebiete zu wandern (Abb. 7). Neben dem ehemaligen Grenzkerngebiet werden deshalb vielerorts auch angrenzende ehemalige Sperrgebiete als Wanderkorridore zu den anliegenden Naturschutzgebieten unter Schutz gestellt.

\footnotetext{
41 Abb. 5: http://commons.wikimedia.org/wiki/File:Sorge_German_Green_Belt.jpg, 06.11.2013. Abb. 6: http://commons.wikimedia.org/wiki/File:Lynx_lynx_1_\%28Martin_Mecnarowski\%29.jpg. 42 BUND-Projektbüro Rettungsnetz Wildkatze (2006), S. 29.

${ }^{43}$ www.luchsprojekt-harz.de/de/wk/diewildkatze/?darstellung=anpassen\&java=true, 20.03.2013.

${ }^{44}$ www.goethe.de/ges/mol/del/pan/de9370906.htm, 26.03.2013.
} 
Tabelle 1: Stand $2002^{45}$

\begin{tabular}{|l|l|}
\hline 109 & verschiedene Biotoptypen \\
\hline $48 \%$ & gefährdete Biotoptypen nach der Roten Liste Deutschlands \\
\hline $28 \%$ & Naturschutzgebiete \\
\hline $38 \%$ & Flora-Fauna-Habitatgebiete \\
\hline $60 \%$ & Fließ-/Standgewässer, extensives Grünland, Brachflächen und Wälder \\
\hline $85 \%$ & der Fläche und $80 \%$ der Länge sind noch naturnah \\
\hline
\end{tabular}

Anders als in den meisten Naturschutzgebieten Deutschlands finden sich im Grünen Band auch Übergangszonen zwischen den verschiedenen Biotoptypen, welche ökologische Wechselbeziehungen zwischen Arten und Populationen zulassen. ${ }^{46}$

Bei der Unterschutzstellung der Flächen stoßen Landesregierung und Naturschutzorganisationen jedoch nicht selten auf Widerstand. Unter dem Titel „,Grünes Band' darf nicht ,Grüne Grenze' werden“ veranstaltete der Deutsche Bauernverband zuletzt im März 2013 in der Nähe von Göttingen ein Treffen bezüglich der Naturschutzprojekte der Heinz-Sielmann-Stiftung entlang der ehemaligen innerdeutschen Grenze bei Duderstadt und Göttingen. Bauern und Grundbesitzer, welche sich nach dem Mauergrundstücksgesetz Flächen zurückgekauft hatten, fürchten Einschränkungen bei der Bewirtschaftung ihrer Felder und damit verbundene Verdienstausfälle bis hin zur Existenzbedrohung. ${ }^{47}$ Friedhelm Decker, Präsident des Rheinischen Landwirtschafts-Verbands entkräftet auch den Wunsch, das Grüne Band als historisches Denkmal zu erhalten:

„Im Gegensatz zu diesem Naturschutzkonzept könne auch die Wiederaufnahme der historischen Nutzung der Flächen durch die Land- und Forstwirtschaft als Sinnbild für die Wiedervereinigung angesehen werden“ (Pressemitteilung Deutscher Bauernverband 2013).

Auch fürchtet man einen großen Wertverlust der eigenen Grundstücke, da diese, neben Einschränkungen bei Land- und Forstwirtschaft, nach der Unterschutzstellung für viele Bebauungsprojekte wie Windanlagen nicht mehr genutzt werden dürfen. Auch Waldbesitzer sprachen sich gegen den Naturschutz entlang der ehemaligen Grenze aus. Dazu sammelten Landwirte und Waldbesitzer im Raum Göttingen und Duderstadt knapp 1.500 Unterschriften gegen die Ausweisung von neuen Naturschutzgebieten. ${ }^{48}$ Michael Spielmann, Geschäftsführer der HeinzSielmann-Stiftung, hat daraufhin die Projektfläche um ein Drittel reduziert. ${ }^{49}$

\footnotetext{
${ }^{45}$ www.erlebnisgruenesband.de/gruenes-band/deutschland/natur.html, 20.02.2013.

$46 \mathrm{BfN}$ u. BUND (2002), S. 14.

${ }^{47}$ www.landvolk-goe.de/2012/gruenes-Band-2012.htm, 24.03.2013.

48 www.ndr.de/regional/niedersachsen/harz/gruenesband203.html, 26.03.2013.

${ }^{49}$ www.ndr.de/regional/niedersachsen/harz/gruenesband203.html, 27.03.2013.
} 


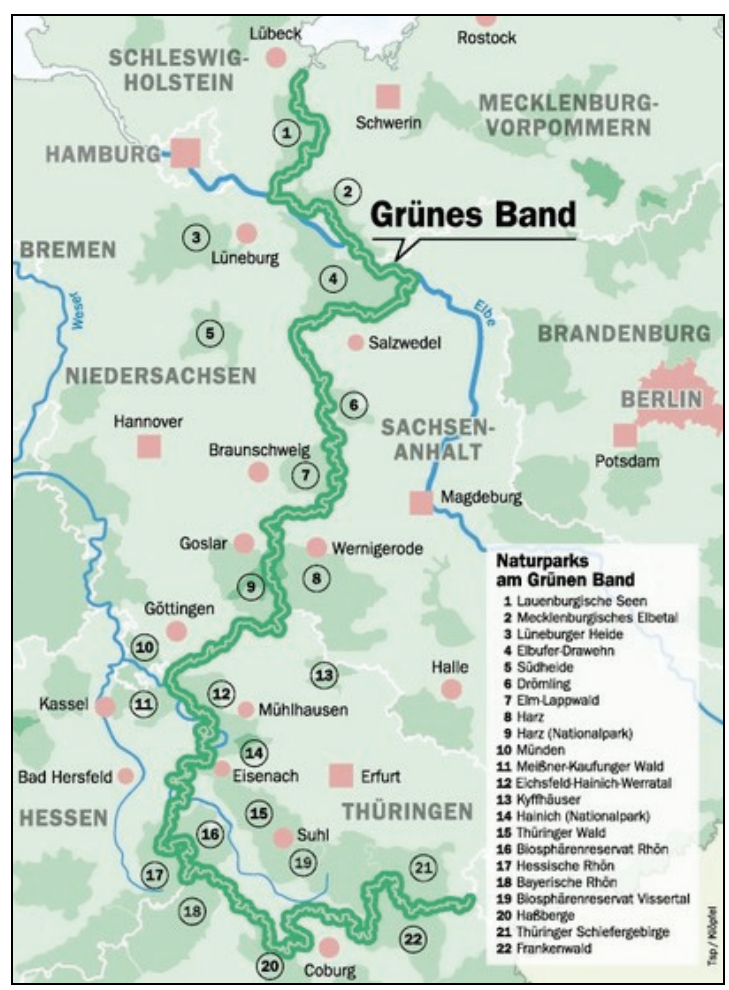

Abb. 7: Große Naturschutzgebiete entlang des Grünen Bandes. ${ }^{50}$

\section{Die Zukunft des Grünen Bandes}

Die Unterschutzstellung der Gebiete entlang der ehemaligen innerdeutschen Grenze verläuft auch nach über 20 Jahren nach der Grenzöffnung noch schleppend. Die Biotope entlang des Grünen Bandes haben sich in dieser Zeit vielerorts verändert und sind teilweise, aufgrund der fehlenden Pflegemaßnahmen durch die Grenzsicherung, verwildert und durch Sukzession zugewachsen. ${ }^{51}$ Neben dem Umweltschutzgedanken soll das Grüne Band aber auch als lebendiges Denkmal für die friedliche Überwindung des Eisernen Vorhangs dienen und möglichst in Gänze als Struktur in der Landschaft erhalten bleiben. ${ }^{52}$ Dazu sind Pflegemaßnahmen notwendig, welche in der Vergangenheit durch ungewisse Besitzverhältnisse und aus Kostengründen vielerorts nicht durchgeführt worden sind. Auf einer vom BUND und BfN im November 2011 abgehaltenen Fachtagung zum Management

\footnotetext{
${ }^{50}$ www.tagesspiegel.de/wissen/tierwelten/gruene-band-vom-todesstreifenzur-lebenslinie/1918086.html, 21.03.2013.

${ }^{51}$ Management des Grünen Bandes, www.bfn.de/0311_gruenes_band.html, 26.03.2013.

52 BUND u. BfN (2012), S. 5.
} 
am Grünen Band wurden Leitbilder zur Pflege der Flächen verabschiedet. Die Planungen wurden von 50 Experten aus Behörden, Hochschulen, Verbänden, Stiftungen und Planungsbüros durchgeführt, ${ }^{53}$ die zusammen Leitbilder zur Pflege und Erhaltung der verschiedenen Biotope mit ihren unterschiedlichen Pflegeansprüchen erarbeiteten. Im Zuge der Tagung wurde die Publikation „Biotopmanagement am Grünen Band“ erstellt, die allen Akteuren als Handlungsleitfaden und Hilfestellung zum Umgang mit den Flächen dienen soll. Vor allem Wiesen müssen laut Biotoppflegebeschluss regelmäßig gemäht werden, dazu werden unter anderem in Sachsen mehrere hundert Schafe und Ziegen eingesetzt. ${ }^{54}$

Den durch den Verkauf von ehemaligen Grenzflächen entstandenen Lücken im Grünen Band versucht man seit 2012 mit dem aus dem Bundesprogramm „Biologische Vielfalt“ geförderten Projekt „Lückenschluss Grünes Band“ entgegenzuwirken. Sie sollen durch Rückkäufe der Flächen und Umwandlung zurück zu den ursprünglichen Biotopen geschlossen werden. Soweit dies nicht möglich ist, sollen „Bypass-Lösungen“ umgesetzt werden, wodurch Wanderkorridore und Biotopverbunde durch Unterschutzstellung von Flächen abseits der ehemaligen Grenze gesichert werden sollen. ${ }^{55}$

Um der Bevölkerung das Grüne Band auch viele Jahre nach Öffnung der Grenze als historisches Mahnmal im Kontext „Natur, Kultur, Geschichte“ nahe zu bringen und in der Zukunft zu erhalten, fördert das BfN das Projekt „Erlebnis Grünes Band“. Durch die Ausweisung von Rad- und Wanderwegen, die Beschilderung historisch interessanter Orte sowie die Einrichtung von Ausstellungen sollen Angebote für den Tourismus geschaffen werden. Auch versucht man so, die Akzeptanz in der lokalen Bevölkerung zu steigern, da durch den Tourismus vielerorts neue Einnahmequellen entstehen. Das Projekt beschränkt sich zurzeit auf die Gebiete Elbe-Altmark-Wendland, Harz und Naturparke im Thüringer Wald. ${ }^{56}$

Im Jahr 2002 gab Michail Gorbatschow während der Einweihung des WestÖstlichen Tors, eines Denkmals für die Einigung von Ost und West, bekannt, dass es Planungen für ein Grünes Band durch Europa gibt. Dieses soll entlang der $12.500 \mathrm{~km}$ langen Grenzen des ehemaligen Eisernen Vorhangs entlang von 24 Staaten verlaufen und wie das Grüne Band Deutschland und das Denkmal WestÖstliches Tor als ein Symbol für die friedliche Wiedervereinigung stehen. Umweltschutzorganisationen hoffen durch dieses Projekt zukünftig grenzübergreifenden Naturschutz koordinieren zu können. ${ }^{57}$

Sigmar Gabriel, Bundesminister für Umwelt, Naturschutz und Reaktorsicherheit 2005-2009, hat im August 2009 das Grüne Band Deutschland für die Ausweisung zum ersten Nationalen Naturmonument vorgeschlagen. ${ }^{58}$ Ein Antrag dazu

\footnotetext{
${ }^{53}$ www.erlebnisgruenesband.de/fachtagung/praesentationen-und-programm.html, 26.03.2013.

${ }^{54}$ BUND u. BfN (2012), S. 15.

${ }^{55}$ Lückenschluss Grünes Band, http://www.bfn.de/0311_gruenes_band.html, 26.03.2013.

56 Erlebnis Grünes Band, http://www.bfn.de/0311_gruenes_band.html, 26.03.2013.

${ }^{57}$ www.europeangreenbelt.org/, 26.03.2013.

$58 \mathrm{http} / /$ gruene-fraktion.thueringen.de/gr\% $\% \mathrm{C} 3 \% \mathrm{BC}$ es-band/gr $\% \mathrm{C} 3 \% \mathrm{BC}$ es-band-als-nationales
} 
erging durch Bündnis90/Grüne im Februar 2011 an den Thüringer Landtag. Die Schutzkategorie Nationales Naturmonument ist eine seit dem 1. März 2010 im Bundesnaturschutzgesetz neu definierte Kategorie zum Schutze von historisch bedeutsamen Naturgebieten und schützt ein Gebiet nach der IUCN Norm III „Naturdenkmal.“59 Die gesetzlichen Anforderungen nach \$24 BNatSchG sind:

1. Die Gebiete müssen aus wissenschaftlichen, naturgeschichtlichen, kulturhistorischen (siehe $\int 26$ Abs. 1 Nr. 2 BNatSchG) oder landeskundlichen Gründen von herausragender Bedeutung sein.

2. Wegen ihrer Seltenheit, Eigenart oder Schönheit von herausragender Bedeutung sein (siehe $\int 23$ Abs. 1 Nr. 2 und 3 BNatSchG).

Das Grüne Band erfüllt die Vorgaben, sodass mit einer künftigen gesetzlichen Unterschutzstellung gerechnet wird. ${ }^{60}$

Das Grüne Band Deutschland und Europa dient auch als Vorlage für aufkommende weltweite Projekte. Im Februar 2012 hat das BfN eine Kooperationsvereinbarung bezüglich der Errichtung eines Grünen Bandes entlang der demilitarisierten Zone (DMZ) zwischen Süd- und Nordkorea unterzeichnet (Abb. 8). Die Erfahrungen aus Deutschland sollen bei der weiteren Zusammenarbeit zur Errichtung von Schutzgebieten entlang der seit 1953 bestehenden und ca. $248 \mathrm{~km}$ langen Zone helfen. ${ }^{61}$

\footnotetext{
naturmonument-ausweisen, 30.07.2013.

${ }^{59}$ Vahdat (2013), S. 71.

${ }^{60}$ Grünes Band als „Nationales Naturmonument“ ausweisen, Antrag der Fraktion BÜNDNIS 90/DIE GRÜNEN - Drs. 6/517 Stellungnahme des BUND Landesverband Sachsen-Anhalt, 14. März 2012.

${ }^{61}$ Joint Declaration of Intent of The Federal Agency For Nature Conservation, Federal Republic of Germany and The Gyeonggi Province, Republic of Korea, 2012.
} 


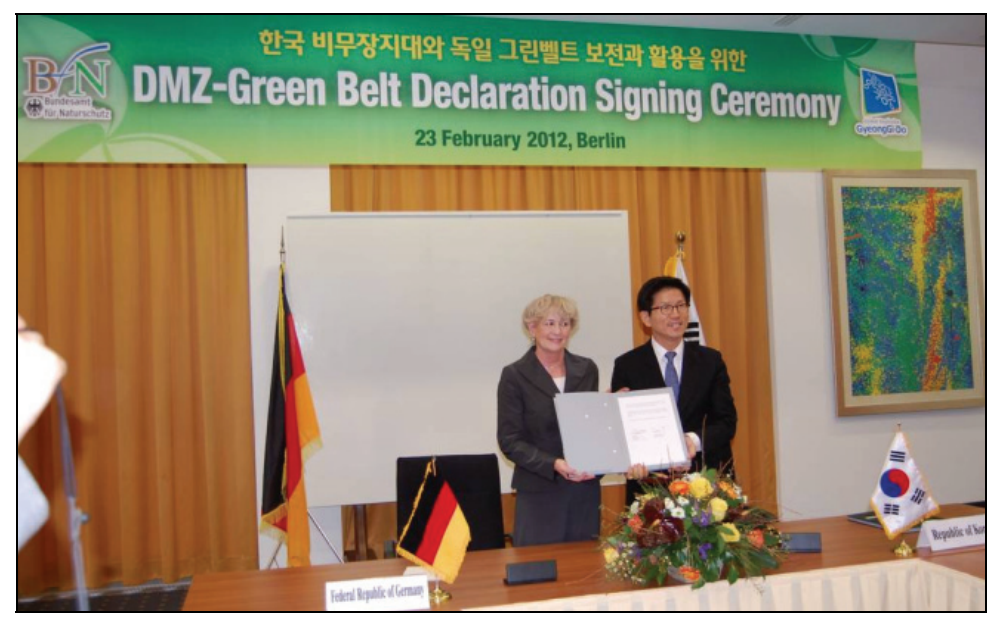

Abb. 8: Unterzeichnung der Kooperationsvereinbarung zur Errichtung eines Grünen Bandes in Korea. ${ }^{62}$

\section{$6 \quad$ Fazit}

Die ehemalige innerdeutsche Grenze bot der Natur über viele Jahre hinweg, zunächst für den Menschen lange unbemerkt, ein Refugium, in dem einzigartige und seltene Biotope entstanden. Ost- und westdeutsche Naturschützer erkannten noch während des Bestehens der Grenze die Einzigartigkeit dieser Gebiete und initiierten nach Öffnung der Grenze das erste grenzübergreifende Naturschutzprojekt Deutschlands. Aufgrund von Interessenkonflikten und Finanzierungsfragen kam es immer wieder zu großen Verzögerungen und Problemen bei der Umsetzung der Schutzplanungen, wodurch einige Teile der seltenen Biotope verschwunden sind. Es mag etwas verwundern, dass bei einem so geschichtsträchtigen Gebiet, welches nur 0,028 \% der Landesfläche ausmacht, die Unterschutzstellung über Jahrzehnte hinweg durch eine Fülle an Problemen verzögert und erschwert wird. Zu hoffen bleibt, dass die Pflegemaßnahmen durch die Bundesländer und Umweltorganisationen das Grüne Band als historisches Denkmal erhalten und die verbleibenden Biotope des Grenzgebiets für die Zukunft bewahren.

\section{Literatur}

Bezakova K (2009) Die gesellschaftliche Wirkung der Umweltbewegung unter dem Einfluss der Massenmedien am Beispiel von Greenpeace. GRIN Verlag.

\footnotetext{
62 www.bfn.de/0401_pm.html?cHash=23c8b62171dc4b0c6b990e552e80b9d1\&tx_ ttnews $\% 5$ Btt_news $\% 5 \mathrm{D}=4117,26.03 .2013$.
} 
BUND-Projektbüro Rettungsnetz Wildkatze (2006) Auf leisen Pfoten durch das Grüne Band. 04.2006.

BfN, BUND (2002) Das Grüne Band - Ein Handlungsleitfaden.

Frobel K, Riecken U, Ullrich K (2009) Das „Grüne Band“ - das

Naturschutzprojekt Deutsche Einheit. Natur und Landschaft 84: 399-403.

Geidezis L, Kreutz M (2010) Das Grüne Band Deutschland und Europa - Vom „Eisernen Vorhang“ zum Biotopverbund, BUND.

Gras M (2009) Vom Eisernen Vorhang zum Grünen Band - Der innerdeutsche Naturschutzkorridor und sein Initiator Kai Frobel. SWR2 Leben Manuskriptdienst.

Leupold D (2009) Das Grüne Band- vom Eisernen Vorhang zur Lebenslinie Europas. BUND LV Sachsen-Anhalt e.V.

Maute K (2011) Markenkriterien \& Kommunikationswege von NGOs am Beispiel von Greenpeace. GRIN Verlag.

Schlumprecht L, Geidezis L, Frobel K (2006) Naturschutzfachliche Schwerpunktgebiete im Grünen Band. BfN-Skripten 152.

Steinsiek P-M, Laufer J (2012) Quellen zur Umweltgeschichte in Niedersachsen vom 18. bis 20. Jahrhundert. Vandenhoeck \& Ruprecht, Göttingen.

Vahdat V (2013) Das Grüne Band Europas: Im Spannungsfeld von Naturschutz und Tourismus. Diplomica, Hamburg.

\section{Internetquellen}

BfN, Grünes Band als Teil des Nationalen Naturerbes. www.bfn.de/0311_gruenes_band1.html (Abruf: 06.11.2013).

BUND, Grünes Band Deutschland - Vielfalt am laufenden Band. www.erlebnisgruenesband.de/gruenes-band/deutschland/natur.html (Abruf: 20.02.2013).

BUND, Biotope am Grünen Band. www.bund.net/themen_und_projekte/gruenes_band/natur_am_gruenen_ban d/lebensraeum (Abruf: 22.03.2013).

BUND, Pflanzen am Grünen Band. www.bund.net/themen_und_projekte/gruenes_band/natur_am_gruenen_ban d/pflanzen/ (Abruf: 26.03.2013). 
BUND, Gemeinsame Fachtagung von BUND und BfN zum Grünen Band. www.erlebnisgruenesband.de/fachtagung/praesentationen-undprogramm.html (Abruf: 26.03.2013).

BUND, Das Grüne Band Deutschland - kostbare Natur am ehemaligen Grenzstreifen. www.bund.net/themen_und_projekte/ gruenes_band/geschichte_gruenes_band (Abruf: 21.03.2013).

Bundesregierung.de, Deutsche Einheit, Die Mauer fiel - auch wegen der Umweltbewegung. www.bundesregierung.de/Content/DE/ Artikel/2012/11/2012-11-25-umweltbibliothek-ddr.html (Abruf: 29.07.2013).

Bundesregierung.de, Grenze soll „Grüne Band“ werden. www.bundesregierung.de/Webs/Breg/DE/Themen/Deutsche_Einheit/2Chronik-Wende/chronik-uebersicht/ereignisse/chronik-1989-12-09-erstesgesamtdeutsches-naturschutzprojekt.html (Abruf: 08.11.2013).

Dehmer D, Vom Todesstreifen zur Lebenslinie, Der Tagesspiegel, www.tagesspiegel.de/wissen/tierwelten/gruene-band-vom-todesstreifen-zurlebenslinie/1918086.html (Abruf: 21.03.2013).

European Green Belt, Borders separate. Nature unites! www.europeangreenbelt.org/ (Abruf: 26.03.2013).

Faber, Annegret, 20 Jahre Grünes Band am innerdeutschen Grenzstreifen, Deutschlandfunk. www.dradio.de/dlf/sendungen/umwelt/1527491/ (Abruf: 20.03.2013).

Frobel K (2009) Pressemitteilung BUND/BfN/Sielmann-Stiftung. https://www.sielmann-stiftung.de/presse/pressemeldungen/details/ grenzenlos-natur-20-jahre-gruenes-band-1989-2009-gemeinsamepressemitteilung-bund-ev-des-bund/

Geilhufe M, Ökologische Erinnerungsorte, Das Grüne Band, http://umweltunderinnerung.de/index.php/kapitelseiten/oekologischezeiten/96-das-gruene-band (Abruf: 23.03.2013).

Göttinger Tageblatt, Stand des Naturschutzprojekts - Birkner: Grünes Band kann noch scheitern, www.goettinger-tageblatt.de/Nachrichten/

Duderstadt/Uebersicht/Birkner-Gruenes-Band-kann-noch-scheitern (Abruf: 24.03.2013).

Grüne Fraktion Thüringen, „Grünes Band“ als „Nationales Naturmonument“ ausweisen. http://gruene-fraktion.thueringen.de/ gr\% $\% 3 \%$ BCnesband $/ \mathrm{gr} \% \mathrm{C} 3 \% \mathrm{BC}$ es-band-als-nationales naturmonument-ausweisen (Abruf: 30.07.2013).

Hallberg S, Naturdenkmal der Zeitgeschichte: Das „Grüne Band“, Goethe-Institut, www.goethe.de/ges/mol/del/pan/de9370906.htm (Abruf: 21.03.2013). 
Informationsarchiv zur Fragen der Deutsch-Deutschen Geschichte, Fotogalerie. www.informationsarchiv.de/galerie3.htm (Abruf: 28.03.2013).

Landvolk Göttingen, „Grünes Band“ darf nicht „Grüne Grenze“ werden. www.landvolk-goe.de/2012/gruenes-Band-2012.htm (Abruf: 24.03.2013).

May H, Kleines Meer, was nun? Interview mit Czybulka, Prof. D., Naturschutz heute - Ausgabe 4/00 vom 22. November 2000. www.nabu.de/nh/400/czybulka400.htm (Abruf: 24.03.2013).

Nationalpark Harz, Die Wildkatze - Kein verwilderter Stubentiger. www.luchsprojekt-harz.de/de/wk/diewildkatze/? darstellung=anpassen\&java=true (Abruf: 20.03.2013).

NDR, Grünes Band? Nein danke. www.ndr.de/regional/niedersachsen/ harz/gruenesband229.html (Abruf: 08.11.2013).

Ökologische Bildungsstätte Oberfranken, Pressemitteilung: Umweltminister Schnappauf, Vertreter der thüringischen Landesregierung und der Bund Naturschutz kritisieren Pläne von Bundesfinanzminister Eichel zum Verkauf von Flächen im ehemaligen Todesstreifen; bayerischer und thüringischer Arten- und Biotopschutz in Oberfranken, www.oekologischebildungsstaette.de/absp/presse.htm (Abruf: 21.03.2013). 



\title{
Der Otterstein in Kaltennordheim: Eine Geschichte der Kreuzotter
}

\author{
Patrick Masius
}

\section{Einleitung}

Gefährliche Tiere leben in den meisten Fällen fern des Menschen und meiden ihn. Wolf und Schlange sind heimlich und scheu. Trotzdem berühren sie die menschliche Geschichte und das nicht nur in Fantasie und Märchen. In der Moderne setzte sich der Staat mithilfe von Wissenschaft mit gefährlichen Tieren auseinander und versuchte dem Sicherheitsverspechen an seine Bürger gerecht zu werden. Gleichzeitig gab es auch lokale Erfahrungen zwischen Mensch und Tier, die in anderen normativen Schemata stattfanden als die offizielle Politik. In der Landschaft hinterlassen weder Wölfe noch Schlangen Spuren, die längere Zeiträume überdauern. In Form von Gedenksteinen existieren aber bis heute kulturelle Marker, die an bestimmte Aspekte der Mensch-Tier-Interaktionen in der Geschichte erinnern. Im Fall der Wölfe sind eine Reihe von solchen Denkmälern erhalten, für die Kreuzotter, soweit mir bekannt, nur ein einziges. Dies ist kein Zufall, sondern hängt mit der Bedeutung der jeweiligen Denkmalkultur zusammen: Die Denkmäler für den Wolf betreffen gewöhnlich den letzten geschossenen Wolf in einer Region. Der Otterstein dagegen erinnert an einen seltenen Todesfall durch Kreuzotterbiss. Innerhalb der Mensch-Tier-Beziehung signalisieren beide Erinnerungskulturen ein antagonistisches Verhältnis. Aber im Gegensatz zur Kreuzotter steht der Wolf auf der Seite des Opfers: Er wurde Ende des 19. Jahrhunderts vollständig ausgerottet, während die Giftschlange allen Versuchen zum Trotz überlebte. 
Im Folgenden wird eine Geschichte der Beziehung zwischen Mensch und Kreuzotter ausgehend von dem Otterstein und seiner Funktion erzählt. In naturwissenschaftlichen wie auch politischen Diskursen um die Kreuzotter blieb der Otterstein bislang unberücksichtigt; und das obwohl zwei der wichtigsten Kreuzotterforscher aus Thüringen kamen: Sowohl Lenz als auch Klingelhoefer wussten ungeachtet der regionalen Nähe nichts von dem Otterstein in Kaltennordheim und seiner Geschichte.

\section{Biologie der Kreuzotter}

In Deutschland gibt es von einer Ausnahme abgesehen nur eine einzige Giftschlange, die Kreuzotter (Vipera berus). Sie wird durchschnittlich 60 bis $80 \mathrm{~cm}$ lang und ist durch ein dunkles Zickzackband gekennzeichnet, das über den Rücken verläuft. Die Färbung ist extrem variabel, auch kommen regelmäßig schwarze Exemplare vor, bei denen die charakteristische Rückenzeichnung dann nicht mehr zu erkennen ist. Ihre Gestalt ist plumper und kurzschwänziger als bei anderen einheimischen Schlangen. Im Oberkiefer stecken zwei 3 bis $4 \mathrm{~cm}$ lange Giftzähne (Solenoglypha), die von einem Kanal durchzogen sind. ${ }^{1}$ In der Ernährung ist die Kreuzotter hauptsächlich auf Kleinsäuger sowie Eidechsen und Frösche angewiesen. Letztere stellen insbesondere für die Jungottern eine wichtige Ernährungsgrundlage dar. Die Beute wird tödlich vergiftet, dann anhand ihrer Duftspur verfolgt und mit dem Kopf zuerst verschlungen. Sie selbst hat allerdings auch zahlreiche Fressfeinde. Neben Greifvögeln, Wildschweinen und Iltis gehört auch der Igel dazu. Bleibt der Kreuzotter keine Zeit zu fliehen, setzt sie sich bei Bedrohung mit Zischen und Scheinangriffen zur Wehr, wobei der vordere Körperteil in Drohhaltung aufgerichtet wird. ${ }^{2}$

Ihr Gesamtverbreitungsgebiet ist immens. Von Frankreich und England im Westen reicht es bis an die ostasiatische Pazifikküste. Im Norden dringt keine andere Reptilienart näher an den Polarkreis vor. Sie bevorzugt ein feucht-kühles Klima und kommt in Deutschland vor allem in strukturreichen, halboffenen Lebensräumen wie Mooren, Heiden und offenen Waldbiotopen vor. Entscheidend ist, dass sowohl genügend Sonnenplätze als auch frostsichere Winterquartiere zur Verfügung stehen. In Deutschland fehlt die Art nur in Rheinland-Pfalz und dem Saarland. Im Norddeutschen Tiefland ist sie in Heide- und Moorgebieten verbreitet. In den Mittelgebirgslagen bevorzugt sie die (nadel)waldreichen, montan geprägten Gebiete. Durch bestimmte Formen der Waldbewirtschaftung entstand hier eine Vielzahl von Lichtungen und Schneisen, die der Kreuzotter einen geeigneten Lebensraum boten. Sie besiedelt hier Waldlichtungen oder Wegränder, an denen alte Baumstümpfe als Sonnenplatz dienen. ${ }^{3}$

\footnotetext{
${ }^{1}$ Schiemenz et al. (1996), S. 711, 714.

2 Ebd., S. 727.

${ }^{3}$ Ebd., S. 718-722
} 
Als Tagesversteck nutzt die Kreuzotter Kleinsäugerbauten, hohle Baumstümpfe oder Erdspalten. Für die Überwinterung sucht sie ähnliche Verstecke auf, die allerdings frostfrei sein müssen. Hier sammelt sich oft an geeigneten Quartieren eine beträchtliche Anzahl von Kreuzottern zur Winterruhe. Nach dem Verlassen der Winterquartiere sonnen die Tiere ausgiebig und häuten sich. Die Paarung findet an warmen Tagen im Frühjahr statt und dauert zwischen zehn Minuten und drei Stunden. Häufig paaren sich dieselben Tiere mehrmals und auch mit anderen Partnern. Die Ottern erreichen ein Höchstalter von zehn bis fünfzehn Jahren. ${ }^{4}$
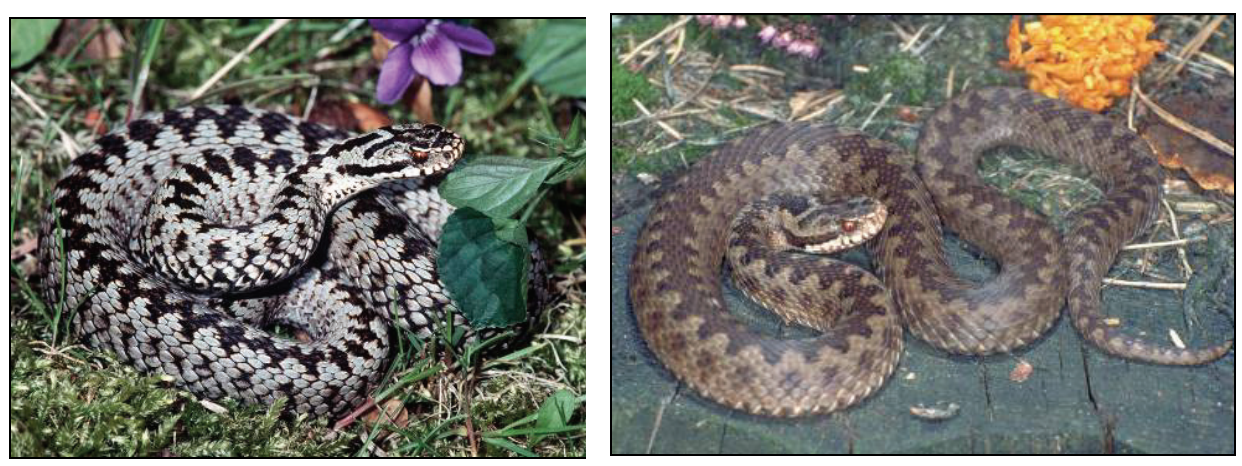

Abb. 1: Färbungsvarianten von Kreuzottern aus Deutschland: Männchen bei Steinhaus, Weibchen bei Michelsrombach (Aufnahmen: H. Nicolay, Hann. Münden).

Wie gefährlich die Kreuzotter für den Menschen ist, kann nicht allein naturwissenschaftlich beantwortet werden. Für die jüngste Zeit zeigt sich, dass die Gefahr, an einem Kreuzotterbiss $\mathrm{zu}$ sterben, statistisch gesehen sehr gering ist. Bissunfälle kommen immer wieder vor, nehmen aber nur selten einen tödlichen Ausgang. In den letzten fünfzig Jahren sind zwei letale Bissunfälle in Deutschland registriert, der letzte im Jahr 2004, als eine ältere Frau in ihrem Garten auf Rügen tödlich gebissen wurde. ${ }^{5}$

\section{Tödliches Gift: Aufklärungsarbeit und Ausrottungsfantasien}

Verbürgte Todesfälle durch Kreuzotterbiss sind schon immer selten. Wie auch bei Übergriffen von Wölfen auf Menschen fehlte der betroffenen ländlichen Bevölkerung häufig der Zugang zu entsprechenden Kommunikationsmitteln, um diese Fälle im öffentlichen Gedächtnis zu erinnern. Im 19. Jahrhundert konsultierten arme Familien nur in Ausnahmefällen einen Arzt und selbst wenn, gab es keine Statistiken, in die Behandlungsverläufe eingegangen wären. Deshalb zeichnet sich

\footnotetext{
${ }^{4}$ Schiemenz et al. (1996), S. 719-727.

5 Giftnotruf Erfurt: www.ggiz-erfurt.de/aktuelles/akt_press_04_juli_kreuzotter_ostsee.htm [Zugang am 16. März 2012].
} 
der Gedenkstein in Kaltennordheim, der die Geschichte eines Bissunfalles im Jahr 1842 im lokalen Gedächtnis verankert hat, besonders aus. Die Aufschrift des Ottersteins gibt die Eckdaten wieder: „A. Kath. Clas/geb. am 10. Jan./ 1831/zu Kanordh./gest. 18. Junius/ 1842/ an Otterbiß“. Verifizieren lässt sich die Geschichte durch das örtliche Kirchenbuch. Im Sterberegister ist vermerkt „Am 18. Juni 1842, abends um 9.00 Uhr, ist Anna Katharina Clas an dem Biss einer Kreuzotter verstorben“. Als Gewährsmänner wurden zwei Mediziner aufgeführt. ${ }^{6}$

Der Hergang des Unfalls ist mündlich überliefert. Demnach war die elfjährige Anna Katharina zusammen mit ihrer Schwester am 18. Juni 1842 zur Wiese am Ergel hinaufgestiegen, um mit einer Sichel Futter für das Vieh zu holen. Es war ein extrem trockenes Jahr, weshalb saftiges Gras vom schattigen Waldrand gebraucht wurde. Mit der Sichel begannen die Kinder das Gras zu schneiden und in die Kötze (ein Tragekorb, der auf dem Rücken getragen wurde) zu bringen. Die Arbeit ging gut voran als Anna Katharina einen stechenden Schmerz am rechten Handgelenk fühlte. Eine Kreuzotter, die im Gras lag, hatte sie gebissen. Zwei nebeneinander liegende blutende Einstiche zeugten vom Biss der Schlange. Das Mädchen band sich die Wunde mit einem Taschentuch ab und erst als die Kötze gefüllt war, trat sie mit ihrer Schwester den anstrengenden Heimweg an. Am Abend verstarb sie an den Folgen des Bisses. ${ }^{7}$

Die Geschichte von Anna Katharina diente in der Folgezeit als mahnendes Beispiel für Schulkinder und wurde zu Aufklärungszwecken über die heimische Giftschlange genutzt. Noch Anfang des 20. Jahrhunderts gingen die Kinder des Ortes regelmäßig mit ihrem Lehrer zum Otterstein, wo ihnen die Geschichte des kleinen Mädchens erzählt wurde und wie wichtig es ist, sofort etwas gegen das Gift zu unternehmen. Als Maßnahmen riet der Lehrer 1905, die Wunde auszusaugen, dann das Gift auszuspucken und auf dem schnellsten Weg einen Arzt aufzusuchen. Außerdem sollte man immer festes Schuhwerk tragen und wenn man eine Schlange sieht ihr aus dem Weg gehen. ${ }^{8}$

Der Otterstein blieb also lange Zeit ein lebendiger Erinnerungsort, der der Aufklärung der einheimischen Kinder diente. Dieser Umgang mit der Naturgefahr Kreuzotter unterschied sich deutlich von den Diskursen in Politik und Wissenschaft des 19. Jahrhunderts. In jenen wurden tödliche Bissunfälle nicht als Mahnung zur Vorsicht gegenüber der Giftschlange gesehen, sondern als triftiger Grund für ihre Ausrottung. In diesem Licht sind auch alle Forschungsbemühungen des 19. Jahrhunderts bezüglich der Kreuzotter zu sehen.

Die ersten Sammlungen von Todesfällen durch Kreuzotterbiss waren wenig systematisch und nicht auf eine Gesamtzahl von Bissunfällen bezogen. Lenz hatte 1832 in seiner Schlangenkunde eine größere Anzahl von Fällen zusammengestellt.

\footnotetext{
${ }^{6}$ Kirchenbuch Kaltennordheim.

7 Schriftl. Mittl. Carola und Klaus Schmidt; Heimat- und Geschichtsverein Kaltennordheim (Apr. 2013). Schmidt u. Schmidt (2014) Otterstein.

${ }^{8}$ Ebd.
} 
Der Fall von Anna K. Clas kam darin nicht vor, weil er sich erst ein Jahrzehnt später ereignete. Auch in die zweite überarbeitete Auflage, die 1872 erschien, fand er keinen Eingang. Sowohl was den Zeitraum als auch den räumlichen Bezug sowie die Verlässlichkeit der Quellen anging war Lenz Zusammenstellung von 1832 so heterogen, dass das vermittelte Bild einer überaus hohen Mortalitätsrate von über $20 \%$ kaum der Wirklichkeit entsprach; insbesondere auch deshalb nicht, weil hier nur die schwersten Bissunfälle gesammelt worden waren. ${ }^{9}$ Dies wirkte sich auf die Relevanz dieser Fallsammlung allerdings keineswegs negativ aus. Beinahe konkurrenzlos lieferte sie Anlass für die Sächsisch-Altenburgische Regierung Kopfgeldprämien für Kreuzottern auszusetzen. ${ }^{10}$ Lenz war als Gutachter und Experte herangezogen worden, um sich in der Frage der Gefährlichkeit der Kreuzotter zu äußern. Durch sein Werk „Schlangenkunde“ konnte er die Einschätzungen der beiden anderen Gutachter, ein praktischer Arzt und ein Naturkundler, die die Kreuzotter für relativ ungefährlich hielten, überstimmen. Sein Urteil hatte nicht nur politische Auswirkungen in Form konkreter Bekämpfungsmaßnahmen, sondern verbreitete sich in der Folge auch in wissenschaftlichen und populärwissenschaftlichen Schriften. Die „Schlangenkunde“ war das Standardwerk des 19. Jahrhunderts und keine Abhandlung über Schlangen kam ohne einen Bezug darauf aus. Für eine weite Verbreitung der Vorstellung von der Kreuzotter als tödlicher Gefahr sorgten naturkundliche Lehrbücher sowie das Tierlexikon, das in kaum einem gutbürgerlichen Bücherschrank fehlte: Brehms Thierleben. Der Kreuzotterartikel darin bestand zu über der Hälfte aus wörtlichen Auszügen aus Lenz' Schlangenkunde. ${ }^{11}$

Die klare schlangenfeindliche Haltung passte sich ausgezeichnet in das hochmoderne Ideal absoluter Naturkontrolle durch den Menschen ein. ${ }^{12}$ Zur Kultivierung der Natur gehörte auch die Bekämpfung schädlicher und gefährlicher Tiere. Die Wölfe fielen dieser Logik zum Opfer und waren Ende des 19. Jahrhunderts aus Deutschland verschwunden. Bezüglich der Kreuzotter mündete die Klassifikation als schädliches Tier um 1900 in preußenweite Ausrottungsprogramme. Für jede getötete Kreuzotter wurde der Bevölkerung von der lokalen Verwaltung oder den Forstbehörden eine Belohnung ausgezahlt. Meist handelte es sich bei den abgelieferten Kreuzottern um Einzelfunde. Dennoch kamen in kreuzotterreichen Gegenden erhebliche Mengen von getöteten Kreuzottern auf diese Weise zusammen. Allein der versteckten Lebensweise, der relativ hohen Reproduktionsrate und ihrer Anpassungsfähigkeit war es zu verdanken, dass drei Jahrzehnte systematische Kreuzotterbekämpfung nicht zu ihrer Ausrottung führten. Bemerkenswerterweise hatte die Verfolgung nicht einmal eine Verminderung der Populationen herbeigeführt. Die Ergebnisse der Langzeitstudie von Georg Klingelhoefer für Ostthürin-

\footnotetext{
${ }^{9}$ Lenz (1832).

${ }^{10}$ NFG Osterland (1840).

${ }^{11} \mathrm{Brehm}(1869)$.

12 Vgl. Scott (1998); Blackbourn (2006).
} 
gen belegen, „daß durch das Prämiierungssystem eine Ausrottung der Kreuzotter nicht herbeizuführen war, es war noch nicht einmal eine Verminderung zu erreichen, es ist im Gegenteil eine Vermehrung der Kreuzotter in den Revieren des Kreises Altenburg in den letzten hundert Jahren feststellbar" ${ }^{\text {“ }}{ }^{13}$ Detaillierte Listen zu drei Fangperioden (1837-1842, 1895-191914 und 1925-1930) im Bereich um Altenburg belegen eindeutig eine Zunahme der Kreuzotter über die Zeit. Die jährlichen Durchschnittszahlen der gefangenen Kreuzottern stiegen von 195 (1. Periode) auf 402 (2. Periode) und 421 Exemplare (3. Periode). In der zweiten Periode (1895-1919) verläuft die Kurve der Fangzahlen im Durchschnitt relativ konstant. Ihren Hochpunkt erreicht sie 1912 nach knapp zwei Jahrzehnten der Verfolgung mit 855 gefangenen Tieren. 1895 hatte die Kreuzotterprämierung mit 118 Stück begonnen.

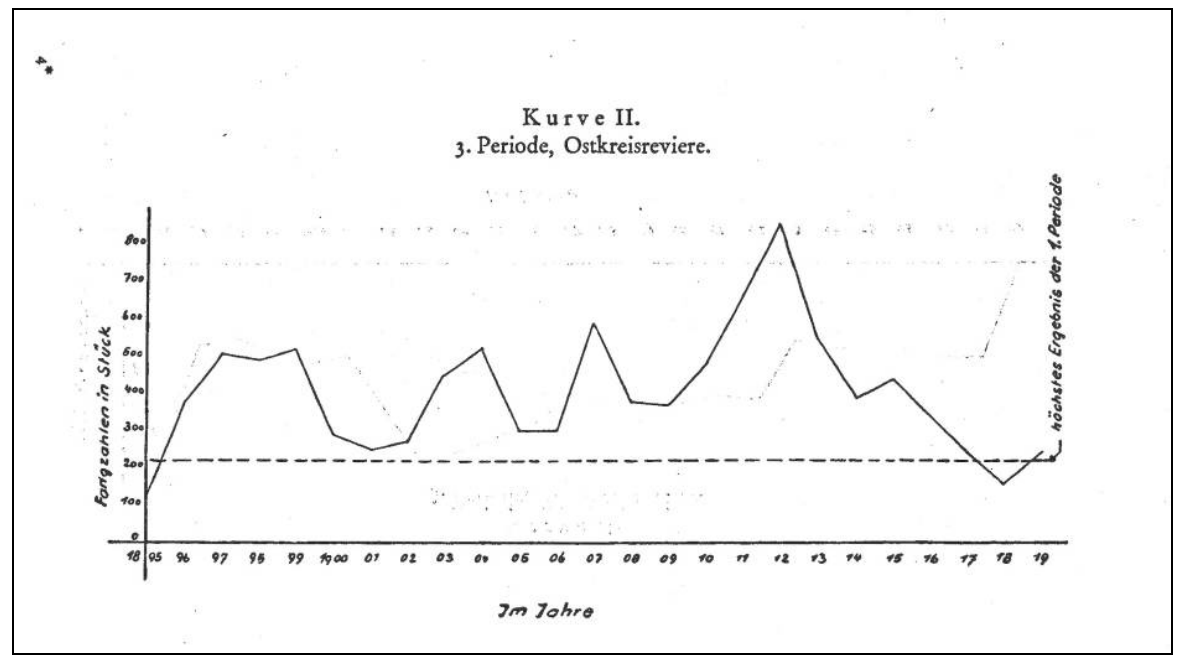

Abb. 2: Entwicklung der Fangzahlen in Ostthüringen (Klingelhöfer (1941), S. 47).

Die Fluktuationen in der Kreuzotterhäufigkeit hielt Klingelhoefer in seiner Dissertation für klimatisch bedingt. ${ }^{15}$ Aufgrund ihrer Erfolglosigkeit wurden die preuBenweiten Bekämpfungsmaßnahmen schließlich 1930 wieder abgeschafft. ${ }^{16}$ Bis dahin waren auch bereits einige Arbeiten erschienen, die die Gefährlichkeit des

\footnotetext{
${ }^{13}$ Klingelhöfer (1941), S. 67.

14 Die Zahlen für 1920-1922 wurden aufgrund der Inflation ausgeklammert. Die 2. Fangperiode bei Klingelhöfer, das Jahr 1890, blieb wegen der eingeschränkten Bedeutung unberücksichtigt.

${ }^{15}$ Klingelhöfer (1941), S. 42 ff.

${ }^{16}$ Die Geschichte, wie genau es dazu kam, ist sehr aufschlussreich, was die Verknüpfungen zwischen Wissenschaft, Politik und Normativität betrifft, würde aber hier zu weit führen (siehe Masius (2014)).
} 
Kreuzotterbisses stark relativierten, die aber keinerlei Einfluss auf die öffentliche Wahrnehmung hatten. ${ }^{17}$

Rekapituliert man die Entwicklung der Perspektive auf die Kreuzotter im 19. Jahrhundert, so zeigt sich, dass die vermeintlich solidere wissenschaftliche Perspektive stark von normativen Vororientierungen beeinflusst war und sich im Laufe der Zeit als kaum haltbar herauskristallisierte. Auf der anderen Seite steht die lokale Geschichte von Anna Katharina Clas, die im Sinne lebendiger Erinnerungskultur erhalten und genutzt wurde. Es konnten praktische Erkenntnisse für die Alltagswelt abgeleitet werden, ohne allgemeine normative Aussagen treffen zu müssen. Diese erwiesen sich rückblickend als wesentlich stabiler als die Ideen der Wissenschaftler. Eine Ursache dafür war sicherlich die Rückbindung wissenschaftlicher Forschung an das normative Leitbild der Hochmoderne: absolute Naturkontrolle. Nur vor diesem Hintergrund war es den Schlangenforschern möglich, die Relevanz ihrer Untersuchungen zu begründen. Als dieses Leitbild Risse bekam und schließlich durch die Heimat- und Naturschutzbewegung sowie zivilisationskritische Stimmen in Frage gestellt wurde, waren die Biologen gezwungen von dem normativen Leitbild des 19. Jahrhunderts Abstand zu nehmen. Die Aufklärung von Schulkindern in der Rhön ist jedoch nach wie vor relevant.

\section{Rehabilitation und Restauration: Die Kreuzotter im Zeichen von Naturschutz und Denkmalpflege}

Die Naturschützer begrüßten, dass die staatlichen Prämiensysteme zur Bekämpfung von Kreuzottern ab 1930 endlich der Vergangenheit angehörten. Die Abschaffung ,ist von jedem Naturfreund, der Verständnis für den wirklichen Naturschutzgedanken besitzt, mit vollem Herzen begrüßt worden“, hieß es in der Zeitschrift „Naturschutz“. ${ }^{18}$

Auch die Berichterstattung in der Presse war ausgesprochen wohlwollend: Die Kreuzotter wurde in allen Punkten rehabilitiert, sie sei scheu und wehre sich nur, wenn sie angegriffen werde, Vergiftungen seien verhältnismäßig leicht und darüber hinaus sei sie die „beste Mäusevertilgerin“.19 Andere Zeitungen übernahmen diese Argumentation wortgetreu. ${ }^{20}$

Der Regierung kam die Abschaffung von Kopfgeldprämien angesichts der angegriffenen Staatskassen nicht ungelegen. Ende 1930 war der Preußische Landwirtschaftsminister dem Erlass des Innenministers zur Aufhebung des Prämienwesens gefolgt, und auch der Innenminister des Reiches wandte sich in diesem Sinne an

\footnotetext{
17 z. B. Müller (1891); Banzer (1895).

18 Reepel (1935), S. 275.

${ }^{19}$ Kölnische Volkszeitung, Jg. 72, Nr. 319 am 9. Juli 1931.

20 Zum Beispiel Euskirchener Volksblatt am 11. August 1931.
} 
die Landesregierungen. ${ }^{21}$ Für die meisten Kreise ergaben sich durch die Aufhebung des Prämienwesens keine Schwierigkeiten. ${ }^{22}$ In Baden wurde sogar eine Regelung eingeführt, die eine behördliche Genehmigung zum Fang von Kreuzottern bzw. für Prämienaktionen vorsah. ${ }^{23}$ Auf lokaler Ebene überdauerte die Kreuzotterbekämpfung durch Prämienverfahren in vielen deutschen Staaten. Auch in Preußen hielten manche Kreisverwaltungen es noch immer für notwendig, Prämien für die Tötung von Kreuzottern auszusetzen, wie eine Umfrage des Innenministers im Jahr 1933 ergeben hatte. ${ }^{24}$ Im Ostenholzer Moor tötete der Reichsarbeitsdienst 1934 beispielsweise 300 Kreuzottern. ${ }^{25}$ Auf dem Darß zahlte die Verwaltung 1935 immer noch rund 1.000 Mark (50 Pfennig/Stück) an Kreuzotterprämien aus. ${ }^{26}$

Jedenfalls sahen sich die Naturschützer weiter gefordert, das Prämienwesen endgültig zu beseitigen. Federführend in dieser Angelegenheit war Walther Schoenichen, der Direktor der Staatlichen Stelle für Naturdenkmalpflege in Preußen und Herausgeber von „Naturschutz“. ${ }^{27}$ Von der Kreuzotter als Schädling könne nicht gesprochen werden, da sie als wichtiger Mäusevertilger „unzweifelhaft zu den landwirtschaftlich nützlichen Schlangen zählt“. Auch der Begriff „Ungeziefer“ sei unangebracht, da er sich auf Schädlinge im Haus und in der Landwirtschaft bezöge. ${ }^{28}$ Schoenichen und Weber gingen im Kommentar zum Reichsnaturschutzgesetz auch ausführlich auf die Sinnlosigkeit des Prämiensystems ein. Ihre Hauptargumente waren der damit verbundene „Massenmord nützlicher und schutzbedürftiger Kriechtiere" durch Verwechslung und die geringe Gefährlichkeit des Kreuzotterbisses für den Menschen. Die Erlasse des preußischen Innenministers und Landwirtschaftministers von 1930 führten sie als richtungsweisend an. Anstelle von Prämienverfahren sollte man in Gegenden, in denen Kreuzottern häufig vorkommen, Warnschilder aufstellen und die Bevölkerung darüber aufklären, nicht barfuß zu gehen. ${ }^{29}$ Damit nähert sich der politisch-wissenschaftliche Diskurs um die Kreuzotter, dem lokalen Diskurs um den Otterstein für kurze Zeit einmal an.

21 Min. Bl. D. preuß. Verw. F. L.D.F. Nr. 50 vom 27. Dezember 1930. BA Berlin-Lichterfelde, Reichsgesundheitsamt, Abt. IV, R 86/ 3681, Brief des Reichsministers des Innern an die Landesregierungen (außer Preußen) am 23. Dezember 1930.

22 So z. B. in Hessen und Sigmaringen (HStA Marburg, Best. 180 LA Hersfeld, Nr. 9462, HStA Wiesbaden, Best. Abt. 410 LA Dillenburg, Nr. 665-668 und HStA Sigmaringen, HO 235 T19/22, 849, Abt. I-III, Briefe der Landräte aus Sigmaringen und Hechingen im Februar 1934).

23 BA Berlin-Lichterfelde, Reichsgesundheitsamt, Abt. IV, R 86/ 3681, Der preußische Kultusminister an den Reichsminister des Innern am 16. Januar 1931.

${ }^{24}$ HStA Marburg, Best. 100 LA Frankenberg, Nr. 3200, Brief des Direktors der Staatlichen Stelle für Naturdenkmalpflege in Preußen an die Regierungspräsidenten am 28. Mai 1934.

25 Müller (1976), S. 288.

26 Piechocki (2004), S. 240.

27 Uekötter (2006), S. 12, 26. Walter Schoenichen war der einflussreichste Naturschutzvertreter seiner Zeit. Er war ein linientreuer Anhänger des Nationalsozialismus und bereits 1933 in die Partei eingetreten. Im Vorwort seines Buches zur „Urwaldwildnis in deutschen Landen“ von 1934 beschwor er beispielsweise den „Geist unseres großen Führers“ (Fischer (2005), S. 184).

28 Im Gegensatz dazu stehen die Vorstellungen von Ungeziefer aus dem 18. Jahrhundert, in denen Schlangen Teil des Konzeptes waren. Windelen (2010), S. 7.

${ }^{29}$ Weber u. Schoenichen (1936), S. 119. 
Von der Veröffentlichung der Reichsnaturschutzverordnung an waren Prämienverfahren zur Kreuzotterbekämpfung vor dem Gesetz bei Strafe verboten. Nach seinen Studien über die Kreuzotter in Ostthüringen erklärte Klingelhöfer, dass Prämiensysteme unerwünscht seien:

„Wir gehen jetzt nicht mehr von bloßen Nützlichkeitserwägungen aus, sondern bekennen uns zu der Anschauung, daß ein jedes Wesen unserer deutschen Natur seine Existenzberechtigung hat, weil es zur Eigenart unserer Natur gehört. Wir wollen unter den Tieren unserer Heimat auch die Kreuzotter nicht missen. “30

Dies bedeutete natürlich nicht, dass die Kreuzotter auch unter Naturschutz stand: Im Gegensatz zu allen anderen heimischen Reptilien gehörte die Kreuzotter, wie auch die giftige Aspisviper, nach $\int 24$ der Reichsnaturschutzverordnung nicht zu den geschützten Tierarten. ${ }^{31}$ Klingelhöfer hielt es für wichtig, massenhaftes Auftreten der Kreuzotter zu verhindern. Ein solches sei ökologisch bedingt; zum Beispiel durch großflächige Fichtenmonokulturen und einen Mangel an natürlichen Feinden wie Raubvögeln. In einem intakten ökologischen Mischwald würden die Kreuzotterbestände nicht mehr überhand nehmen können, sondern durch natürliche Mechanismen auf eine ,erträgliche Anzahl“ reduziert werden. ${ }^{32}$

Mit der ökologischen Revolution um 1970 entwickelte sich ein Umweltbewusstsein in der westlichen Welt, das in Ausmaß und Charakter einzigartig war. ${ }^{33}$ Auch wenn die Ursprünge dieser neuen Umweltbetrachtung mindestens bis in die Romantik zurückreichen, erreichten die Ideale von Ökologie und Nachhaltigkeit erst jetzt den Status orientierungsstiftender Normen für weite Teile gesellschaftlichen Handelns. Ein wichtiger Faktor für diese ökologische Revolution war die Erfahrung der 1950er Jahre, in denen ein exorbitanter Ressourcenverbrauch insbesondere durch die Nutzung von Erdöl einsetzte. ${ }^{34}$ Außerdem hatten die beiden Weltkriege, die Katastrophe von Hiroshima und Nagasaki und die Erfahrung des Holocausts ihre Spuren hinterlassen. Das Vertrauen in die technologische Zivilisation war erschüttert. Waren in den Diskursen des 19. Jahrhunderts Gefahren noch als Naturgefahren erschienen, setzte sich seit der Mitte des 20. Jahrhunderts langsam das Bild von Zivilisationsgefahren im gesellschaftlichen Bewusstsein fest. ${ }^{35} \mathrm{Zu}$

\footnotetext{
${ }^{30}$ Klingelhöfer (1941).

31 Weber u. Schoenichen (1936), S. 121; Ecke (1958), S. 66 f.

32 Klingelhöfer (1941), S. 84 f.

33 Radkau (2011), S. 124 ff. Blackbourn vergleicht den schlagartigen Wandel zu einem neuen Umweltbewusstsein mit dem Wechsel des Aggregatzustandes von Wasser: „When that changed, it changed quickly. In September 1970 just forty per cent of the West German public claimed to be familiar with the term ,environmental protection'; by November 1971 the number had risen to 90 per cent. This was like water turning suddenly into ice or steam, one of those instant transitions that sometimes occur in the human as well as the natural world." (Blackbourn (2006), S. 316).

${ }^{34}$ Radkau (2002). Christian Pfister hat in diesem Zusammenhang den Begriff „50er Jahre Syndrom“ geprägt.

35 Masius (2012). Vgl. Walter (2010). Nach Walter setzte der Wandel der Sicherheitskultur allerdings schon nach dem Ersten Weltkrieg ein.
} 
diesem Wandel der Sicherheitskultur trugen die ökologischen Folgeschäden von Wirtschaftswunder und zweiter Industrialisierung bei. Was Rachel Carson anhand der Verwendung von DDT ${ }^{36}$ in den USA gezeigt hatte, war auch für die BRD eine Warnung, denn auch hier führten Wasser- und Luftverschmutzung zu Schäden für Mensch und Umwelt. Wald- und Fischsterben waren die Folge und Politik und Öffentlichkeit reagierten.

Den vielleicht deutlichsten Hinweis auf die fortschreitende Zerstörung der Umwelt lieferte der Rückgang von Tier- und Pflanzenarten. Populäre Bücher wie Hubert Weinzierls „Das große Sterben” unterstrichen die Brisanz der Umweltprobleme. Das weltweite Artensterben war ein reales Problem, dem sich Experten, Naturschutzorganisationen und Politiker zunehmend stellten. ${ }^{37}$ In Westdeutschland hatte beispielsweise die Verschmutzung des Rheins durch die anliegenden chemischen Fabriken und Großstädte bis 1975 ein ungekanntes Ausmaß erreicht. Die Folge war, dass etwa die Hälfte aller dort bekannten Fischarten verschwunden oder hochgradig vom Aussterben bedroht war. ${ }^{38}$

Dabei war die Rechtslage für den Artenschutz seit dem Erlass der Reichsnaturschutzverordnung von 1936 beinahe unverändert geblieben. Die Kreuzotter gehörte auch in der „Verordnung zum Schutze der wildwachsenden Pflanzen und der nicht-jagdbaren wildlebenden Tiere" vom 6. Juni 1963 nicht zu den schützenswerten Arten. ${ }^{39}$ Dieser status quo sollte sich jedoch ändern.

Neben einer Aufhebung der juridischen Trennung von jagdbaren und nichtjagdbaren Arten forderten Naturschützer eine stärkere wissenschaftliche Verankerung des Artenschutzes. Im Zuge dessen wurde auch eine Neufassung der Listen geschützter Tierarten in der Bundesrepublik Deutschland angestrebt. Diese sollten unter Beteiligung von Experten und ,in einer für die interessierte Öffentlichkeit [...] transparenten Weise“" geschehen. ${ }^{40}$ Im Diskussionsforum einer Tagung von der „Bundesanstalt für Vegetationskunde, Naturschutz und Landschaftspflege“41 zum Thema Artenschutz im Jahr 1971 forderte ein Diskutant explizit die Unterschutzstellung der Kreuzotter.

„Unbedingter Schutz ist erforderlich für alle Amphibien (auch Wasser- und Grasfrosch), alle Reptilien, ganz besonders auch für die Kreuzotter (dieses Versäumnis hat schon Millionen von geschützten Schlangen und Blindschleichen das Leben gekostet). “ 42

\footnotetext{
${ }^{36}$ Dichlordiphenyltrichlorethan ist ein hochwirksames Insektizit.

${ }^{37}$ Siehe z. B. Wilson (1992). Die Verabschiedung der Biodiversitätskonvention (1992), bei der über 180 Vertragsstaaten unterzeichneten, war ein Meilenstein für den internationalen Artenschutz.

38 Cioc (2002), S. 158. Als Vergleichszeitpunkt diente das Jahr 1880 wo je nach Rheinabschnitt 42, 45 oder 47 Fischarten nachgewiesen worden waren.

${ }^{39}$ Scheerer (1968), S. 65.

${ }^{40}$ Erz (1972), S. 27.

411975 wurde die „Bundesanstalt für Vegetationskunde, Naturschutz und Landschaftspflege“ umbenannt in „Bundesforschungsanstalt für Naturschutz und Landschaftsökologie“.

42 Erz (1972), S. 30 (Hervorhebung P.M.).
} 
Diesen Forderungen wurde auch tatsächlich nachgekommen, allerdings erst ein Jahrzehnt später. Die Anlage 1 der neuen Bundesartenschutzverordnung (BArtSchV) vom 25. August 1980 verzeichnete sowohl alle europäischen Reptilien, einschließlich der Giftschlangen, als auch alle Amphibien. Damit stand auch die Kreuzotter im Sinne von $\int 22$ des Bundesnaturschutzgesetzes (1976) unter besonderem Schutz. ${ }^{43}$ Eine bedeutende Rolle spielte in dieser Entwicklung die Erstellung der sogenannten Roten Listen der gefährdeten Tiere und Pflanzen auf Landes- und Bundesebene.

Im Zuge dieser Unterschutzstellung vermittelten Naturschützer, Wissenschaftler und Medien ein neues Bild der Kreuzotter. Sie war nicht mehr furchterregendes Monster, sondern seltene und bedrohte Tierart. Es wurden Schutzprojekte ins Leben gerufen, um Kreuzotterhabitate zu erhalten und zu verbessern. In Thüringen wurden sogar spezielle Schutzgebiete für die Kreuzotter eingerichtet. ${ }^{44}$ Belohnt wurden die Bürger von nun an nicht mehr für die Ablieferung toter Giftschlangen, sondern für Hinweise auf die letzten Vorkommen lebender Kreuzottern. Entsprechende Aufrufe zur Mitarbeit erließen Naturschützer in den lokalen Zeitungen. Das Bewusstsein für das weltweite Artensterben als zivilisatorischer Nebenfolge hatte eine Sensibilisierung gegenüber der Tierwelt geschaffen, die sogar Giftschlangen mit umfasste. Sie wurden als Teil einer ökologischen Sphäre betrachtet, die nicht allein menschlichen Zwecken dingbar gemacht werden sollte, sondern einen Wert um ihrer selbst Willen besaß. In Thüringen wird seit den 1980er Jahren deshalb nicht mehr der Mensch vor der Kreuzotter geschützt, sondern die Kreuzotter vor dem Menschen. Das Erschlagen von Schlangen wird als moralisch verwerflich angesehen und rechtlich verfolgt. Betrachtet man wie sich die Perspektive auf die Kreuzotter in der Moderne gewandelt hat, so werden Schlangenlinien erkennbar. Ganz anders, nämlich geradlinig, verlief die Perspektive auf die Kreuzotter, die vom Otterstein ausging.

Im Laufe des 20. Jahrhunderts verblasste die Erinnerung an die Geschichte der kleinen Anna Katharina Clas. Die Grundschulkinder wanderten nicht mehr auf den Ergel und die Gravur auf dem Gedenkstein wurde unleserlich. Wenn sie nicht gepflegt werden, geraten Erinnerungen in Vergessenheit und aus einem Gedenkstein wird wieder ein Stein. In den 1990er Jahren hatten Wind und Wetter die Gedenkschrift fast vollständig verblassen lassen. Der Versuch einer Restaurierung durch einen anonymen Kaltennordheimer führte zu einer Fehlrekonstruktion des Todesdatums. Anstelle des 18. Junius/ 1842 hieß es nun der 16. August/ 1847. Außerdem war der Geburtstag nicht nachgearbeitet worden. Nur das Geburtsjahr blieb verzeichnet, 1831. Damit war das Mädchen Anna Katharina nun 16 oder 17 Jahre alt und nicht mehr 11. Als Schlangenexperte Harald Nicolay 2002 Kaltennordheim auf der Suche nach Kreuzottern besuchte, fand er diesen Stein und in unmittelbarer Nähe anstelle giftiger Kreuzottern, ungiftige Schlingnattern (Abb. 3 (2)). Auf

\footnotetext{
43 Arnold (1982), S. 126.

${ }^{44}$ Nöllert (2004).
} 
diesen Angaben basierend, interpretierte er den Fall Anna Katharina als habe es sich um ein junges Mädchen gehandelt, das von einem Vertreter der Kirche geschwängert worden und dann gezwungen war Gift zu nehmen. Dass es sich wirklich um eine Kreuzotter gehandelt haben könnte, schloss er aufgrund seiner Feldforschung vor Ort aus. 45
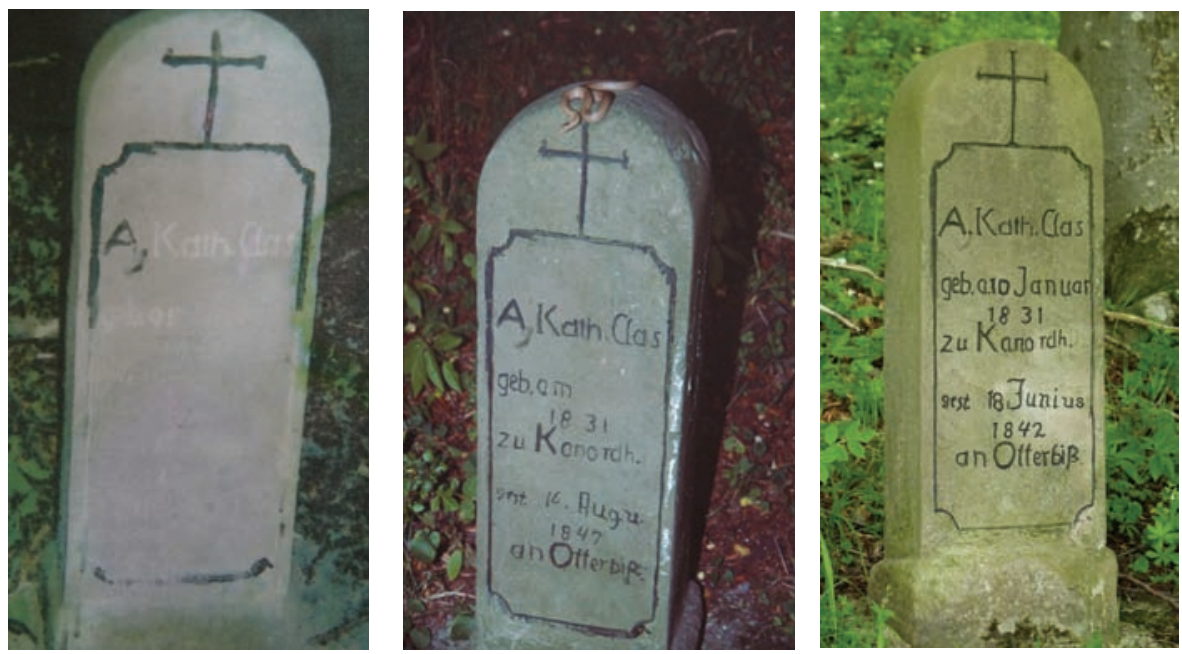

Abb. 3: Dreimal der Otterstein am Ergel in Kaltennordheim. 1997 mit verblasster Aufschrift (Aufnahme: C. Schmidt), 2002 mit unvollständiger und fehlerhafter Aufschrift und dazugelegter Schlingnatter (Aufnahme: H. Nicolay) und 2013 mit restaurierter Aufschrift (Eigene Aufnahme).

Erst durch die Recherchen des Ehepaars Schmidt vom Heimat- und Geschichtsverein Kaltennordheim wurde die tatsächliche Inschrift und die dazugehörige Geschichte wieder rekonstruiert. In Rückgriff auf das Kirchenbuch und die mündliche und schriftliche Überlieferung innerhalb des Vereins belebten sie die fast verloren gegangene lokale Erinnerungskultur wieder. Im April 2013 berichtigten sie die Gedenkschrift auf dem Stein und im Sommer 2013 erschien die rekonstruierte Geschichte in den „Mitteilungen aus dem Biosphärenreservat Rhön“.46 Bemerkenswerterweise gerät diese Erinnerungskultur nicht in Konflikt mit den Naturschutzinteressen, die im Biosphärenreservat Rhön bezüglich der Kreuzotter vertreten werden. Das wird durch die Veröffentlichung in einem hauseigenen Organ deutlich. Heute engagiert sich der Heimat- und Geschichtsverein Kaltennordheim

\footnotetext{
45 Harald Nicolay mdl. Mittl. April 2013.

${ }^{46}$ Schmidt, Schmidt (2013).
} 
dafür, dass Schulklassen wieder den Otterstein aufsuchen und über die einheimische Giftschlange aufgeklärt werden.

\section{$5 \quad$ Fazit}

Einerseits hat sich die Einstellung zur Kreuzotter in den Diskursen von Wissenschaft, Politik und Medien um 180 Grad gedreht, andererseits ist sie auf der lokalen Ebene unverändert geblieben. Dies deutet darauf hin, dass diejenigen Diskurse, die aufgrund der Quellenlage meist die einzig zugänglichen sind, nicht auch notwendigerweise die alleinige Deutungshoheit inne haben. Auf lokaler Ebene können sich alternative Diskurse entwickeln und über lange Zeit unabhängig von den gröBeren Diskursen behaupten. Interessant ist, dass sie in keinerlei Konflikt miteinander geraten, obwohl dies inhaltlich durchaus denkbar wäre. Weil sie auf einer anderen Ebene liegt, hat die lokal überlieferte Geschichte, die am Otterstein erinnert wird, nie den politisch-wissenschaftlichen Diskurs erreicht und deshalb keinerlei Einfluss auf diesen ausgeübt. Genauso wenig wurde die lokale Tradition durch überregionale normative Haltungen in Kreuzotterfragen verändert. Es handelt sich um zwei Parallelgeschichten, die Umwelthistorikern eine Möglichkeit bieten, die Gleichzeitigkeit semantischer Differenzen von Natur exemplarisch zu begreifen.

\section{Literatur}

Arnold E (1982) Naturschutzrecht. Bundesnaturschutzgesetz, Washingtoner Artenschutzübereinkommen mit Zustimmungsgesetz und allgemeinen Verwaltungsvorschriften, Bundesartenschutzverordnung, Landesnaturschutzgesetze. Deutscher Taschenbuchverlag, München.

Banzer A (1891) Die Kreuzotter. Ihre Lebensweise, ihr Biss und ihre Verbreitung mit besonderer Berücksichtigung ihres Vorkommens in Bayern. Akademische Buchdruckerei F. Straub, München.

Blackbourn D (2006) The Conquest of Nature. Water, landscape and the making of modern Germany. Jonathan Cape, London.

Brehm A (1869), Illustrirtes Thierleben: eine allgemeine Kunde des Thierreichs, Bd. 3. Bibliogr. Institut, Hildburghausen.

Cioc M (2002) The Rhine: An Eco-Biography 1815-2000. Seattle: Univ. of Washington.

Ecke H (1958) Die geschützten Tierarten. Bühlerscher Verlag, Gießen.

Erz W (1972) Erfordernisse für die Neufassung der Listen geschützter Tierarten in der Bundesrepublik Deutschland. In: Schriftenreihe für Landschaftspflege und 
Naturschutz, 7. Artenschutz (Bonn Bad-Godeserg: Bundesanstalt für

Vegetationskunde, Naturschutz und Landschaftspflege), S. 27-30.

Fischer L (2005) Die „Urlandschaft“ und ihr Schutz. In: J. Radkau, F. Uekötter

(Hg.) Naturschutz und Nationalsozialismus. Campus, Frankfurt a. M., S. 183-

205.

Klingelhöfer G (1941) Die Kreuzotter in Ostthüringen, ihre Verbreitung,

Häufigkeit und Bedeutung. Robert Noske, Borna-Leipzig.

Lenz HO (1832) Schlangenkunde. Beckersche Buchhandlung, Gotha.

Masius P (2012) Natur und Kultur als Quellen von Gefahr. Zum historischen

Wandel der Sicherheitskultur. In: C. Daase, P. Offermann, V. Rauer (Hg.)

Sicherheitskultur: Soziale und politische Praktiken der Gefahrenabwehr.

Campus, Frankfurt a. Main, S. 183-204.

Masius P (2014) Schlangenlinien. Eine Geschichte der Kreuzotter. Vandenhoeck \& Ruprecht, Göttingen.

Müller AW (1895) Statistik der Verletzungen durch Schlangenbiss in Pommern nebst einem Anhange über die Verbreitung der Kreuzotter in Pommern. Julius Abel, Greifswald.

Müller P (1976) Arealveränderungen von Amphibien und Reptilien in der

Bundesrepublik Deutschland. In: H. Sukopp, W. Trautmann (Hg.)

Veränderungen der Flora und Fauna in der Bundesrepublik Deutschland.

Schriftenreihe für Vegetationskunde, 10 (Bonn Bad-Godesberg: Bundesanstalt

für Vegetationskunde, Naturschutz und Landschaftspflege), S. 269-294.

Naturforschende Gesellschaft des Osterlandes (NFG Osterland) (1840) Ueber die Schädlichkeit der Kreuzotter. In: Mittheilungen aus dem Osterlande, 4, S. 4064.

Nöllert A (2004) Verbreitung, Lebensraum und Bestandsituation der

Kreuzotter Vipera berus berus (Linnaeus, 1758) im Freistaat Thüringen. In: U. Joger, R. Wollesen (Hg.) Verbreitung, Ökologie und Schutz der Kreuzotter (Vipera berus [Linnaeus, 1758]), Mertensiella 15, 2004, 52-89.

Piechocki R (2004) In „Natur und Landschaft“ zurückgeblättert -17. Vor 75

Jahren: Kreuzotterängste. In: Natur und Landschaft, 79 (5), S. 240.

Radkau J (2002) Natur und Macht. Eine Weltgeschichte der Umwelt. C.H. Beck, München.

Radkau J (2011) Die Ära der Ökologie. C.H. Beck, München.

Reepel C (1935) Achtung! Kreuzottern! Ein photographischer und zoologischer Streifzug. In: Naturschutz, 16 (12), S. 274-279. 
Scheerer H (1968) Geschützte Pflanzen und Tiere. In: Landesanstalt für Erziehung und Unterricht \& Landesstelle für Naturschutz und Landschaftspflege (Hg.), Naturschutz und Bildung. Eigenverlag, Stuttgart, S. 46-68.

Schiemenz H, Biella H-J, Günther R, Völkl W (1996) Kreuzotter - Vipera berus (Linnaeus, 1758). In: R. Günther (Hg.), Die Amphibien und Reptilien Deutschlands. Gustav Fischer, Jena.

Schmidt C, Schmidt K (2013) Der Otterstein bei Kaltennordheim. In: Mitteilungen aus dem Biosphärenreservat Rhön, 18.

Scott J (1998) Seeing like a state. How certain schemes to improve the human condition have failed. Yale University Press, New Haven, London.

Uekötter F (2006) The Green and the Brown. A History of Conservation in Nazi Germany. Cambridge University Press, Cambridge.

Walter F (2010) Katastrophen. Eine Kulturgeschichte vom 16. bis ins 21. Jahrhundert. Reclam, Stuttgart.

Weber W, Schoenichen W (1936) Der Schutz von Pflanzen und Tieren nach der Naturschutzverordnung vom 18. März 1936. Hugo Bermühler Verlag, BerlinLichterfeld.

Wilson EO (Hg.) (1992) Ende der Biologischen Vielfalt? Der Verlust an Arten, Genen und Lebensräumen und die Chancen für eine Umkehr. Spektrum Akademischer Verlag, Heidelberg.

Windelen S (2010) Mäuse, Maden, Maulwürfe. Zur Thematisierung von Ungeziefer im 18. Jahrhundert. Dissertation, Göttingen. 
In diesem Sammelband werden Schauplätze der Umweltgeschichte aus dem heutigen Bundesland Niedersachsen vorgestellt. Damit werden Mensch-Umwelt-Interaktionen in Vergangenheit und Gegenwart an ausgewählten Orten in den Blick genommen. Das Themenspektrum reicht von Küstenschutz und Landschaftswandel bis zu Rohstoffgewinnung und Naturschutz und liefert so einen umwelthistorischen Querschnitt. Insgesamt zeigen sich eindrücklich die engen lokalen Verflechtungen von Umwelt und Gesellschaft, was zu einem besseren Verständnis aktueller Mensch-Umwelt-Beziehungen und ihrer Probleme beiträgt. 